\title{
Heterogeneity in human atherosclerotic gene expression profiles from man to macrophages
}

Citation for published version (APA):

Kisters, N. (2008). Heterogeneity in human atherosclerotic gene expression profiles from man to macrophages. [Doctoral Thesis, Maastricht University]. Maastricht University. https://doi.org/10.26481/dis.20081205nk

Document status and date:

Published: 01/01/2008

DOI:

10.26481/dis.20081205nk

Document Version:

Publisher's PDF, also known as Version of record

\section{Please check the document version of this publication:}

- A submitted manuscript is the version of the article upon submission and before peer-review. There can be important differences between the submitted version and the official published version of record. People interested in the research are advised to contact the author for the final version of the publication, or visit the DOI to the publisher's website.

- The final author version and the galley proof are versions of the publication after peer review.

- The final published version features the final layout of the paper including the volume, issue and page numbers.

Link to publication

\footnotetext{
General rights rights.

- You may freely distribute the URL identifying the publication in the public portal. please follow below link for the End User Agreement:

www.umlib.nl/taverne-license

Take down policy

If you believe that this document breaches copyright please contact us at:

repository@maastrichtuniversity.nl

providing details and we will investigate your claim.
}

Copyright and moral rights for the publications made accessible in the public portal are retained by the authors and/or other copyright owners and it is a condition of accessing publications that users recognise and abide by the legal requirements associated with these

- Users may download and print one copy of any publication from the public portal for the purpose of private study or research.

- You may not further distribute the material or use it for any profit-making activity or commercial gain

If the publication is distributed under the terms of Article $25 \mathrm{fa}$ of the Dutch Copyright Act, indicated by the "Taverne" license above, 


\section{HETEROGENEITY IN HUMAN ATHEROSCLEROTIC GENE EXPRESSION PROFILES}

FROM MAN TO MACROPHAGES 
(c) Copyright Natasja Kisters, Maastricht 2008

ISBN:

978-90-6464-296-8

Cover design:

Ponsen \& Looijen

Printed by:

Ponsen \& Looijen 


\title{
HETEROGENEITY IN HUMAN ATHEROSCLEROTIC GENE EXPRESSION PROFILES
}

\author{
FROM MAN TO MACROPHAGES
}

\author{
Proefschrift \\ ter verkrijging van de graad van doctor aan de Universiteit Maastricht, \\ op gezag van de Rector Magnificus, Prof. mr. G.P.M.F. Mols, \\ volgens het besluit van het College van Decanen, \\ in het openbaar te verdedigen \\ op vrijdag 5 december 2008 om 14:00 uur.
}

door

Natasja Kisters

geboren op 3 april 1975 te Sittard 


\section{Promotor}

Prof. dr. M.J.A.P. Daemen

\section{Copromotor}

Dr. K.B.J.M. Cleutjens

\section{Beoordelingscommissie}

Prof. dr. M.P. van Dieijen-Visser (voorzitter)

Prof. dr. G. Kraal (VU, Amsterdam)

Prof. dr. C.J.S. Kleinjans

Prof. dr. W.H. Mess

Dr. C.P.M. Reutelingsperger

Financial support by the Netherlands Heart Foundation and the J.E. Jurriaanse stichting for the publication of this thesis is gratefully acknowledged. Part of the studies described in this thesis was supported by grant of the Netherlands Heart Foundation (NHF-2002B033). Also Schering-Plough Research Institute is gratefully acknowledged for their financial support. 
Het keerpunt

is nooit

een plaatsnaam

een datum

een man

Het is een ovale lijn

die ongemerkt

langzaam

maar onomkeerbaar

op een dag

alles anders laat lijken 



\section{CONTENTS}

Chapter 1 General introduction

Chapter 2 Dead or Alive: Gene expression profiles of advanced atherosclerotic plaques from autopsy and surgery

Chapter 3 Site specificity of gene expression signatures in human atherosclerosis

Chapter 4 Transcript levels of genes involved in the intrinsic/ extrinsic mediated initiation of apoptosis are elevated during progression of human atherosclerosis

Chapter 5 Gene profiling of cathepsin K deficiency in atherogenesis: profibrotic but lipogenic

Chapter 6 Stage specific gene expression profiles of macrophages isolated from human atherosclerotic lesions: focus on the transcription factors TGIF and ID4

Chapter 7 TWIST1: A marker of macrophage foam cells

Chapter 8 General discussion

Full color figures

Summary

Samenvatting

Dankwoord

Curriculum Vitae 


\section{ABBREVIATIONS}

\begin{tabular}{|c|c|}
\hline$A B C$ & ATP-binding cassette transporters \\
\hline ACAT & Acyl Coenzyme A cholesterol Acyl Transferase \\
\hline ACE & angiotensin-converting Enzyme \\
\hline $\mathrm{AHA}$ & American Heart Association \\
\hline AIC & akaike information criterion \\
\hline apoE-/- & apolipoprotein E knockout \\
\hline aRNA & amplified ribonucleic acid \\
\hline bHLH & basis helix loop helix \\
\hline BM & bone marrow \\
\hline catK & cathepsin $\mathrm{K}$ \\
\hline CDNA & complimentary deoxyribonucleic acid \\
\hline $\mathrm{CsCl}$ & cesium chloride \\
\hline DiI & 1,1'-dioctadecyl-3,3,3',3'-tetramethylindocarbocyanine perchlorate \\
\hline DNA & deoxyribonucleic acid \\
\hline DTT & dithiotreitol \\
\hline EC & endothelial cell \\
\hline ECM & extracellular matrix \\
\hline FACS & fluorescence-activated cell sorting \\
\hline FasL & fas ligand \\
\hline FDR & false discovery rate \\
\hline FGF & fibroblast growth factor \\
\hline GenMAPP & gene map annotator and pathway profiler \\
\hline GO & gene ontology \\
\hline GSEA & gene set enrichment analysis \\
\hline HDL & high density lipoprotein \\
\hline HE & haematoxylin and eosin \\
\hline HUVEC & human umbilical vein endothelial cell \\
\hline ICAM & intercellular adhesion molecule \\
\hline ID & inhibitor of DNA binding \\
\hline IFN & interferon \\
\hline IGF & insulin-like growth factor \\
\hline IL & interleukin \\
\hline IPA & ingenuity pathway analysis \\
\hline KEGG & kyoto encyclopedia of genes and genomes \\
\hline LCM & laser capture microdissection \\
\hline LDL & low density lipoprotein \\
\hline LDLR-/- & low density lipoprotein receptor knockout \\
\hline LPS & lipopolysaccharide \\
\hline MCP & monocyte chemoattractant protein \\
\hline M-CSF & macrophage-colony stimulating factor \\
\hline
\end{tabular}




$\begin{array}{ll}\text { MMP } & \text { matrix metalloproteinase } \\ \text { MPTC } & \text { maastricht pathology tissue collection } \\ \text { mRNA } & \text { messenger ribonucleic acid } \\ \text { NFKB } & \text { nuclear factor kappa B } \\ \text { NO } & \text { nitric oxide } \\ \text { OxLDL } & \text { oxidized low density lipoprotein } \\ \text { PBMC } & \text { peripheral blood mononuclear cell } \\ \text { PBS } & \text { phosphate-buffered saline } \\ \text { PCR } & \text { polymerase chain reaction } \\ \text { PDGF } & \text { platelet derived growth factor } \\ \text { PMA } & \text { phorbol 12-myristate 13-acetate } \\ \text { Q-RT PCR } & \text { quantitative real time polymerase chain reaction } \\ \text { RDA } & \text { cDNA representational difference analysis } \\ \text { RNA } & \text { ribonucleic acid } \\ \text { SAM } & \text { statistical analysis of microarrays } \\ \text { SMC } & \text { smooth muscle cell } \\ \text { Sm-MHC } & \text { smooth muscle myosin heavy chain } \\ \text { SR-A } & \text { scavenger receptor class A } \\ \text { SR-BI } & \text { scavenger receptor class B type I } \\ \text { SSH } & \text { suppressive subtractive hybridization } \\ \text { TBS } & \text { tris-buffered saline } \\ \text { TF } & \text { tissue factor } \\ \text { TGF } & \text { transforming growth factor } \\ \text { TGIF } & \text { transforming growth factor } \beta \text { induced factor } \\ \text { TIMP } & \text { tissue inhibitor of matrix metalloproteinase } \\ \text { TLR } & \text { toll like receptor } \\ \text { TNF } & \text { tumour necrosis factor } \\ \text { TRAIL } & \text { tumour necrosis factor-related apoptosis-inducing ligand } \\ \text { VCAM } & \text { vascular cell adhesion molecule } \\ \text { VEGF } & \text { vascular endothelial growth factor } \\ & \end{array}$





\section{Chapter 1}

\section{General Introduction}




\section{Clinical implications of atherosclerosis}

Cardiovascular diseases are the main cause of morbidity and mortality in the developed countries ${ }^{1}$. In 2004 in the Netherlands, 45,445 individuals died of cardiovascular diseases, accounting for $33 \%$ of all causes of death ${ }^{2}$. The main underlying pathology of many cardiovascular diseases is atherosclerosis, which literally means hardening of the arteries ("sclerosis") due to the accumulation of lipids, cells and connective tissue ("atheroma") in the most inner layer of a blood vessel, the intima. Atherosclerosis is a progressive, systemic disease of the large and medium sized arteries that affects all humans to some extent. Atherosclerosis develops already during childhood although these early stages of atherosclerosis are (usually) clinically silent ${ }^{3}$. During disease progression large lesions can develop without clinical symptoms, since arteries are to some extent capable to compensate for the narrowing of the lumen by active remodeling (compensatory enlargement) ${ }^{4}$. Most clinical symptoms present themselves as acute manifestations due to rupture of the atherosclerotic lesion, leading to the formation of a blood clot and (partial) occlusion of the artery. Therefore, atherosclerosis is often referred to as "the silent killer" ${ }^{5,6}$.

Depending on the end organ of the affected vascular bed, the disease can lead to distinct clinical manifestations. The presence of atherosclerosis in the coronary arteries might cause angina pectoris and myocardial infarction whereas atherosclerosis of the carotid arteries may lead to transient cerebral events and stroke. Atherosclerosis of the peripheral circulation can cause a variety of clinical symptoms such as acute limb ischemia and gangrene, ischemic renal failure and hypertension and mesenteric ischemia and bowel infarction ${ }^{7}$. Atherosclerosis is a multifactorial disease that involves both environmental and genetic factors that affect and/or lead to elevated levels of low density lipoprotein (LDL), reduced levels of high density lipoproteins (HDL), elevated homocysteine levels, hypertension, obesity, diabetes, smoking, high fat diet, stress, infectious agents and a lack of physical exercise ${ }^{8,9}$. Up to now, therapy is aimed at reduction of these risk factors by using various medications, such as, lipid lowering drugs (statins) ${ }^{10}$ and/or anti-hypertensive drugs (Angiotensin Converting Enzyme (ACE) inhibitors, $\beta$-blockers) ${ }^{11}$ and/or by adjusting life style.

\section{Pathogenesis of atherosclerosis}

During the last decade it has become clear that atherosclerosis is a chronic inflammatory disease, involving several inflammatory cells such as macrophages and T-lymphocytes ${ }^{12-16}$. 


\section{Chronic inflammation}

Atherosclerosis is initiated by endothelial dysfunction which can be caused by for example elevated levels of (modified) LDL. As a consequence of this endothelial dysfunction, vascular endothelial cells become activated and upregulate adhesion molecules, such as E-selectin, vascular cell adhesion molecule (VCAM) and intercellular adhesion molecule (ICAM), and growth factors such as macrophage colony-stimulating factor (M-CSF). The expression of adhesion molecules results in the attachment of monocytes and Tlymphocytes to the activated endothelial cells (ECS). Besides activation of the ECs, endothelial dysfunction also leads to increased vascular permeability for macromolecules such as LDL, leading to accumulation of the (modified) LDL in the subendothelial space. After attachment, the monocytes and T-lymphocytes migrate into the subendothelial space under the influence of chemokines, such as monocyte chemoattractant protein-1 (MCP-1), which are produced by the vascular wall. Once inside the vascular wall the monocytes proliferate and differentiate into macrophages under the influence of M-CSF. Macrophages (besides other antigen-presenting cells in the lesion, such as dendritic cells, mast cells and even endothelial cells) can take up antigens (such as oxidized LDL (oxLDL)) through scavenger receptors (including CD36 and SR-A) and other pattern-recognition receptors, such as toll like receptors (TLRs). Uptake of OxLDL leads to foam cell formation ${ }^{17-19}$ and activation of the cells. These activated macrophages produce inflammatory cytokines which in turn activate $T$ cells. This activation can be divided into two responses; a Th1 and a Th2 response. Cytokines that promote a Th1 response dominate in atherosclerotic lesions, leading to the production of the pro-inflammatory cytokine interferon (IFN) $\gamma$, which augments the synthesis of the inflammatory cytokines tumour necrosis factor (TNF) $\alpha$ and interleukin (IL) $1{ }^{20,21}$. These cytokines influence again the production of other inflammatory and cytotoxic molecules by macrophages and other vascular cells, eventually leading to a chronic state of inflammation. Along the same lines as described above for the $T$ cells, the concept of $\mathrm{M} 1$ and $\mathrm{M} 2$ macrophages has recently been proposed. In that concept macrophage phenotypes are subdivided in pro-inflammatory (M1) and anti-inflammatory (M2) macrophages with unique phenotypic features ${ }^{22-25}$ (see section "Heterogeneity within the individual cell types" of this general introduction).

\section{Lipid metabolism in atherosclerosis}

As outlined above, one of the earliest events in atherogenesis is the formation of foam cells due to scavenger receptor (SR-A and CD36) mediated uptake of 
modified LDL. Once inside the macrophage, lipoprotein associated cholesterol esters are hydrolyzed by a lysosomal acidic cholesterol hydrolase, into free cholesterol. This free cholesterol is subsequently esterified into cholesterol esters by Acyl CoenzymeA:cholesterol Acyl Transferase (ACAT). In addition, these cholesterol esters are hydrolysed into free cholesterol by a neutral cholesterol hydrolase, such as hormone sensitive lipase. This process continues until the (unesterified) free cholesterol is removed from the macrophage by specific cholesterol acceptors such as HDL. This process is called reverse cholesterol transport and is mediated by the enzymes ATP-binding cassette transporters (ABC)-A and $A B C-G{ }^{26,27}$. A schematic representation of these processes is depicted in Figure 1.1.

\section{Fibrous cap formation}

Foam cells also produce growth factors such as insulin-like growth factor (IGF)1, transforming growth factor (TGF) $\beta$ and platelet derived growth factor (PDGF) which stimulate vascular smooth muscle cell (vSMC) proliferation ${ }^{14,} 28$. IL1 and TNF $\alpha$ produced by foam cells enhance the expression of PDGF by the VSMCs and ECs, which also stimulates SMC migration ${ }^{29}$.

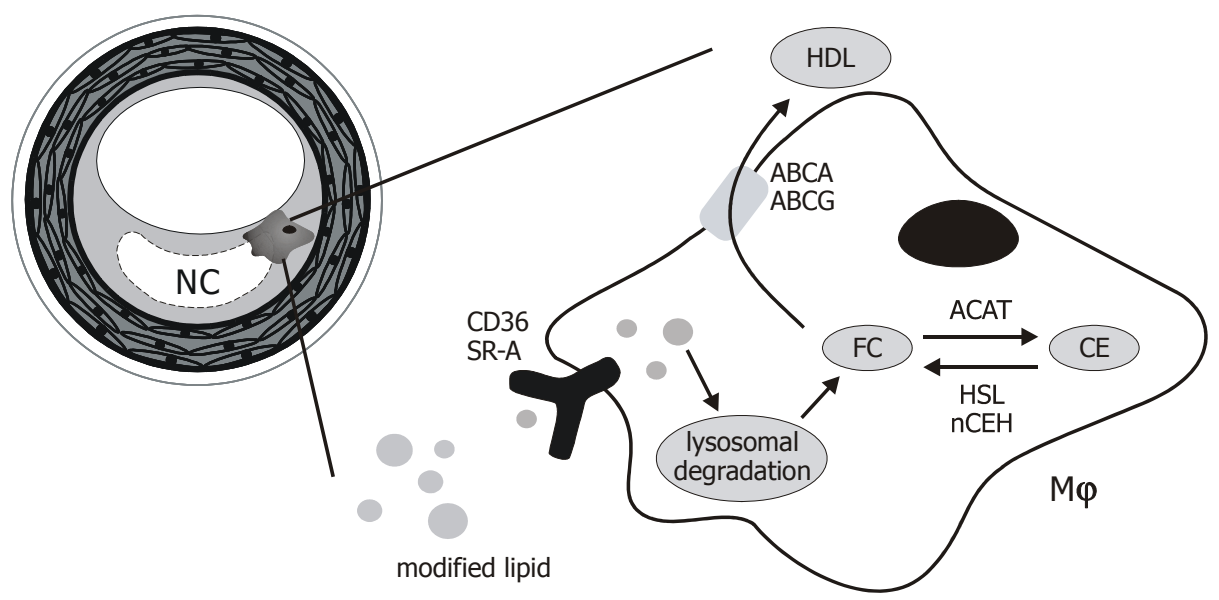

Figure 1.1

Modified lipids are taken up by the macrophage via scavenger receptors such as CD36 and SR-A. Inside the cell the lipid-associated cholesterol ester is hydrolysed by a lysosomal acidic cholesterol ester hydrolase leading to the formation of free cholesterol (FC). This free cholesterol is modified into cholesterol esters (CE) by acyl coenzymeA:cholesterol acyltransferase (ACAT). Cholesterol esters can be hydrolysed into free chrolesterol (FC) by a neutral cholesterol ester hydrolase (nCEH) such as hormone sensitive lipase (HSL). Free cholesterol is transferred to HDL by ATP binding cassette transporters (ABC) A and G which are located at the membrane. This process is called reverse cholesterol transport. 


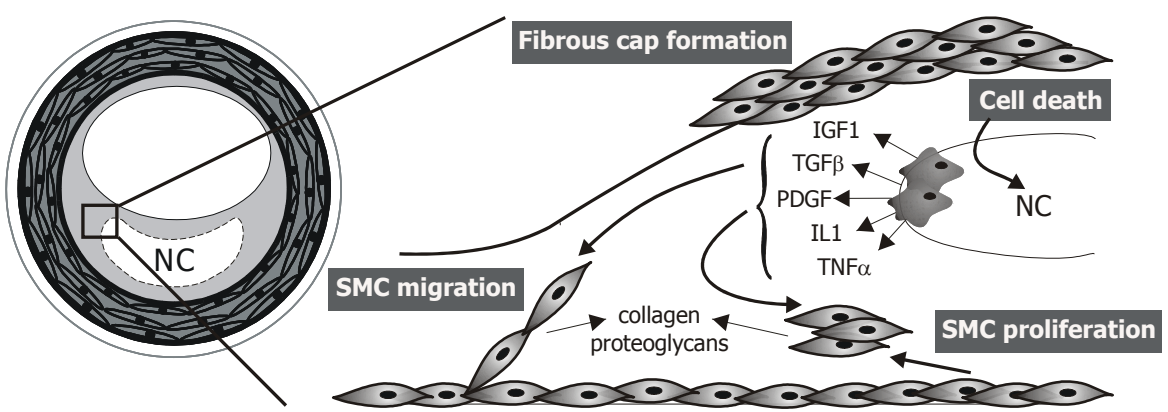

Figure 1.2

Progression of an atherosclerotic lesion is characterized by the formation of a fibrous cap by SMC migration and proliferation and the formation of a necrotic core. Foam cells produce cytokines, such as IL1 and TNF $\alpha$, and growth factors, such as PDGF, IGF- 1 and TGF $\beta$, which stimulate the SMC to migrate and proliferate. These migrating and proliferating SMCs produce ECM constituents such as collagen and proteoglycans, leading to the formation of a fibrous cap covering the necrotic core which is the predominant result of cell death.

SMCs migrate (from the media) and start to proliferate and produce extracellular matrix (ECM) constituents such as collagen and proteoglycans leading to formation of a fibrous cap. The fibrous cap covers the necrotic core which is composed of cell debris, as a result of cell death induced by apoptosis, necrosis or autophagy, cholesterol esters, free cholesterol, phospholipids and triglycerides. Figure 1.2 depicts a schematic representation of the fibrous cap formation.

\section{Apoptosis}

Besides cell proliferation, cell death is another important feature in atherogenesis. Cell death includes apoptosis and necrosis ${ }^{30}$ and affects all cells in the atherosclerotic lesion, including the macrophage. Cell death is an important regulator of lesion size and lesion stability. For instance the number of macrophages in the lesion is determined by the net balance between "monocytes/macrophage entry and proliferation" and "macrophage death and egress" ${ }^{31-34}$. Lesional macrophages contribute to SMC death by the production of cytotoxic amounts of NO, release of proinflammatory cytokines (e.g. IFN $\gamma$, $\mathrm{TNF} \alpha$ ) and direct cell-cell contact (e.g. Fas/Fas-L interactions) ${ }^{35,36}$. This SMC death results in decreased synthesis of extracellular matrix and interstitial collagen fibers, subsequently leading to thinning of the fibrous cap ${ }^{37}$. Several factors, present in atherosclerotic lesions, are capable to induce macrophage apoptosis, such as IL18 ${ }^{38}$, IFN $\gamma{ }^{39}$, Fas ligand ${ }^{40}$, free cholesterol ${ }^{41}$ and cholesterol crystallization ${ }^{42}$. 


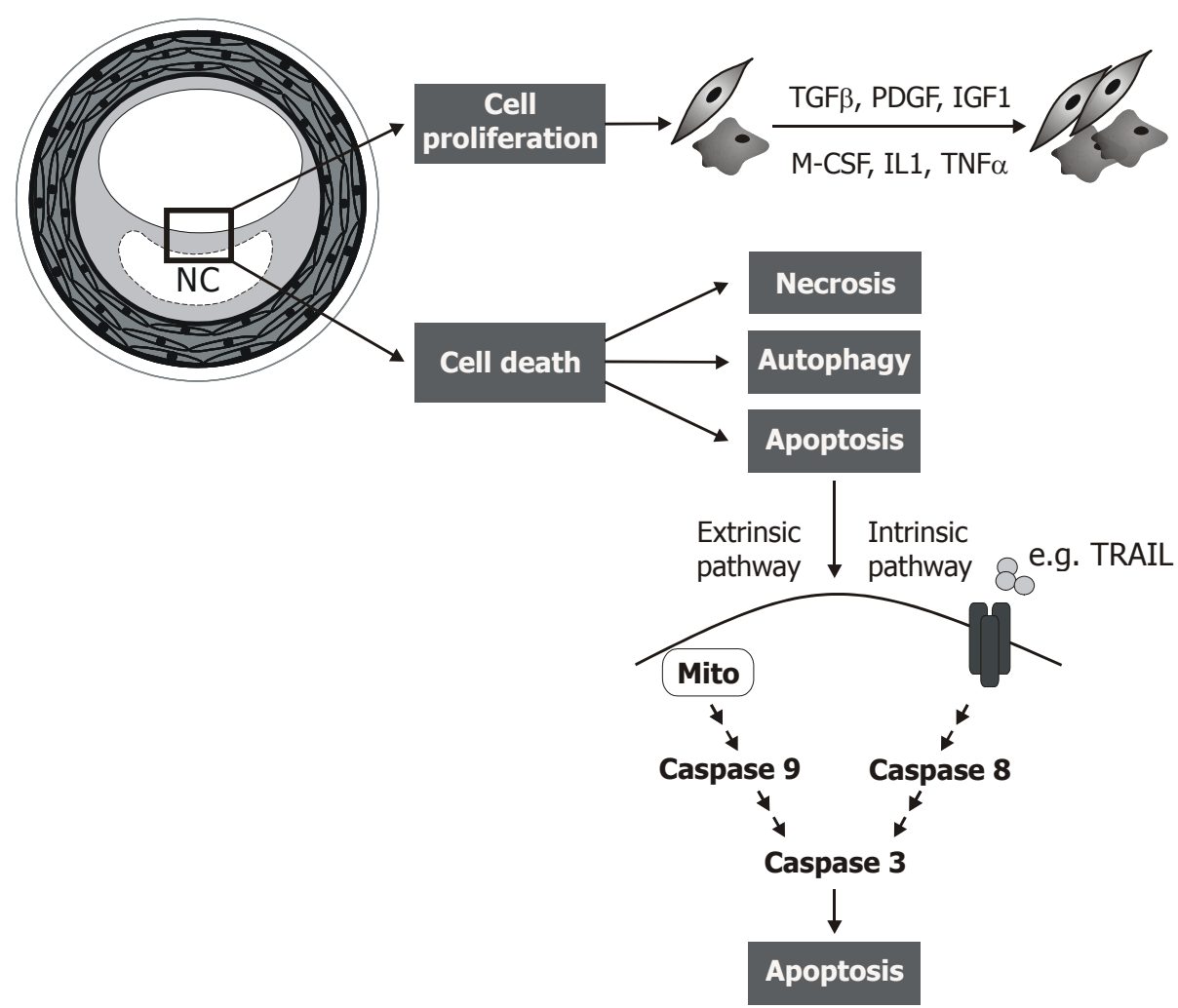

Figure 1.3

Cell turnover is the net balance between cell proliferation and cell death. Cytokines (such as IL1, TNF $\alpha$ ), growth factors (TGF $\beta$, PDGF, IGF1) and colony stimulating factors (such as M-CSF) are responsible for the proliferation of the SMCs and macrophages. Cell death is mainly caused by two processes; necrosis and apoptosis. Subsequently death cells are cleared by macrophages and clearance is dependent on a process in the dying cell: autophagy. Apoptosis can be initiated via the intrinsic pathway or the extrinsic pathway. Initiation of the intrinsic pathway via for instance mitochondrial stress results in a cascade of events leading to the activation of caspase 9 which in turn activates caspase 3. Initiation of the extrinsic pathway occurs after binding of a ligand to its receptor (TRAIL to Death receptor 4/5, Fasl to Fas) which results in a series of events leading to caspase 8 activation. Activated caspase 8 activates caspase 3 which is a so called executioner caspase. Activation of this caspase results in apoptosis $^{141,142}$.

Figure 1.3 shows an overview of processes involved in cell turnover with a focus on apoptosis. Macrophage apoptosis occurs throughout all lesion stages. Whether this macrophage death is beneficial or detrimental for lesion progression is suggested to be dependent on the lesion stage ${ }^{40}$. An important factor conferring this dependency on lesion stage is the ability (or lack) of phagocytes in the different stages of atherosclerosis to safely clear dead macrophages. In normal conditions apoptotic cells are effectively recognized and removed, by both professional phagocytes, such as macrophages and 
neutrophils, and other cell types such as epithelial cells ${ }^{43,44}$. Efficient apoptotic cell removal suppresses inflammatory signaling and activation of antiinflammatory pathways ${ }^{43}, 44$. On the contrary, phagocytic removal of necrotic cells often leads to an inflammatory response ${ }^{45}$.

The phagocytic clearance of apoptotic macrophages in early atherosclerotic lesions is efficient, as mouse studies have shown that a decrease in macrophage apoptosis results in an increase of lesion area. This implies that normal macrophage apoptosis (including efficient apoptotic clearance) limits lesion area ${ }^{46-48}$. Advanced lesions contain more apoptotic macrophages as compared to early lesions, suggesting defective phagocytic clearance ${ }^{32,}{ }^{49}$, a hypothesis that is supported by data showing that advanced atherosclerotic lesions contained a substantial number of apoptotic cells, which were not engulfed by phagocytes ${ }^{50}$. This defective or impaired clearance of apoptotic macrophages leads to necrosis of the apoptotic macrophages and subsequently to a heightened state of inflammation ${ }^{51,52}$. The accumulation of non-cleared apoptotic cells and post-apoptotic necrotic cells likely has important proatherogenic effects such as stimulation of tissue factor (TF) expression ${ }^{53,54}$, the release of thymidine phosphorylase, a potent angiogenic factor ${ }^{55}$, and the secretion of matrix degrading proteases by surrounding macrophages that are stimulated by the inflammatory factors in the necrotic core ${ }^{56}$. The overall effect is the generation of a necrotic core, which promotes further inflammation, lesion instability and thrombosis. Thus macrophage apoptosis in advanced lesions, where phagocytic clearance of apoptotic cells is defective or impaired, promotes lesion progression and ultimately lesion disruption.

\section{Extracellular marix trnover in atherosclerosis}

The extracellular matrix (ECM) is an important constituent of an atherosclerotic lesion and contributes to lesion growth and stability. ECM proteins are secreted by SMCs and macrophages. The amount of matrix proteins is determined by the balance between matrix synthesis, maturation and degradation. Matrix degradation is a highly regulated process and is closely linked to stability of the atherosclerotic lesion. Macrophages play a prominent role in matrix degradation by producing ECM degrading enzymes such as MMPs ${ }^{56-58}$ and cysteine proteases (cathepsins) ${ }^{59-62}$ which degrade the ECM leading to weakening of the fibrous cap and rupture of the atherosclerotic lesion. Figure 1.4 depicts a schematic representation of matrix turnover in atherosclerotic lesions. 


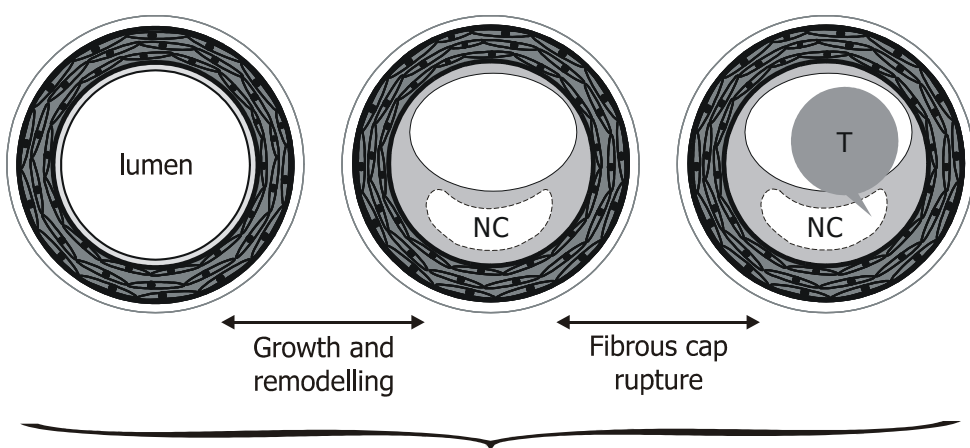

Matrix turnover

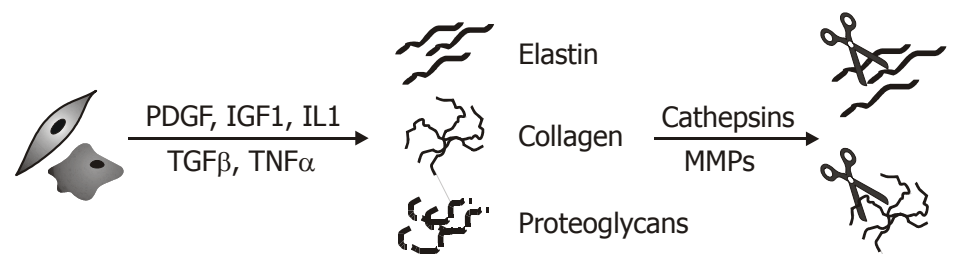

Figure 1.4

ECM turnover plays an important role in the progression of an atherosclerotic lesion especially in the regulation of lesion stability. SMCs produce elastin, collagen and proteoglycans under the influence of cytokines (which can be secreted by activated macrophages), such as IL1 and TNF $\alpha$, and growth factors, such as PDGF, IGF1 and TGF $\beta$. This increase in ECM deposition contributes to lesion progression and lesion stabilization. Macrophages play an important role in the degradation of ECM proteins since they secrete ECM degrading enzymes such as cathepsins and MMPs. Increased degradation of the ECM proteins can lead to the weakening of the fibrous cap and eventually to rupture of this fibrous cap.

\section{Lesion rupture}

The large majority of the clinical symptoms of atherosclerosis are due to either fibrous cap rupture, intraplaque bleeding or lesion erosion with subsequent thrombosis. Intraplaque bleeding is associated with an increased amount of (leaky) intraplaque vessels and lesion erosion with endothelial denudation. Fibrous cap rupture is associated with smooth muscle cell death and extracellular degradation. When the fibrous cap ruptures, the underlying necrotic core comes into contact with blood. This necrotic core is highly thrombogenic due to the presence of lipids and pro-coagulant factors, such TF which is produced, among others, by activated macrophages and foam cells ${ }^{63}$. This will result in the thrombus formation which leads to acute clinical complications such as myocardial infarction, stroke and peripheral ischemia.

In conclusion, atherosclerosis is a complex, chronic inflammatory disease, mediated by a dynamic interplay between inflammation, lipid metabolism and cell turnover and remodeling of the ECM. 


\section{Classification of atherosclerotic lesions}

Over the years several classifications of human atherosclerotic lesions have been proposed and applied, such as the American Heart Association (AHA) classification. The classification that is used in this thesis is developed by Virmani et al ${ }^{1}$ who modified the AHA classification to some extent. Using the Virmani classification lesions can be divided into three main groups that is early lesions, late lesions and ruptured lesions. "Intimal thickening", "intimal xanthoma" and "pathological intimal thickening" are considered as early lesions. They represent clinically silent lesions mainly consisting of lipid laden macrophages, SMCs and lymphocytes. The group of advanced stable lesions is composed of "thick fibrous cap atheromas" "thin fibrous cap atheromas" and the "fibro-calcific lesions". Thick fibrous cap atheromas are lesions with a necrotic core, covered by a fibrous cap. The thin fibrous cap atheromas are "fibrous cap atheroma" with a thin fibrous cap (less than $65 \mu \mathrm{m}$ thick). These lesions are thought to be more prone to rupture. "Fibro-calcific lesions" are predominantly composed of dense collagen and contain extensive accumulations of calcium. The third group comprises of ruptures lesions and includes lesions with a luminal thrombus, lesions with an intraplaque haemorrhage and lesions with endothelial erosion. Ruptured lesions are lesions which a distinct disruption of the fibrous cap and a thrombus that is in contact with the necrotic core. Lesions with erosion are lesions which display a (luminal) thrombus without signs of fibrous cap rupture. Erosion is mainly observed in lesions that are rich in SMCs and ECM and contain minimal inflammation. Finally, intraplaque haemorrhage is suggested to be the result of fissures in the fibrous cap rather than a disruption of the cap. The presence of plaque fissures may represent precursors or subtypes of lesion rupture. Alternatively, Paterson et $a /{ }^{64}$ proposed that intraplaque haemorrhage is secondary to rupture of lesion microvessels. Recently it has been suggested that the presence of immature (and therefore "leaky") microvessels in advanced lesions are also a likely source of intraplaque haemorrhage ${ }^{65,66}$. Figure 1.5 shows a schematic representation of human atherosclerotic lesion development. 

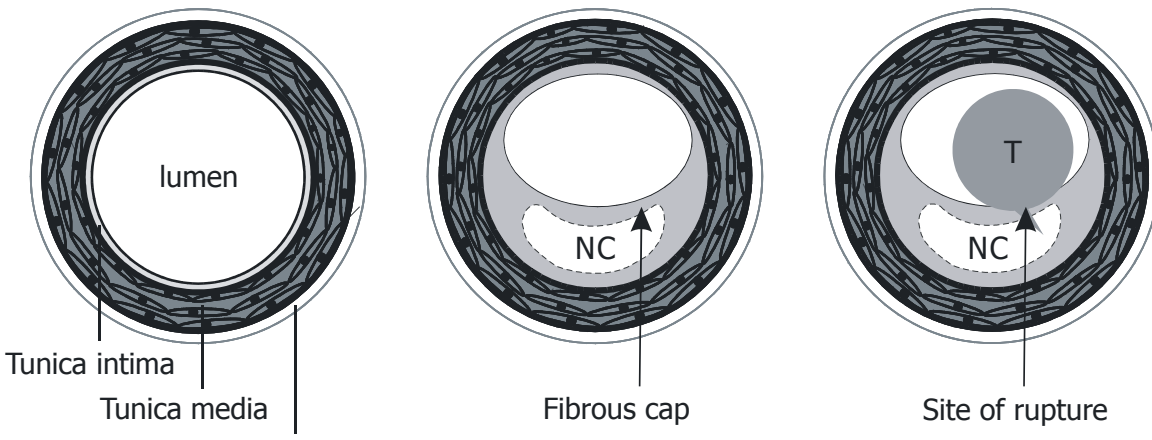

Tunica adventitia
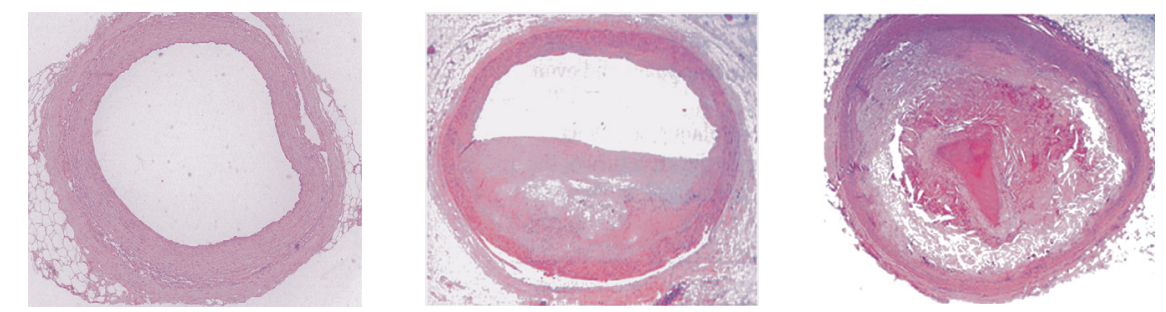

Figure 1.5

Schematic representation of human atherosclerotic lesion development (upper panel). A normal artery (left picture) consist of three layers: the tunica intima (the innermost layer), tunica media (the middle layer) and the tunica adventitia (the outermost layer). During lesion development cells, lipid and matrix accumulate in the tunica intima leading to the development of a necrotic core, which is covered by a fibrous cap (illustrated by the middle figure). Thinning and weakening of the fibrous cap may lead to rupture of the lesion and formation of a thrombus, which may (partially) occlude the lumen of the vessel (right picture). Hematoxylin and Eosin (HE) stained sections of the corresponding lesion stages are shown in the lower panel.

\section{Gene expression studies in human atherosclerosis}

In the last decade several techniques have been used to study the gene expression profiles of human atherosclerosis (reviewed in ${ }^{67,68}$ ), like microarray analysis ${ }^{69-83}$ CDNA representational difference analysis (RDA) ${ }^{84}$ and suppression subtractive hybridization (SSH) ${ }^{85}$. These approaches enable to simultaneously study the expression level of several hundreds to thousands of genes. The disadvantage of microarray analysis compared to RDA and SSH is that the outcome is limited by the genes represented on the array. SSH and RDA are polymerase chain reaction (PCR)-based techniques which only amplify those transcripts which are differentially expressed between the different (experimental) conditions. These techniques, however, do not provide quantitative information on the differences in mRNA levels. The above mentioned studies yielded valuable information on the (molecular) mechanism underlying atherosclerosis and stresses the importance of processes such as 
inflammation $74,75,78,86$ matrix degradation ${ }^{69,75,86}$, lipid metabolism ${ }^{69,75}$ and cell turnover ${ }^{69,74,75,78,86}$ in atherogenesis. Aside from valuable information on the pathogenesis of atherosclerosis these studies also revealed several individual genes such as early growth response gene (ERG)-1 ${ }^{70}$, deathassociated protein kinase (DAPK)-1 ${ }^{71}$, Perilipin ${ }^{85}$, cathepsin $\mathrm{K}^{87}$ and Vasculin ${ }^{88}$ as candidates to modulate or diagnose the progression of atherosclerosis. Although the previously mentioned studies made a prominent contribution to our current knowledge of the mechanisms underlying atherosclerosis, the low statistical power to detect differentially expressed genes is an important limitation. This low statistical power is the result of the high variability in the gene expression profiles, pooling of samples or a small number of biological replicates. The variability within gene expression profiles is a result of heterogeneity, which can either be present within the study population, within the origination of the biological sample or within the sample itself. In the following paragraphs we will discuss the consequences of a limited statistical power in microarray studies. Furthermore a detailed overview will be given of the possible sources of heterogeneity and the level of heterogeneity in the human atherosclerotic gene expression profiling studies published.

\section{Heterogeneity}

The presence of heterogeneity introduces an increase in the variability of gene expression profiles and results in a drop of statistical power. As a consequence of this limited statistical power, subtle changes in gene expression profiles will be missed. These subtle changes might be the reflection of the expression profile of a specific population in the biological samples. For example, genes which are only differentially expressed during atherogenesis in patients on statin treatment or in the macrophages will be missed when combining patients on various medications or when using an entire vascular segment containing ECs, SMCs, T cells and macrophages. The limited statistical power also has an advantage as heterogeneity independent, (common) denominators underlying the atherosclerotic process will be identified. As will be discussed below, in most of the published gene expression studies at least one form of heterogeneity is present. An increase in statistical power, which is possible by reducing the heterogeneity, might lead to the detection of additional molecules/pathways and increased insights into the development or progression of atherosclerosis. 
Chapter 1

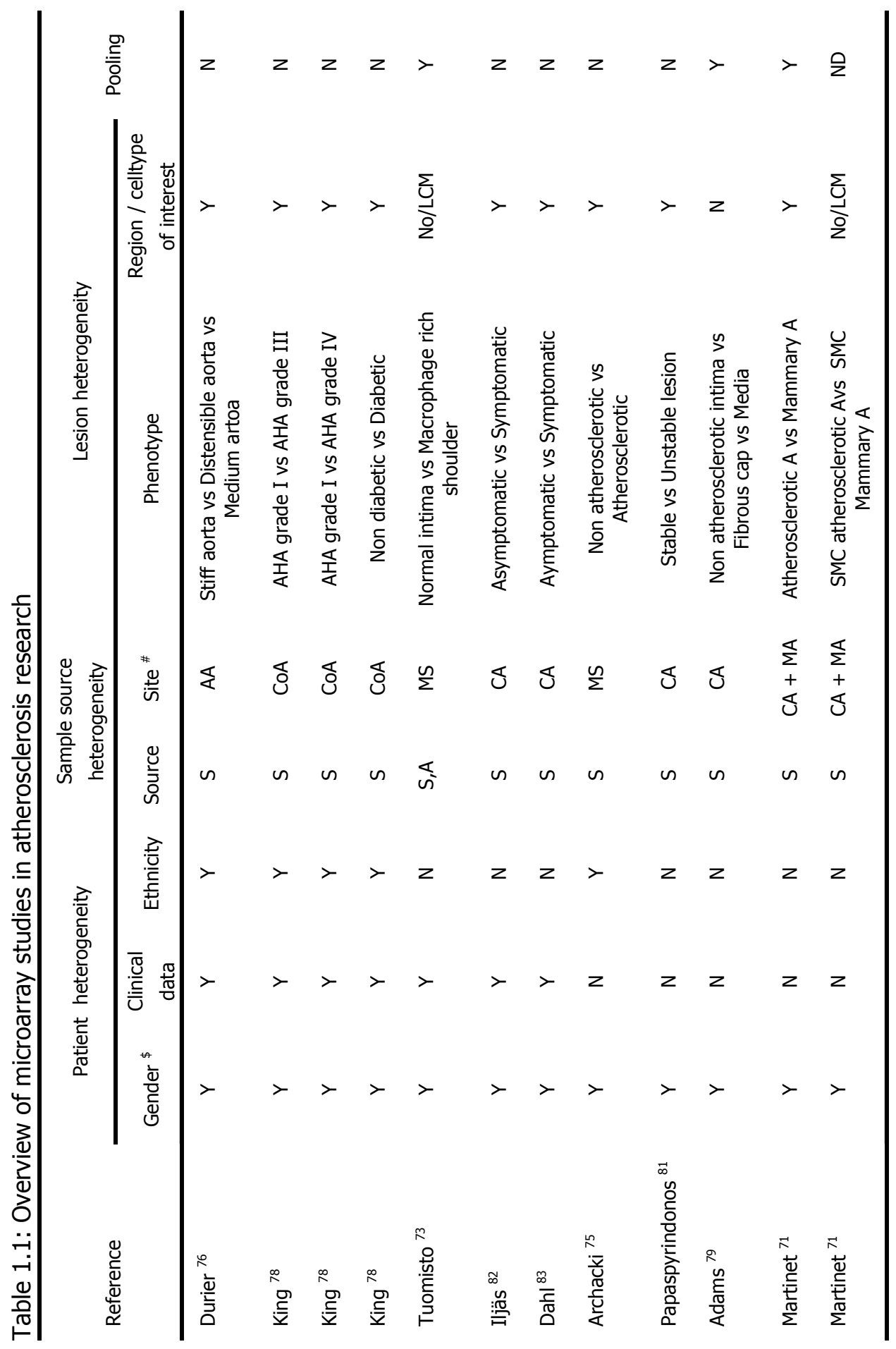


General introduction

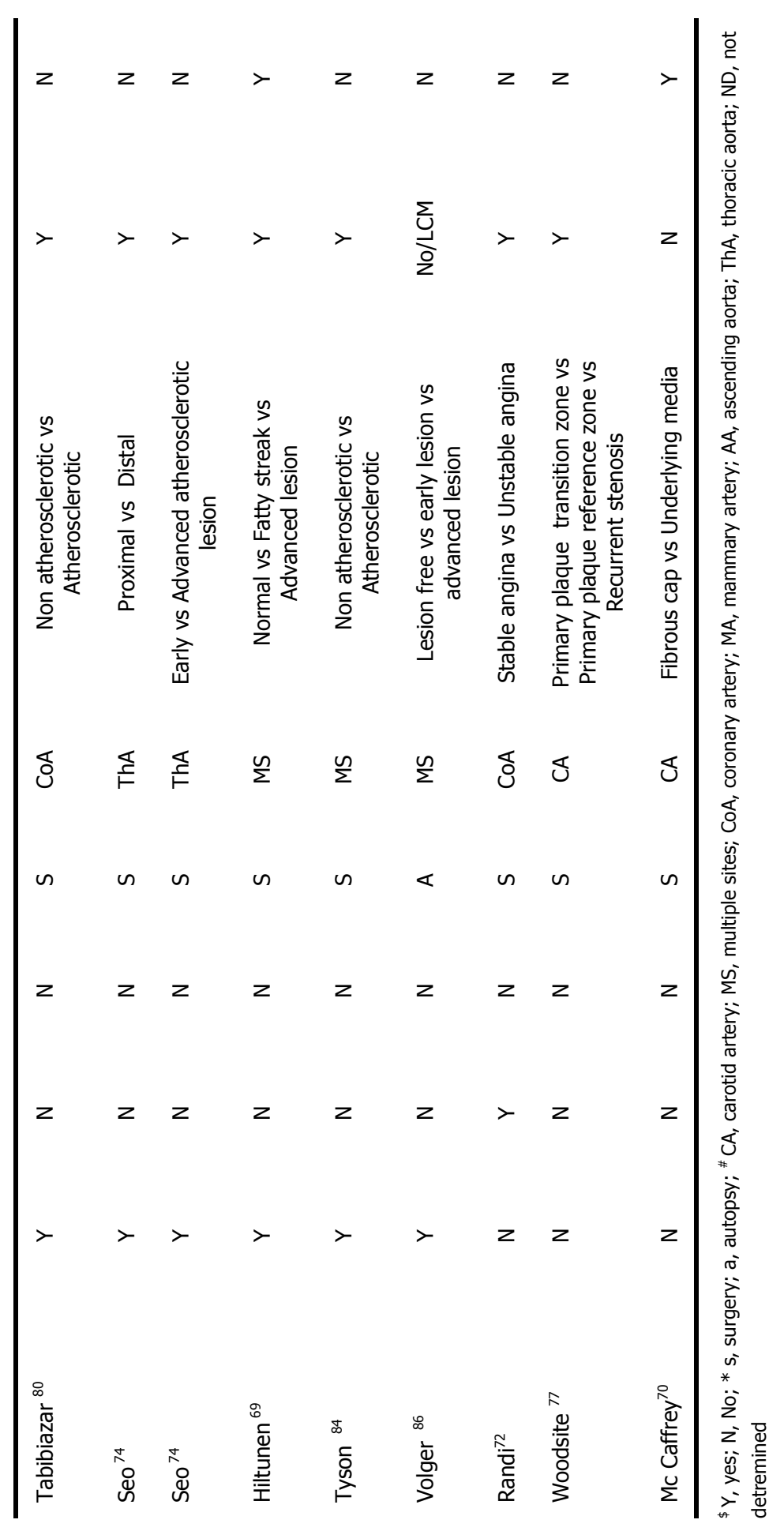




\section{Patient heterogeneity}

Gender, age, ethnic background and the clinical data (e.g. medication, hypercholesteremia, smoking, diabetes, family history etc.) of the donors all influence the gene expression profiles. The use of different donors introduces several of these confounding factors (e.g. gender, medication etc.) in the study and affects the gene expression profiles of atherosclerotic lesions derived from these donors, which increases its variability. The use of human vascular samples makes a certain amount of variability inevitable, however by using samples obtained from donors of the same age, same gender, same ethnic background and patients with comparable clinical data or alternatively by performing intra patient comparisons variability can be lowered substantially. It is therefore very important to have access to individual anonymous donor data.

\section{Gender}

As shown in Table 1.1, the information about the donors' gender is most often known; in 15 out of the 18 published studies the gender was known. Although combining data from both sexes might assist the quest for "general" atherosclerotic genes, genes which are only differentially expressed in a single gender will be missed. It is generally accepted that premenopausal women are relatively protected against atherosclerosis and that sex hormones may affect the development of atherosclerosis ${ }^{89}$. Knowledge about these gender specific genes might thus result in a better understanding in how sex hormones affect atherogenesis. Furthermore these data might lead to the development of gender specific therapies.

\section{Clinical data and Ethnicity}

In most studies only limited clinical data or ethnic background of the donor are provided (Table 1.1). In only 6 out of 18 studies clinical information was provided, while in even less (only 3 of the 18) studies information on the ethnic background of the donors was provided. It is well known that medication, such as statins, and the risk factors for atherosclerosis affect the atherosclerotic process in distinct ways. Therefore combining donors using different medications and/or donors exposed to different risk factors will increase the variability of the gene expression profiles. Besides gender and clinical data, also the ethnic background of donors can affect the atherosclerotic process. It has been shown that the prevalence and severity of coronary artery calcification differs among patients with different ethnic backgrounds ${ }^{90}$. Furthermore a 
recent study showed that endothelial reactivity is impaired in African black patients compared to white patients ${ }^{91}$. Thus, combining different ethnic backgrounds in a study might lead to an increased variability in the gene expression profiles. Although stratification for the relevant clinical data and the ethnic background of a patient will increase the statistical power, it is difficult to include these parameters in a study design, since most researchers do not have access to this information.

\section{Samples source heterogeneity}

Besides the above described patient based heterogeneity, the origin of the vascular segments can be a source of heterogeneity. The two major causes of sample source heterogeneity are the procedure by which the vascular segments were obtained e.g. autopsy or surgery, and the location within the vascular system from which the specimen originates.

\section{Source}

Some recent papers provide evidence for a significant difference in gene expression profiles of samples obtained from autopsy and surgery ${ }^{92-94}$. With the exception of one study ${ }^{73}$, all human atherosclerotic gene expression studies included samples obtained from a single source, thus reducing the variability due to sample source heterogeneity (Table 1.1). Most studies used surgical samples. This minimizes the risk of RNA degradation, which is thought to occur more frequently in samples obtained from autopsy. However, mRNA from samples obtained during autopsy has been shown to be fairly resistant to degradation in a wide variety of tissues ${ }^{92,95,96}$. Total mRNA remained intact up to 48 hours postmortem ${ }^{92,96}$ and microarray expression data were found to be reliable even when mRNA was partially degraded ${ }^{95}$. A disadvantage of samples obtained during surgical procedures, like atherectomies, is the lack of the availability of non-diseased arteries, early lesions or information from the media and adventitia. One exception is the samples from patients undergoing heart transplantations, in which non-diseased arteries and specimens containing early lesions might be available. 
Site

Another cause of sample source heterogeneity is the location of the vascular specimen within the vascular bed. The various sites of the vascular bed differ in embryonic origin ${ }^{97}$, haemodynamic forces or cellular composition. For instance, the thoracic aorta contains much more transmedial lamellar units, more elastin and less collagen than the abdominal aorta ${ }^{98,99}$. As a result of this, the various sites of the vascular bed is expected to respond in different ways to the systemic effects, which will most likely be reflected at the gene expression level ${ }^{100}$. As showed in Table 1.1, in 6 of the 18 human atherosclerotic gene expression studies samples obtained from different sites of the vascular bed were combined ${ }^{69,71,73,84-86}$. However, the majority of the studies compared identical sites of the vascular bed thus reducing the sample source variability.

\section{Lesion heterogeneity}

Besides patient heterogeneity and sample source heterogeneity, lesion heterogeneity can be discriminated. The two major causes of lesion heterogeneity are the phenotype of the lesions/vascular specimen and the lesional region and/or cell type of interest.

\section{Lesion phenotype}

It is well recognized that the phenotypic differences in lesions are reflected by their gene expression profiles. In most studies alterations in gene expression of different lesion phenotypes is the main subject of the study and is therefore recognized in the study design.

\section{Region and/or cell type of interest}

With the exception of 5 studies ${ }^{70,71,73,79,86}$, all studies used the entire lesion or even an entire vascular segment (whole mount lesion) to study gene expression patterns in human atherogenesis (Table 1.1). A potential pitfall in analyzing a complex tissue is that it is made up of several types, with each cell type having its own unique gene expression profile. In a complex structure as an atherosclerotic lesion it might be hard to determine whether the observed differences in gene expression profiles reflect a changed cellular composition of the vessel wall (e.g. thinning of the medial smooth muscle layer or the infiltration of T-lymphocytes) or a change in gene expression profile of the cell 
type of interest. In addition, a large cellular heterogeneity might mask subtle changes in gene expression profiles. A powerful solution to the problem of cellular heterogeneity is the isolation by macrodissection, microdissection or culturing one cell type isolated from the vascular segment. An advantage of the cell culture approach is that the amount of material is not the limiting factor, thus omitting the need of pooling samples. However, a disadvantage is that in vitro culturing may induce differentiation of the cells causing a shift in the gene expression profiles. As a consequence these gene expression profiles might not be representative for the in vivo situation. In this thesis we focus on human atherosclerotic specimens. Therefore we have not included articles using in vitro experiments to study atherosclerosis.

In two studies macrodissection was used to separate complete regions of an atherosclerotic lesion such as the fibrous cap ${ }^{70,79}$, the media and the intima ${ }^{79}$. To achieve this, the intima was dissected from the overlying tissue and the fibrous cap was dissected from the necrotic core and the macrophage rich shoulder regions. In three other studies ${ }^{71,73,86}$ laser microdissection was used to microdissect the SMCs and/or macrophages and ECs from entire atherosclerotic lesions to determine cell specific changes in gene expression profiles. In the following sections of this introduction the principle of laser capture microdissection (LCM) and its application in atherosclerosis/ cardiovascular research will be discussed.

\section{Laser capture microdissection}

This technique was developed in 1996 by Michael R. Emmert-Buck ${ }^{101}$. At that time several tissue microdissection techniques, including gross dissection of frozen tissue block to enrich for a specific cell population ${ }^{102,103}$, irradiation of manually ink-stained sections in order to destroy unwanted genetic material ${ }^{104}$, touch preparations of frozen tissue specimens ${ }^{105}$ and microdissection with manual tools ${ }^{106-109}$ were available. Unfortunately none of these methods offered the ease, precision and efficiency that was necessary to use it in routine molecular diagnostic applications or research. To overcome these drawbacks, the LCM technique was developed. In this method a thin, transparent film, still allowing microscopically visualization is placed on top of a tissue section. Cells of interest are positioned in the center of the optical field. Activation of a fixed infrared laser leads to adhesion of the transparent film to the desired cells. The film containing the adhered cells is then removed from the tissue section and is placed directly into tissue lysis buffers for subsequent RNA, DNA or protein isolation methods. The heat which is a result of the infrared laser activation is mainly absorbed by the thermoplastic film and hardly absorbed by the tissue or cells, thereby preventing degradation of DNA, RNA and/or protein ${ }^{110}$. 


\section{Limitations of the LCM technique}

The introduction of the LCM technique offered a variety of new perspectives to study (molecular) mechanisms involved in diseases affecting complex heterogeneous tissues. However, like every technique, also LCM has some drawbacks.

Since the tissue sections are not covered by a cover slide during microscopic visualization, the optical resolution is far from optimal. This leads to difficulties in the localization of the cells of interest ${ }^{111}$. These can be identified (after histological stainings, such as a Haematoxylin Eosin (HE) staining) by their typical morphology. As not all cell types can be distinguished solely on morphological characteristics, an immunohistological staining could facilitate their further identification. Unfortunately conventional immunohistochemical stainings require several hours of incubation in aqueous media, leading to RNA degradation. Although several studies describe rapid staining procedures using either increased antibody concentrations, addition of RNase inhibitors ${ }^{112}$ and the use of direct fluorescently conjugated antibodies ${ }^{113}$, the results of these studies are at best contradictory. Some authors claim preserving the RNA ${ }^{114}$, while others report massive RNA degradation ${ }^{112}$. Another concern is the small amount of RNA that can be isolated by LCM. To obtain sufficient amounts of RNA, pooling of the samples and/or amplification of the RNA is necessary. The use of the T7 based amplification and its possible limitations have extensively been studied (reviewed by ${ }^{115}$ ). Although variations in differential gene expression between amplified and non amplified total RNA can be observed, linear amplification using a T7 based method results in reproducible RNA amplification and improved sensitivity of gene expression profiling ${ }^{116}$.

\section{$\underline{\text { LCM in atherosclerosis research }}$}

Although LCM is frequently used in oncology research ${ }^{117}$ its application in atherosclerosis research is still limited (Table 1.2).

In the study described by Engelse et al ${ }^{118}$ LCM was successfully applied to isolate medial SMCs from cuffed femoral mouse arteries. Trogan et al ${ }^{119}$ clearly demonstrated that microdissection of macrophages from mouse atherosclerotic lesions resulted in an enrichment of macrophage specific genes compared to the whole mount lesion as assessed by quantitative realtime PCR. In the study described by Babaev et $a^{120}$ the combination of LCM and quantitative realtime PCR was used to verify suppressed scavenger receptor (SR) B type I and increased nuclear factor- $\mathrm{KB}(\mathrm{NF} \kappa \mathrm{B})$ gene expression levels in macrophages of $\mathrm{PPAR}^{-1-} \mathrm{LDLR}^{-/}$mice compared to macrophages of $\mathrm{PPAR}^{+/+} \mathrm{LDLR}^{-1-}$ mice. Stagliano et al ${ }^{114}$ used LCM technique to microdissect the tunica media from 
Table 1.2: Overview of LCM application in atherosclerosis research

\begin{tabular}{|c|c|c|c|c|}
\hline $\begin{array}{l}\text { Author and } \\
\text { reference }\end{array}$ & Species & Cell type & Comparison & $\begin{array}{l}\text { Application/ } \\
\text { technique }\end{array}$ \\
\hline Engelse ${ }^{118}$ & Mouse & $\begin{array}{l}\text { Medial smooth } \\
\text { muscle cells }\end{array}$ & $\begin{array}{c}\text { Activin A treated vs Non } \\
\text { treated cuffed femoral } \\
\text { arteries }\end{array}$ & $\mathrm{q}-\mathrm{PCR}$ \\
\hline Trogan ${ }^{119}$ & Mouse & Macrophages & $\begin{array}{c}\text { Macrophage vs Whole } \\
\text { mount } \\
\text { LPS treated vs Non treated }\end{array}$ & $\mathrm{q}-\mathrm{PCR}$ \\
\hline Babaev $^{120}$ & Mouse & Macrophages & $\begin{array}{c}\text { PPAR }^{+/+} \text {LDLLR }^{-/} \text {mice vs } \\
\text { PPAR }^{-1-} \text { LDLR }^{-1-}\end{array}$ & $\mathrm{q}-\mathrm{PCR}$ \\
\hline Stagliano ${ }^{114}$ & Human & $\begin{array}{l}\text { Medial smooth } \\
\text { muscle cells }\end{array}$ & Veins vs Arteries & $\mathrm{q}-\mathrm{PCR}$ \\
\hline Tiwari ${ }^{121}$ & Human & $\begin{array}{l}\text { Medial smooth } \\
\text { muscle cells }\end{array}$ & $\begin{array}{l}\text { Atherosclerosis affected } \\
\text { vs Non affected regions }\end{array}$ & $\mathrm{q}-\mathrm{PCR}$ \\
\hline Bagnato ${ }^{122}$ & Human & Heterogeneous & $\begin{array}{l}\text { Intima, media and } \\
\text { adventitia }\end{array}$ & $\begin{array}{c}\text { Proteomic } \\
\text { analysis }\end{array}$ \\
\hline Martinet ${ }^{71}$ & Human & $\begin{array}{l}\text { Medial smooth } \\
\text { muscle cells }\end{array}$ & $\begin{array}{l}\text { Atherosclerotic vs } \\
\text { Mammary artery }\end{array}$ & Microarray \\
\hline Tuomisto $^{73}$ & Human & Macrophages & $\begin{array}{c}\text { Macrophage rich shoulder } \\
\text { vs } \\
\text { Normal intima }\end{array}$ & Microarray \\
\hline Volger ${ }^{86}$ & Human & Endothelial cells & $\begin{array}{l}\text { Lesion free vs early } \\
\text { lesions vs Advanced } \\
\text { lesions }\end{array}$ & Microarray \\
\hline
\end{tabular}

normal human arteries and veins and showed successful RNA isolation. Tiwari et al ${ }^{121}$ microdissected medial vascular smooth cells from human vessel segments affected and not affected by atherosclerosis and showed alternative splicing of the Cav1.2a1 subunit in atherosclerosis. The study described by Bagnato et $a^{122}$ used the LCM technique in combination with a proteomics analysis. The intima, media and adventitia were microdissected from human coronary atherosclerotic lesions and used in proteomic techniques. This study showed that the LCM technique is compatible with proteomic techniques such as liquid chromatography and tandem mass spectrometry.

Also the combination of microarray analysis and LCM has been described in atherosclerosis research. Martinet et al ${ }^{71}$ compared the gene expression profiles of carotid medial SMCs with those of the non-diseased mammary artery 
using a dedicated nylon membrane based array containing apoptosis related genes. In the study described by Tuomisto et $a^{73}$, the macrophage inflammatory rich shoulder regions and the SMC rich intima were microdissected and compared using microarray analysis. Volger et $a^{8}{ }^{86}$ microdissected the ECs from lesion free vessels, early atherosclerotic lesions and advanced atherosclerotic lesions and performed microarray analyses. They identified differential enrichment of a set of chemokines and NFKB, p53 and TGF $\beta$ related genes in endothelium of advanced atherosclerotic lesions.

\section{Heterogeneity within the individual cell types}

Besides sample, lesion and patient based heterogeneity, heterogeneity can also occur within a specific cell type. This heterogeneity is mainly due to differences in differentiation of the cells or the existence of different subtypes within a single cell type. This becomes apparent when a cell type is subjected to different (micro) environmental factors (e.g. ECs in arteries compared to veins 123 or synthetic SMCs compared to contractile SMCs ${ }^{5,124}$ ). When various subtypes of a single cell type reside within a tissue specimen, genes differentially expressed within a specific subpopulation might easily be missed. In the next sections the major cell types represented in an atherosclerotic lesion and their heterogeneity will be discussed briefly.

\section{Endothelial cells}

ECs line the lumen of blood and lymphatic vessels and therefore play an important role in the regional specialization of the vascular structure and physiology. Heterogeneity in ECs is likely to provide at least two advantages: first it allows the endothelium to adapt to the various needs of the underlying tissues and secondly it provides the endothelium with the capacity to adapt to different micro environments (e.g. the hypoxic environment of inner medulla of the kidney compared to the well oxygenated environment of pulmonary alveoli) 125 .

One reason underlying the phenotypic heterogeneity of ECs is the spatial and temporal difference in the extracellular environment (reviewed by Aird et $a^{125,}$ $\left.{ }^{126}\right)$. For example, Chi et al ${ }^{127}$ conducted a large scale microarray analysis to determine the expression profiles of 53 multiple passaged cultured ECs obtained from 5 different arteries, 2 different veins and 7 different tissues to gain insight in endothelial specialization. This study revealed differences in the transcriptional profiles between arterial and venous ECs, and between macrovascular and microvascular ECs. Recently, Volger et al ${ }^{86}$ demonstrated 
that ECs microdissected from human atherosclerotic lesions exhibit differential gene expression profiles during atherogenesis. This study provides evidence for a prominent role for chemokines and the $\mathrm{NF}_{\kappa} \mathrm{B}$, p53 and TGF $\beta$ signaling pathways in ECs during atherogenesis.

\section{Smooth muscle cells}

It has been shown that SMCs, the dominant cell type in the fibrous cap, can undergo a phenotypic switch, which would imply that there are subpopulations of SMCs present in atherosclerotic lesions. Activated endothelium secretes mediators which induce migration of the contractile medial SMCs to the intima were they further proliferate and (reversibly) switch their phenotype towards a more synthetic state, in which they secrete ECM proteins. Studies in human atherosclerosis and animal models of arterial injury indeed demonstrate that the SMCs in the intima are phenotypically different from medial SMCs and display differences in marker profiles. For example, a decrease of contractile markers, such as sm-MHC (smooth muscle myosin heavy chain) and Calponin, has been observed whereas the expression of synthetic markers such as cytokeratin 8 and 18 increases ${ }^{5,124,128}$. This heterogeneity in the SMCs has also been observed in gene expression studies. Mulvihill et $a{ }^{129}$ showed that although the SMC cultures obtained from lesional and medial SMCs were nearly indistinguishable by morphological features, gene expression profiling revealed extensive differences. In another study the gene expression profiles of different SMC-rich lesion components, such as the intima, media and fibrous cap, clearly demonstrated the presence of SMC diversity within the intima and fibrous cap, where loss of RGS5, alcohol dehydrogenase $1 \mathrm{~B}(\mathrm{ADH} 1 \mathrm{~B})$ and mitogen-activated protein kinase kinase kinase 10 (MAP3K10), distinguished the fibrous cap SMC 79.

\section{$T$ cells}

T cells play a central role in cell mediated immunity and a diversity of $T$ cell subtypes have been described, each with a distinct function. In general the cytotoxic $T$ cells destroy virally infected cells and tumor cells, whereas the helper $\mathrm{T}$ cells mediate the adaptive immune system. Once activated $\mathrm{T}$ cells rapidly divide and secrete cytokines that regulate the immune response. The natural killer $T$ cell bridges the adaptive immune system with the innate immune system and the regulatory $T$ cell tunes down the immunity. Atherosclerotic lesions contain many of the $T$ cell subtypes including cytotoxic $T$ cell (CD8 ${ }^{+} \mathrm{T}$ cell), helper $\mathrm{T}$ cells $\left(\mathrm{CD} 4^{+} \mathrm{T}\right.$ cell), natural killer $\mathrm{T}$ cells ${ }^{15}$ and 
regulatory $\mathrm{T}$ cells ${ }^{130}$. In addition, these different types of $\mathrm{T}$ cells can undergo further differentiation upon stimulation by cytokines. For example, upon specific cytokine stimuli the $\mathrm{CD}^{+}{ }^{+} \mathrm{T}$ cell can differentiate into either a Th1-subtype or a Th2-subtype. The Th1 response typically involves pro-inflammatory and mainly pro-atherogenic mediators, such as IFNy, TNF $\alpha$ and IL2, whereas the Th2 response typically favors the production of the anti-inflammatory and antiatherogenic cytokines such as IL4, IL5, IL10 and IL13 ${ }^{131}$. IL12 induces a Th1 response, whereas IL10 induces a Th2 response. In addition these Th1 and Th2 cytokines are cross regulatory, since IL10 inhibits the Th1 response whereas IFN- $\gamma$ inhibits the Th2 response. It can be appreciated that the presence of several $T$ cell subpopulations, with each their distinct function, in an atherosclerotic lesion introduces a high variability in the gene expression profiles and the subsequent difficulty in detecting differential genes for a specific subpopulation.

\section{Monocytes/macrophages}

It has long been recognized that macrophage heterogeneity is at least in part the result of the differentiation of tissue macrophages in specific micro environments. Circulating monocytes, the precursors of macrophages, are already heterogeneous, although the physiological relevance of this heterogeneity is not completely understood. Monocytes were initially identified by their expression of CD14. However, the observation that antigenic markers were differentially expressed showed that monocytes in human peripheral blood are heterogeneous. This lead to the first clues to the diverse physiological activities of monocytes subsets. Based on the differential expression of CD14 and $\mathrm{CD} 16$, the monocytes could be divided into two subsets; $\mathrm{CD} 14^{\text {high }} \mathrm{CD} 16^{+}$ and $\mathrm{CD} 14^{+} \mathrm{CD} 16^{-132}$. These two subsets also display distinct chemokine receptor (CCR5 and CCR2) expression profiles ${ }^{133}$. Recently is has been shown that in mice monocytes that express high levels of a marker antigen, Ly-6C, dominate hypercholesterolemia-associated monocytosis and give rise to macrophages in atherosclerotic lesions ${ }^{134}$. In addition, it was recently reported that monocytes subsets differentially use/employ the chemokine receptors $\mathrm{C}-\mathrm{C}$ motif chemokine receptor 2 (CCR2), CCR5 and C-X3-C motif chemokine receptor 1 (CX3CR1) to accumulate within atherosclerotic lesions ${ }^{135}$. This indicates that macrophage heterogeneity is not solely the result of monocyte differentiation under the influence of specific micro environments, but also depends on the existence of different monocyte subsets.

Tissue macrophages have a broad role in the maintenance of tissue homeostasis through the clearance of senescent cells and the remodeling and repair of tissue after inflammation ${ }^{136}$. Macrophage heterogeneity reflects the 
specialization of function that is adopted by macrophages in different anatomical locations. Examples are the ability of osteoclasts to remodel bone and of tingle-body macrophages in the germinal centre of the spleen to clear apoptotic lymphocytes (reviewed in ${ }^{22,137}$ ). Besides macrophage heterogeneity in different organs, macrophage heterogeneity can also be observed within a distinct organ.

As outlined above macrophages play an important role in the progression of atherosclerotic lesions, in which macrophage heterogeneity has also been observed. The protein perilipin, which was exclusively expressed in ruptured atherosclerotic lesions, appeared to be predominantly expressed in macrophages lining the rim of the necrotic core compared to macrophages in subendothelial space ${ }^{85}$.

Recently, a model has been proposed that characterizes the complexity of inflammatory - monocyte-derived macrophage responses. In this model the M1 and M2 nomenclature describes the two extremes of a spectrum of possible forms of macrophage activation. The polarized macrophage populations differ regarding receptor expression, cytokine production and chemokine repertoires (reviewed in ${ }^{24,25}$ ). Lipopolysaccharide (LPS), IFNy and TNF elicit a classical M1 form of macrophage activation leading to a type I inflammation, tumor resistance and killing of intracellular pathogens. $M 2$ is a universal name for the various macrophage responses (M2a, M2b and M2c) other than the classical M1 and includes macrophages exposed to IL4 or IL13, immune complexes and toll like receptor (TRL) or IL1R ligands and IL10. M2 cells are diverse, but generally involved in type II inflammation. They exhibit an immunoregulatory function, are involved in killing and encapsulation of parasites and promote tissue remodeling, angiogenesis and tumor growth. Another feature of polarized macrophages is their differential cytokine production. The M1 macrophage is typically IL12 ${ }^{\text {high }}$, IL13 high, TNF ${ }^{\text {high }}$, IL1 ${ }^{\text {high }}$ and IL10 ${ }^{\text {low }}$, whereas the various versions of the M2 macrophages are IL12 ${ }^{\text {low }}$, IL13 ${ }^{\text {low }}$, TNF ${ }^{\text {high }}$, IL1ra ${ }^{\text {high }}$ and IL10 ${ }^{\text {high }} 22-25$. Figure 1.6 shows a schematic overview of the inducers and functional properties of the different polarized macrophage populations.

As highlighted above and illustrated in Figure 1.7, heterogeneity is a widespread phenomenon and exists at various levels in human atherosclerotic lesions. Besides patient based heterogeneity (donor, age, gender), sample source and lesion heterogeneity as well as heterogeneity due to cellular differentiation and subtypes are important potential confounding factors in gene expression profiling of human atherosclerosis.

Heterogeneity will increase the variability in the gene expression profiles, and lower the statistical power to detect differentially expressed genes. Pooling of samples will further limit the detection of differentially expressed genes. In 6 of the 18 human atherosclerotic gene expression studies (Table 1.1) the gene expression profiles were generated from pooled samples $69-71,73,79,85$. 


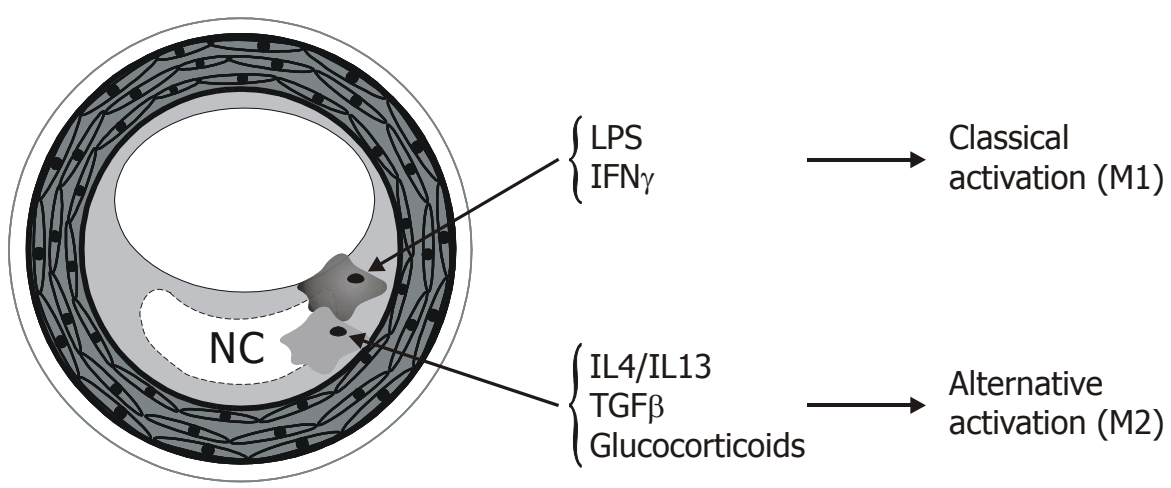

Figure 1.6

Schematic overview of the inducers and selected functional properties of the different polarized macrophage populations. Macrophages polarize and acquire different functional properties in response to signals from the environment. Macrophages exposed to IFNy, LPS or TNF undergo M1 polarization resulting in cytotoxic properties. M2 macrophages are in general more prone to immunoregulatory activities. In particular, M2a (induced by exposure to IL4 and IL13) and M2b (induced by combined exposure to immune complexes (IC) and TLR or IL1R agonists) exert immunoregulatory functions whereas M2c (induced by IL10) are more related to suppression of the immune responses and tissue remodeling. (Adapted from Mantovani et $\left.a\right|^{24,25}$ ).

A. Gender

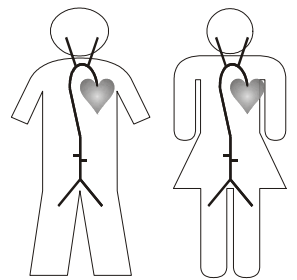

B. Source

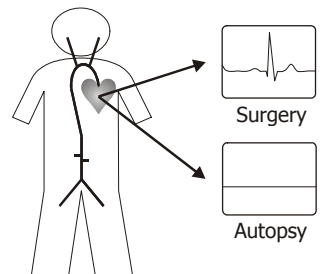

C. Site

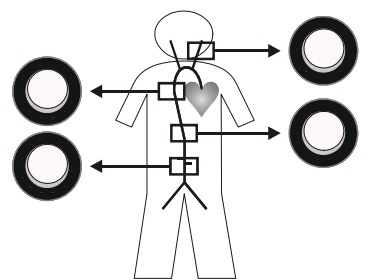

D. Lesion type

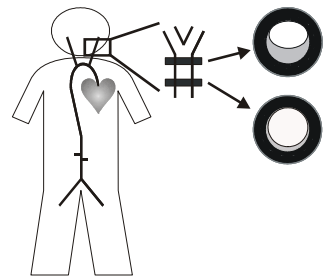

E. Cell type: lesion

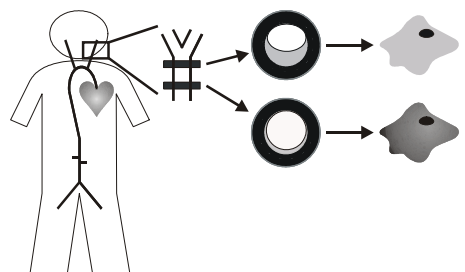

F. Cell type: organs

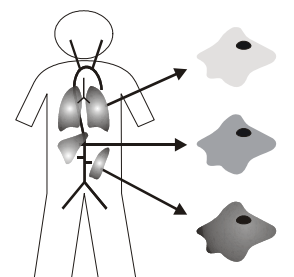

Figure 1.7

Schematic overview of the different levels and sources of heterogeneity in atherosclerotic related gene expression studies. 
The "first generation" microarrays used to study the expression profiles of human atherosclerosis required a relatively large amount of RNA to perform these analyses. In those conditions it was inevitable to pool RNA samples from different patients, genders, locations of the vascular bed to obtain sufficient amounts of RNA. In time the "second generation" microarrays became available, which required less RNA compared to the "first generation" microarrays, and it became possible to amplify RNA. This resulted in a shift towards the use of individual samples instead of pooled samples and to improved statistical power.

\section{Data analysis: statistics and bioinformatics}

There are several analytical approaches to identify genes that are differentially expressed in an experimental setting. The simplest and most intuitive approach to detect differentially expressed genes is to determine the fold change in expression level between the experimental conditions. The majority of microarray analysis in atherosclerotic research indeed identified differentially expressed genes by determining the fold change $70,71,73,75,77,79$. This method can not be used to determine a statistical probability and it does not give any information regarding the reproducibility of the observed fold change (reviewed in ${ }^{138}$ ). To assign a confidence level to the differential expression, comparison statistics need to be used such as a Student's T test ${ }^{75,78,80,82,83,86}$, ANOVA ${ }^{72,81}$ and Wilcoxon ANOVA ${ }^{75}$. These statistical analysis require biological replicates and use the variability within these replicates to assign a probability value. This value indicates the likelihood of incorrectly assigning a gene as being differentially expressed and can thus not be used on pooled samples. One needs to keep in mind that the expression levels of thousands of genes are analyzed at the same time using microarrays. This implies that a certain amount of genes will be considered statistical significant simply due to change. For instance, an analysis of a microarray containing 15,000 genes, with a $\mathrm{P}<0.01$ being considered as statistical significant, will yield 150 genes being statistical significant simply due to chance. To reduce this number of genes being significant due to chance (false positives), the probability value needs to be adjusted for multiple testing errors (reviewed in ${ }^{138}$ ). Correction for multiple testing errors has been performed in 5 recent human atherosclerotic microarray studies. Methods used to correct for multiple testing errors include significance analysis of microarrays ${ }^{139}$ (SAM) ${ }^{78,}{ }^{80}$, custom-made algorithms including permutation to study multiple sets of time course microarrays ${ }^{80}$, comparison with randomized datasets to determine the false positive frequency in the data set ${ }^{79}$ and the Benjamini Hochberg correction ${ }^{82,83}$. 
All these statistical analyses aim to identify genes that are differentially expressed on a gene by gene level. Another way to analyze the complex microarray data is to determine the correlation between differentially expressed genes that perform similar functions or belong to the same biological pathway. In atherosclerosis research hierarchical clustering ${ }^{72}, \mathrm{~K}$-means clustering ${ }^{74}$, principle component analysis, ${ }^{80,81}$ and Gene Set Enrichment Analysis ${ }^{140}$ (GSEA) ${ }^{86}$ have been used to determine the presence of a cluster of biological related genes with the same function or belonging to the same biological pathway.

To gain insight in the biological relevance of the gene expression profiles, one needs to obtain biological information from the differentially expressed genes. To achieve this one can perform literature mining using NCBI, Gene Ontology (GO), Kyoto Encyclopedia of Genes and Genomes (KEGG) or Biocarta databases. In atherosclerosis research 7 studies ${ }^{69,73,74,76,78,80,82}$ used the GO terms to categorize the differentially expressed genes. Table 1.3 gives a summary of the above mentioned approaches to analyze the microarray data.

Apart from the above mentioned studies two studies used the gene expression data to classify the atherosclerotic samples according to location ${ }^{74}$ or disease state ${ }^{74,80}$ based on so called classifier genes. Classifier genes are "informative genes" which are selected based on the correlation of their gene expression level with the specific "question" (for instance the location or the disease state). Subsequently the classifier genes are used to make a prediction for a "new sample" based on the expression levels of these classifier genes.

From the above it can be concluded that the knowledge and availability of methods to analyze the complex microarray data is rapidly improving. Meeting the statistical challenge analyzing these complex datasets will enable us to gain more insight in the biological pathways underlying atherosclerosis. Table 1.3 summarizes the applied statistical tools in atherosclerosis research so far.

Table 1.3: Overview of statistical and bioinformatical tools to analyse microarray data

\begin{tabular}{ll}
\hline Gene by gene approach & Pathway approach \\
\hline Fold change & Hierarchical clustering \\
Student'sT-test & K-means clustering \\
ANOVA & Principle component analysis \\
Multiple testing correction & Gene set enrichment analysis \\
& Literature mining; GO, KEGG or Biocarta \\
\hline
\end{tabular}




\section{Hypothesis and outline of this thesis}

From all the above it is evident that heterogeneity does occur in human atherosclerosis and that it has to be taken into account in designing large scale gene expression profiling studies as it drops the statistical power of the study and lowers the power to identify subtle changes in gene expression, that may be specific for a subpopulation of cells in a lesion. Our main hypothesis is that a study design that takes into account this heterogeneity will enable the detection of genes and/or pathways that show subtle changes in expression.

To test this hypothesis we performed microarray analysis on whole mount human atherosclerotic lesions and macrophages microdissected from human atherosclerotic lesions. Each study was designed in such way that the influence of the above mentioned sources of heterogeneity could be investigated.

In chapter 2 we compared samples with identical lesion phenotypes obtained either at autopsy and surgery to determine the effect of the sample source on gene expression profiles, whereas in chapter 3 the influence of the location of the atherosclerotic lesion in the vascular bed was investigated. In chapter 4 we compared early and advanced lesions within the same vessel to reduce the heterogeneity caused by gender, ethnic background and medication. The effect of genetic disruption of the cathepsin $\mathrm{K}$ gene, one of the promising novel candidates found in chapter 4, is described in chapter 5. In the next two chapters we determined the gene expression profiles of macrophages microdissected from atherosclerotic lesions. Cellular heterogeneity was thus addressed in chapters 6 and 7. In chapter 6 we compared the gene expression profile of macrophages microdissected from early lesions with those from advanced lesions, whereas in chapter 7 the differences between macrophages from atherosclerotic lesions and from non atherosclerotic tissues were determined. The results and possible implications of the findings, possible future directions of these studies and their implications are discussed in chapter 8. 


\section{REFERENCES}

1. Virmani $\mathrm{R}$, Kolodgie $\mathrm{FD}$, Burke $\mathrm{AP}$, et al. Lessons from sudden coronary death: a comprehensive morphological classification scheme for atherosclerotic lesions. Arterioscler Thromb Vasc Biol. May 2000;20(5):1262-1275.

2. Koek HL, Engelfriet - Rijk CJM, Bots ML. Hart - en vaatziekten in Nederland 2006, cijfers over ziekte en sterfte, 2006: 9-13.

3. Stary HC. Macrophage foam cells in the coronary artery intima of human infants. Ann $N Y$ Acad Sci. 1985;454:5-8.

4. Pasterkamp G, Wensing PJ, Post MJ, et al. Paradoxical arterial wall shrinkage may contribute to luminal narrowing of human atherosclerotic femoral arteries. Circulation. Mar 1 1995;91(5):1444-1449.

5. Stary $H C$, Chandler $A B$, Dinsmore $R E$, et al. $A$ definition of advanced types of atherosclerotic lesions and a histological classification of atherosclerosis. A report from the Committee on Vascular Lesions of the Council on Arteriosclerosis, American Heart Association. Arterioscler Thromb Vasc Biol. Sep 1995;15(9):1512-1531.

6. Lee RT, Libby P. The unstable atheroma. Arterioscler Thromb Vasc Biol. Oct 1997;17(10):1859-1867.

7. Hirsch AT, Haskal ZJ, Hertzer NR, et al. ACC/AHA 2005 Practice Guidelines for the management of patients with peripheral arterial disease (lower extremity, renal, mesenteric, and abdominal aortic): a collaborative report from the American Association for Vascular Surgery/Society for Vascular Surgery, Society for Cardiovascular Angiography and Interventions, Society for Vascular Medicine and Biology, Society of Interventional Radiology, and the ACC/AHA Task Force on Practice Guidelines (Writing Committee to Develop Guidelines for the Management of Patients With Peripheral Arterial Disease): endorsed by the American Association of Cardiovascular and Pulmonary Rehabilitation; National Heart, Lung, and Blood Institute; Society for Vascular Nursing; TransAtlantic Inter-Society Consensus; and Vascular Disease Foundation. Circulation. Mar 21 2006;113(11):e463-654.

8. Fruchart JC, Nierman MC, Stroes ES, et al. New risk factors for atherosclerosis and patient risk assessment. Circulation. Jun 15 2004;109(23 Suppl 1):III15-19.

9. Tegos TJ, Kalodiki E, Sabetai MM, et al. The genesis of atherosclerosis and risk factors: a review. Angiology. Feb 2001;52(2):89-98.

10. Shepherd J. Who should receive a statin these days? Lessons from recent clinical trials. $J$ Intern Med. Oct 2006;260(4):305-319.

11. Fogari R, Zoppi A. Antihypertensive drugs and fibrinolytic function impact of dual calcium channel and Renin-Angiotensin system blockade. Am J Hypertens. Dec 2006;19(12):12931299.

12. Libby $\mathrm{P}$, Ridker PM, Maseri A. Inflammation and atherosclerosis. Circulation. Mar 5 2002;105(9):1135-1143.

13. Lusis AJ. Atherosclerosis. Nature. Sep 14 2000;407(6801):233-241. 
14. Ross R. Atherosclerosis--an inflammatory disease. N Engl J Med. Jan 14 1999;340(2):115126.

15. Hansson GK. Inflammation, atherosclerosis, and coronary artery disease. $N$ Eng/ J Med. Apr 21 2005;352(16):1685-1695.

16. Hansson GK, Libby P. The immune response in atherosclerosis: a double-edged sword. Nat Rev Immunol. Jul 2006;6(7):508-519.

17. Peiser L, Mukhopadhyay S, Gordon S. Scavenger receptors in innate immunity. Curr Opin Immunol. Feb 2002;14(1):123-128.

18. Janeway CA, Jr., Medzhitov R. Innate immune recognition. Annu Rev Immunol. 2002;20:197-216.

19. Boullier A, Bird DA, Chang MK, et al. Scavenger receptors, oxidized LDL, and atherosclerosis. Ann N Y Acad Sci. Dec 2001;947:214-222; discussion 222-213.

20. Szabo SJ, Sullivan BM, Peng SL, et al. Molecular mechanisms regulating Th1 immune responses. Annu Rev Immunol. 2003;21:713-758.

21. Frostegard J, Ulfgren AK, Nyberg $P$, et al. Cytokine expression in advanced human atherosclerotic plaques: dominance of pro-inflammatory (Th1) and macrophagestimulating cytokines. Atherosclerosis. Jul 1999;145(1):33-43.

22. Gordon S, Taylor PR. Monocyte and macrophage heterogeneity. Nat Rev Immunol. Dec 2005;5(12):953-964.

23. Ghassabeh GH, De Baetselier P, Brys L, et al. Identification of a common gene signature for type II cytokine-associated myeloid cells elicited in vivo in different pathologic conditions. Blood. Jul 15 2006;108(2):575-583.

24. Mantovani A, Sica A, Sozzani $S$, et al. The chemokine system in diverse forms of macrophage activation and polarization. Trends Immunol. Dec 2004;25(12):677-686.

25. Mantovani A, Sica A, Locati M. New vistas on macrophage differentiation and activation. Eur J Immunol. Jan 2007;37(1):14-16.

26. Faber BC, Heeneman S, Daemen MJ, et al. Genes potentially involved in plaque rupture. Curr Opin Lipidol. Oct 2002;13(5):545-552.

27. Lewis GF, Rader DJ. New insights into the regulation of HDL metabolism and reverse cholesterol transport. Circ Res. Jun 24 2005;96(12):1221-1232.

28. van der Wal AC, Becker AE. Atherosclerotic plaque rupture--pathologic basis of plaque stability and instability. Cardiovasc Res. Feb 1999;41(2):334-344.

29. Heldin $\mathrm{CH}$, Westermark B. Mechanism of action and in vivo role of platelet-derived growth factor. Physiol Rev. Oct 1999;79(4):1283-1316.

30. Clarke M, Bennett M, Littlewood T. Cell death in the cardiovascular system. Heart. Jun 2007;93(6):659-664.

31. Sakai M, Kobori S, Miyazaki A, et al. Macrophage proliferation in atherosclerosis. Curr Opin Lipidol. Oct 2000;11(5):503-509.

32. Kockx MM. Apoptosis in the atherosclerotic plaque: quantitative and qualitative aspects. Arterioscler Thromb Vasc Biol. Oct 1998;18(10):1519-1522.

33. Gerrity RG. The role of the monocyte in atherogenesis: II. Migration of foam cells from atherosclerotic lesions. Am J Pathol. May 1981;103(2):191-200. 
34. Llodra J, Angeli V, Liu J, et al. Emigration of monocyte-derived cells from atherosclerotic lesions characterizes regressive, but not progressive, plaques. Proc Natl Acad Sci U S A. Aug 10 2004;101(32):11779-11784.

35. Martinet W, Kockx MM. Apoptosis in atherosclerosis: focus on oxidized lipids and inflammation. Curr Opin Lipidol. Oct 2001;12(5):535-541.

36. Kavurma MM, Bhindi $\mathrm{R}$, Lowe $\mathrm{HC}$, et al. Vessel wall apoptosis and atherosclerotic plaque instability. J Thromb Haemost. Mar 2005;3(3):465-472.

37. Clarke MC, Figg N, Maguire Jj, et al. Apoptosis of vascular smooth muscle cells induces features of plaque vulnerability in atherosclerosis. Nat Med. Sep 2006;12(9):1075-1080.

38. Mallat Z, Corbaz A, Scoazec A, et al. Expression of interleukin-18 in human atherosclerotic plaques and relation to plaque instability. Circulation. Oct 2 2001;104(14):1598-1603.

39. Inagaki $\mathrm{Y}$, Yamagishi $\mathrm{S}$, Amano $\mathrm{S}$, et al. Interferon-gamma-induced apoptosis and activation of THP-1 macrophages. Life Sci. Oct 11 2002;71(21):2499-2508.

40. Tabas I. Consequences and therapeutic implications of macrophage apoptosis in atherosclerosis: the importance of lesion stage and phagocytic efficiency. Arterioscler Thromb Vasc Biol. Nov 2005;25(11):2255-2264.

41. Yao PM, Tabas I. Free cholesterol loading of macrophages is associated with widespread mitochondrial dysfunction and activation of the mitochondrial apoptosis pathway. J Biol Chem. Nov 9 2001;276(45):42468-42476.

42. Geng YJ, Phillips JE, Mason RP, et al. Cholesterol crystallization and macrophage apoptosis: implication for atherosclerotic plaque instability and rupture. Biochem Pharmacol. Oct 15 2003;66(8):1485-1492.

43. Henson PM, Bratton DL, Fadok VA. Apoptotic cell removal. Curr Biol. Oct 2 2001;11(19):R795-805.

44. Savill J, Fadok V. Corpse clearance defines the meaning of cell death. Nature. Oct 12 2000;407(6805):784-788.

45. Roos A, Xu W, Castellano G, et al. Mini-review: A pivotal role for innate immunity in the clearance of apoptotic cells. Eur J Immunol. Apr 2004;34(4):921-929.

46. van Vlijmen BJ, Gerritsen G, Franken AL, et al. Macrophage p53 deficiency leads to enhanced atherosclerosis in APOE*3-Leiden transgenic mice. Circ Res. Apr 27 2001;88(8):780-786.

47. Liu J, Thewke DP, Su YR, et al. Reduced macrophage apoptosis is associated with accelerated atherosclerosis in low-density lipoprotein receptor-null mice. Arterioscler Thromb Vasc Biol. Jan 2005;25(1):174-179.

48. Arai $\mathrm{S}$, Shelton JM, Chen $\mathrm{M}$, et al. A role for the apoptosis inhibitory factor AIM/Spalpha/Api6 in atherosclerosis development. Cell Metab. Mar 2005;1(3):201-213.

49. Kockx MM, Herman AG. Apoptosis in atherosclerosis: beneficial or detrimental? Cardiovasc Res. Feb 2000;45(3):736-746.

50. Schrijvers DM, De Meyer GR, Kockx MM, et al. Phagocytosis of apoptotic cells by macrophages is impaired in atherosclerosis. Arterioscler Thromb Vasc Biol. Jun 2005;25(6):1256-1261. 
51. Khan M, Pelengaris S, Cooper M, et al. Oxidised lipoproteins may promote inflammation through the selective delay of engulfment but not binding of apoptotic cells by macrophages. Atherosclerosis. Nov 2003;171(1):21-29.

52. Grainger DJ, Reckless J, McKilligin E. Apolipoprotein E modulates clearance of apoptotic bodies in vitro and in vivo, resulting in a systemic proinflammatory state in apolipoprotein E-deficient mice. J Immunol. Nov 15 2004;173(10):6366-6375.

53. Mallat Z, Hugel B, Ohan J, et al. Shed membrane microparticles with procoagulant potential in human atherosclerotic plaques: a role for apoptosis in plaque thrombogenicity. Circulation. Jan 26 1999;99(3):348-353.

54. Greeno EW, Bach RR, Moldow CF. Apoptosis is associated with increased cell surface tissue factor procoagulant activity. Lab Invest. Aug 1996;75(2):281-289.

55. Boyle JJ, Wilson B, Bicknell $\mathrm{R}$, et al. Expression of angiogenic factor thymidine phosphorylase and angiogenesis in human atherosclerosis. $J$ Pathol. Oct 2000;192(2):234-242.

56. Galis ZS, Sukhova GK, Lark MW, et al. Increased expression of matrix metalloproteinases and matrix degrading activity in vulnerable regions of human atherosclerotic plaques. $J$ Clin Invest. Dec 1994;94(6):2493-2503.

57. Newby AC. Do metalloproteinases destabilize vulnerable atherosclerotic plaques? Curr Opin Lipidol. Oct 2006;17(5):556-561.

58. Dollery CM, Libby P. Atherosclerosis and proteinase activation. Cardiovasc Res. Feb 15 2006;69(3):625-635.

59. Sukhova GK, Shi GP, Simon DI, et al. Expression of the elastolytic cathepsins S and K in human atheroma and regulation of their production in smooth muscle cells. $J$ Clin Invest. Aug 1 1998;102(3):576-583.

60. Liu J, Sukhova GK, Sun JS, et al. Lysosomal cysteine proteases in atherosclerosis. Arterioscler Thromb Vasc Biol. Aug 2004;24(8):1359-1366.

61. Lutgens SP, Kisters N, Lutgens E, et al. Gene profiling of cathepsin K deficiency in atherogenesis: profibrotic but lipogenic. J Pathol. Nov 2006;210(3):334-343.

62. Lutgens SP, Cleutjens KB, Daemen MJ, et al. Cathepsin cysteine proteases in cardiovascular disease. Faseb J. Oct 2007;21(12):3029-3041.

63. Taubman MB, Fallon JT, Schecter $A D$, et al. Tissue factor in the pathogenesis of atherosclerosis. Thromb Haemost. Jul 1997;78(1):200-204.

64. Paterson JC. Capillary rupture with intimal hemorrhage as a causative factor in coronary thrombosis. Arch Pathol 1938;25:474-487.

65. Virmani R, Kolodgie FD, Burke AP, et al. Atherosclerotic plaque progression and vulnerability to rupture: angiogenesis as a source of intraplaque hemorrhage. Arterioscler Thromb Vasc Biol. Oct 2005;25(10):2054-2061.

66. Moreno PR, Purushothaman KR, Sirol M, et al. Neovascularization in human atherosclerosis. Circulation. May 9 2006;113(18):2245-2252.

67. Bijnens AP, Lutgens E, Ayoubi T, et al. Genome-wide expression studies of atherosclerosis: critical issues in methodology, analysis, interpretation of transcriptomics data. Arterioscler Thromb Vasc Biol. Jun 2006;26(6):1226-1235. 
68. Tuomisto TT, Binder BR, Yla-Herttuala S. Genetics, genomics and proteomics in atherosclerosis research. Ann Med. 2005;37(5):323-332.

69. Hiltunen MO, Tuomisto $\mathrm{TT}$, Niemi $\mathrm{M}$, et al. Changes in gene expression in atherosclerotic plaques analyzed using DNA array. Atherosclerosis. Nov 2002;165(1):23-32.

70. McCaffrey TA, Fu C, Du B, et al. High-level expression of Egr-1 and Egr-1-inducible genes in mouse and human atherosclerosis. J Clin Invest. Mar 2000;105(5):653-662.

71. Martinet W, Schrijvers DM, De Meyer GR, et al. Gene expression profiling of apoptosisrelated genes in human atherosclerosis: upregulation of death-associated protein kinase. Arterioscler Thromb Vasc Biol. Dec 1 2002;22(12):2023-2029.

72. Randi AM, Biguzzi E, Falciani $F$, et al. Identification of differentially expressed genes in coronary atherosclerotic plaques from patients with stable or unstable angina by CDNA array analysis. J Thromb Haemost. Apr 2003;1(4):829-835.

73. Tuomisto TT, Korkeela A, Rutanen J, et al. Gene expression in macrophage-rich inflammatory cell infiltrates in human atherosclerotic lesions as studied by laser microdissection and DNA array: overexpression of HMG-CoA reductase, colony stimulating factor receptors, CD11A/CD18 integrins, and interleukin receptors. Arterioscler Thromb Vasc Biol. Dec 2003;23(12):2235-2240.

74. Seo D, Wang $\mathrm{T}$, Dressman $\mathrm{H}$, et al. Gene expression phenotypes of atherosclerosis. Arterioscler Thromb Vasc Biol. Oct 2004;24(10):1922-1927.

75. Archacki SR, Angheloiu G, Tian XL, et al. Identification of new genes differentially expressed in coronary artery disease by expression profiling. Physiol Genomics. Sep 29 2003;15(1):65-74.

76. Durier S, Fassot C, Laurent $\mathrm{S}$, et al. Physiological genomics of human arteries: quantitative relationship between gene expression and arterial stiffness. Circulation. Oct 14 2003;108(15):1845-1851.

77. Woodside KJ, Hernandez A, Smith FW, et al. Differential gene expression in primary and recurrent carotid stenosis. Biochem Biophys Res Commun. Mar 14 2003;302(3):509-514.

78. King JY, Ferrara R, Tabibiazar R, et al. Pathway analysis of coronary atherosclerosis. Physiol Genomics. Sep 21 2005;23(1):103-118.

79. Adams LD, Geary RL, Li J, et al. Expression profiling identifies smooth muscle cell diversity within human intima and plaque fibrous cap: loss of RGS5 distinguishes the cap. Arterioscler Thromb Vasc Biol. Feb 2006;26(2):319-325.

80. Tabibiazar R, Wagner RA, Ashley EA, et al. Signature patterns of gene expression in mouse atherosclerosis and their correlation to human coronary disease. Physiol Genomics. Jul 14 2005;22(2):213-226.

81. Papaspyridonos M, Smith A, Burnand KG, et al. Novel candidate genes in unstable areas of human atherosclerotic plaques. Arterioscler Thromb Vasc Biol. Aug 2006;26(8):18371844.

82. Ijas P, Nuotio K, Saksi J, et al. Microarray Analysis Reveals Overexpression of CD163 and HO-1 in Symptomatic Carotid Plaques. Arterioscler Thromb Vasc Biol. Nov 92006. 
83. Dahl TB, Yndestad A, Skjelland M, et al. Increased expression of visfatin in macrophages of human unstable carotid and coronary atherosclerosis: possible role in inflammation and plaque destabilization. Circulation. Feb 27 2007;115(8):972-980.

84. Tyson $\mathrm{KL}$, Weissberg $\mathrm{PL}$, Shanahan $\mathrm{CM}$. Heterogeneity of gene expression in human atheroma unmasked using cDNA representational difference analysis. Physiol Genomics. 2002;9(2):121-130.

85. Faber $\mathrm{BC}$, Cleutjens $\mathrm{KB}$, Niessen $\mathrm{RL}$, et al. Identification of genes potentially involved in rupture of human atherosclerotic plaques. Circ Res. Sep 14 2001;89(6):547-554.

86. Volger OL, Fledderus JO, Kisters N, et al. Distinctive expression of chemokines and transforming growth factor-beta signaling in human arterial endothelium during atherosclerosis. Am J Pathol. Jul 2007;171(1):326-337.

87. Lutgens $\mathrm{E}$, Lutgens $\mathrm{SP}$, Faber $\mathrm{BC}$, et al. Disruption of the cathepsin $\mathrm{K}$ gene reduces atherosclerosis progression and induces plaque fibrosis but accelerates macrophage foam cell formation. Circulation. Jan 3 2006;113(1):98-107.

88. Bijnens AP, Gils A, Jutten $B$, et al. Vasculin, a novel vascular protein differentially expressed in human atherogenesis. Blood. Oct 15 2003;102(8):2803-2810.

89. Iemolo F, Martiniuk A, Steinman DA, et al. Sex differences in carotid plaque and stenosis. Stroke. Feb 2004;35(2):477-481.

90. Orakzai $\mathrm{SH}$, Orakzai $\mathrm{RH}$, Nasir $\mathrm{K}$, et al. Subclinical coronary atherosclerosis: racial profiling is necessary! Am Heart J. Nov 2006;152(5):819-827.

91. Marchesi S, Lupattelli G, Sensini A, et al. Racial difference in endothelial function: role of the infective burden. Atherosclerosis. Mar 2007;191(1):227-234.

92. Sanoudou D, Kang PB, Haslett JN, et al. Transcriptional profile of postmortem skeletal muscle. Physiol Genomics. Jan 15 2004;16(2):222-228.

93. Lemos FB, Ijzermans JN, Zondervan PE, et al. Differential expression of heme oxygenase1 and vascular endothelial growth factor in cadaveric and living donor kidneys after ischemia-reperfusion. J Am Soc Nephrol. Dec 2003;14(12):3278-3287.

94. Baan C, van Gelder T, Peeters A, et al. Living kidney donors and hypoxia-inducible factor1alpha. Transplantation. Feb 27 2003;75(4):570-571.

95. Lee J, Hever A, Willhite $D$, et al. Effects of RNA degradation on gene expression analysis of human postmortem tissues. Faseb J. Aug 2005;19(10):1356-1358.

96. Kuliwaba JS, Fazzalari NL, Findlay DM. Stability of RNA isolated from human trabecular bone at post-mortem and surgery. Biochim Biophys Acta. Apr 15 2005;1740(1):1-11.

97. Larsen WJ. Development of the vasculature. Human Embryology. New York: Churchill Livingstone Inc; 1993:167-204.

98. Wolinsky $\mathrm{H}$, Glagov S. Comparison of abdominal and thoracic aortic medial structure in mammals. Deviation of man from the usual pattern. Circ Res. Dec 1969;25(6):677-686.

99. Clark JM, Glagov S. Structural integration of the arterial wall. I. Relationships and attachments of medial smooth muscle cells in normally distended and hyperdistended aortas. Lab Invest. May 1979;40(5):587-602. 
100. VanderLaan PA, Reardon CA, Getz GS. Site specificity of atherosclerosis: site-selective responses to atherosclerotic modulators. Arterioscler Thromb VasC Biol. Jan 2004;24(1):12-22.

101. Emmert-Buck MR, Bonner RF, Smith PD, et al. Laser capture microdissection. Science. Nov 8 1996;274(5289):998-1001.

102. Fearon ER, Hamilton SR, Vogelstein B. Clonal analysis of human colorectal tumors. Science. Oct 9 1987;238(4824):193-197.

103. Radford DM, Fair K, Thompson AM, et al. Allelic loss on a chromosome 17 in ductal carcinoma in situ of the breast. Cancer Res. Jul 1 1993;53(13):2947-2949.

104. Shibata D, Hawes D, Li ZH, et al. Specific genetic analysis of microscopic tissue after selective ultraviolet radiation fractionation and the polymerase chain reaction. $\mathrm{Am} \mathrm{J}$ Pathol. Sep 1992;141(3):539-543.

105. Kovach JS, McGovern RM, Cassady JD, et al. Direct sequencing from touch preparations of human carcinomas: analysis of p53 mutations in breast carcinomas. $J$ Nat/ Cancer Inst. Jul 17 1991;83(14):1004-1009.

106. Emmert-Buck MR, Roth MJ, Zhuang Z, et al. Increased gelatinase A (MMP-2) and cathepsin B activity in invasive tumor regions of human colon cancer samples. $A m ~ J$ Pathol. Dec 1994;145(6):1285-1290.

107. Zhuang Z, Bertheau P, Emmert-Buck MR, et al. A microdissection technique for archival DNA analysis of specific cell populations in lesions $<1 \mathrm{~mm}$ in size. Am J Pathol. Mar 1995;146(3):620-625.

108. Noguchi S, Motomura K, Inaji $\mathrm{H}$, et al. Clonal analysis of predominantly intraductal carcinoma and precancerous lesions of the breast by means of polymerase chain reaction. Cancer Res. Apr 1 1994;54(7):1849-1853.

109. Park TW, Felix JC, Wright TC, Jr. X chromosome inactivation and microsatellite instability in early and advanced bilateral ovarian carcinomas. Cancer Res. Nov 1 1995;55(21):47934796.

110. Sirivatanauksorn Y, Drury R, Crnogorac-Jurcevic T, et al. Laser-assisted microdissection: applications in molecular pathology. J Pathol. Oct 1999;189(2):150-154.

111. Simone NL, Bonner RF, Gillespie JW, et al. Laser-capture microdissection: opening the microscopic frontier to molecular analysis. Trends Genet. Jul 1998;14(7):272-276.

112. Fend F, Emmert-Buck MR, Chuaqui $R$, et al. Immuno-LCM: laser capture microdissection of immunostained frozen sections for mRNA analysis. Am J Pathol. Jan 1999;154(1):6166.

113. Murakami H, Liotta L, Star RA. IF-LCM: laser capture microdissection of immunofluorescently defined cells for mRNA analysis rapid communication. Kidney Int. Sep 2000;58(3):1346-1353.

114. Stagliano NE, Carpino AJ, Ross JS, et al. Vascular gene discovery using laser capture microdissection of human blood vessels and quantitative PCR. Ann NY Acad Sci. Dec 2001;947:344-349. 
115. Nygaard V, Hovig E. Options available for profiling small samples: a review of sample amplification technology when combined with microarray profiling. Nucleic Acids Res. 2006;34(3):996-1014.

116. Polacek DC, Passerini AG, Shi C, et al. Fidelity and enhanced sensitivity of differential transcription profiles following linear amplification of nanogram amounts of endothelial mRNA. Physiol Genomics. Apr 16 2003;13(2):147-156.

117. Esposito G. Complementary techniques: laser capture microdissection--increasing specificity of gene expression profiling of cancer specimens. Adv Exp Med Biol. 2007;593:54-65.

118. Engelse MA, Lardenoye $\mathrm{JH}$, Neele JM, et al. Adenoviral activin a expression prevents intimal hyperplasia in human and murine blood vessels by maintaining the contractile smooth muscle cell phenotype. Circ Res. May 31 2002;90(10):1128-1134.

119. Trogan E, Choudhury RP, Dansky HM, et al. Laser capture microdissection analysis of gene expression in macrophages from atherosclerotic lesions of apolipoprotein E-deficient mice. Proc Natl Acad Sci U S A. Feb 19 2002;99(4):2234-2239.

120. Babaev VR, Ishiguro $H$, Ding $L$, et al. Macrophage expression of peroxisome proliferatoractivated receptor-alpha reduces atherosclerosis in low-density lipoprotein receptordeficient mice. Circulation. Sep 18 2007;116(12):1404-1412.

121. Tiwari S, Zhang $\mathrm{Y}$, Heller J, et al. Atherosclerosis-related molecular alteration of the human CaV1.2 calcium channel alpha1C subunit. Proc Natl Acad Sci U $S$ A. Nov 7 2006;103(45):17024-17029.

122. Bagnato C, Thumar J, Mayya V, et al. Proteomics analysis of human coronary atherosclerotic plaque: a feasibility study of direct tissue proteomics by liquid chromatography and tandem mass spectrometry. Mol Cell Proteomics. Jun 2007;6(6):1088-1102.

123. Deng DX, Tsalenko A, Vailaya A, et al. Differences in vascular bed disease susceptibility reflect differences in gene expression response to atherogenic stimuli. Circ Res. Feb 3 2006;98(2):200-208.

124. Orlandi A, Ehrlich HP, Ropraz P, et al. Rat aortic smooth muscle cells isolated from different layers and at different times after endothelial denudation show distinct biological features in vitro. Arterioscler Thromb. Jun 1994;14(6):982-989.

125. Aird WC. Phenotypic heterogeneity of the endothelium: I. Structure, function, and mechanisms. Circ Res. Feb 2 2007;100(2):158-173.

126. Aird WC. Phenotypic heterogeneity of the endothelium: II. Representative vascular beds. Circ Res. Feb 2 2007;100(2):174-190.

127. Chi JT, Chang HY, Haraldsen G, et al. Endothelial cell diversity revealed by global expression profiling. Proc Natl Acad Sci U S A. Sep 16 2003;100(19):10623-10628.

128. Newby AC, George SJ. Proliferation, migration, matrix turnover, and death of smooth muscle cells in native coronary and vein graft atherosclerosis. Curr Opin Cardiol. Nov 1996;11(6):574-582.

129. Mulvihill ER, Jaeger J, Sengupta R, et al. Atherosclerotic plaque smooth muscle cells have a distinct phenotype. Arterioscler Thromb Vasc Biol. Jul 2004;24(7):1283-1289. 


\section{Chapter 1}

130. Mallat $\mathrm{Z}$, Ait-Oufella $\mathrm{H}$, Tedgui A. Regulatory $\mathrm{T}$ cell responses: potential role in the control of atherosclerosis. Curr Opin Lipidol. Oct 2005;16(5):518-524.

131. Tedgui A, Mallat Z. Cytokines in atherosclerosis: pathogenic and regulatory pathways. Physiol Rev. Apr 2006;86(2):515-581.

132. Passlick B, Flieger D, Ziegler-Heitbrock HW. Identification and characterization of a novel monocyte subpopulation in human peripheral blood. Blood. Nov 15 1989;74(7):25272534.

133. Weber $\mathrm{C}$, Belge $\mathrm{KU}$, von Hundelshausen $\mathrm{P}$, et al. Differential chemokine receptor expression and function in human monocyte subpopulations. J Leukoc Biol. May 2000;67(5):699-704.

134. Swirski FK, Libby $\mathrm{P}$, Aikawa $\mathrm{E}$, et al. Ly-6Chi monocytes dominate hypercholesterolemiaassociated monocytosis and give rise to macrophages in atheromata. $J$ Clin Invest. Jan 2007;117(1):195-205.

135. Tacke F, Alvarez D, Kaplan TJ, et al. Monocyte subsets differentially employ CCR2, CCR5, and CX3CR1 to accumulate within atherosclerotic plaques. J Clin Invest. Jan 2007;117(1):185-194.

136. Gordon S. The role of the macrophage in immune regulation. Res Immunol. Sep-Oct 1998;149(7-8):685-688.

137. Stout RD, Suttles J. Functional plasticity of macrophages: reversible adaptation to changing microenvironments. J Leukoc Biol. Sep 2004;76(3):509-513.

138. Draghici S. Statistical intelligence: effective analysis of high-density microarray data. Drug Discov Today. Jun 1 2002;7(11 Suppl):S55-63.

139. Tusher VG, Tibshirani R, Chu G. Significance analysis of microarrays applied to the ionizing radiation response. Proc Natl Acad Sci U S A. Apr 24 2001;98(9):5116-5121.

140. Subramanian A, Tamayo P, Mootha VK, et al. Gene set enrichment analysis: a knowledgebased approach for interpreting genome-wide expression profiles. Proc Natl Acad Sci U S A. Oct 25 2005;102(43):15545-15550.

141. Adams JM. Ways of dying: multiple pathways to apoptosis. Genes Dev. Oct 15 2003;17(20):2481-2495.

142. Hengartner MO. The biochemistry of apoptosis. Nature. Oct 12 2000;407(6805):770-776. 




\section{Chapter 2}

Dead or Alive: Gene expression profiles of advanced atherosclerotic plaques from autopsy and surgery

Natasja Kisters', Judith C. Sluimer ${ }^{*}$, Kitty B. Cleutjens, Oscar L. Volger, Anton J. Horrevoets, Luc H. van den Akker, Ann-Pascale J. Bijnens, Mat J. Daemen

* Both authors contributed equally to this work

Physiol Genomics. 2007 Aug 20;30(3):335-41. 


\section{ABSTRACT}

Since inclusion of atherosclerotic tissues from different sources is often indispensable to study the full atherogenic spectrum, we investigated to what extent the expression profiles of advanced but stable atherosclerotic lesions obtained during autopsy and surgery are comparable. The gene expression profiles of human carotids with advanced atherosclerosis obtained at autopsy and at vascular surgery were studied using microarray analysis. Expression analysis was performed both at the single gene (Rosetta, Gene Ontology) and at the pathway level using Ingenuity and Gene Set Enrichment Analysis (GSEA). In addition, mRNA and protein expression levels were validated using Q-PCR and immunohistochemistry on unrelated advanced carotid lesions from autopsy and surgery.

Microarray analysis indicated that the $97.2 \%$ of genes showed similar expression levels in advanced atherosclerotic lesions from autopsy and surgery. While the expression data revealed no differences in common atherosclerotic related pathways such as lipid metabolism and inflammation, the differentially expressed genes were mainly involved in basal cell metabolism and hypoxia driven pathways. Q-PCR confirmed the differential expression of hypoxia-driven genes VEGF-A (2.3 fold $\uparrow$ ), GLUT1 (2.5 fold $\uparrow$ ), GLUT3 (8.3 fold $\uparrow$ ) and HK1 (2.4 fold $\uparrow$ ) in autopsy versus surgical specimens. Immunohistochemistry revealed that the transcriptional differences in these hypoxia-related genes were not reflected at the protein level. The gene expression profiles of advanced atherosclerotic lesions from autopsy and surgery are largely similar. However, over 500 genes, mostly involved in basal cell metabolism and hypoxia were differentially expressed at mRNA, but not at the protein level. 


\section{INTRODUCTION}

A myriad of expression profiling studies have been conducted over the past few years to unravel the molecular pathways involved in the initiation and progression of human atherosclerosis (reviewed in ${ }^{1}$ ). These studies compared complete atherosclerotic lesions ${ }^{2-4}$ or specific lesion regions ${ }^{5-7}$ to non-diseased arteries/regions. Transcript levels were analyzed to study either the early phases of atherosclerosis ${ }^{2,3,8,9}$ or the progression from stable to ruptured lesions ${ }^{10,11}$. However, none of these studies have investigated the full spectrum of atherogenesis ranging from a non-diseased artery to early, advanced, stable and advanced, ruptured lesions. In the optimal profiling study tissue would be used that represents all these stages obtained from one type of artery and one source, i.e. autopsy or surgery, to ensure reliable and reproducible results. However, in practice there is a lack of available tissue from the same source. For instance, carotid arteries with early lesions are only available from autopsy, while ruptured carotid lesions are hardly available from this source. To overcome this obstacle different sites ${ }^{6,10,12}$ and/or sources have combined ${ }^{6}$. Obviously, these approaches may introduce a high degree of variability and may even obscure the expression profile of genes or pathways associated with atherogenesis.

Interestingly, there are no data available comparing the gene expression profiles of atherosclerotic tissue obtained at autopsy and surgery. The aim of this study was to compare gene expression profiles of atherosclerotic tissue with a stable advanced lesion phenotype from autopsy and surgery using microarray analysis. Expression analysis was performed both at single gene and pathway level to study biological functions and pathways associated with expression profiles of autopsy and surgery. In addition, results were validated on mRNA and protein expression levels using quantitative real-time PCR and immunohistochemistry.

\section{METHODS AND MATERIALS}

\section{Tissue collection}

A total of 26 atherosclerotic carotid artery segments were obtained at autopsy ( $n=11$ donors; Department of Pathology, University Hospital Maastricht) or from patients undergoing vascular surgery ( $n=11$ donors; Department of Surgery, Maasland Hospital Sittard). The postmortem interval was $<24$ hours. The difference in mean age of the donors, $82 \pm 4$ years and $65 \pm 4$ years for autopsy and surgical donors respectively, was not significant $(p=0.06)$. The gender 


\section{Chapter 2}

distribution was also not significantly different between autopsy $(72 \%(n=8)$ male) and surgery $(64 \%(n=7)$ male; $p=0.65)$. Detailed patient characteristics are presented in Table 2.1. The tissue was obtained from the Maastricht Pathology Tissue Collection (MPTC) and collection, storage and use of tissue and patient data were performed in agreement with the "Code for Proper Secondary Use of Human Tissue". Immediately after resection the atherosclerotic tissue was divided into parallel segments of $5 \mathrm{~mm}$. Snap frozen segments for RNA isolation were alternated by formalin-fixed segments for histology. The lesion stage was classified based on haematoxylin-eosin (HE) stained sections $(4 \mu \mathrm{m})$ according to Virmani et $a l^{13}$. Snap frozen samples were only included when both adjacent HE stained sections were classified as stable, advanced atherosclerotic lesions.

Table 2.1 Patient characteristics

\begin{tabular}{|c|c|c|c|c|}
\hline Source & Patient Code & $\begin{array}{c}\text { Age } \\
\text { (years) }\end{array}$ & Gender & Purpose \\
\hline \multirow{11}{*}{ Autopsy } & 1 & 74 & $M$ & MA \\
\hline & 2 & 93 & $M$ & MA \\
\hline & 3 & 79 & $\mathrm{~F}$ & MA \\
\hline & 4 & 82 & $\mathrm{~F}$ & MA \\
\hline & 5 & 71 & $M$ & Q-PCR \\
\hline & 6 & 73 & M & Q-PCR \\
\hline & 7 & 76 & $M$ & $\mathrm{Q}-\mathrm{PCR}+\mathrm{IHC}$ \\
\hline & 8 & 83 & $M$ & $\mathrm{Q}-\mathrm{PCR}+\mathrm{IHC}$ \\
\hline & 9 & 65 & M & $\mathrm{Q}-\mathrm{PCR}+\mathrm{IHC}$ \\
\hline & 10 & 76 & $M$ & $\mathrm{IHC}$ \\
\hline & 11 & 81 & $\mathrm{~F}$ & $\mathrm{IHC}$ \\
\hline \multirow{11}{*}{ Surgery } & 12 & 57 & M & MA \\
\hline & 13 & 70 & $\mathrm{~F}$ & MA \\
\hline & 14 & 68 & $\mathrm{~F}$ & $M A+I H C$ \\
\hline & 15 & 81 & $F$ & Q-PCR \\
\hline & 16 & 74 & $M$ & Q-PCR \\
\hline & 17 & 75 & M & Q-PCR \\
\hline & 18 & 68 & $\mathrm{~F}$ & Q-PCR \\
\hline & 19 & 49 & M & IHC \\
\hline & 20 & 57 & $M$ & $\mathrm{IHC}$ \\
\hline & 21 & 35 & M & $\mathrm{IHC}$ \\
\hline & 22 & 62 & $M$ & $\mathrm{IHC}$ \\
\hline
\end{tabular}

Abbreviations: M, male; F, female; Q-PCR, quantitative real-time PCR; MA, microarray; IHC, immunohistochemistry 


\section{RNA isolation}

Total RNA was isolated from advanced, stable carotid lesions collected at autopsy ( $n=4)$ or surgery $(n=3)$ using the guanidine isothiocyanate/CsCl method ${ }^{14}$ followed by RNeasy extraction according to the manufacturer (Qiagen, Hilden, Germany). RNA quantity and quality were determined using a Nanodrop spectophotometer (Witec AG, Littau, Switzerland) and a 2100 Bioanalyzer (Agilent Technologies, Palo Alto, USA) respectively. All samples included had a RNA Integrity Number (RIN) $\geq 5$.

\section{Microarray hybridization and data analysis}

Human oligonucleotide libraries (Cat \# HUMLIB384) were obtained from Sigma -Compugen Incorporated. Technical support was supplied by LabOnWeb (http://www.labonweb.com/cgi-bin/chips/full_loader.cgi). The libraries represent in total 18,600 LEADS $^{\mathrm{TM}}$ clusters plus 231 controls. The oligonucleotide library was printed with a $2 \times 12$ pin Lucidea Array Spotter (GEHealthcare, Piscataway, USA) on commercial UltraGAPS slides (aminosilane -coated slides, Corning 40017) and processed according to the manufacturer's instructions. The slides contained 60-mer oligonucleotides and the batch was checked for the quality of spotting by hybridizing with SpotCheck Cy3 labelled nonamers (Genetix, New Milton Hampshire, UK).

One $\mu \mathrm{g}$ of total RNA was amplified a single round using the Ambion MessageAmp kit (Cat No. 1750, Ambion, Huntingdon, UK), with $50 \%$ of rUTP ribonucleotides replaced by aminoallyl-rUTP (Sigma-Aldrich \#A5660, Zwijndrecht, The Netherlands). Next, labelled cRNA probes were fragmented followed by purification using the RNeasy mini kit (Qiagen, Hilden, Germany). Aminoallyl-modified amplified RNA was labelled with either Cy3 (common reference sample) or Cy5 (samples) monoreactive dyes (GE Healthcare, Uppsala, Sweden). RNA concentration as well as dye incorporation was measured using the Nanodrop spectrophotometer. Equal amounts of labelled CRNA's (typically $1 \mu \mathrm{g}$ ) were applied in duplicate to oligonucleotide arrays and were hybridized for $16 \mathrm{hr}$ at $40^{\circ} \mathrm{C}{ }^{15}$. All samples were hybridized against a common reference sample composed of a pool of RNA isolated from HUVEC, the monocytic cell-line THP-1 and whole mount human carotid and aortic lesions to allow comparison between different hybridizations. The complete data set has been made available at http://www.ebi.ac.uk/arrayexpress (accession \# E-MEXP-1004).

Images were acquired using the Agilent II scanner (Agilent Technologies, Palo Alto, USA) and feature extraction was done using ArrayVision 8.0 software (GE Healthcare Europe, Diegem, Belgium). Background subtracted intensities were 
LOESS normalized (LIMMA package, Bioconductor software, http://www.bioconductor.org) and imported into Rosetta Resolver (Rosetta Biosoftware, Seattle, WA, USA). The Benjamini-Hochberg method to correct for multiple testing ${ }^{16}$ was used to identify genes significantly differentially expressed between advanced atherosclerotic lesions from autopsy and surgery. A p-value $<0.01$ was considered as statistically significant.

The differentially expressed genes were analyzed using gene ontology (GO) analysis (DAVID version 1, NIH). Ingenuity Pathway Analysis (Ingenuity Systems, Mountain View, CA, USA; https:// analysis.ingenuity.com/pa) was performed on genes with an intensity level $>50$ ( $2.5 \mathrm{x}$ background) in either of the phenotypes, a fold change $>1.4$ or $<-1.4$ and a p-value $<0.01$. In addition, the expression data were analyzed using Gene Set Enrichment Analysis (GSEA) ${ }^{17}$. This method analyzes expression data at the level of predefined gene sets instead of individual genes to detect significant, concordant differences in biological processes between two phenotypes. We acknowledge the use of the GSEA 1.0 software and Molecular Signature Database of genesets (MSigDB) C2 release 1 (http://www.broad.mit.edu/gsea). All genes in the data set were ranked based on their correlation to the autopsy phenotype and the rank positions of all members of a given gene set was used to calculate an enrichment score. Subsequently, 1000 permutations were used to determine which gene sets were significantly enriched in autopsy or surgery (false discovery rate $(F D R)<25 \%)$.

\section{Quantitative real-time PCR (Q-PCR)}

Total RNA from additional samples from autopsy $(n=5)$ and surgery $(n=4)$ was reverse transcribed and q-PCR performed as described ${ }^{18}$. Primers directed against HIF $2 \alpha^{19}$, VEGFA ${ }^{20}$, VEGFB ${ }^{20}$ and housekeeping gene $18 \mathrm{~S}^{21}$ were used

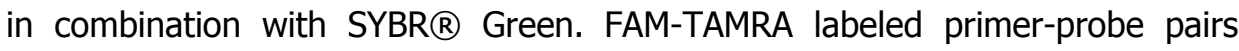
were obtained for HIF1 $\alpha$, GLUT1 and GLUT3, HK1 and HK2 and housekeeping gene GAPDH (Applied Biosystems, Foster City, USA). Samples and runs were performed in duplicate. RNA copy numbers were calculated using a standard curve and normalized to housekeeping gene mRNA expression. 
Genomic profiles of atherosclerotic plaques from autopsy vs surgery

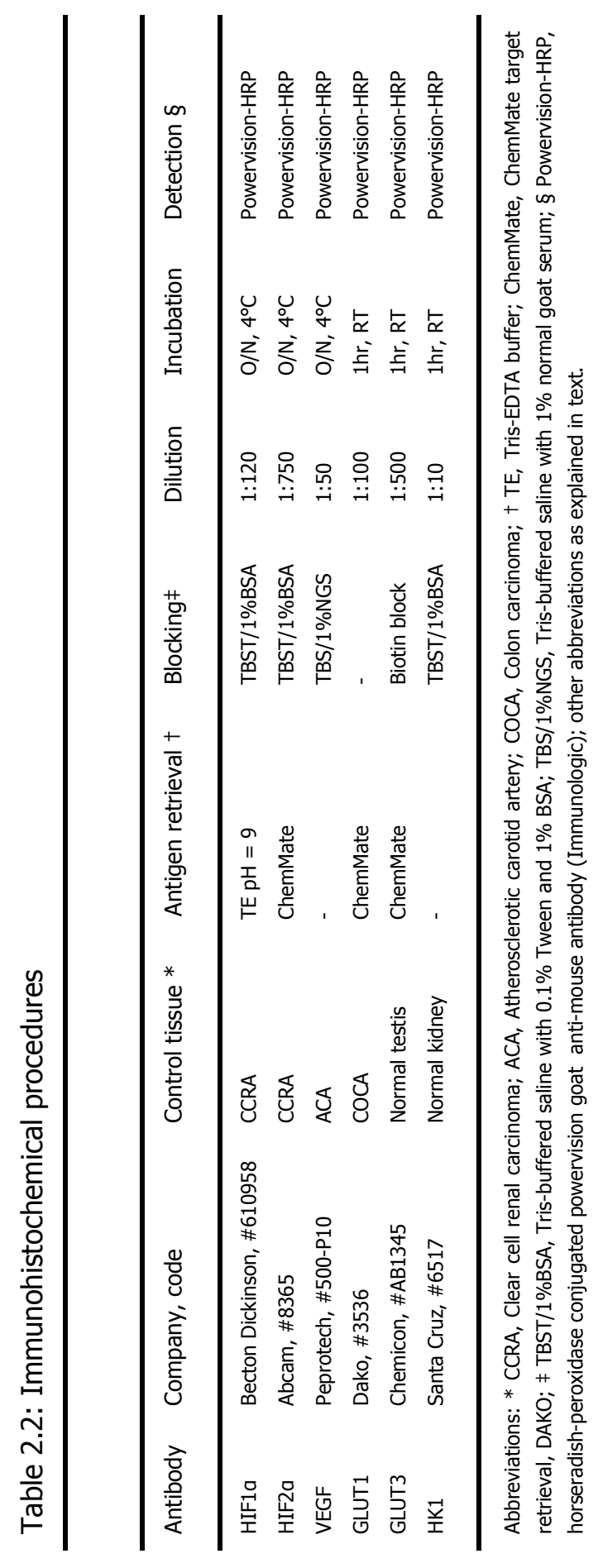




\section{Quantitative immunohistochemistry (qIHC)}

Immunohistochemistry was performed on paraffin-embedded carotid arteries obtained at autopsy $(n=5)$ or surgery $(n=5)$. Expanded immunohistochemical methods can be found in Table 2.2. Sections were stained with primary antibodies against HIF1 $\alpha$, HIF2 $\alpha$, VEGF, GLUT1, GLUT3 and HK1 diluted in Trisbuffered saline (TBS) with $0.1 \%$ Tween and $1 \%$ bovine serum albumin (BSA). Sections were then incubated with appropriate secondary antibodies and staining was visualized as a brown precipitate using 3,3'-diaminobenzidine tetrachloride (ChemMate Envision detection kit, DAKO, Glostrup, Denmark). Sections incubated without the primary antibody served as a negative control. The sections were quantitatively assessed for a difference in immunoreactivity between autopsy and surgery by computer-assisted color image analysis (Leica QWin V3, Cambridge, UK). Immunoreactivity was quantified within 5 random fields at $100 x$ magnification. The percentage of positive staining as a function of total tissue area was determined.

\section{Statistical analysis of patient characteristics, Q-PCR qIHC}

All Q-PCR results are presented as mean \pm SEM. Groups were compared using a Mann-Whitney rank-sum test for continuous variables and Chi-square test for dichotomous variables (SPSS 11.0, Chicago, USA) and were considered statistically different when $\mathrm{P}<0.05$.

\section{RESULTS}

\section{Expression profiles in autopsy and surgery}

Expression analysis using Rosetta Resolver and the Benjamini-Hochberg correction for multiple testing showed that $97.2 \%$ of genes showed similar expression profiles in advanced, stable lesions from autopsy and surgery. Gene expression data were subjected to Gene Set Enrichment Analysis (GSEA), which also showed no significant differences (FDR > 25\%) in expression level between autopsy and surgery samples for the predefined gene sets in the GSEA application.

However, expression analysis showed that 515 genes (2.8\%) were significantly differentially expressed between autopsy and surgery. These genes showed a fold change autopsy/surgery ranging from -8.5 to 7.6 and the majority of differential genes $(n=343)$ was upregulated in autopsy samples. 


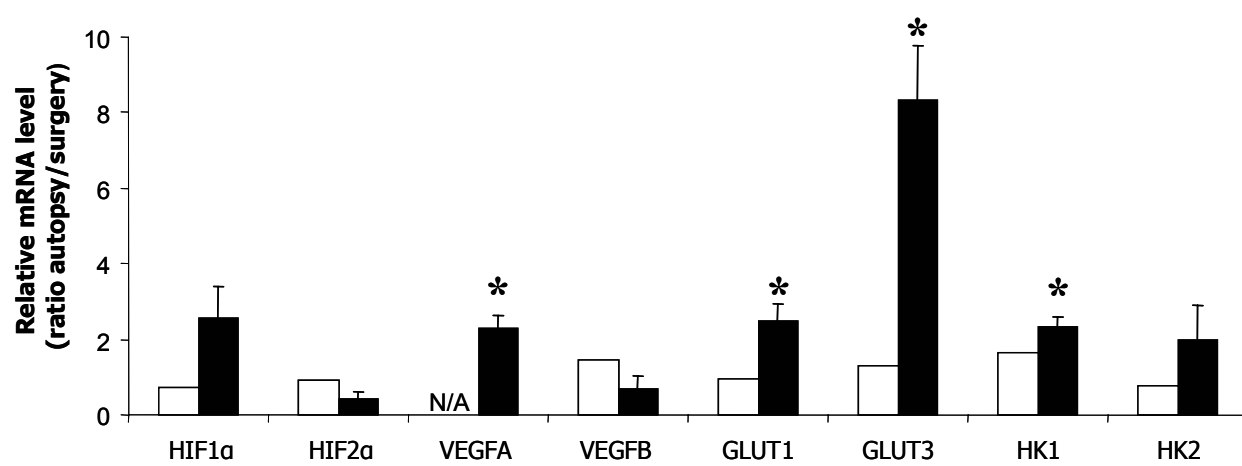

Figure 2.1

Expression ratio between advanced lesions from autopsy and surgery of genes involved in hypoxia and VEGF signaling.

Ratio (autopsy/surgery) of mRNA expression level on microarray (white bars) and qRT-PCR (black bars) of genes involved in hypoxia and VEGF signaling. QRT-PCR of an independent set of samples showed the differential expression of VEGFA, GLUT1, GLUT3 and HK1 between advanced lesions from autopsy and surgery. The data are represented as ratio of autopsy / surgery. ${ }^{*}$ indicates $\mathrm{P}<0.05$ for q-PCR; N/A, indicates VEGFA probe not available on microarray.

\section{Differentially expressed genes are involved in hypoxia-driven pathways}

The differentially expressed genes were further analyzed using Ingenuity pathway analysis to identify the involved biological functions and pathways and revealed significant differential expression of only two canonical pathways: "Vascular endothelial growth factor (VEGF) signaling" $(P<0.0001)$ and "Hypoxia in cardiovascular disease" $(P<0.01)$. Both pathways are associated with oxygen homeostasis.

Expression of mRNA as determined by microarray was validated with Q-PCR for several genes of these hypoxia-driven pathways on an independent set of atherosclerotic samples (Figure 2.1). QRT-PCR showed the significantly higher expression of GLUT1 (2.5 fold up), GLUT3 ( 8.3 fold up) and HK1 (2.4 fold up), in advanced lesions from autopsy compared to surgery samples. These differences in expression level were even higher than the differences determined in the microarray analysis. Expression of HIF1 $\alpha$, HIF2 $\alpha$, VEGFB and HK2 were not differentially expressed when assessed by real-time PCR. In addition, Q-PCR showed that VEGFA, for which no probe was present on the microarray, was 2.4 fold higher expressed in autopsy samples. 
Chapter 2

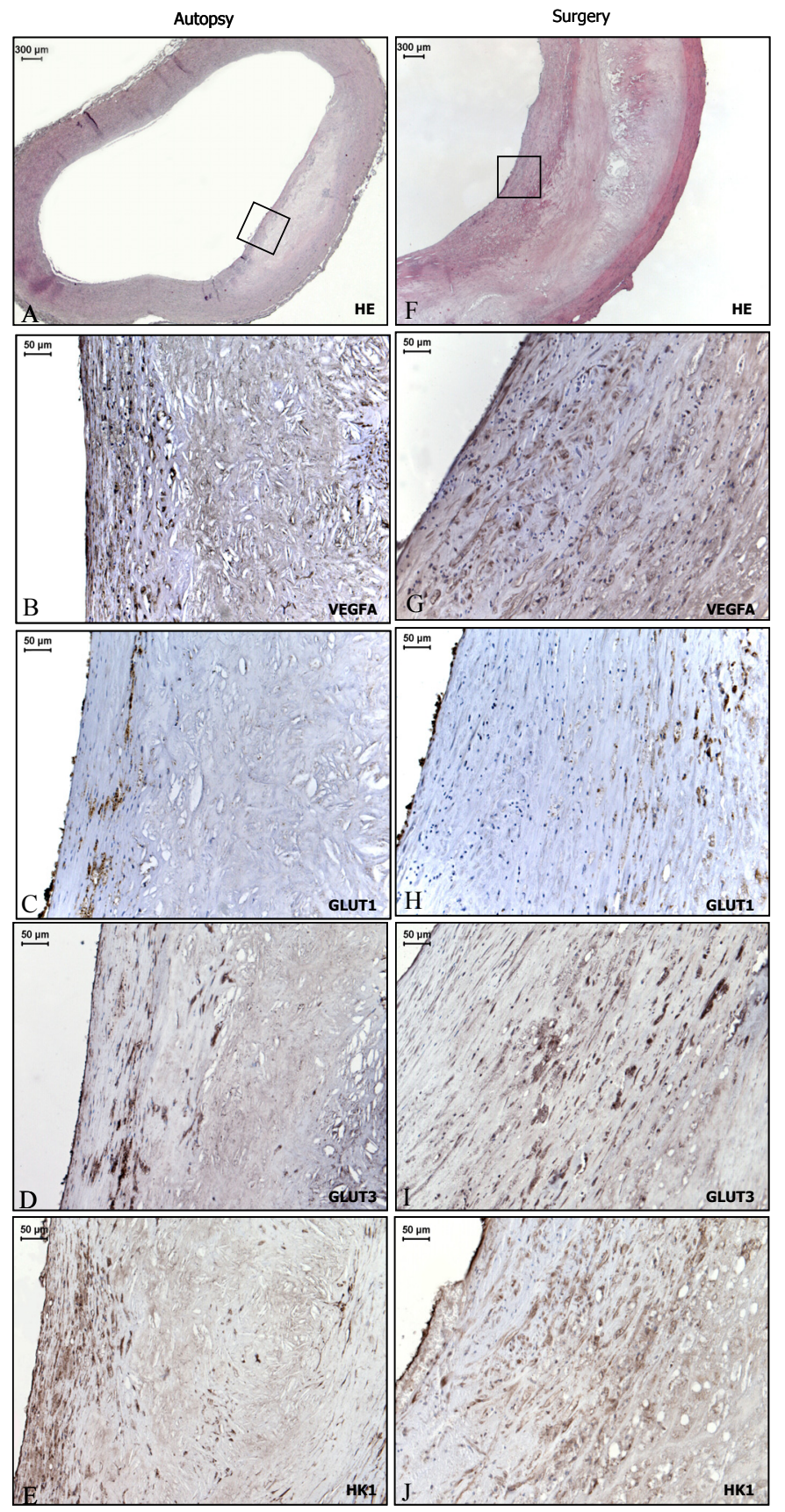

Figure 2.2

Immunohistochemical staining of proteins involved in hypoxia-driven pathways. Advanced lesions from autopsy (A-E) and surgery (F-J) were immunohistochemically stained and quantitative analysis showed similar immunoreactivity of VEGFA (B, G), GLUT1 (C, H), GLUT3 (D, I) and HK1 (E, J) between autopsy and surgery. 
Quantitative immunohistochemical analysis of the hypoxia-driven genes, HIF1 $\alpha$, $2 \alpha$, VEGFA, GLUT1, GLUT3 and HK1 showed that immunoreactivity and cellular distribution of these proteins were similar in advanced atherosclerotic lesions from autopsy and surgery (Figure 2.2 and 2.3). Macrophage foam cells of the atherosclerotic lesion were the most prominent cell type showing immunoreactivity of HIF1 $\alpha$ (data not shown), HIF2 $\alpha$ (data not shown), VEGFA (Figure 2.2B-G), GLUT1 (Figure 2.2C-H), GLUT3 (Figure 2.2D-J) and HK1 (Figure 2.2E-J). In addition, smooth muscle and endothelial cells in the atherosclerotic lesion showed less intense staining of HIF1 $\alpha$, HIF2 $\alpha$ and VEGFA compared to macrophages (Figure 2.2).

Table 2.3: Top 6 differential networks between advanced lesions from autopsy and surgery demonstrated by Ingenuity Pathway analysis

\begin{tabular}{|c|c|}
\hline Gen & Fu \\
\hline 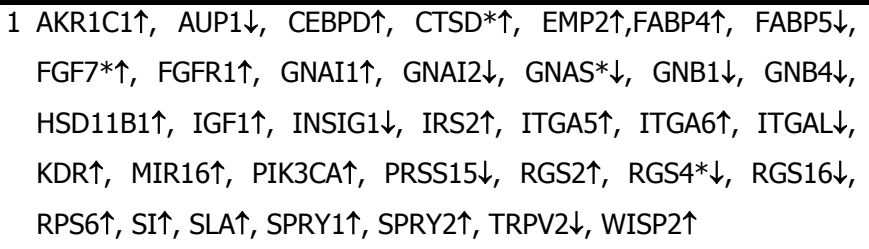 & $\begin{array}{l}\text { Signalling; } \\
\text { DNA replication, } \\
\text { recombination, repair; } \\
\text { Nucleic acid metabolism }\end{array}$ \\
\hline 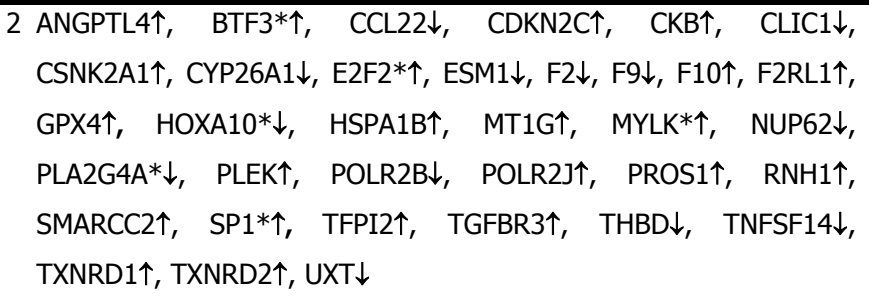 & $\begin{array}{l}\text { Hematological system } \\
\text { development and } \\
\text { function; } \\
\text { Cardiovascular disease; } \\
\text { Hematological disease }\end{array}$ \\
\hline 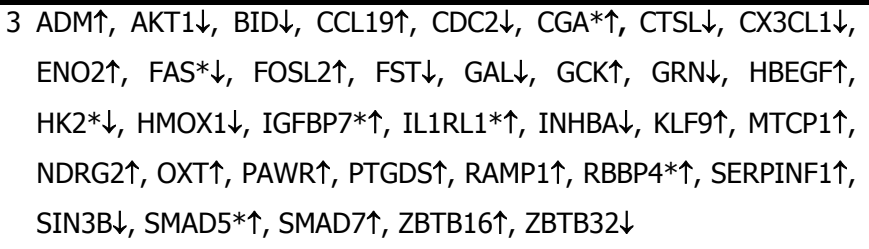 & $\begin{array}{l}\text { Cellular growth and } \\
\text { proliferation; } \\
\text { Cell death; } \\
\text { Cancer }\end{array}$ \\
\hline 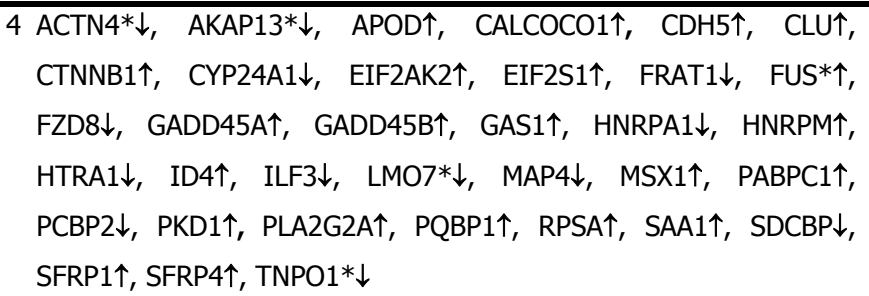 & $\begin{array}{l}\text { Cellular growth and } \\
\text { proliferation; } \\
\text { Cell cycle; } \\
\text { Cellular function and } \\
\text { maintenance }\end{array}$ \\
\hline
\end{tabular}




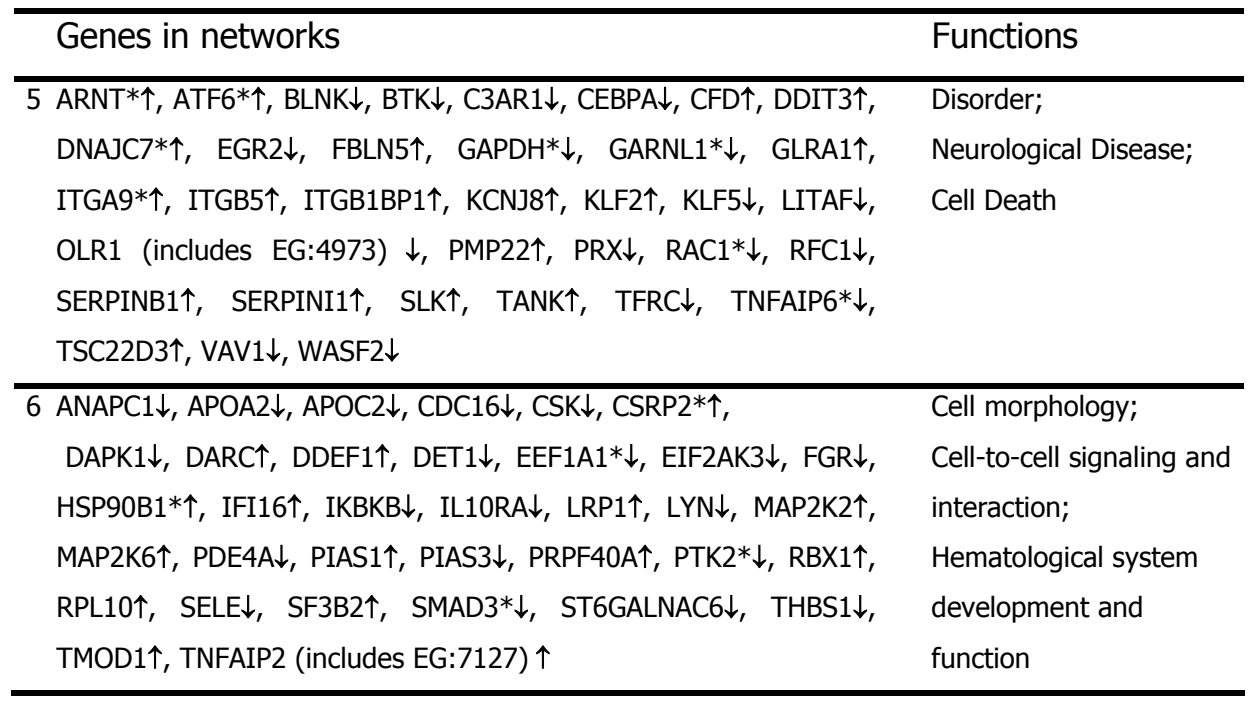

Ingenuity Pathway analysis reveals networks of genes involved in basal cell machinery, such as cell signaling, nucleic acid metabolism, cellular growth and proliferation, cell cycle and cell death. $\uparrow$ indicates increased expression in autopsy, $\downarrow$ indicates increased expression in surgery. All genes depicted have an intensity level > 50 ( $2.5 \mathrm{x}$ background) in at least one of the phenotypes, a fold change $>1.4$ or $<-1.4$ and a P-value $<0.01$. All networks presented showed a $P<E-42$. Asterisks indicate scores of individual genes with $P<E-11$, which indicates the chance that the genes are in a network due to random chance.

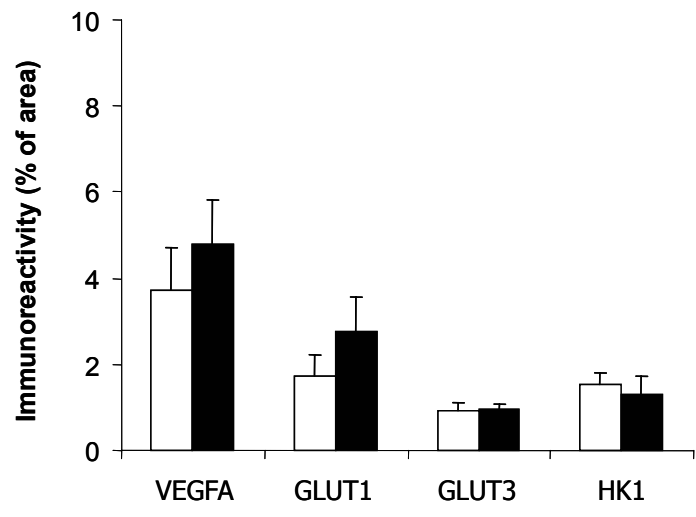

Figure $\mathbf{2 . 3}$

Quantitative immunohistochemical analysis of proteins involved in hypoxia-driven pathways.

Quantitative immunohistochemical analysis showed a similar expression of VEGFA, GLUT1, GLUT3 and HK1 in advanced lesions from autopsy (white bars) and surgery (black bars). 
Table 2.4: Gene Ontology classification of differential genes after BenjaminiHochberg correction

\begin{tabular}{|c|c|}
\hline GO term & Genes (N) \\
\hline Cell growth and/or maintenance & 79 \\
\hline Nucleobase, nucleoside, nucleotide and nucleic acid metabolism & 64 \\
\hline Signal transduction & 59 \\
\hline Protein metabolism & 54 \\
\hline Response to external stimulus & 29 \\
\hline Biosynthesis & 26 \\
\hline Organogenesis & 23 \\
\hline Catabolism & 21 \\
\hline Cell adhesion & 21 \\
\hline Response to stress & 17 \\
\hline Cell death & 15 \\
\hline Immune response & 15 \\
\hline Cell-cell signaling & 14 \\
\hline Neurophysiological process & 14 \\
\hline Phosphorus metabolism & 14 \\
\hline Lipid metabolism & 13 \\
\hline Organismal movement & 12 \\
\hline Electron transport & 10 \\
\hline Regulation of cell proliferation & 10 \\
\hline Organic acid metabolism & 8 \\
\hline Carbohydrate metabolism & 6 \\
\hline Cell motility & 6 \\
\hline Coenzyme and prosthetic group metabolism & 5 \\
\hline Energy pathways & 4 \\
\hline Extracellular matrix organization and biogenesis & 4 \\
\hline Regulation of body fluids & 4 \\
\hline Response to endogenous stimulus & 4 \\
\hline Alcohol metabolism & 3 \\
\hline Amine metabolism & 3 \\
\hline Blood coagulation & 3 \\
\hline Unclassified & 273 \\
\hline
\end{tabular}




\section{Differentially expressed genes are involved in basal cell metabolism}

In addition to changes related to hypoxia pathways, Ingenuity pathway analysis also listed highly significant networks involved in functions such as cell signaling, DNA replication, nucleic acid metabolism, cardiovascular disease, cellular growth and differentiation, cell cycle and cell death (Table 2.3). Likewise, GO analysis showed that the differential genes were mainly involved in cell growth and maintenance (99 genes; 19\%), signal transduction (79 genes; $15 \%$ ), nucleic acid metabolism (77 genes; $15 \%$ ) and protein metabolism (66 genes; $13 \%$ ) and to a smaller extent in cell death (15 genes; $3 \%$ ) and cell signaling (14 genes; 3\%) (Table 2.4).

\section{Differentially expressed genes are not related to atherosclerosis}

The gene expression data were also analyzed to establish whether the differences in expression were related to atherosclerosis. All 515 differentially expressed genes were manually compared to a recently published list of 92 genes related to processes involved in atherosclerotic disease, such as lipid metabolism, inflammation and matrix degradation ${ }^{22}$. Probes representing these 92 genes were indeed present on our microarray and the expression of 87 genes $(95 \%)$ was similar between autopsy and surgery. Only the expression levels of 5 genes were different after Benjamini-Hochberg correction for multiple testing (Table 2.5). Lamin A/C, Fas, thrombin, fibrillin were downregulated 1.4, 1.5, 1.7 and 1.9 fold respectively in autopsy, whereas hydroxysteroid (11-beta) dehydrogenase 1 was upregulated 2.1 fold in samples obtained at autopsy. Thus, the expression of the majority of atherosclerosisrelated genes was similar between autopsy and surgery and consequently the combination of autopsy and surgery samples for transcriptional analysis might not obscure the atherosclerosis-specific expression profile. 
Table 2.5: Genes previously related to atherosclerosis and differentially expressed between atherosclerotic samples from autopsy and surgery

\begin{tabular}{lllll}
\hline Gene symbol & Gene name & Function & FC* & P-value \\
\hline LMNA & Lamin A/C & $\begin{array}{l}\text { Nuclear lamina constituent } \\
\text { involved in Hutchinson-Gilford } \\
\text { progeria }\end{array}$ & -1.4 & $0.2 \mathrm{E}-03$ \\
& & Apoptosis & \\
TNFRSF6/Fas & TNF receptor super family, & & \\
& member 6 & -1.5 & $2.9 \mathrm{E}-09$ \\
F2 & Thrombin & Blood coagulation & -1.7 & $1.5 \mathrm{E}-06$ \\
FBN1 & Fibrillin & $\begin{array}{l}\text { Extracellular matrix } \\
\text { constituent, arterial wall } \\
\text { stiffness }\end{array}$ & -1.9 & $9.6 \mathrm{E}-12$ \\
HSD11B1 & Hydroxysteroid (11-beta) & $\begin{array}{l}\text { Glucocorticoid metabolism, } \\
\text { adipocyte function and } \\
\text { dehydrogenase1 }\end{array}$ & 2.1 & $1.6 \mathrm{E}-12$ \\
& & differentiation & \\
\hline
\end{tabular}

Microarray expression levels of single, differentially expressed genes were linked to 92 genes involved in atherogenesis ${ }^{22}$. The expression of all genes was comparable in advanced lesions from autopsy and surgery, apart from the four genes presented in this table. * Fold change autopsy/surgery; P-values corrected for multiple testing by Benjamini-Hochberg method.

\section{DISCUSSION}

Microarray analysis combined with GO analysis and extensive pathway profiling (Ingenuity and GSEA), Q-PCR and immunohistochemistry were used to study the expression profiles of advanced atherosclerotic lesions from autopsy and surgery. Our results clearly showed that more than $97 \%$ of genes (including several genes known to be involved in atherosclerosis), were unaffected by the source of the tissue, i.e. autopsy or surgery. However, 515 genes primarily involved in basal cell metabolism and hypoxia-driven pathways, were differentially expressed and mainly associated with active postmortem transcription. Nevertheless, immunohistochemistry showed that the transcriptional differences in hypoxia-driven genes were not reflected at the protein level.

Sanoudou et al compared the transcriptome of skeletal muscle from autopsy and surgery and also showed the differential expression of only a minority of genes $(1.1 \%)^{23}$. Remarkably, also in human skeletal muscle, only genes involved in basal cell metabolism, i.e. cell growth/-maintenance, nucleic acid and protein metabolism and cell communication showed differential expression between autopsy and surgical samples. In their study, all differential transcripts 
showed increased expression in postmortem samples. It seems likely that these processes represent a cellular survival response triggered by the complex environmental changes associated with the cessation of life.

In addition to the cellular response of increased basal metabolism, hypoxiadriven pathways were also initiated. The hypoxic response is regulated by the protein stabilization of hypoxia-inducible transcription factors (HIF) 1 and 2 in hypoxic cells. These oxygen sensors orchestrate the transcription of several hypoxia responsive genes involved in angiogenesis, glucose metabolism and cell proliferation/survival and include vascular endothelial growth factor (VEGF), glucose transporters (GLUT) 1 and 3 and hexokinases (HK) 1 and $2^{24}$. It may be appreciated that cessation of life is undeniably associated with cellular ischemia/hypoxia, as our data clearly show. HIF1 $\alpha$ mRNA expression in postmortem kidney compared to surgery was significantly increased in postmortem human kidney ${ }^{25,}{ }^{26}$ but surprisingly VEGF mRNA was decreased in the same samples. Postmortem skeletal muscle did not show a significant increase in HIF1 $\alpha$ and VEGF mRNA expression ${ }^{23}$.

The differences in gene expression we observed were not reflected at protein level. Our findings are corroborated by similar VEGF protein expression in tubuli and arteries of human kidney from deceased and living donors. However, in the same sections a slightly different expression was shown in glomeruli. It seems that differences in protein expression between postmortem and living tissue, if any, are smaller than the transcriptional differences. Theoretically, perishing cells might be able to start transcription and/or translation, but their evident death will prevent them from continuing any process. In addition, protein turnover is a more time-consuming process than mRNA turnover and therefore less sensitive to detect changes. However, changes in post-translational modifications such as phosphorylation or glycosylation may occur within minutes, but are beyond the scope of this study.

A potential concern using autopsy samples to study gene expression would be the quality and integrity of mRNA derived from this source. However, mRNA from autopsy is fairly resistant to degradation in a wide variety of tissues ${ }^{23,27}$, ${ }^{28}$. Total mRNA remained intact up to 48 hours postmortem ${ }^{23,28}$ and microarray expression data were found to be reliable even when mRNA was partially degraded ${ }^{27}$. More specifically, others studied the transcript levels of HIF1 $\alpha$ and VEGF mRNA using qRT-PCR which were shown to be resistant to degradation up to 48 hours postmortem ${ }^{29}$. Therefore, any degradation is unlikely to influence detection of gene expression using microarray and Q-PCR. Aside from the source possibly influencing RNA integrity, another concern was raised by a recent report on the presence of RNA damage in human atherosclerosis ${ }^{30}$. However, a mRNA quality control was applied ensuring similar mRNA integrity of samples from autopsy and surgery. Therefore, any differences in expression 
profile of autopsy and surgery are not expected to be caused by a difference in mRNA quality and integrity between these two sources.

In conclusion, the gene expression profiles of advanced atherosclerotic lesions from autopsy and surgery are largely similar. However, specific gene pathways, mostly involved in basal cell metabolism and hypoxia, were differentially expressed at the mRNA level. Despite the transcriptional differences in hypoxiarelated genes, protein expression in advanced atherosclerotic lesions from autopsy and surgery was comparable. Nevertheless, human expression profiling studies using a combination of both sources should be analyzed with caution. 


\section{REFERENCES}

1. Bijnens AP, Lutgens $E$, Ayoubi $T$, et al. Genome-wide expression studies of atherosclerosis: critical issues in methodology, analysis, interpretation of transcriptomics data. Arterioscler Thromb Vasc Biol. Jun 2006;26(6):1226-1235.

2. Seo D, Wang $\mathrm{T}$, Dressman $\mathrm{H}$, et al. Gene expression phenotypes of atherosclerosis. Arterioscler Thromb Vasc Biol. Oct 2004;24(10):1922-1927.

3. King JY, Ferrara R, Tabibiazar R, et al. Pathway analysis of coronary atherosclerosis. Physiol Genomics. Sep 21 2005;23(1):103-118.

4. Ijas P, Nuotio K, Saksi J, et al. Microarray Analysis Reveals Overexpression of CD163 and HO-1 in Symptomatic Carotid Plaques. Arterioscler Thromb Vasc Biol. Nov 92006.

5. Martinet W, Schrijvers DM, De Meyer GR, et al. Gene expression profiling of apoptosisrelated genes in human atherosclerosis: upregulation of death-associated protein kinase. Arterioscler Thromb Vasc Biol. Dec 1 2002;22(12):2023-2029.

6. Tuomisto $\pi$, Korkeela A, Rutanen J, et al. Gene expression in macrophage-rich inflammatory cell infiltrates in human atherosclerotic lesions as studied by laser microdissection and DNA array: overexpression of HMG-CoA reductase, colony stimulating factor receptors, CD11A/CD18 integrins, and interleukin receptors. Arterioscler Thromb Vasc Biol. Dec 2003;23(12):2235-2240.

7. Adams LD, Geary RL, Li J, et al. Expression profiling identifies smooth muscle cell diversity within human intima and plaque fibrous cap: loss of RGS5 distinguishes the cap. Arterioscler Thromb Vasc Biol. Feb 2006;26(2):319-325.

8. Archacki $S R$, Angheloiu $G$, Tian $X L$, et al. Identification of new genes differentially expressed in coronary artery disease by expression profiling. Physiol Genomics. Sep 29 2003;15(1):65-74.

9. Tabibiazar R, Wagner RA, Ashley EA, et al. Signature patterns of gene expression in mouse atherosclerosis and their correlation to human coronary disease. Physiol Genomics. Jul 14 2005;22(2):213-226.

10. Faber BC, Cleutjens $\mathrm{KB}$, Niessen RL, et al. Identification of genes potentially involved in rupture of human atherosclerotic plaques. Circ Res. Sep 14 2001;89(6):547-554.

11. Papaspyridonos M, Smith A, Burnand KG, et al. Novel candidate genes in unstable areas of human atherosclerotic plaques. Arterioscler Thromb Vasc Biol. Aug 2006;26(8):18371844.

12. Hiltunen MO, Tuomisto $\mathrm{TT}$, Niemi $\mathrm{M}$, et al. Changes in gene expression in atherosclerotic plaques analyzed using DNA array. Atherosclerosis. Nov 2002;165(1):23-32.

13. Virmani R, Kolodgie FD, Burke AP, et al. Lessons from sudden coronary death: a comprehensive morphological classification scheme for atherosclerotic lesions. Arterioscler Thromb Vasc Biol. May 2000;20(5):1262-1275.

14. Chomczynski P, Sacchi N. Single-step method of RNA isolation by acid guanidinium thiocyanate-phenol-chloroform extraction. Anal Biochem. Apr 1987;162(1):156-159. 
15. Dekker RJ, Boon RA, Rondaij MG, et al. KLF2 provokes a gene expression pattern that establishes functional quiescent differentiation of the endothelium. Blood. Jun 1 2006;107(11):4354-4363.

16. Baldi P, Long AD. A Bayesian framework for the analysis of microarray expression data: regularized $\mathrm{t}$-test and statistical inferences of gene changes. Bioinformatics. Jun 2001;17(6):509-519.

17. Subramanian A, Tamayo P, Mootha VK, et al. Gene set enrichment analysis: a knowledgebased approach for interpreting genome-wide expression profiles. Proc Natl Acad Sci U S A. Oct 25 2005;102(43):15545-15550.

18. Demir AY, Groothuis PG, Nap AW, et al. Menstrual effluent induces epithelialmesenchymal transitions in mesothelial cells. Hum Reprod. Jan 2004;19(1):21-29.

19. Favier J, Plouin PF, Corvol P, et al. Angiogenesis and vascular architecture in pheochromocytomas: distinctive traits in malignant tumors. $\mathrm{Am} J$ Pathol. Oct 2002;161(4):1235-1246.

20. Thijssen VL, Brandwijk RJ, Dings RP, et al. Angiogenesis gene expression profiling in xenograft models to study cellular interactions. Exp Cell Res. Oct 1 2004;299(2):286-293.

21. Meex SJ, van der Kallen CJ, van Greevenbroek MM, et al. Up-regulation of CD36/FAT in preadipocytes in familial combined hyperlipidemia. Faseb J. Dec 2005;19(14):2063-2065.

22. Ghazalpour A, Doss $S$, Yang $X$, et al. Thematic review series: The pathogenesis of atherosclerosis. Toward a biological network for atherosclerosis. $J$ Lipid Res. Oct 2004;45(10):1793-1805.

23. Sanoudou D, Kang PB, Haslett JN, et al. Transcriptional profile of postmortem skeletal muscle. Physiol Genomics. Jan 15 2004;16(2):222-228.

24. Semenza GL. Targeting HIF-1 for cancer therapy. Nat Rev Cancer. Oct 2003;3(10):721732.

25. Lemos FB, Ijzermans JN, Zondervan PE, et al. Differential expression of heme oxygenase1 and vascular endothelial growth factor in cadaveric and living donor kidneys after ischemia-reperfusion. J Am Soc Nephrol. Dec 2003;14(12):3278-3287.

26. Baan C, van Gelder T, Peeters A, et al. Living kidney donors and hypoxia-inducible factor1alpha. Transplantation. Feb 27 2003;75(4):570-571.

27. Lee $\mathrm{J}$, Hever A, Willhite $D$, et al. Effects of RNA degradation on gene expression analysis of human postmortem tissues. Faseb J. Aug 2005;19(10):1356-1358.

28. Kuliwaba JS, Fazzalari NL, Findlay DM. Stability of RNA isolated from human trabecular bone at post-mortem and surgery. Biochim Biophys Acta. Apr 15 2005;1740(1):1-11.

29. Zhao D, Zhu BL, Ishikawa $T$, et al. Real-time RT-PCR quantitative assays and postmortem degradation profiles of erythropoietin, vascular endothelial growth factor and hypoxiainducible factor 1 alpha mRNA transcripts in forensic autopsy materials. Leg Med (Tokyo). Mar 2006;8(2):132-136.

30. Martinet W, De Meyer GR, Herman AG, et al. RNA damage in human atherosclerosis: pathophysiological significance and implications for gene expression studies. RNA Biol. Jan 2005;2(1):4-7. 



\section{Chapter 3}

Site specificity of gene expression signatures in human atherosclerosis

Natasja Kisters, Kitty B. Cleutjens, Moniek Faessen, Patrick J. Lindsey, Oscar L. Volger, Anton J. Horrevoets, Ann P. Bijnens, Mat J. Daemen

In preparation 


\section{ABSTRACT}

Although knowledge about site specific gene expression is essential for extrapolating data of one site to other sites of the vasculature, very little is known about differences in gene expression profiles between distinct sites of the vascular bed. To determine site specific differences in transcription profiles, we used microarray analysis to compare the gene expression profiles of human stable atherosclerotic lesions obtained from various sites of the vasculature. Expression analysis was performed both at the single gene level, using a Gaussian linear regression model, and at the pathway level, using Ingenuity pathway analysis software. Using stringent selection criteria we revealed 36 abdominal aorta-, 57 thoracic aorta-, 58 aortic arch- and 58 carotid arteryspecific genes. Although the number of site specific differentially expressed genes was modest, pathway analysis and literature mining revealed several biological processes to be associated with a single vascular bed only. Atherosclerotic lesions in the carotid artery were characterized by a prominent expression of genes involved in inflammation and immunity, whereas the majority of aortic arch specific genes were involved in cell adhesion. Some of the thoracic aorta specific genes are known for their function in oxygen related processes such as hypoxia and generation and deactivation of reactive oxygen species, whereas the abdominal aorta specific genes were mainly involved in cardiovascular development and function.

In conclusion, our study clearly shows that there are site-specific differences in atherosclerosis-related gene expression between various sites of the vasculature. This observation might lead to novel insights in site-specific mechanisms of atherosclerosis and stresses the importance of a careful design of future atherosclerotic research projects using tissues from different sites. 


\section{INTRODUCTION}

Atherosclerosis is a complex chronic inflammatory disease preferentially affecting a number of large and medium sized arteries ${ }^{1}$. Although it is well recognized that haemodynamic forces play an important role in this predisposition, these forces alone are not sufficient to induce atherosclerosis. Thus far additional factors that are responsible for the predisposition of atherogenesis to specific sites of the vasculature have not been unmasked.

During recent years a myriad of gene expression studies to unravel the molecular mechanism underlying the initiation and progression of human atherosclerosis have been performed (recently reviewed by ${ }^{2,}{ }^{3}$ ), see also Chapter 1 of this thesis. Although the vast majority of human studies focused on the gene expression profiles of atherosclerotic lesions originating from a single vascular bed, the very well acknowledged athero-resistant nature of the internal mammary artery ${ }^{4,5}$ is indeed reflected by a unique gene expression profile and several studies revealed site-specific effects in murine atherosclerosis (reviewed in ${ }^{1}$ ). We therefore hypothesized that human atherosclerotic lesions will also display site-specific differences in their expression profile. As a result, both systemic risk factors and a given treatment may differentially affect the phenotype of human atherosclerotic lesions throughout the vasculature. Therefore, a more complete understanding of genes and pathways operating at different sites is indispensable.

In the present study we compared the gene expression profiles of human stable atherosclerotic lesions obtained during autopsy from 4 different sites of the vasculature; that is the abdominal aorta, thoracic aorta, aortic arch and the carotid artery, the athero-resistant mammary artery and the vena cava. Using a comprehensive study design, microarray analysis and detailed bio-informatical and statistical analysis, we identified several site specific differences in the expression profile of individual genes, molecular pathways and biological functions.

\section{METHODS AND MATERIALS}

\section{Tissue harvesting and histological analysis}

A total of 43 vascular wall segments ( 25 donors) were obtained at autopsy (Department of Pathology, University Hospital Maastricht). The distribution of these 43 segments across the vascular bed was as follows; 12 segments were derived from the carotid artery, 10 segments from the abdominal aorta, 9 segments from the thoracic aorta, 5 segments from the aortic arch, 4 segments from the vena cava and 3 segments from the mammary artery (reference site). 
Collection, storage in the Maastricht Pathology Tissue Collection (MPTC), and use of tissue and patient data were performed in agreement with the "Code for Proper Secondary Use of Human Tissue" (http://www.fmwv.nl). The mean age of the donors was $71.1 \pm 13.5$ years and $56 \%(n=14)$ was male (see Table 3.1). Samples were processed as described previously ${ }^{6}$. Briefly, immediately after resection, the vascular segments were divided into parallel segments of 5 $\mathrm{mm}$. A snap frozen segment for RNA isolation was alternated by a formalinfixed segment for histology. The histological sections $(4 \mu \mathrm{m})$ were stained with haematoxylin and eosin (HE) and used for classification according to Virmani et al ${ }^{7}$ and morphometric analysis (Leica QWin V3, Cambridge, UK). Only stable atherosclerotic lesions were included in the study. Within each lesion, five fields (magnification 50x, each area $6.04 \mathrm{~mm}^{2}$ ) were subjected to area measurements on lipid core, calcified regions, fibrous tissue sites, inflammatory regions $(n=5$ each site). The percentages of the individual areas as a function of total intima area were determined. Moreover, for each lesion the intima-media-adventitia area was determined.

\section{RNA isolation and quantification}

Total RNA was isolated using the guanidine isothiocyanate/CsCl ${ }^{8}$ method followed by further purification and concentration over RNeasy mini columns (Qiagen, Hilden, Germany). RNA quantity and quality were determined using a nanodrop spectrophotometer (Witec AG, Littau, Switzerland) and a 2100 Bioanalyser (Agilent Technologies, Palo Alto, USA) respectively. Only RNA samples with a RIN value $\geq 4.5$ were included for microarray hybridization.

\section{Microarray hybridization}

Microarray hybridization was performed as described in Chapter 2 of this thesis.

\section{Statistical analysis of the microarray}

All expression data were analyzed using a Gaussian linear regression, ( $\mathrm{N}\left(\mu, \sigma^{2}\right)$ where $\mu$ is the mean and $\sigma^{2}$ is the variance) including the gender, age, hybridization day, RNA integrity (RIN), concentration, labeling efficiency, repeat and variability in expression levels of the common reference (GeneR 2.4.0, R-project, http://www.R-project.org/). The inference criterion used for comparing the models is their ability to predict the observed data, i.e. models are compared directly through their minimized minus log-likelihood. 
Table 3.1: Donor characteristics

\begin{tabular}{|c|c|c|c|c|}
\hline Patient code & $\begin{array}{l}\text { \# Specimens } \\
\text { collected }\end{array}$ & Gender & Age (years) & Collected sites \\
\hline D-1 & 2 & $\mathrm{~F}$ & 79 & Abd A; CA \\
\hline D-2 & 2 & M & 58 & Abd $A ; A A$ \\
\hline D-3 & 4 & M & 62 & Abd A; CA; AA; VC \\
\hline$D-4$ & 2 & $\mathrm{~F}$ & 74 & $\mathrm{CA} ; \mathrm{VC}$ \\
\hline D-5 & 4 & M & 74 & Abd A; CA; $A A ; V C$ \\
\hline D-6 & 2 & $M$ & 74 & $\mathrm{CA}(2 \mathrm{x})$ \\
\hline D-7 & 2 & $M$ & 87 & Abd A; TA \\
\hline D-8 & 2 & M & 69 & Abd A; TA \\
\hline D-9 & 3 & $\mathrm{~F}$ & 79 & Abd A; TA (2x) \\
\hline D-10 & 2 & $\mathrm{~F}$ & 84 & Abd A; MA. \\
\hline D-11 & 2 & M & 66 & Abd A; TA \\
\hline D-12 & 2 & $\mathrm{~F}$ & 66 & $\mathrm{CA} ; \mathrm{TA}$ \\
\hline D-13 & 2 & $\mathrm{~F}$ & 58 & $\mathrm{AA} ; \mathrm{MA}$ \\
\hline D-14 & 1 & M & 36 & Abd A \\
\hline D-15 & 1 & $\mathrm{~F}$ & 71 & MA \\
\hline D-16 & 1 & M & 63 & $\mathrm{CA}$ \\
\hline D-17 & 1 & M & 73 & AA \\
\hline D-18 & 1 & $\mathrm{~F}$ & 40 & VC \\
\hline D-19 & 1 & $\mathrm{~F}$ & 79 & $\mathrm{CA}$ \\
\hline D-20 & 1 & $\mathrm{~F}$ & 81 & $\mathrm{CA}$ \\
\hline D-21 & 1 & $\mathrm{~F}$ & 82 & $\mathrm{CA}$ \\
\hline D-22 & 1 & $M$ & 93 & $\mathrm{CA}$ \\
\hline D-23 & 1 & $M$ & 79 & $\mathrm{TA}$ \\
\hline D-24 & 1 & $M$ & 75 & $\mathrm{TA}$ \\
\hline D-25 & 1 & M & 78 & $\mathrm{TA}$ \\
\hline
\end{tabular}

Abbreviations: F, Female; M, Male; Abd A, Abdominal Aorta; CA, Carotid Artery; AA, Aortic Arch; VC, Vena Cava; TA, Thoracic Aorta; MA, Mammary Artery

When the numbers of parameters in models differ, they are penalized by adding the number of estimated parameters, a form of the Akaike information criterion (AIC) ${ }^{9}$.

For each gene, a model containing the relevant covariates mentioned above $(\mathrm{E}(y)=$ Gender + Age + Hyb. + Rin + Conc. + Lab. Eff. + Rep. + Ref. $)$ was fitted in order to obtain a reference AIC. For each gene the site was sequentially added to the model $(\mathrm{E}(y)=$ Gender $+\ldots+$ Ref. + Site $)$. The gene under consideration was found to be differentially expressed if the AIC of any of these three models decreased compared to the reference AIC. 


\section{Identification of site specific differentially expressed genes and pathway profiling}

Statistical analysis revealed a number of genes significantly differentially expressed between stable lesion samples from a particular vascular bed and the reference site, the non-diseased mammary artery. To determine which of these genes were significantly differentially expressed in one vascular bed only, we performed step and pairwise comparisons, as indicated in Figure 3.1. To uncover the biological processes represented by these site specific differentially expressed genes, pathway profiling using Ingenuity Pathway Analysis (IPA) software (Ingenuity Systems, Mountain View, CA, USA; https://analysis.ingenuity.com/pa) was performed.

\section{Statistical analyses of histological features}

All results are presented as mean \pm SEM. First, the data set was analyzed using the non-parametric Kruskal-Wallis test to identify differences between the selected four sites of the vascular bed and the lesion specific areas. When a statistical difference was detected, the non-parametric Mann-Whitney test in combination with the Bonferroni correction for multiple testing was performed to determine which of the sites were different, regarding the lesion specific area (SPSS 12.1, Chicago, IL). P $<0.05$ was considered statistically different.

\section{RESULTS}

First, we determined whether lesions from different sites in the vascular bed could be distinguished based on characteristic phenotypes such as lipid core content, calcification, (areas with massive) inflammation, regions containing fibrosis, intimal, medial and adventitial area. To that end we performed a quantitative morphometric analysis $(\mathrm{N}=4-5)$ which showed no statistical differences. Thus lesions of the different sites of the vascular bed showed a comparable composition (see Table 3.2).

In a first statistical analysis we performed extensive Gaussian linear regression modeling on all samples. Next, using step and pair wise comparisons for each site, we identified those genes differentially expressed in a single vascular bed only (see Figure 3.1 for a schematic overview of the comparison strategy).

The first analysis, comparing 4 diseased sites with the non-diseased mammary artery, revealed 994 genes which were differentially expressed between the abdominal aorta and the mammary artery, 1056 genes differentially expressed between the thoracic aorta and the mammary artery, 897 between the aortic 
arch and the mammary artery and 927 genes that were differentially expressed between the carotid compared to the mammary artery (see Table 3.3). Selection of genes significantly differentially expressed in a single site only, revealed 91 abdominal aorta specific genes, 173 thoracic aorta specific genes, 142 aortic arch specific genes and 139 carotid artery specific genes (see Table 3.3).

In an additional analysis we included vena cava derived expression data to the 4 diseased sites in the Gaussian linear regression model to further increase the statistical power. This second analysis, including the vena cava derived expression profile, revealed respectively 1201 genes differentially expressed between abdominal aorta and the mammary artery, 1263 genes differentially expressed between thoracic aorta and the mammary artery, 1078 genes differentially expressed between the aortic arch and the mammary artery and 1135 genes differentially expressed between the carotid artery and the mammary artery (see Table 3.3). From these genes respectively 99 (abdominal aorta), 201 (thoracic aorta), 161 (aortic arch) and 179 (carotid artery) showed a unique differential expression pattern in a single artery segment (see Table 3.3).

To minimize the risk of including false positives, we focused on those genes that were site specific differentially expressed in both analyses. Ultimately, our strict regime/criteria revealed 36 abdominal aorta, 57 thoracic aorta, 58 aortic arch and 58 carotid specific atherosclerosis-related genes (see Table 3.3).

To gain insight in the (molecular) functions represented by these site specific differentially expressed genes, we applied Ingenuity Pathway Analysis (IPA) software and literature mining. Table 3.4 lists a summary of the key processes

Table 3.2: Results of histological quantification of human atherosclerotic lesions

\begin{tabular}{lcccl}
\hline \multicolumn{5}{c}{ Site } \\
\hline & Abdominal artery & Thoracic artery & Aortic arch & Carotid artery \\
& & & & \\
\hline$\%$ lipid core & $11.04 \pm 8.27$ & $15.91 \pm 11.9$ & $9.63 \pm 8.58$ & $2.34 \pm 1.53$ \\
$\%$ inflammation & $0.20 \pm 0.10$ & $0.061 \pm 0.05$ & $0.15 \pm 0.06$ & $0.13 \pm 0.05$ \\
$\%$ calcification & $1.49 \pm 1.33$ & $0.17 \pm 0.15$ & 0 & $0.09 \pm 0.09$ \\
$\%$ fibrosis & $2.59 \pm 2.58$ & $0.83 \pm 0.53$ & 0 & 0 \\
Intima area $\left(\mathrm{mm}^{2}\right)$ & $2.00 \pm 0.20$ & $2.52 \pm 0.64$ & $1.15 \pm 0.36$ & $1.82 \pm 0.25$ \\
Media area $\left(\mathrm{mm}^{2}\right)$ & $2.03 \pm 0.33$ & $1.90 \pm 0.45$ & $2.94 \pm 0.30$ & $1.64 \pm 0.07$ \\
Advential area $\left(\mathrm{mm}^{2}\right)$ & $0.30 \pm 0.09$ & $0.15 \pm 0.04$ & $0.51 \pm 0.05$ & $0.64 \pm 0.06$ \\
\hline
\end{tabular}

No significant differences were detected. Data are expressed as mean \pm SEM. 

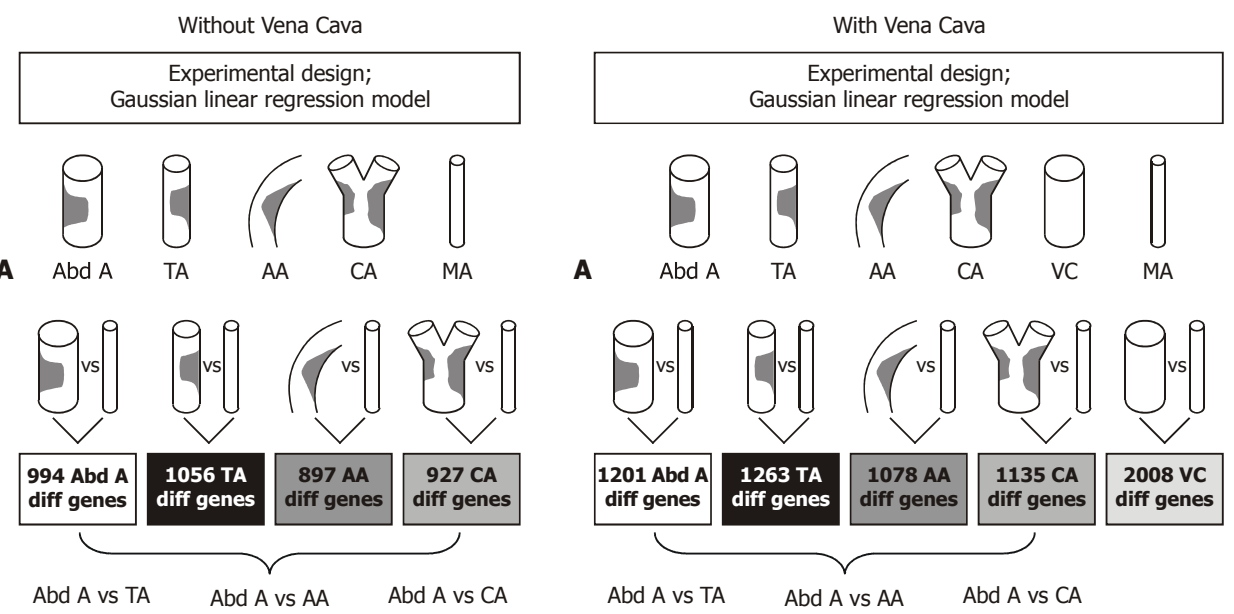

B
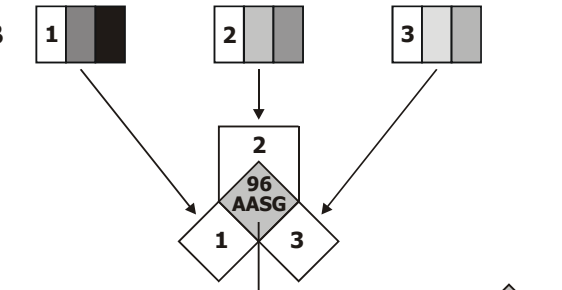

Abd A vs TA

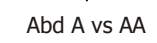

B 1

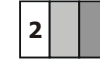

3

C
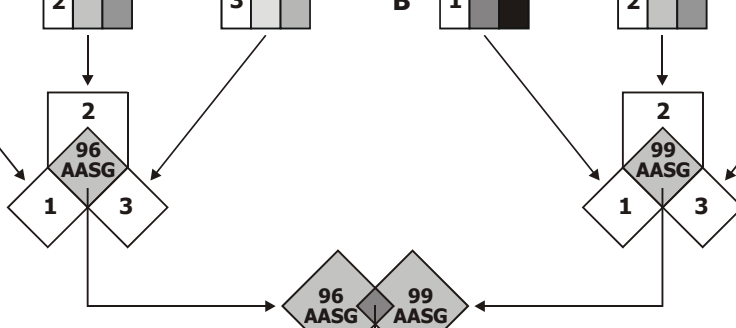

D

36 "True" Abdominal Aorta Specific Genes (TAASG)

Figure 3.1

Flowchart depicting an overview of our experimental design to detect site specific differential genes. (A) Using a Gaussian linear regression model, genes differentially expressed between a given site and the reference site (mammary artery) were detected. (B) Site selective genes were identified by pair wise filtering of the differentially expressed genes (abdominal aorta is used as an example). 1 indicates genes specific for abdominal aorta compared to thoracic aorta, 2 indicates genes specific for abdominal aorta compared to aortic arch and 3 indicates genes specific for abdominal aorta compared to carotid artery. (C) The overlap of the three site selective gene sets for each site (abdominal aorta in our example) was determined and those genes which were site selective in both analyses were the site specific genes (D). Abbreviations; Diff., differential; Abd A, Abdominal Aorta; MA, Mammary Artery; TA, Thoracic Aorta; AA, Aortic Arch; CA, Carotid Artery; VC, Vena Cava; (T) AASG, (True) Abdominal Aorta Specific Genes. 
and corresponding genes characteristic for the different sites. Pathway profiling of the 36 abdominal arch specific differentially expressed genes revealed a prominent role of genes involved in "cardiovascular system development and function". This process is exemplified by genes such as CBS (cystathionine-betasynthase), CTSH (cathepsin H), PRL (prolactin) and AVP (arginine vasopressin). The biological function/process associated with thoracic aorta specific genes was "cellular growth and proliferation". The following key genes were associated with this function: super oxide dismutase 3 (SOD3), phosphatase and tensin homolog (PTEN), endothelial pas domain protein 1 (EPAS) and SLC6A4 solute carrier family 6 (SLC6A4). Some of these genes are also involved in oxygen related processes such as hypoxia (EPAS) and inactivation of reactive oxygen species in cells (SOD3).

Pathway profiling further revealed genes involved in cell adhesion to be specifically linked to stable lesion containing aortic arch segments. Processes and key genes associated with cell adhesion were "cell to cell signaling and interaction"/ "cellular morphology" (dipeptidase 1 (DPP1) and E2F transcription factor 1 (E2F1)) and "cellular movement" (regulator of G-protein signaling 1 (RGS1) and integrin alpha4 (ITG $\alpha 4)$ ).

Of the carotid artery specific transcripts, genes involved in "inflammatory and immune" were most prominent. Key genes associated with this function are toll like receptor 4 (TLR4), vascular endothelial growth factor c (VEGFC), transforming growth factor alpha (TGF $\alpha$ ) and interleukin 7 (IL7). The canonical pathways involved in the carotid specific differential expressed genes confirmed the importance of inflammatory disease related processes, since the pathways "Toll like receptor signaling" and "NFKB signaling" were significantly ( $\mathrm{P}=0.012$ and $\mathrm{P}=0.0071$ respectively) associated with the carotid artery segments only.

Table 3.3: Results of Gaussian linear regression analysis

\begin{tabular}{lccccc}
\hline \multicolumn{1}{c}{ Site } & $\begin{array}{c}\text { 4 diseased sites vs mammary } \\
\text { artery }\end{array}$ & $\begin{array}{c}\text { 4 diseased sites and vena } \\
\text { cava vs mammary artery }\end{array}$ & $\begin{array}{c}\text { Site specific } \\
\text { genes in } \\
\text { both analysis }\end{array}$ \\
\cline { 2 - 6 } & \# Dif. genes & \# Spec. genes & \# Dif. genes & \# Spec. genes & Genes \\
\hline Abd. aorta & 994 & 91 & 1201 & 99 & 36 \\
Th. aorta & 1056 & 173 & 1263 & 201 & 57 \\
Aortic arch & 897 & 142 & 1078 & 161 & 58 \\
Carotid artery & 927 & 139 & 1135 & 179 & 58 \\
Vena Cava & - & - & 2008 & - & - \\
\hline
\end{tabular}

Abbreviations: Abd. aorta, abdominal aorta; Th. aorta, thoracic aorta; \#Dif. Genes, number of genes significantly different compared to reference site; \# Spec. genes, number of differential genes specific for the given site. 
Chapter 3

Table 3.4: Functions and key atherosclerosis-related genes specifically associated with a particular vascular site.

\begin{tabular}{lll}
\hline Site & Functions & Key genes \\
\hline Abdominal aorta & Cardiovascular development and function & $\begin{array}{l}\text { CTSH }(\downarrow), \text { PRL }(\uparrow), \text { AVP } \\
(\downarrow), \text { CBS }(\uparrow)\end{array}$ \\
Thoracic aorta & $\begin{array}{l}\text { Cellular growth and proliferation /oxygen } \\
\text { related processes }\end{array}$ & $\begin{array}{l}\text { SOD3 }(\uparrow), \text { EPAS }(\downarrow), \text { PTEN } \\
(\downarrow), \text { SLC6A4 }(\downarrow)\end{array}$ \\
Aortic arch & Cell adhesion & DPP1 $(\uparrow), \operatorname{RGS1}(\uparrow)$, ITG $\alpha 4$ \\
& & $(\uparrow)$, E2F1 ( $\uparrow)$ \\
Carotid artery & Inflammatory and immune response & $\begin{array}{l}\text { TLR4 }(\uparrow), \operatorname{VEGFC~}(\uparrow), \text { TGF } \alpha \\
(\uparrow), \operatorname{IL7}(\uparrow)\end{array}$ \\
\hline
\end{tabular}

Abbreviations: $(\downarrow)=$ downregulated and $(\uparrow)=$ upregulated when compared to mammary artery. CTSH, cathepsin $\mathrm{H}$; PRL, prolactin; AVP, arginine vasopressin; CBS, cystathionine-beta-synthase; SOD3, super oxide dismutase 3; EPAS endothelial pas domain protein 1; PTEN, phosphatase and tensin homolog; SLC6A4, solute carrier family 6; DPP1, dipeptidase 1; RGS1, regulator of G-protein signaling 1; ITG $\alpha$ 4, integrin alpha4; E2F1, E2F transcription factor 1 ; TLR4,toll like receptor 4; VEGFC, vascular endothelial growth factor c; TGF $\alpha$, transforming growth factor alpha; IL7, interleukin 7.

\section{DISCUSSION}

Microarray analysis was used to compare the gene expression profiles of stable atherosclerotic lesions obtained from different sites in the human vasculature. Our study reveals site-specific gene expression profiles of stable human atherosclerotic lesions. Pathway analysis and literature mining revealed specific biological processes that were differentially expressed in each vascular bed.

One of the most straightforward explanations for this observation could be that lesions samples from the different sites of the vasculature had a different cellular composition. The results of the morphological analysis demonstrated however no significant differences in morphometric characteristics between the different sites of the vasculature. Therefore, the observed differences in gene expression profiles are not due to a difference in cellular composition of the stable lesions at the different sites.

While this is the first gene expression study aiming at the identification of site specific differences in atherosclerosis-related gene expression profiles, it has been recognized before that human atherosclerosis and its complications exhibit site selectivity. For instance, patients with type II diabetes show a 2-4 fold increase in the incidence of peripheral artery disease, with a predisposition to 
the lower legs, compared to the incidence of atherosclerotic lesions in the aorta, coronary and carotid lesions ${ }^{10,11}$. Another strong suggestion for regional selectivity in atherosclerotic responses to systemic risk factors comes from the Pathological Determination of Atherosclerosis in Youth (PDAY) study. In this study the effects of risk factors on atherosclerosis were studied in the right coronary artery, the thoracic aorta and the abdominal aorta of relatively healthy subjects. It was shown that smoking leads to an increased incidence of raised lesions in the abdominal aorta ( 3 fold), while atherosclerosis burden in the right coronary artery was not influenced. On the contrary, high levels of glycohemoglobin were associated with more extensive atherosclerotic lesions in the right coronary artery while the abdominal aorta remained unaffected ${ }^{12-14}$. An important question is how the various systemic risk factors associated with atherosclerosis result in these observed site specific differences in gene expression profiles. A widely accepted contributor is the difference in shear stress, which may differentially prime the endothelial cells to these systemic risk factors ${ }^{15,16}$.

Elegant in vitro studies demonstrated that ECs exposed to disturbed flow displayed a (more) pro-inflammatory gene expression profile ${ }^{17}$ whereas cells exposed to shear stress show induction of athero-protective genes, such as $\mathrm{KLF} 2$, eNOS and thrombomodulin ${ }^{18,}{ }^{19}$. Also in vivo studies demonstrated that ECs isolated from disturbed and undisturbed blood flow regions displayed unique gene expression profiles. Pig ECs from shear stress regions displayed a pro-inflammatory and, as a compensatory mechanism/response, a protective antioxidant gene expression profile ${ }^{20}$. Cheng et a/demonstrated that regions of lowered, increased, and lowered/oscillatory shear stresses in mouse carotid arteries had different effects on lesion development. Lowered shear stress induced larger lesions with a vulnerable lesion phenotype, oscillatory shear stress induces stable lesions ${ }^{21}$. In humans it has also been demonstrated that the carotid artery with a lower mean shear stress is more affected by atherosclerosis than its counterpart ${ }^{22}$.

Some but not all of the site specific genes identified in our study are indeed shear responsive genes, such as CD34, VEGFC, IL19, SOD3, Semaphorin 5A, SP2 and Matrilin ${ }^{18-20,23,24}$. Most probably there are many more shear stress responsive genes underlying the site selectivity but this study design, using the entire vascular segments, is unsuitable to detect subtle changes in gene expression of low abundant cells, such as endothelial cells. A laser capture microdissection approach, performing genome wide expression profiling on microdissected endothelial cells from various sites of the vasculature would give more insight in site specificity of shear responsive genes.

Interestingly, although our study revealed a relative modest number $(1.14 \%)$ of site specific atherosclerosis-related genes, certain genes could be categorized in functionally related groups already known to be involved in atherogenesis. 
Several genes linked to inflammation and the immune system, processes with a well-known role in the initiation and progression of atherosclerosis, were specifically expressed in the carotid artery ${ }^{25}$. Furthermore, the abdominal aorta specific expressed genes include both cathepsin $\mathrm{H}$ and $\mathrm{O}$. Cathepsins are known for their extracellular matrix degrading capacities and cathepsins have been implicated to play a role in atherogenesis before ${ }^{26-29}$. See also chapter 5 of this thesis. Furthermore, cathepsins might play a role in abdominal aortic aneurysm formation ${ }^{29-31}$.

Some of the specific differentially expressed genes in the thoracic aorta are known for their function in oxygen related processes such as hypoxia. In human atherosclerotic lesions hypoxia can induce neovascularization, which has a role in lesion initiation, progression and destabilization ${ }^{32-35}$.

Four of the key genes identified in the current study, cathepsin H (CTSH), Regulator of G protein signaling 1 (RGS1), Superoxide dismutase 3 (SOD3) and Endothelial Pas domain protein 1 (EPAS1), showed differentially expression patterns in earlier microarray studies using human atherosclerotic specimens. Seo et a/ showed that the RGS1 expression was associated with disease burden in the thoracic aorta ${ }^{36}$. Others found RGS1 to be higher expressed in atherosclerotic coronary arteries compared to coronary arteries with no lesions ${ }^{37}$ and in unstable compared to stable regions of the carotid artery ${ }^{38}$. Cathepsin $\mathrm{H}$ was found to be differentially regulated between non-diseased coronary arteries compared to coronary arteries with atherosclerotic lesions ${ }^{37,}{ }^{39}$. SOD3 expression was associated with disease burden and the location within the thoracic aorta, e.g. the proximal or distal part ${ }^{36}$. Others showed SOD3 to be differentially expressed between stable and unstable regions of the carotid artery ${ }^{38}$. The study described by Adams et al demonstrated a higher EPAS1 expression in the media compared to the fibrous cap of carotid artery lesions ${ }^{40}$. These studies, however, aimed to compare different lesion stages within the distinct arteries, whereas the aim of our study was to identify (general) site specific differences in atherosclerotic gene expression profiles in the various vascular sites.

In conclusion, this is the first human atherosclerotic gene expression profiling study demonstrating site specific gene expression. Furthermore, our study provides insights in the different biological processes involved in atherosclerotic lesion development at various sites of the vasculature, which might explain the differences in extent and clinical complications of atherosclerotic lesions throughout the vascular bed. Therefore, the results of our study might lead to new insights in atherogenesis, opening perspectives for site specific therapies. 


\section{REFERENCES}

1. VanderLaan PA, Reardon CA, Getz GS. Site specificity of atherosclerosis: site-selective responses to atherosclerotic modulators. Arterioscler Thromb VasC Biol. Jan 2004;24(1):12-22.

2. Bijnens AP, Lutgens $E$, Ayoubi $T$, et al. Genome-wide expression studies of atherosclerosis: critical issues in methodology, analysis, interpretation of transcriptomics data. Arterioscler Thromb Vasc Biol. Jun 2006;26(6):1226-1235.

3. Tuomisto TT, Binder BR, Yla-Herttuala S. Genetics, genomics and proteomics in atherosclerosis research. Ann Med. 2005;37(5):323-332.

4. Qin M, Zeng Z, Zheng J, et al. Suppression subtractive hybridization identifies distinctive expression markers for coronary and internal mammary arteries. Arterioscler Thromb Vasc Biol. Mar 1 2003;23(3):425-433.

5. Sisto $\mathrm{T}$, Isola J. Incidence of atherosclerosis in the internal mammary artery. Ann Thorac Surg. Jun 1989;47(6):884-886.

6. Faber $B C$, Cleutjens $K B$, Niessen $R L$, et al. Identification of genes potentially involved in rupture of human atherosclerotic plaques. Circ Res. Sep 14 2001;89(6):547-554.

7. Virmani $R$, Kolodgie $F D$, Burke $A P$, et al. Lessons from sudden coronary death: a comprehensive morphological classification scheme for atherosclerotic lesions. Arterioscler Thromb Vasc Biol. May 2000;20(5):1262-1275.

8. Chomczynski $P$, Sacchi N. Single-step method of RNA isolation by acid guanidinium thiocyanate-phenol-chloroform extraction. Anal Biochem. Apr 1987;162(1):156-159.

9. Akaike $\mathrm{H}$. Information theory and an extension of the maximum likelihood principle. In: Petrov B, Csàki F, eds. Second International Symposium on Inference Theory. Budapest; 1973:267-281.

10. Newman AB, Siscovick DS, Manolio TA, et al. Ankle-arm index as a marker of atherosclerosis in the Cardiovascular Health Study. Cardiovascular Heart Study (CHS) Collaborative Research Group. Circulation. Sep 1993;88(3):837-845.

11. Uusitupa MI, Niskanen LK, Siitonen 0 , et al. 5-year incidence of atherosclerotic vascular disease in relation to general risk factors, insulin level, and abnormalities in lipoprotein composition in non-insulin-dependent diabetic and nondiabetic subjects. Circulation. Jul 1990;82(1):27-36.

12. McGill HC, Jr., McMahan CA. Determinants of atherosclerosis in the young. Pathobiological Determinants of Atherosclerosis in Youth (PDAY) Research Group. Am J Cardiol. Nov 26 1998;82(10B):30T-36T.

13. McGill HC, Jr., McMahan CA, Zieske AW, et al. Associations of coronary heart disease risk factors with the intermediate lesion of atherosclerosis in youth. The Pathobiological Determinants of Atherosclerosis in Youth (PDAY) Research Group. Arterioscler Thromb Vasc Biol. Aug 2000;20(8):1998-2004.

14. McGill HC, Jr., McMahan CA, Herderick EE, et al. Effects of coronary heart disease risk factors on atherosclerosis of selected regions of the aorta and right coronary artery. PDAY 
Research Group. Pathobiological Determinants of Atherosclerosis in Youth. Arterioscler Thromb Vasc Biol. Mar 2000;20(3):836-845.

15. Aird WC. Mechanisms of endothelial cell heterogeneity in health and disease. Circ Res. Feb 3 2006;98(2):159-162.

16. Aird WC. Phenotypic heterogeneity of the endothelium: I. Structure, function, and mechanisms. Circ Res. Feb 2 2007;100(2):158-173.

17. Dai G, Kaazempur-Mofrad MR, Natarajan S, et al. Distinct endothelial phenotypes evoked by arterial waveforms derived from atherosclerosis-susceptible and -resistant regions of human vasculature. Proc Natl Acad Sci U S A. Oct 12 2004;101(41):14871-14876.

18. Fledderus JO, van Thienen JV, Boon RA, et al. Prolonged shear stress and KLF2 suppress constitutive pro-inflammatory transcription through inhibition of ATF2. Blood. Jan 23 2007.

19. Dekker RJ, van Soest S, Fontijn RD, et al. Prolonged fluid shear stress induces a distinct set of endothelial cell genes, most specifically lung Kruppel-like factor (KLF2). Blood. Sep 1 2002;100(5):1689-1698.

20. Passerini AG, Polacek DC, Shi C, et al. Coexisting proinflammatory and antioxidative endothelial transcription profiles in a disturbed flow region of the adult porcine aorta. Proc Natl Acad Sci U S A. Feb 24 2004;101(8):2482-2487.

21. Cheng $C$, Tempel $D$, van Haperen $R$, et al. Atherosclerotic lesion size and vulnerability are determined by patterns of fluid shear stress. Circulation. Jun 13 2006;113(23):2744-2753.

22. Gnasso A, Irace C, Carallo $\mathrm{C}$, et al. In vivo association between low wall shear stress and plaque in subjects with asymmetrical carotid atherosclerosis. Stroke. May 1997;28(5):993-998.

23. Dekker RJ, Boon RA, Rondaij MG, et al. KLF2 provokes a gene expression pattern that establishes functional quiescent differentiation of the endothelium. Blood. Jun 1 2006;107(11):4354-4363.

24. McCormick SM, Eskin SG, McIntire LV, et al. DNA microarray reveals changes in gene expression of shear stressed human umbilical vein endothelial cells. Proc Natl Acad Sci U $S A$. Jul 31 2001;98(16):8955-8960.

25. Hansson GK. Inflammation, atherosclerosis, and coronary artery disease. N Engl J Med. Apr 21 2005;352(16):1685-1695.

26. Sukhova GK, Shi GP, Simon DI, et al. Expression of the elastolytic cathepsins S and K in human atheroma and regulation of their production in smooth muscle cells. $J$ Clin Invest. Aug 1 1998;102(3):576-583.

27. Lutgens SP, Kisters N, Lutgens $E$, et al. Gene profiling of cathepsin K deficiency in atherogenesis: profibrotic but lipogenic. J Pathol. Nov 2006;210(3):334-343.

28. Lutgens $\mathrm{E}$, Lutgens $\mathrm{SP}$, Faber $\mathrm{BC}$, et al. Disruption of the cathepsin $\mathrm{K}$ gene reduces atherosclerosis progression and induces plaque fibrosis but accelerates macrophage foam cell formation. Circulation. Jan 3 2006;113(1):98-107.

29. Tung WS, Lee JK, Thompson RW. Simultaneous analysis of 1176 gene products in normal human aorta and abdominal aortic aneurysms using a membrane-based complementary DNA expression array. J Vasc Surg. Jul 2001;34(1):143-150. 
30. Liu J, Sukhova GK, Sun JS, et al. Lysosomal cysteine proteases in atherosclerosis. Arterioscler Thromb Vasc Biol. Aug 2004;24(8):1359-1366.

31. Abdul-Hussien $\mathrm{H}$, Soekhoe RG, Weber $\mathrm{E}$, et al. Collagen degradation in the abdominal aneurysm: a conspiracy of matrix metalloproteinase and cysteine collagenases. $\mathrm{Am} \mathrm{J}$ Pathol. Mar 2007;170(3):809-817.

32. Moreno PR, Purushothaman KR, Sirol M, et al. Neovascularization in human atherosclerosis. Circulation. May 9 2006;113(18):2245-2252.

33. Herrmann J, Lerman LO, Mukhopadhyay D, et al. Angiogenesis in atherogenesis. Arterioscler Thromb Vasc Biol. Sep 2006;26(9):1948-1957.

34. Chen X, Niroomand F, Liu Z, et al. Expression of nitric oxide related enzymes in coronary heart disease. Basic Res Cardiol. Jul 2006;101(4):346-353.

35. Sluimer JC, Gasc JM, van Wanroij JL, et al. Hypoxia, hypoxia-inducible transcription factor, and macrophages in human atherosclerotic plaques are correlated with intraplaque angiogenesis. J Am Coll Cardiol. Apr 1 2008;51(13):1258-1265.

36. Seo $D$, Wang $T$, Dressman $H$, et al. Gene expression phenotypes of atherosclerosis. Arterioscler Thromb Vasc Biol. Oct 2004;24(10):1922-1927.

37. Tabibiazar R, Wagner RA, Ashley EA, et al. Signature patterns of gene expression in mouse atherosclerosis and their correlation to human coronary disease. Physiol Genomics. Jul 14 2005;22(2):213-226.

38. Papaspyridonos $M$, Smith A, Burnand KG, et al. Novel candidate genes in unstable areas of human atherosclerotic plaques. Arterioscler Thromb Vasc Biol. Aug 2006;26(8):18371844.

39. Archacki SR, Angheloiu G, Tian $X \mathrm{~L}$, et al. Identification of new genes differentially expressed in coronary artery disease by expression profiling. Physiol Genomics. Sep 29 2003;15(1):65-74.

40. Adams LD, Geary RL, Li J, et al. Expression profiling identifies smooth muscle cell diversity within human intima and plaque fibrous cap: loss of RGS5 distinguishes the cap. Arterioscler Thromb Vasc Biol. Feb 2006;26(2):319-325. 



\section{Chapter 4}

Transcript levels of genes involved in the intrinsic/extrinsic mediated initiation of apoptosis are elevated during progression of human atherosclerosis

Natasja Kisters, M. Veronica Herias, Erwin P. Wijnands, Maarten D. Sollewijn Gelpke, Susanne Baurschmidt, Anneke Sijbers, Kitty B. Cleutjens, Mat J. Daemen, Ann P. Bijnens

In preparation 


\section{ABSTRACT}

Inter-patient variability, such as gender, medication use, age and ethnic background, may introduce noise in the analysis of gene expression studies between different atherosclerotic lesion stages. To reduce this heterogeneity, we compared the gene expression profiles of early and advanced lesions within the same carotid artery. RNA from 8 carotid samples (4 donors) obtained during autopsy was hybridized in duplicate to the HGU133 2.0 Plus Array (Affymetrix, Santa Clara, USA, CA) according to standard Affymetrix protocols. The Significance Analysis of Microarray (SAM) method was used in combination with pathway analysis (Ingenuity and GeneGO) to analyze the microarray data.

We identified a group of apoptosis related genes with modest, but coordinated upregulated expression levels in advanced lesions. These genes were involved in either the intrinsic and/or extrinsic initiation pathways of apoptosis. Differential expression of these genes was confirmed using quantitative real time PCR validation on a series of independent carotid samples.

Since the differentially expressed gene TRAIL is one of the activators of the extrinsic apoptosis pathway, we focused on this gene for further validation. Immunohistochemical analysis showed that TRAIL, as well as its receptors, was predominantly expressed by macrophages. These macrophages also stained positive for cleaved caspase 3, indicative for apoptosis induction. In vitro studies demonstrated that TRAIL was able to induce apoptosis (Annexin V positivity and caspase 3 cleavage) in THP-1 derived macrophages. Furthermore we demonstrated that TRAIL induces apoptosis via activation of the extrinsic pathway (caspase 8 cleavage).

In conclusion, intra-vessel gene expression profiling of early and advanced lesions followed by pathway analysis led to the identification of a group of functionally related genes with modest but coordinate changes in the expression levels. These gene expression data in combination with the in vitro data indicate TRAIL to be an interesting candidate for therapeutic interventions in atherogenesis. 


\section{INTRODUCTION}

The aim of this study was to perform a genome-wide expression analysis to study the earlier stages of atherosclerosis. We analyzed early and advanced atherosclerotic lesions from the same donor $(n=4)$ and the same vessel type to reduce the variability in the gene expression profiles. Instead of focusing on individual differential expressed genes we aimed at the identification of important biological processes based upon extensive pathway analysis. Using this approach, we identified a group of apoptosis related genes with modest, but coordinated upregulated expression levels in advanced atherosclerotic lesions. For further validation, we focused on tumor necrosis factor-related apoptosis-inducing ligand (TRAIL). The data presented in this study, together with recent data from literature, suggest TRAIL to be an interesting candidate for therapeutic in vitro and in vivo interventions in atherosclerotic research.

\section{METHODS AND MATERIALS}

\section{Tissue collection}

A total of 82 atherosclerotic carotid artery segments (46 donors) were obtained at autopsy (Department of Pathology, University Hospital Maastricht). Collection, storage in the Maastricht Pathology Tissue Collection (MPTC) and use of tissue and patient data were performed in agreement with the "Code for Proper Secondary Use of Human Tissue" (http://www.fmwv.nl). The mean age of the donors was $70.2 \pm 10.8$ years and $53 \%(n=25)$ were males. Samples were processed essentially as described previously ${ }^{1}$. Briefly, immediately after resection, the carotid artery specimen was divided into parallel sections for RNA isolation and histological analysis. Carotid artery segments were snap frozen for RNA isolation and adjacent sections were fixed and embedded in paraffin. Based on haematoxylin-eosin stained sections $(4 \mu \mathrm{m})$, the vessel segments were classified according to Virmani et $a l^{2}$. Only samples designated as early ((pathological) intimal thickening and intimal xanthoma) or advanced (thin or thick fibrous cap atheroma) lesions were included in our study. Although this initially reduced the number of donors to 16 , only 4 donors yielded good quality RNA.

\section{RNA isolation and quantification}

Total RNA was isolated using the guanidine isothiocyanate/ $\mathrm{CsCl}{ }^{3}$ method followed by further purification and concentration using RNeasy mini columns 
(Qiagen, Hilden, Germany). RNA quantity and quality were determined using a nanodrop spectrophotometer (Witec AG, Littau, Switzerland) and a 2100 Bioanalyser (Agilent Technologies, Palo Alto, USA) respectively.

\section{Microarray hybridization and data analysis}

Although we started with 16 donors, from only 4 donors we were able to collect good quality RNA (RIN $\geq 5$ ) from both an early lesion as an advanced lesion (Table 4.1). Double-stranded CDNA was synthesized from 2.0 $\mu \mathrm{g}$ of total RNA using the One-Cycle Target Labeling Kit (Affymetrix, Santa Clara, USA, CA), and used as a template for the preparation of biotin-labeled CRNA using the GeneChip IVT Labeling Kit (Affymetrix, Santa Clara, USA, CA). Biotin-labeled CRNA was hybridized in duplicate to the HGU133 2.0 Plus Array (Affymetrix, Santa Clara, USA, CA), washed, stained with phycoerythrin-streptavidin conjugate (Molecular Probes, Eugene, USA), and the signals were amplified by staining with biotin-labeled anti-streptavidin antibody (Vector Laboratories, Burlingame, USA) followed by phycoerythrin-streptavidin. The arrays were laser scanned with the GeneChip Scanner 3000 (Affymetrix, Santa Clara, USA) according to the manufacturer's instructions. Data were saved as a raw image file and quantified using GCOS 1.2 (Affymetrix). Pre-processing and normalization of signal intensities was carried out using the error model of Rosetta Resolver Version 4, specifically developed for Affymetrix GeneChips. Technical and biological duplicates were combined to obtain intensities and standard errors per group. Significance Analysis of Microarrays (SAM) was used to identify probe sets whose signals were significantly different between early and advanced lesions from the same donor. Repeated random sample permutations were used to estimate the percentage of genes identified by chance (false-discovery rate, FDR) due to multiple testing ${ }^{4}$. Subsequent pathway analysis was performed using both Ingenuity Pathway Analysis system (Ingenuity Systems, Mountain View, CA, USA; https://analysis.ingenuity.com/pa and MetaCore (GeneGO, St Joseph, MI). Genes with a false discovery rate $(\mathrm{FDR})<23 \%$ were included in pathway analysis.

\section{Quantitative real-time PCR (Q-PCR)}

RNA from 10 early and 8 stable lesions, which included 6 out of the 8 samples used for microarray analysis, (Table 4.1, RIN > 4.0) was included for quantitative real-time PCR analysis. One $\mu \mathrm{g}$ of total RNA was used as a template to generate CDNA using random primers. Real-time PCR reactions (MyiQ Icycler, Biorad) were carried out with cDNA (50 ng RNA template), 
Apoptosis genes are induced during atherosclerotic lesion progression

Table 4.1: Sample Characteristics

\begin{tabular}{|c|c|c|c|c|}
\hline Lesion stage & Sample ID & Gender & $\begin{array}{l}\text { Age } \\
\text { (years) }\end{array}$ & Purpose \\
\hline early & 1 & $M$ & 83 & MA \\
\hline early & 2 & M & 74 & MA \\
\hline early & 6 & $F$ & 79 & MA/Q-PCR \\
\hline early & 8 & $F$ & 82 & MA/Q-PCR \\
\hline early & 12 & $F$ & 74 & Q-PCR \\
\hline early & 13 & $F$ & 41 & Q-PCR \\
\hline early & 14 & $M$ & 74 & Q-PCR \\
\hline early & 16 & M & 69 & Q-PCR \\
\hline early & 17 & M & 60 & Q-PCR \\
\hline early & 18 & $M$ & 74 & Q-PCR \\
\hline early & 19 & $F$ & 81 & Q-PCR \\
\hline early & 20 & $F$ & 81 & Q-PCR \\
\hline early & 23 & $M$ & 63 & IHC \\
\hline early & 24 & M & 36 & $\mathrm{IHC}$ \\
\hline early & 25 & M & 58 & $\mathrm{IHC}$ \\
\hline early & 26 & $F$ & 77 & $\mathrm{IHC}$ \\
\hline early & 27 & $F$ & 75 & IHC \\
\hline early & 28 & $F$ & 77 & $\mathrm{IHC}$ \\
\hline early & 34 & $F$ & 88 & IHC \\
\hline advanced & 3 & M & 83 & MA/Q-PCR \\
\hline advanced & 4 & M & 74 & MA/Q-PCR \\
\hline advanced & 5 & $F$ & 79 & MA/Q-PCR \\
\hline advanced & 7 & $F$ & 82 & MA/Q-PCR \\
\hline advanced & 9 & $\mathrm{~F}$ & 79 & Q-PCR \\
\hline advanced & 10 & M & 60 & Q-PCR \\
\hline advanced & 11 & M & 73 & Q-PCR \\
\hline advanced & 15 & M & 71 & Q-PCR \\
\hline advanced & 29 & M & 83 & IHC \\
\hline advanced & 30 & $F$ & 74 & $\mathrm{IHC}$ \\
\hline advanced & 31 & M & 73 & $\mathrm{IHC}$ \\
\hline advanced & 32 & $F$ & 62 & $\mathrm{IHC}$ \\
\hline advanced & 33 & M & 60 & IHC \\
\hline
\end{tabular}

Abbreviations: $M$, male; F, female; MA, microarray; Q-PCR, quantitative PCR; IHC, immunohistochemistry 
$\mathrm{IQ}^{\mathrm{tm}} \mathrm{SYBR}^{\circledR}$ Green super mix (Biorad) and $3 \mathrm{mM}$ of forward and reverse primers (Table 4.2). PCR conditions were: 3 minutes at $95^{\circ} \mathrm{C}$ and 40 cycles of 10 seconds at $95^{\circ} \mathrm{C}$ and 45 seconds at $60^{\circ} \mathrm{C}, 1$ minute $95^{\circ} \mathrm{C}$. Samples and runs were performed in duplicate. RNA copy numbers were calculated using a standard curve and normalized to housekeeping gene (18S RNA) mRNA expression.

\section{Immunohistochemistry}

Immunohistochemistry was performed on additional paraffin-embedded sections from human carotid arteries containing an early $(n=7)$ or advanced $(n=5)$ atherosclerotic lesion (see Table 4.1 for donor characteristics). Detailed immunohistochemical methods are provided in Table 4.3. In summary, sections were stained with primary antibodies against BID, caspase 1 , caspase 8 , cleaved caspase 3, CD40, cFLAR, PYCARD, TRAIL, TRAILR1, TRAILR2 and cleaved caspase 3 diluted in TBS with $0.1 \%$ Tween and 1\% BSA. Adjacent sections were stained with antibodies against CD68 (macrophages), ASMA (smooth muscle cells) and CD31 (endothelial cells) in order to determine the cell types showing expression of the above mentioned genes of interest. Sections incubated without the primary antibody served as negative control.

\section{Cell culture}

The human monocyte cell line THP-1 (American Type Culture Collection) was grown in RPMI 1640 medium (Invitrogen) supplemented with $10 \%$ FetalClone III (Hyclone, Perbio), $100 \mathrm{U} / \mathrm{ml}$ penicillin, $100 \mu \mathrm{g} / \mathrm{ml}$ streptomyosin (Invitrogen), $2 \mathrm{mM}$ Glutamax I (Invitrogen), 25 uM HEPES (Invitrogen). To differentiate the THP-1 cells, phorbol 12-myristate 13-acetate (PMA) was added to a final concentration $0.2 \mu \mathrm{M}$ for 72 hours. During experiments, the cells were transferred to a reduced serum medium containing $1 \%$ FetalClone III. Cells were treated for 16 hours with $0.1 \mu \mathrm{g} / \mathrm{ml}$ TRAIL plus $1 \mathrm{mg} / \mathrm{ml} 6 \mathrm{x}$ polyhistidine crosslinking antibody, $0.2 \mu \mathrm{g} / \mathrm{ml}$ TRAIL plus $2 \mathrm{mg} / \mathrm{ml} 6 \mathrm{x}$ polyhistidine crosslinking antibody in the presence or absence of the $20 \mathrm{nM}$ Pi3-kinase inhibitor (Ly294002 Cell Signaling). His-tagged recombinant human TRAIL and $6 x$ polyhistidine crosslinking antibody were purchased from R\&D Systems (Minneapolis, MN, USA). 
Apoptosis genes are induced during atherosclerotic lesion progression

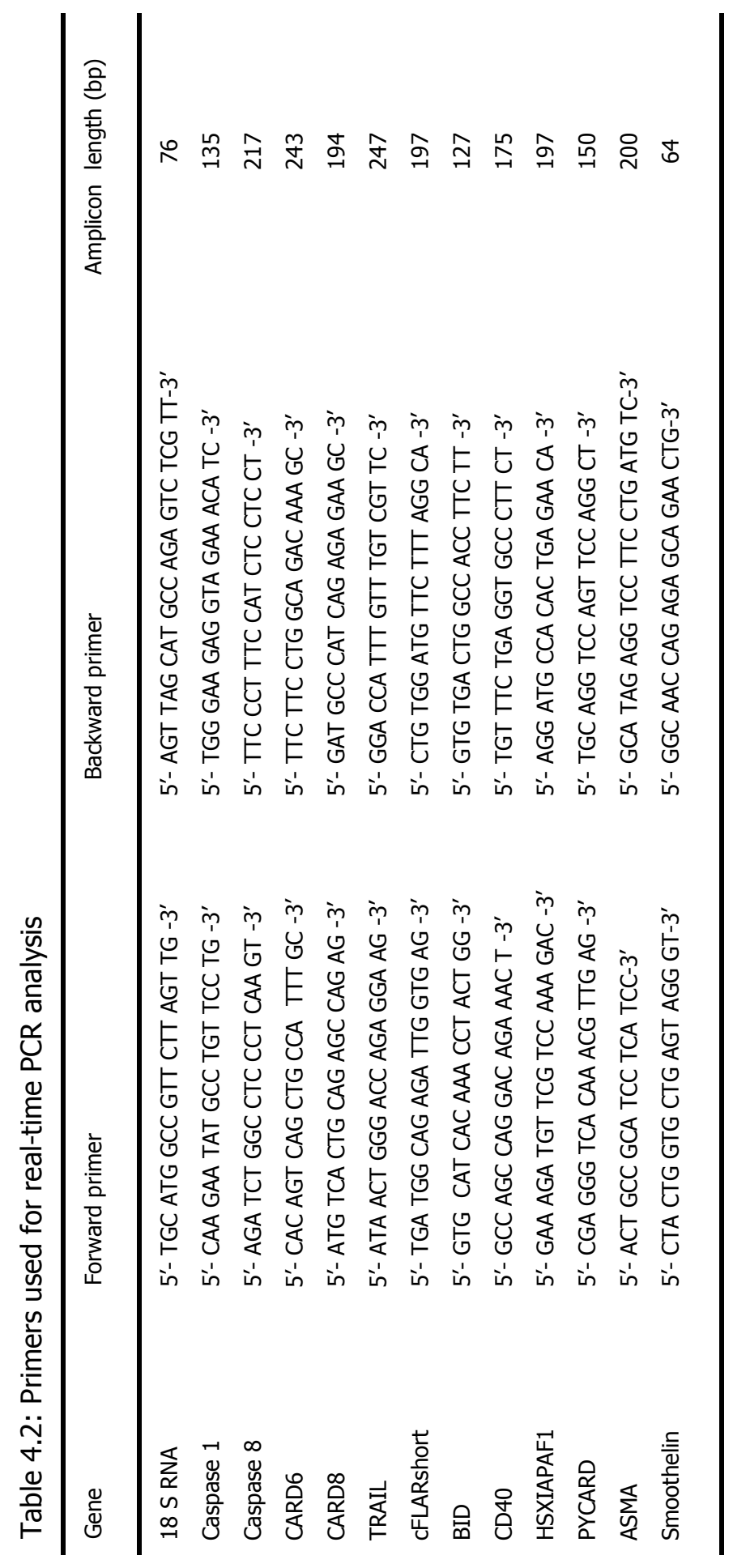




\section{Western blot}

Cells were harvested and total cellular extracts were prepared by lysing the cells in RIPA buffer (50 mM Tris, pH 8; $150 \mathrm{mM} \mathrm{NaCl} ; 1 \%$ No-nidet P40, $0.5 \% \mathrm{Na}$ deoxycholate, $0.1 \%$ SDS, $1 \mathrm{mM}$ EDTA) supplemented with protease inhibitor cocktail (Roche, Mannheim, Germany) for 30 minutes on ice. Lysates were cleared by centrifugation and analyzed for protein content by BioRad protein assay. Equal amounts of protein (50-75 $\mu$ g per lane) were separated on $10 \%$ SDS-polyacrylamide gels and transferred to nitrocellulose membranes (Protran, Schleicher\&Schuell, Dassel, Germany). After transfer, membranes were blocked in TBS, $0.01 \%$ Tween with $5 \%$ not-fat dry milk, incubated with caspase 3 polyclonal antibody (1:500, Cell Signaling, Danvers, USA), caspase 8 monoclonal antibody (1:500, Cell Signaling, Danvers, USA) or caspase 9 polyclonal antibody (1:500, Cell Signaling, Danvers, USA) followed by incubation with horseradish peroxidase conjugated anti-rabbit antibody (1:2000, Cell Signaling, Danvers, USA) or with horseradish peroxidase conjugated anti-mouse secondary antibody (1:500, DAKO, Glostrup, Denmark). Antibodies were diluted in TBS, $0.01 \%$ Tween with $5 \%$ not-fat dry milk Tween-20. Specific antibody binding was visualized using WestPico (Pierce, Perbio Science, The Netherlands).

\section{FACS analysis}

Apoptosis was determined by FACS analysis using an Annexin V-FITC apoptosis detection kit (BD Biosciences). Briefly, following antibody treatment, cells were washed with PBS and labeled with Annexin V-FITC (which stains apoptotic and necrotic cells) and propidium iodide (which stains leaky (necrotic and late apoptotic) cells). Cells that were Annexin V-positive and propidium iodidenegative were considered as pure apoptotic cells.

\section{Statistical analysis Q-PCR}

All data are presented as mean \pm SEM. Groups were compared using a MannWhitney $U$ excact test (SPSS 11.0, Chicago, USA) and were considered statistically different when $\mathrm{P}<0.05$. 
Apoptosis genes are induced during atherosclerotic lesion progression

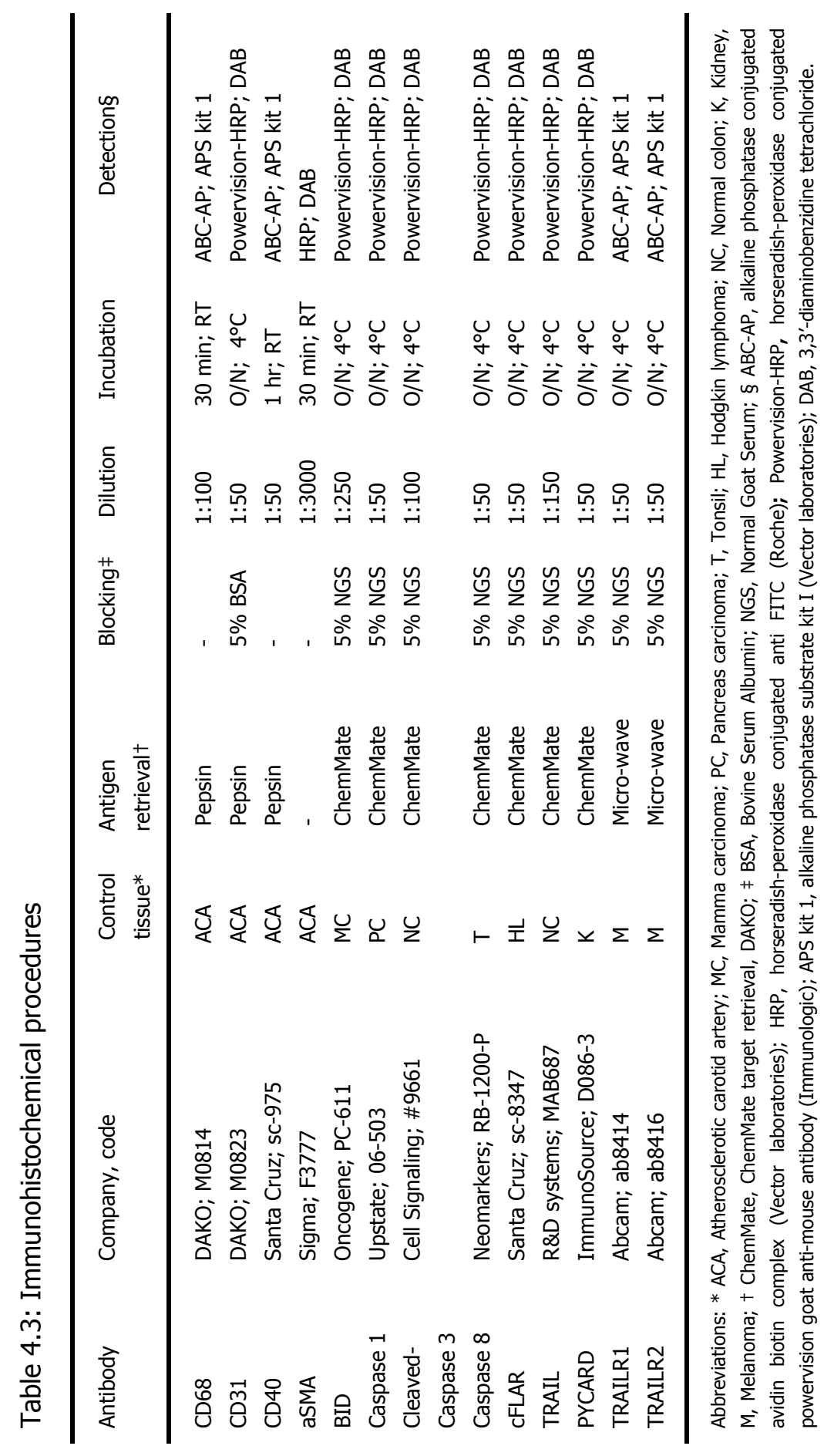




\section{RESULTS}

\section{Microarray analysis}

Biotin-labeled cRNA, generated from RNA of 4 early lesions and 4 advanced lesions from the same donors, was hybridized in duplicate to the HGU133 2.0 Plus Array RNA. The signal intensities were normalized using the error model of Rosetta specifically developed for Affymetrix arrays after which the technical duplicates were combined to obtain intensities and standard errors. The gene expression profiles of the early and advanced lesions from all 4 donors were analyzed in a paired way, using SAM. After correction for multiple testing, 524 genes showed significant (FDR $<23 \%$ ) differential transcript levels between early and advanced lesions. Of these 524 differentially regulated genes, 331 were upregulated and 193 were downregulated in advanced atherosclerotic carotid lesions. Fold changes ranged from 1.03 to 21.5 for the upregulated genes and from 1.07 to 3.6 for the downregulated genes. Of the upregulated genes, 14 genes showed a fold change $>2.5$, while 124 genes showed a fold change between 1.5 and 2.5 and 193 genes showed a fold change less than 1.5. For the downregulated genes 4 genes showed a $>2.5$ downregulation, while 63 genes showed a downregulation ranging from 2.5 to 1.5 and 126 genes showed a downregulation ranging from 1.5 to 1 .

\section{Pathway analysis revealed involvement of apoptosis in the progression of atherosclerosis}

To identify molecular and cellular pathways involved in the progression of atherosclerosis, we performed extensive pathway and network analysis using both MetaCore and Ingenuity Pathway Analysis software.

Pathway analysis with MetaCore identified that many genes involved in cell adhesion $(P=0.00097)$ and apoptosis/cell death $(P=0.0017)$ were among the differentially expressed genes (see Table 4.4 for a complete list). Additionally, Ingenuity Pathway profiling demonstrated an important role for the differentially expressed genes in immunological disease and cell death (see Table 4.5).

Most strikingly, both pathway analysis approaches revealed the upregulation of several genes involved in intrinsic pathway mediated apoptosis (CARD6, CASP1, CARD8 and PYCARD) (Table 4.4 and Table $4.5 ; 2^{\text {nd }}$ network) in advanced lesions compared to early lesions. Additionally, several genes addressed to the receptor mediated initiation of apoptosis (cFLAR (short), TRAIL) (Table 4.5; $1^{\text {st }}$ network) were expressed at increased levels in advanced lesions. Extensive literature mining demonstrated 4 other genes with differential expression 
Table 4.4: Differential* pathways (MetaCore) involved in the progression of atherosclerosis* $\mathrm{P}<0.05$

\begin{tabular}{ll}
\hline Name Pathway & P value \\
\hline Cell signaling/Cell adhesion & $9.687 \mathrm{e}-04$ \\
Plasmin signaling & $2.162 \mathrm{e}-03$ \\
Putative integrins pathway. Part 2 & $9.465 \mathrm{e}-03$ \\
Putative integrins pathway. Part 1 & $2.239 \mathrm{e}-02$ \\
Cell signaling/Cell death/Apoptosis & $1.690 \mathrm{e}-02$ \\
Role of CARD-protein family in caspase cascade regulation and apoptosis & $1.702 \mathrm{e}-03$ \\
Caspase cascade activation by granzyme and other signaling proteins & $6.669 \mathrm{e}-03$ \\
Caspase cascade activation by FADD and RIPK proteins & $7.659 \mathrm{e}-03$ \\
Cytoplasm/mitochondrial transport of proapoptotic proteins Bad and Bax & $5.664 \mathrm{e}-02$ \\
Function groups/Phosphotases protein amino acid dephosphorylation & $7.305 \mathrm{e}-02$ \\
Cytoplasm/mitochondrial transport of proapoptotic proteins Bad and Bax & $5.664 \mathrm{e}-02$ \\
\hline
\end{tabular}

Table 4.5: Networks involved in intrinsic/extrinsic mediated initiation of apoptosis as revealed by Ingenuity

\begin{tabular}{|c|c|c|}
\hline Networks & Functions & $\mathrm{N}$ genes \\
\hline $\begin{array}{l}\text { ARF1, CBX3, CFLAR } \uparrow, \text { CREM, CUGBP2 } \uparrow, \text { E2F6, FADD, } \\
\text { FKBP1A } \uparrow, \text { FOS, GABPB2, GGA1 } \uparrow, \text { IFI35 } \uparrow, \text { IGFBP4 } \uparrow, \text { KRT19, } \\
\text { MAX } \uparrow, \text { MGA, NFATC2, NMI, ODC1, RAB10 } \uparrow, \mathbf{R N F 4 \uparrow , ~ S N A P 2 3 , ~} \\
\text { SNX3 } \uparrow, \text { STX3A } \uparrow, \text { SUPT3H, TAF5L, TBP, TEAD1, TFDP1 } \uparrow, \\
\text { TNFRSF10A, TNFRSF10B, TNFSF10 } \uparrow, \text { VAMP2, VAMP8, YY1 }\end{array}$ & $\begin{array}{l}\text { cell death } \\
\text { cancer } \\
\text { reproductive disease }\end{array}$ & 13 \\
\hline 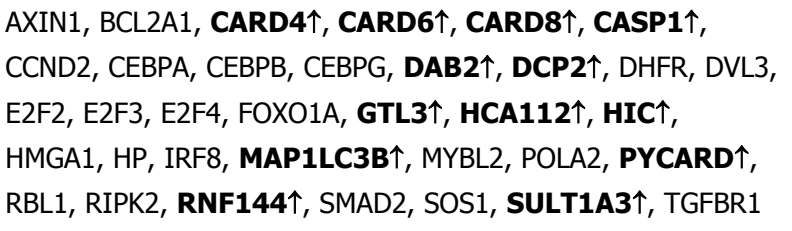 & $\begin{array}{l}\text { cell cycle } \\
\text { cellular development } \\
\text { connective tissue } \\
\text { development }\end{array}$ & 12 \\
\hline 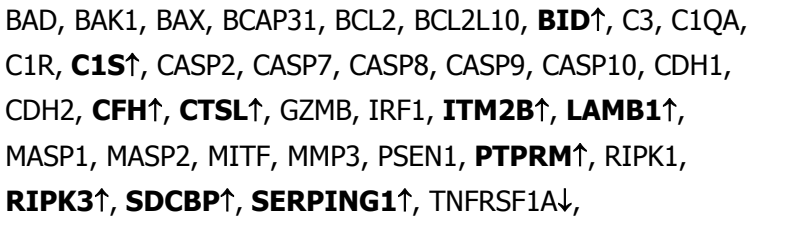 & $\begin{array}{l}\text { cell death } \\
\text { cancer } \\
\text { reproductive disease }\end{array}$ & 10 \\
\hline
\end{tabular}

Ingenuity Pathway analysis revealed networks involved in extrinsic and intrinsic mediated apoptosis. $\uparrow$ indicates upregulation in advanced human atherosclerotic lesions and $\downarrow$ indicates downregulation in advanced human atherosclerotic lesions. Genes depicted in bold have a FDR $<23 \%$. 
levels to be involved in these networks (CD40; CASP8; BID; HSXIAPAF1). Figure 4.1 summarizes the interactions between the above mentioned differentially expressed genes in relation to the initiation of apoptosis. In addition pathway profiling and literature mining of the downregulated genes indicated a possible role for SMC related processes, such as contractility (calponin, caldesmon, tropomyosin, phospholamban) and motility/migration ( $\alpha$-actin, myosin light polypeptide kinase).

\section{Validation of observed differential mRNA levels}

The differential mRNA levels detected by microarray analysis were validated using quantitative real-time PCR (Q-PCR) analysis on a larger set, containing the samples used for microarrays analysis, of carotid lesions. Similar to the microarray results, the expression of all apoptosis related genes was increased

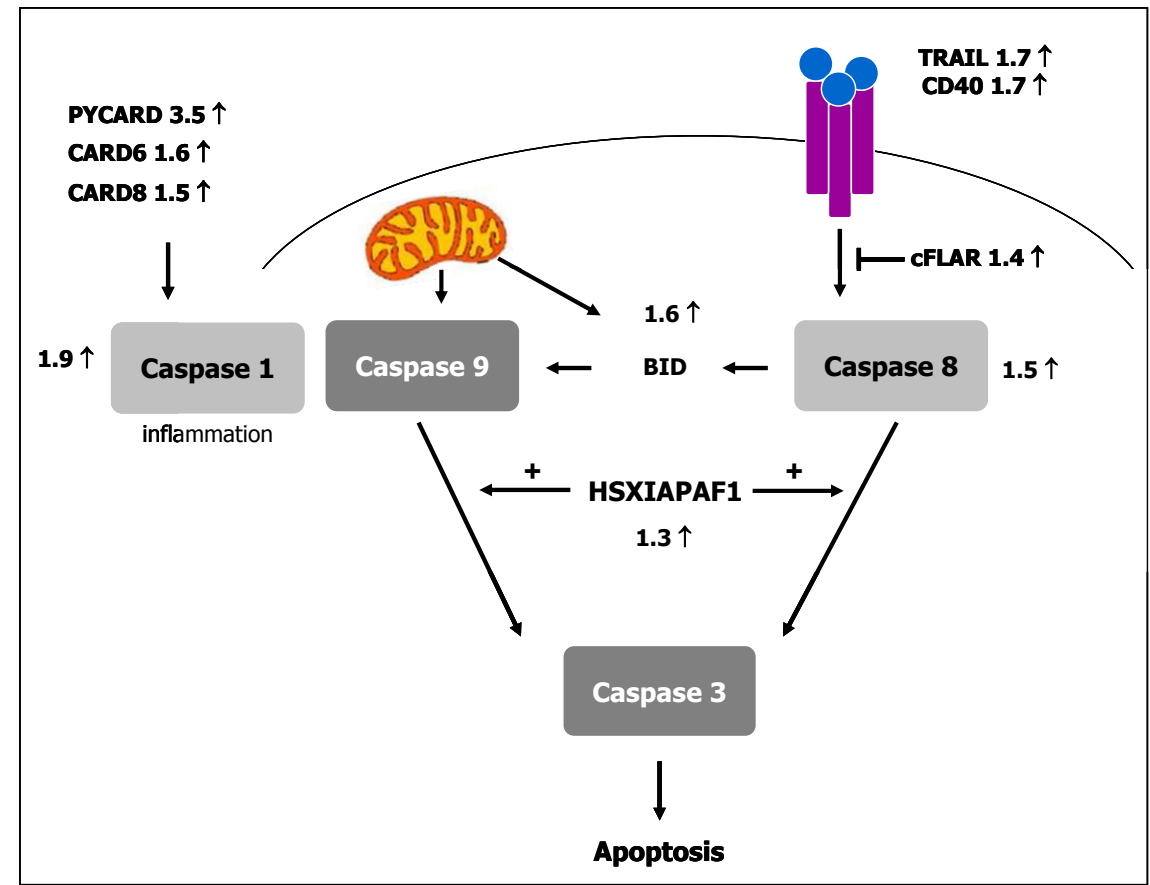

Figure 4.1

Summary of the interactions between the differentially expressed genes in relation to the initiation of apoptosis. Pathway analysis and extensive literature mining resulted in the following connections. Caspase 1, CARD 6, CARD8 and PYCARD are involved in the intrinsic mediated initiation of apoptosis. TRAIL, CD40, Caspase 8 and cFLAR are involved in the initiation of apoptosis via the extrinsic pathway. HSXIAPAF1 and BID are genes which are involved in downstream effects after initiation of the two pathways. The fold increase in mRNA levels in advanced lesions is indicated for each gene. 
in advanced lesions compared to early lesions (Figure 4.2). However, only the upregulation of CARD6, caspase1 and PYCARD in advanced was statistically significant $(P<0.05, P<0.05, P<0.01$ respectively). Furthermore, we also validated two genes which were downregulated in advanced lesions compared to early lesions; a-smooth muscle actin and smoothelin. Quantitative real-time PCR validation confirmed that these genes had lower mRNA levels in advanced lesions, although the detected difference was not significant (Figure 4.2).

\section{Immunohistochemical analysis of atherosclerotic lesions for apoptosis-related proteins}

To determine which cell types within the atherosclerotic lesions expressed the apoptosis related proteins, we performed immunohistochemistry on a different series of 7 early and 5 advanced lesions. Immunoreactivity of TRAIL, CD40, cFLAR, Caspase8, Caspase1, PYCARD and BID was present in macrophages/foam cells, neo-intimal and medial SMCs and ECs of human atherosclerotic carotid lesions. Semiquantitative immunohistochemical assessment did not show a difference in protein expression level between early and advanced atherosclerotic lesions (data not shown).

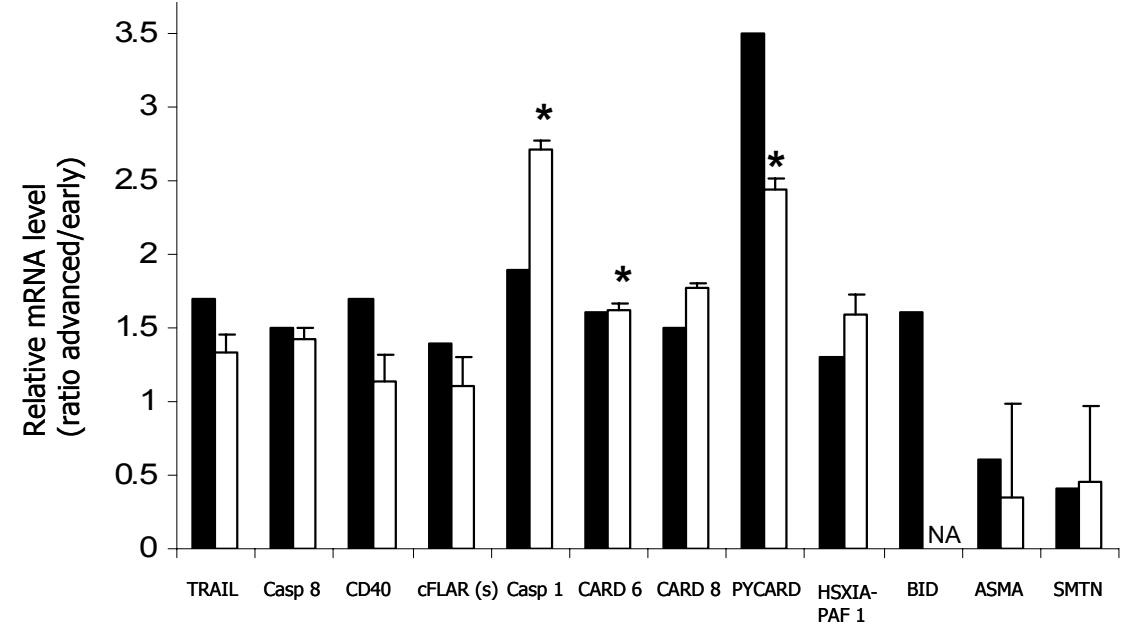

Figure 4.2

Expression ratio between advanced and early lesions of genes involved in apoptosis initiation pathways. Ratio (advanced/early) of mRNA expression level on microarray (black bars) and Q-PCR (white bars) of genes involved the initiation pathways of apoptosis. Q-PCR on a larger set of samples showed the differential expression of all genes between early and advanced lesions.

* indicates P < 0.05 for Q-PCR; Abbreviations: Casp, Caspase; SMTN, Smoothelin; NA, indicates Q-PCR not available. 


\section{Atherosclerotic macrophages undergo apoptosis and express TRAIL and TRAILR2}

Since pathway analysis revealed an important role for apoptosis/cell death we were interested in the cell type that underwent apoptosis. To determine this, we performed an immunohistochemical staining for cleaved caspase 3, the active form of caspase 3. Immunohistochemical analysis demonstrated that the macrophage was the predominant cell type in the atherosclerotic lesion showing protein expression of cleaved caspase 3 (Figure 4.3B). Since it is known that TRAIL is able to induce apoptosis, and TRAIL is expressed in atherosclerotic macrophages (Figure 4.3C), we wanted to investigate whether TRAIL was able to induce apoptosis in macrophages. To test this, we first determined whether the TRAIL receptor (TRAILR) was expressed in human atherosclerotic lesion and performed an immunohistochemical analysis for TRAILR2, one of the two TRAIL receptors with a dead activating domain. Immunohistochemical analysis clearly showed that macrophages in the human atherosclerotic lesion express TRAILR2 (Figure 4.3D).
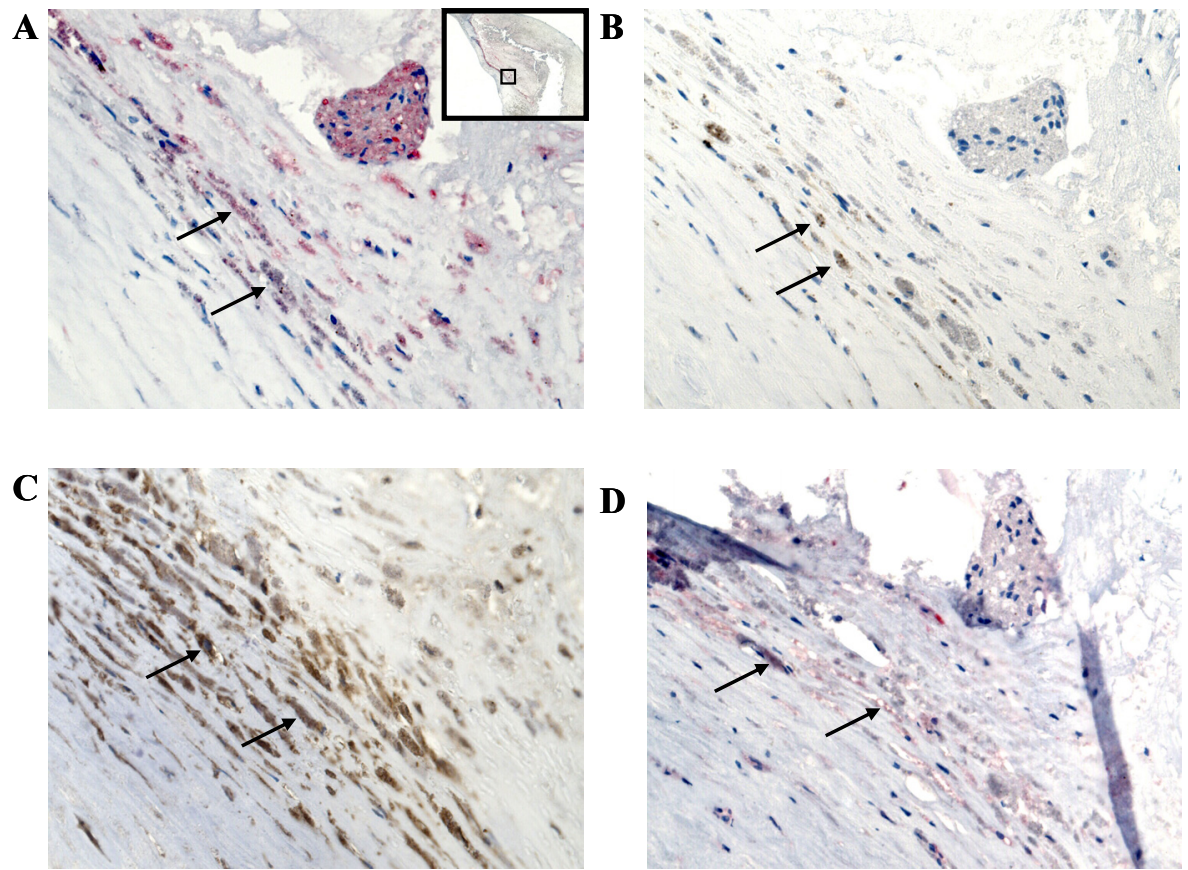

\section{Figure 4.3}

Human atherosclerotic macrophages undergo apoptosis. CD68 immunoreactivity (red) showing the localization of macrophages in an advanced atherosclerotic lesion (A). Macrophages are the predominant cell type staining positive (brown) for cleaved caspase 3 (B), indicative for apoptosis, and the macrophages do express TRAIL (brown) (C). Immunohistochemical analysis also demonstrated that the macrophages express TRAIL receptor with a dead activating domain (red) (D). 400x magnification, inset $25 x$ magnification. 


\section{TRAIL induces apoptosis in THP-1 derived macrophages}

To determine the potential role of TRAIL-induced apoptosis in macrophages we used THP-1-derived macrophages to test whether TRAIL is able to induce apoptosis and determined both the apoptosis percentage using Annexin $\mathrm{V}$ flow cytometry and the presence of caspase 3 cleavage using western blot analysis. Treatment of the THP-1 derived macrophages with TRAIL alone did not induce either Annexin $V$ immunoreactivity or caspase 3 cleavage (data not shown). However, when we treated the THP-1- derived macrophages with TRAIL in the presence of LY294002, an inhibitor of the phosphatidylinositol 3-kinase (PI-3K) pathway which controls a range of cellular processes, including cell growth, survival, differentiation, chemotaxis and metabolism, Annexin $V$ staining (Figure 4.4A) and cleavage of caspase 3 (Figure 4.4B), both indicative for apoptosis, were induced.

\section{TRAIL induces apoptosis via extrinsic pathway in THP-1 derived macrophages}

We performed western blot analysis to detect cleavage of caspase 8 and/or 9 to determine the initiation pathway via which TRAIL induced apoptosis. Cleavage of caspase 8 is indicative for apoptosis initiation via the extrinsic pathway whereas cleavage of caspase 9 is induced via activation of the intrinsic pathway. Western blot analysis on protein lysates of THP-1-derived macrophages treated with TRAIL and a Pi-3K inhibitor demonstrated cleavage of caspase 8 (Figure 4.4C) whereas the caspase 9 protein remained uncleaved (Figure 4.4D), indicating that the TRAIL induced apoptosis in THP-1-derived macrophages is initiated by the activation of the extrinsic pathway.

\section{DISCUSSION}

Several genome wide expression studies have been performed to elucidate the molecular mechanism underlying atherosclerosis (reviewed in ${ }^{5,6}$ ). So far, only one study compared the expression profiles of atherosclerotic samples within the same patient 7 . In this study, the gene expression profiles of macroscopically stable and unstable regions within the carotid artery were compared and Legumain, a gene previously not linked to atherosclerosis was found to be upregulated in unstable lesions compared to stable lesions. Although this study also conducted an intra patient comparison, there are some differences compared to our study. In our study, microscopically well classified atherosclerotic lesions were used instead of macroscopically classified 


\section{Chapter 4}
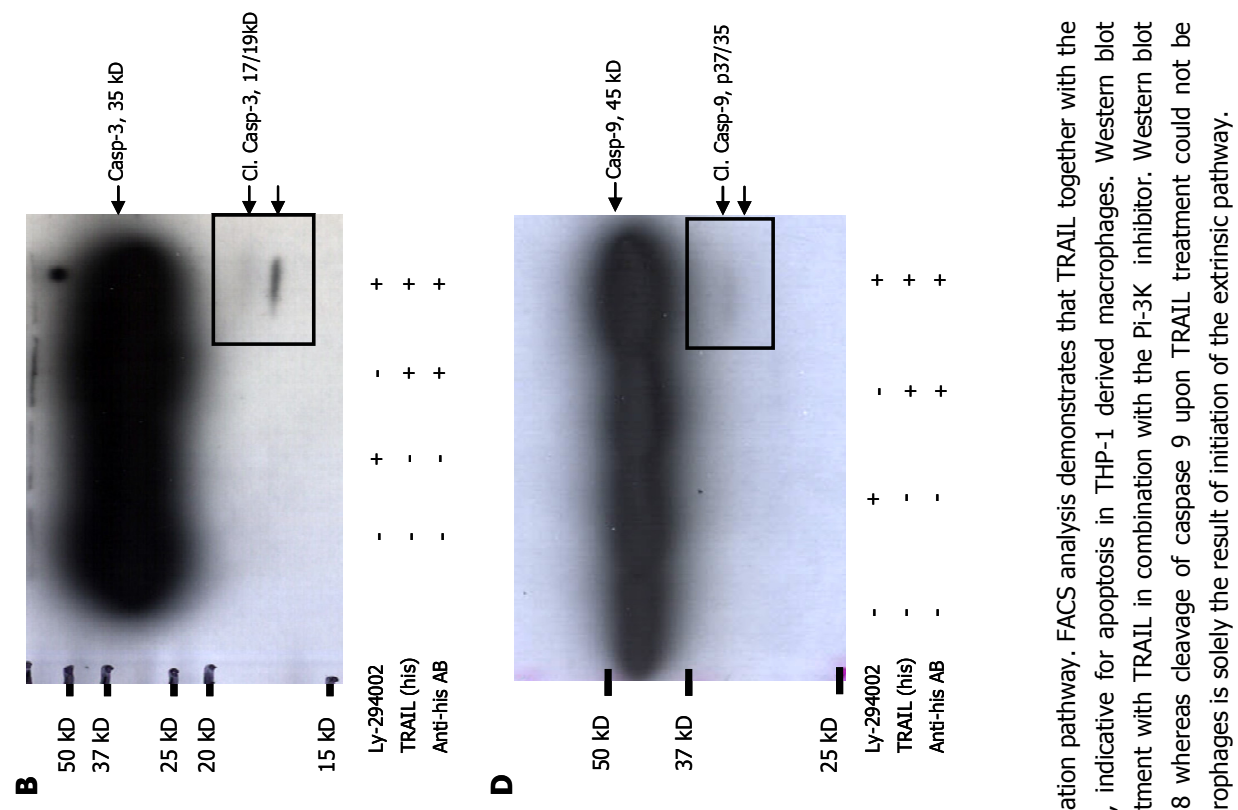

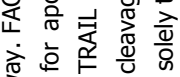

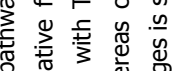

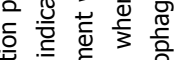

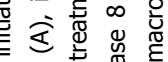

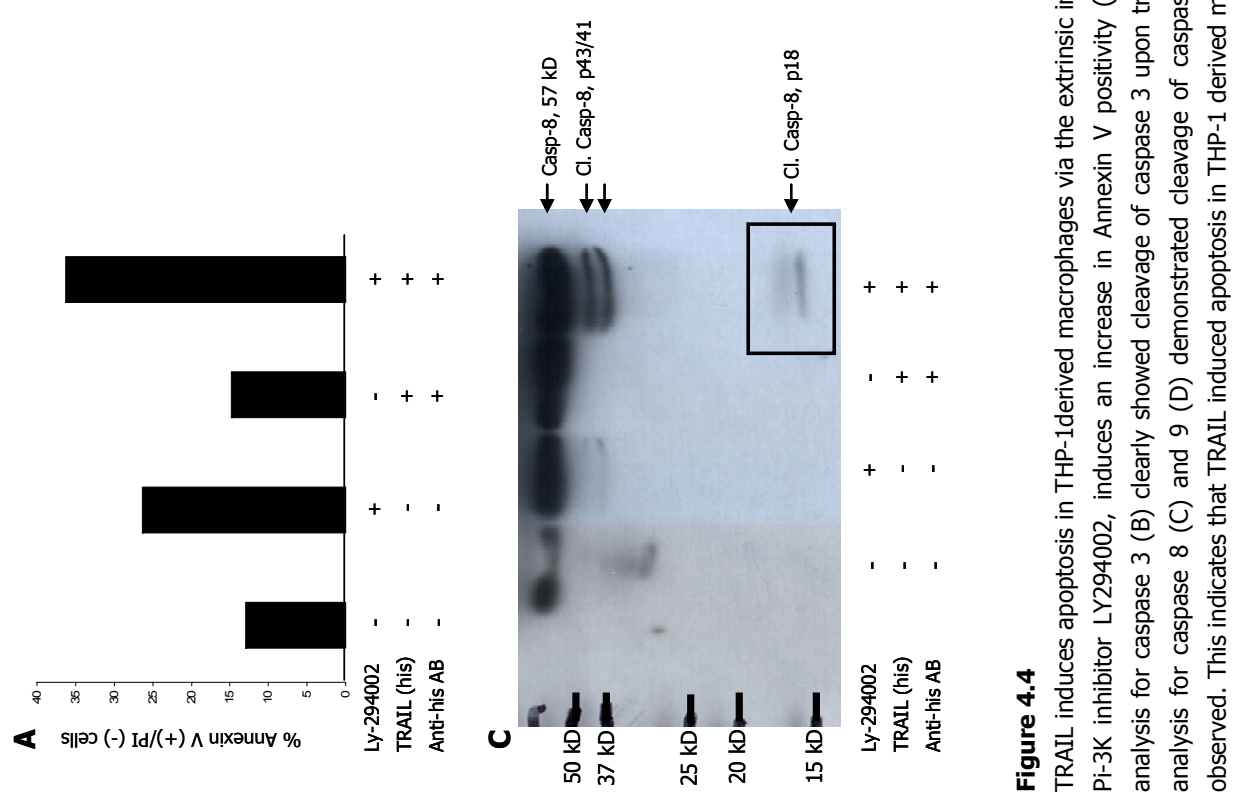


specimens. Furthermore, we examined lesions from specimens early in the atherogenesis (early and advanced lesions instead of advanced and ruptured lesions) and we aimed to look at the pathway level instead of the gene by gene level. Thus far, most genome wide atherosclerotic gene expression studies mainly focused on individual candidate genes. In our opinion, pathway analysis has an additional value since it enabled us to detect genes and pathways with subtle changes in gene expression, which would not have drawn our attention using the gene by gene approach. The study described by King et $a l^{8}$ is to our knowledge the only study which used elaborate pathway analysis to study the expression signature of coronary atherosclerosis progression. They found that early lesions had an increase in the expression of genes involved in SMC differentiation, regulation or activation suggesting that loss of differentiated SMC gene expression is the primary expression signature of disease progression in atherosclerosis.

The identification of apoptosis/cell death as an important pathway involved in atherogenesis was not surprising since apoptosis is believed to play a key role in the rupture of an atherosclerotic lesion. Several mechanisms have been proposed by which apoptosis can contribute to lesion progression ${ }^{9}$. The effect of macrophage death to lesion progression may be dependent on the lesion stage ${ }^{10}$. Macrophage apoptosis in early lesions is considered to be beneficial since removal of apoptotic cells leads to a reduced progression of the lesion. On the contrary, macrophage apoptosis in advanced lesions is considered to be detrimental for lesion progression and vulnerability. Since macrophages are the most abundant "professional" phagocytes in the atherosclerotic lesion, loss of macrophages within the lesion will result in a decreased removal of apoptotic cells ${ }^{11}$. These apoptotic cells may contribute to an increased state of inflammation and to the formation of a necrotic core due to secondary necrosis, which is detrimental for the progression of atherosclerosis.

Other genome wide expression studies also aimed at identifying differential gene expression profiles between early and advanced lesions ${ }^{8,12,13}$, whereas others compared healthy vs diseased vessels ${ }^{14-17}$, stable vs unstable lesions ${ }^{1,7}$ or lesions from asymptomatic patients vs symptomatic patients ${ }^{18-20}$. The study described by Seo et $a^{12}$ also revealed apoptosis to be one of the prominent biological processes, which was represented by the differentially expressed genes. However none of the genes identified in our study were reported by Seo et al. The study of Hiltunen et al ${ }^{13}$ did not reveal any apoptosis related genes whereas the study of King et $a l^{8}$ identified two apoptosis related genes, FAS apoptotic inhibitory molecule (faim) and BCL2-associated transcription factor (Bclaf1).

Although the previously mentioned gene expression studies did not identify the intrinsic and extrinsic mediated apoptosis pathways, several individual genes of these pathways have already been linked to vascular biology or atherosclerosis 


\section{Chapter 4}

before. Protein expression of the active form of caspase 1 was restricted to ruptured lesions, whereas the latent form was also expressed in stable lesions ${ }^{21}$. We and others found that deletion of CD40 ligand in ApoE knockout mice results in a decreased lesion size ${ }^{22,23}$. It was also shown that oxidized LDLelicited cell death in HMEC1 cells results in cleavage of the Bcl2 protein BID ${ }^{24}$. The interplay between TRAIL, caspase 8 and cFLAR had been shown to play an important role in TRAIL induced apoptosis in ECs ${ }^{25}$ and SMCs ${ }^{26}$.

For further validation of our microarrays results, we focused on TRAIL. The role of TRAIL in the initiation of apoptosis is well studied in SMC and EC, but its role in macrophage apoptosis had not been studied extensively ${ }^{27,28}$. TRAIL expression (mRNA and protein) has been shown to be present in stable lesions ${ }^{29}$, atherosclerotic T cells ${ }^{26}$, SMCs and ECs ${ }^{30}$. Furthermore it has been shown that TRAIL is able to induce apoptosis of HUVECs ${ }^{25}$, SMCs ${ }^{26}$ and CD14 ${ }^{+}$ monocytes ${ }^{28}$.

Besides its known function in apoptosis induction TRAIL might also have a role in other processes underlying atherogenesis. Some authors have shown that TRAIL may induce the expression of inflammatory genes on endothelial cells ${ }^{31}$ and others suggest that TRAIL-induced downregulation of the inflammatory cytokines CCL8 and CXCL10 counteracts the adhesion of monocytes to ECs ${ }^{32}$. Furthermore it was shown that TRAIL induces the migration of ECs, differentiation into tube-like structures in matrigel assays and release of nitric oxide (NO) ${ }^{33}$. On the contrary, a recently published study showed antimitogenic effects of TRAIL on HUVECs. This study demonstrated TRAIL to inhibit new vessel formation in an in vitro matrigel model as well as to inhibit blood vessel formation induced by an angiogenic cocktail which was administered in subcutaneous pellets in vivo in mice ${ }^{34}$. These data are suggestive for a possible role for TRAIL in lesion neovascularization.

The data presented in this study and the potential role for TRAIL in inflammation and neovascularization makes TRAIL an interesting candidate for therapeutic interventions in atherosclerosis research. 


\section{REFERENCES}

1. Faber $\mathrm{BC}$, Cleutjens $\mathrm{KB}$, Niessen $\mathrm{RL}$, et al. Identification of genes potentially involved in rupture of human atherosclerotic plaques. Circ Res. Sep 14 2001;89(6):547-554.

2. Virmani R, Kolodgie FD, Burke AP, et al. Lessons from sudden coronary death: a comprehensive morphological classification scheme for atherosclerotic lesions. Arterioscler Thromb Vasc Biol. May 2000;20(5):1262-1275.

3. Chomczynski P, Sacchi N. Single-step method of RNA isolation by acid guanidinium thiocyanate-phenol-chloroform extraction. Anal Biochem. Apr 1987;162(1):156-159.

4. Tusher VG, Tibshirani R, Chu G. Significance analysis of microarrays applied to the ionizing radiation response. Proc Natl Acad Sci U S A. Apr 24 2001;98(9):5116-5121.

5. Bijnens AP, Lutgens E, Ayoubi T, et al. Genome-wide expression studies of atherosclerosis: critical issues in methodology, analysis, interpretation of transcriptomics data. Arterioscler Thromb Vasc Biol. Jun 2006;26(6):1226-1235.

6. Tuomisto TT, Binder BR, Yla-Herttuala S. Genetics, genomics and proteomics in atherosclerosis research. Ann Med. 2005;37(5):323-332.

7. Papaspyridonos M, Smith A, Burnand KG, et al. Novel candidate genes in unstable areas of human atherosclerotic plaques. Arterioscler Thromb Vasc Biol. Aug 2006;26(8):18371844.

8. King JY, Ferrara R, Tabibiazar R, et al. Pathway analysis of coronary atherosclerosis. Physiol Genomics. Sep 21 2005;23(1):103-118.

9. Bennett MR, Macdonald K, Chan SW, et al. Cooperative interactions between RB and p53 regulate cell proliferation, cell senescence, and apoptosis in human vascular smooth muscle cells from atherosclerotic plaques. Circ Res. Apr 6 1998;82(6):704-712.

10. Tabas I. Consequences and therapeutic implications of macrophage apoptosis in atherosclerosis: the importance of lesion stage and phagocytic efficiency. Arterioscler Thromb Vasc Biol. Nov 2005;25(11):2255-2264.

11. Schrijvers DM, De Meyer GR, Kockx MM, et al. Phagocytosis of apoptotic cells by macrophages is impaired in atherosclerosis. Arterioscler Thromb Vasc Biol. Jun 2005;25(6):1256-1261.

12. Seo D, Wang $\mathrm{T}$, Dressman $\mathrm{H}$, et al. Gene expression phenotypes of atherosclerosis. Arterioscler Thromb Vasc Biol. Oct 2004;24(10):1922-1927.

13. Hiltunen MO, Tuomisto $\mathrm{TT}$, Niemi $\mathrm{M}$, et al. Changes in gene expression in atherosclerotic plaques analyzed using DNA array. Atherosclerosis. Nov 2002;165(1):23-32.

14. Martinet W, Schrijvers DM, De Meyer GR, et al. Gene expression profiling of apoptosisrelated genes in human atherosclerosis: upregulation of death-associated protein kinase. Arterioscler Thromb Vasc Biol. Dec 1 2002;22(12):2023-2029.

15. Tyson $\mathrm{KL}$, Weissberg $\mathrm{PL}$, Shanahan $\mathrm{CM}$. Heterogeneity of gene expression in human atheroma unmasked using cDNA representational difference analysis. Physiol Genomics. 2002;9(2):121-130. 
16. Archacki SR, Angheloiu G, Tian $X L$, et al. Identification of new genes differentially expressed in coronary artery disease by expression profiling. Physiol Genomics. Sep 29 2003;15(1):65-74.

17. Tabibiazar R, Wagner RA, Ashley EA, et al. Signature patterns of gene expression in mouse atherosclerosis and their correlation to human coronary disease. Physiol Genomics. Jul 14 2005;22(2):213-226.

18. Randi AM, Biguzzi $E$, Falciani $F$, et al. Identification of differentially expressed genes in coronary atherosclerotic plaques from patients with stable or unstable angina by cDNA array analysis. J Thromb Haemost. Apr 2003;1(4):829-835.

19. Ijas P, Nuotio K, Saksi J, et al. Microarray Analysis Reveals Overexpression of CD163 and HO-1 in Symptomatic Carotid Plaques. Arterioscler Thromb Vasc Biol. Nov 92006.

20. Dahl TB, Yndestad A, Skjelland M, et al. Increased expression of visfatin in macrophages of human unstable carotid and coronary atherosclerosis: possible role in inflammation and plaque destabilization. Circulation. Feb 27 2007;115(8):972-980.

21. Kolodgie FD, Narula J, Burke AP, et al. Localization of apoptotic macrophages at the site of plaque rupture in sudden coronary death. Am J Pathol. Oct 2000;157(4):1259-1268.

22. Lutgens E, Daemen MJ. CD40-CD40L interactions in atherosclerosis. Trends CardiovasC Med. Jan 2002;12(1):27-32.

23. Mach F, Schonbeck U, Sukhova GK, et al. Reduction of atherosclerosis in mice by inhibition of CD40 signalling. Nature. Jul 9 1998;394(6689):200-203.

24. Porn-Ares MI, Saido TC, Andersson T, et al. Oxidized low-density lipoprotein induces calpain-dependent cell death and ubiquitination of caspase 3 in HMEC-1 endothelial cells. Biochem J. Sep 1 2003;374(Pt 2):403-411.

25. Alladina SJ, Song JH, Davidge ST, et al. TRAIL-induced apoptosis in human vascular endothelium is regulated by phosphatidylinositol 3-kinase/Akt through the short form of cellular FLIP and Bcl-2. J Vasc Res. Jul-Aug 2005;42(4):337-347.

26. Sato K, Niessner A, Kopecky SL, et al. TRAIL-expressing T cells induce apoptosis of vascular smooth muscle cells in the atherosclerotic plaque. J Exp Med. Jan 23 2006;203(1):239-250.

27. Kavurma MM, Bennett MR. Expression, regulation and function of trail in atherosclerosis. Biochem Pharmacol. Oct 242007.

28. Secchiero $\mathrm{P}$, Candido R, Corallini $\mathrm{F}$, et al. Systemic tumor necrosis factor-related apoptosis-inducing ligand delivery shows antiatherosclerotic activity in apolipoprotein Enull diabetic mice. Circulation. Oct 3 2006;114(14):1522-1530.

29. Michowitz $Y$, Goldstein E, Roth A, et al. The involvement of tumor necrosis factor-related apoptosis-inducing ligand (TRAIL) in atherosclerosis. J Am Coll Cardiol. Apr 5 2005;45(7):1018-1024.

30. Gochuico BR, Zhang J, Ma BY, et al. TRAIL expression in vascular smooth muscle. Am J Physiol Lung Cell Mol Physiol. May 2000;278(5):L1045-1050.

31. Li JH, Kirkiles-Smith NC, McNiff JM, et al. TRAIL induces apoptosis and inflammatory gene expression in human endothelial cells. J Immunol. Aug 1 2003;171(3):1526-1533. 
Apoptosis genes are induced during atherosclerotic lesion progression

32. Secchiero $\mathrm{P}$, Corallini $\mathrm{F}$, di Iasio MG, et al. TRAIL counteracts the proadhesive activity of inflammatory cytokines in endothelial cells by down-modulating CCL8 and CXCL10 chemokine expression and release. Blood. May 1 2005;105(9):3413-3419.

33. Secchiero $P$, Gonelli A, Carnevale $E$, et al. TRAIL promotes the survival and proliferation of primary human vascular endothelial cells by activating the Akt and ERK pathways. Circulation. May 6 2003;107(17):2250-2256.

34. Cantarella G, Risuglia N, Dell'eva R, et al. TRAIL inhibits angiogenesis stimulated by VEGF expression in human glioblastoma cells. Br J Cancer. May 22 2006;94(10):1428-1435. 



\section{Chapter 5}

Gene profiling of cathepsin K deficiency in atherogenesis: profibrotic but lipogenic

Suzanne P. Lutgens, Natasja Kisters, Esther Lutgens, Rachel I. van Haaften, Chris T. Evelo, Menno P. de Winther, Paul Saftig, Mat J. Daemen, Sylvia Heeneman, Kitty B. Cleutjens

J Pathol. Nov 2006; 210(3):334-343. 


\section{Chapter 5}

\section{ABSTRACT}

Recently, we showed that cathepsin K deficiency reduces atherosclerotic lesion progression, induces lesion fibrosis, but aggravates macrophage foam cell formation in the apoE-/- mouse.

To obtain more insight into the molecular mechanisms by which cathepsin $\mathrm{K}$ disruption evoked the observed phenotypic changes, we used microarray analysis for gene expression profiling of aortic arches of catK-/-/apoE-/- and apoE-/- mice on a mouse oligo microarray. Out of 20,280 reporters, 444 reporters were significantly differentially expressed ( $P$-value of $<0.05$, fold change of $\geq 1.4$ or $\leq-1.4$, and intensity value of $>2.5$ times background in at least one channel). Ingenuity Pathway Analysis and GenMAPP revealed upregulation of genes involved in lipid uptake, trafficking, and intracellular storage, including caveolin-1, $-2,-3$ and CD36, and profibrotic genes involved in transforming growth factor $\beta$ (TGF $\beta$ ) signaling, including TGF $\beta 2$, latent TGF $\beta$ binding protein-1 (LTBP1), and secreted protein, acidic and rich in cysteine (SPARC), in catK-/-/apoE-/- mice. Differential gene expression was confirmed at the mRNA and protein level. In vitro modified low density lipoprotein (LDL) uptake assays, using bone marrow derived macrophages preincubated with caveolae and scavenger receptor inhibitors, confirmed the importance of caveolins and CD36 in increasing modified LDL uptake in the absence of cathepsin $\mathrm{K}$.

In conclusion, we suggest that cathepsin $\mathrm{K}$ deficiency alters lesion phenotype not only by decreasing proteolytic activity, but also by stimulating TGF $\beta$ signaling. Besides this profibrotic effect, cathepsin $\mathrm{K}$ deficiency has a lipogenic effect owing to increased lipid uptake mediated by CD36 and caveolins. 


\section{INTRODUCTION}

Cathepsin K was first described in 1995 as a papain-like cysteine protease and has a distinct extracellular matrix degrading potential; its elastase activity exceeds that of all other elastases, and cathepsin $\mathrm{K}$ harbors a unique collagenolytic activity ${ }^{1-4}$. Cathepsin $\mathrm{K}$ was originally identified to play a role in bone resorption, but is expressed in many other tissues, including arteries, breast, ovary, stomach, and lung ${ }^{2,5-9}$. Sukhova et al showed expression of both cathepsin $\mathrm{S}$ and $\mathrm{K}$ in human atheroma. Furthermore, cathepsin $\mathrm{S}$ was shown to be involved in atherosclerosis, as cathepsin $\mathrm{S}$ deficiency reduced lesion size in low density lipoprotein (LDL) receptor deficient mice ${ }^{10,11}$.

Recently, we reported upregulation of cathepsin $\mathrm{K}$ expression in advanced stable human atherosclerotic lesions in comparison with early lesions and lesions containing a thrombus ${ }^{12}$. In catK-/-/apoE-/- atherosclerotic lesions we showed reduction of atherosclerotic lesion progression, induction of lesion fibrosis, but aggravation of macrophage foam cell formation in comparison with apoE-/- ${ }^{12}$. To unravel further the molecular mechanisms underlying the observed phenotypic changes evoked by cathepsin K deficiency, we performed gene expression profiling of lesion containing aortic arches of catK-/-/apoE-/mice and apoE-/- mice on a mouse oligo microarray.

Microarray analysis was performed in duplicate using dye swap hybridization and data were validated by real-time polymerase chain reaction (PCR), immunohistochemistry, and western blot analysis. Pathway validation revealed an important role for caveolins and CD36 in increasing modified LDL uptake in the absence of cathepsin $\mathrm{K}$. This study suggests that the use of cathepsin $\mathrm{K}$ as a possible therapeutic target for atherosclerosis has to be evaluated with care since cathepsin $\mathrm{K}$ inhibition might lead to a profibrotic, but also to a more lipogenic lesion phenotype.

\section{MATERIALS AND METHODS}

\section{Mice and experimental protocols}

ApoE-/- mice on a C57BL6 background were obtained from Iffa Credo (Lyon, France) and were backcrossed 7-9 times to catK-/- mice on a C57BL6 background. Animal experiments were approved by the regulatory authority of the University of Maastricht and were performed in compliance with the Dutch government guidelines. Normal chow diet and water were provided ad libitum. At the age of 26 weeks, catK-/-/apoE-/- and apoE-/- mice were sacrificed after an 8 hour fast. The complete arterial tree was excised. Tissues of mice were used for RNA extraction (catK-/-/apoE-/- $(n=11)$, apoE-/- $(n=1)$ ), histological 
analysis (catK-/-/apoE-/- $(\mathrm{n}=7)$, apoE-/- $(\mathrm{n}=8)$ ) or protein extraction (catK-//apoE-/- $(n=5)$, apoE-/- $(n=4))$. For RNA and protein extraction, aortic arches including their main branchpoints were cleaned from fatty tissue, excised, rinsed in ice-cold phosphate-buffered saline, snap frozen in liquid nitrogen, and stored at $-80^{\circ} \mathrm{C}$ until further use. For histological analysis, aortic arches, including their main branch points, were processed as described previously ${ }^{13}$, 14 .

\section{RNA isolation}

Aortic arches were disrupted in lysis buffer using a beadmill, and total RNA was isolated using the RNeasy kit (Qiagen, Hilden, Germany). For microarray analysis, atherosclerotic lesion containing aortic arches of both catK-/-/apoE-/and apoE-/- mice were pooled ( $\mathrm{n}=3$ for both groups).

\section{Microarray analysis}

cRNA labeling, microarray hybridization, scanning and data extraction were performed by ServiceXS (Leiden, The Netherlands) using the Mouse Development Oligo Microarray kit (G4120A; Agilent Technologies). This array contains 20,280 (60-mer) probes. Samples were cy3 or cy5 labeled using Agilent fluorescent linear amplification kit (G2554A; Agilent Technologies). In short, a primer which contains poly dT and a T7 polymerase promoter sequence was annealed to $2 \mu \mathrm{g}$ total RNA. CRNA was synthesized using T7 RNA polymerase, which simultaneously incorporated cy3- or cy5-labeled CTP. CRNA was processed using the in situ hybridization kit (5184-3568; Agilent Technologies). Briefly, $0.5 \mu \mathrm{g}$ cRNA was applied to the hybridization chamber and incubated at $60^{\circ} \mathrm{C}$ in a hybridization oven for 17 hours. Subsequently, arrays were washed and dried using a nitrogen-filled air gun. Hybridization was performed in duplicate using a dye swap.

\section{(Statistical) analysis of microarray data}

Array image acquisition and feature extraction were performed using the Agilent G2565AA Microarray Scanner and Feature Extraction software version 5.1. Raw intensity values for cy 3 and cy 5 were normalized to each other based on the mean intensity of all reporters. Feature extraction results were entered into Spotfire ${ }^{\circledR}$ Decisionsite 7.3 for Functional Genomics.

In Spotfire ${ }^{\circledR}$ Decisionsite, a t-test of z-scores normalized values for both experiments was performed. Subsequently, Unigene ID numbers, fold changes, 
t-test P-values and intensity values were imported into the Ingenuity Pathway Analysis software (Ingenuity Systems 2000-2005). SwissProt ID numbers or, if those were not available, Unigene ID numbers, fold changes, t-test P-values and intensity values were imported to GenMAPP (Gene Map Annotator and Pathway Profiler) version 2.0 (Gladstone Institutes 2000-2004, www.GenMAPP.org using gene ontology database (www.geneontology.org): Mm-Std_20040824.gdb and local mapps: Mm-contributed_20041216). Genes were only considered significantly differentially expressed when they had a Pvalue of $<0.05$, a fold change of at least 1.4 , and an intensity value of at least 2.5 times background in at least one channel.

\section{Validation procedures}

\section{Quantitative real-time PCR (Q-PCR)}

Random primers were used for the preparation of cDNA from template RNA. dNTP $(5 \mu \mathrm{l} ; 10 \mathrm{mM}), 2.5 \mu \mathrm{l}$ random primer $(20 \mu \mathrm{g} / \mathrm{ml}$, Promega), $5.0 \mu \mathrm{l} 5 \mathrm{x}$ first strand buffer (Invitrogen), and $11 \mu$ template RNA were added, followed by incubation at $72^{\circ} \mathrm{C}$ for 6 minutes and $37^{\circ} \mathrm{C}$ for 5 minutes. Then, $2.5 \mu$ DTT (100 $\mathrm{mM}$, Invitrogen), $0.5 \mu \mathrm{l}$ RNAsin (40U/ $\mu \mathrm{l}$, Promega), and $0.5 \mu \mathrm{l} \mathrm{MMLV} \mathrm{reverse}$

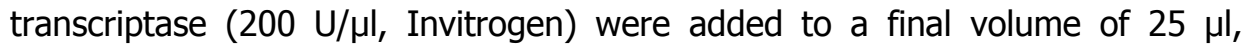
followed by $1 \mathrm{cycle}$ of $37^{\circ} \mathrm{C}$ for 60 minutes and $95^{\circ} \mathrm{C}$ for 5 minutes. CDNA was diluted to a concentration of $2 \mathrm{ng} / \mu \mathrm{l}$. Real-time PCR was performed as described previously ${ }^{12}$ (for primers and probes, see Table 5.1).

\section{Human tissue sampling}

Atherosclerotic lesions from the internal carotid artery were obtained from patients undergoing vascular surgery (Department of General Surgery, University Hospital Maastricht) or at autopsy (Department of Pathology, University Hospital Maastricht) and were collected in compliance with institutional ethical guidelines in accordance with the Helsinki Declaration of 1975 , as revised in 1983. Vascular specimens were processed as previously described ${ }^{15}$ and were classified according to Virmani et al. ${ }^{16}$. 
Chapter 5

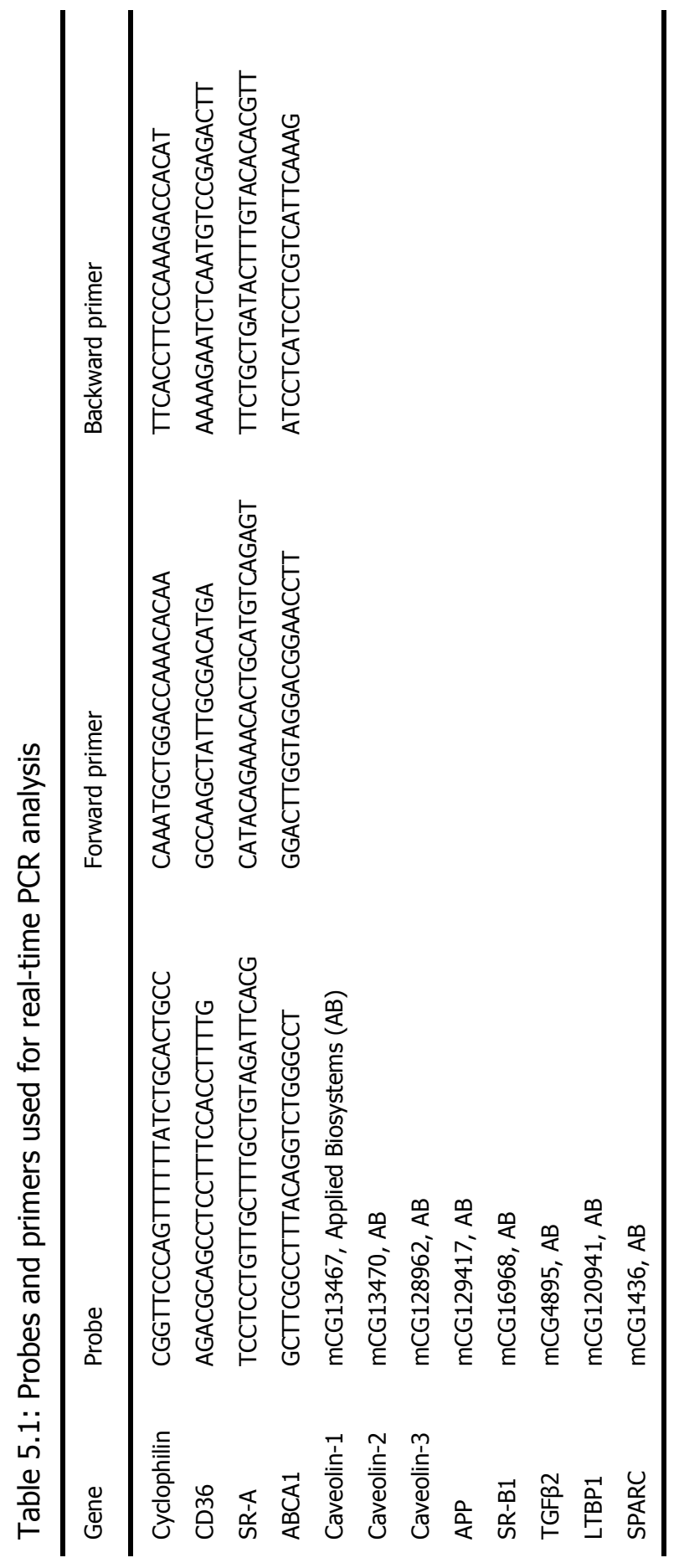




\section{Immunohistochemistry}

(Double) immunohistochemistry was performed as described previously ${ }^{13,14}$ with the following antibodies: caveolin-1 polyclonal antibody (1:800, Santa Cruz), SPARC polyclonal antibody (osteonectin) (1:50, gift from $\mathrm{Dr}$ L. Fisher, University Institute of Pathological Anatomy, Copenhagen, Denmark), $\alpha$-smooth muscle actin monoclonal antibody (1:500, Sigma) as a marker for vascular SMCs and myofibroblasts, MAC3 rat monoclonal antibody (1:30, Pharmingen) to detect macrophages, factor VIII von Willebrand (1:500, Dako) as a marker for ECs, and control mouse IgG (Dako) as a negative control. Caveolin-1 and secreted protein, acidic and rich in protein (SPARC) staining of the atherosclerotic lesion in the left subclavian artery branch were measured using image analysis software (Leica Qwin) as the percentage of positive stained area to total lesion area. Incubation with control mouse IgG or deletion of the primary antibody did not show any staining.

\section{Western blot}

Bone marrow (BM) derived macrophages were obtained according to standard procedures ${ }^{17}$. Blots were incubated with caveolin-1 polyclonal antibody (1:800, Santa Cruz) or phosphate-buffered saline, followed by incubation with horseradish peroxidase-coupled anti-rabbit antibody (1:1500, Dako). Specific antibody binding was visualized with WestPico (Pierce, Perbio Science).

\section{In vitro intervention assay using BM derived macrophages}

LDL was extracted, oxidized, and labeled as described previously ${ }^{12}$. BM derived macrophages were incubated with 25 or $50 \mu \mathrm{g} / \mathrm{ml}$ DiI labeled oxLDL for 3 hours. Inhibitors were added 30 minutes before DiI labeled oxLDL incubation. Methylbetacyclodextrin ( $2 \mathrm{mM}$ and $10 \mathrm{mM}$, Sigma) was used to disrupt caveolae, the smo antibody (monoclonal anti-CD36, $10 \mu \mathrm{g} / \mathrm{ml}$, Ancell) as an inhibiting antibody of CD36, fucoidan (10 $\mu \mathrm{g} / \mathrm{ml}$, Sigma) to inhibit scavenger receptor (SR)-A, and SR-BI/II polyclonal antibody to inhibit SR-BI/II (1:100, Novus Biologicals). OxLDL uptake was determined by fluorescence-activated cell sorting (FACS; BD Biosciences). 


\section{Statistical analysis}

All statistical analyses, except the array analysis in Spotfire ${ }^{\circledR}$, were performed using GraphPad Prism (GraphPad Software Inc). All data were analyzed by the nonparametric Mann-Whitney $U$ test. Data are presented as mean \pm SEM and were considered statistically significant at $P<0.05$.

\section{RESULTS}

\section{Microarray analysis}

After normalization of microarray data and t-test analysis in Spotfire ${ }^{\circledR}$ DecisionSite, 558 of 20,280 reporters were found to be differentially regulated $(P<0.05)$, while 444 reporters had a $P$-value of $<0.05$, a fold change of $\geq 1.4$ or $\leq-1.4$, and an intensity value of $>2.5$ times background in at least one channel.

\section{Pathway analysis and functional clustering}

To identify molecular and cellular pathways by which cathepsin $\mathrm{K}$ disruption evoked the observed increased fibrosis and increased lipid storage in vivo, we performed pathway analysis using both Ingenuity Pathway Analysis and GenMAPP. Table 5.2 lists the most important differentially expressed networks detected by Ingenuity Pathway Analysis.

Of special interest were two networks containing genes involved in lipid metabolism (Table 5.2). A total of 15/35 (43\%) and 13/35 (37\%) genes included in these networks were significantly up- or downregulated, with the majority $(75 \%)$ of genes being significantly upregulated in aortic arches derived from catK-/-/apoE-/- mice. Another network of interest was the merged network involved in matrix turnover (Table 5.2). A total of 27/68 (40\%) genes included were significantly up- or downregulated. Again, the majority (75\%) was significantly upregulated in aortic arches derived from catK-/-/apoE-/- mice. To perform a complete pathway profiling, SwissProt ID or, if not available, Unigene ID numbers of all genes meeting the above mentioned differential expression criteria (a combined criterion consisting of fold inductions, P-values, and intensities) were also forwarded to GenMAPP. The most significant pathways found in GenMAPP were pathways involving caveolae (Gene Ontology (GO) based), TGF $\beta$ signaling (local MAPP), and actin cytoskeleton (GO). Table 5.3 lists the most important networks of GenMAPP. Figure 5.1 shows a flowchart depicting both Ingenuity Pathway and GenMAPP Analysis. 
Gene profiling of cathepsin K deficiency in atherogenesis

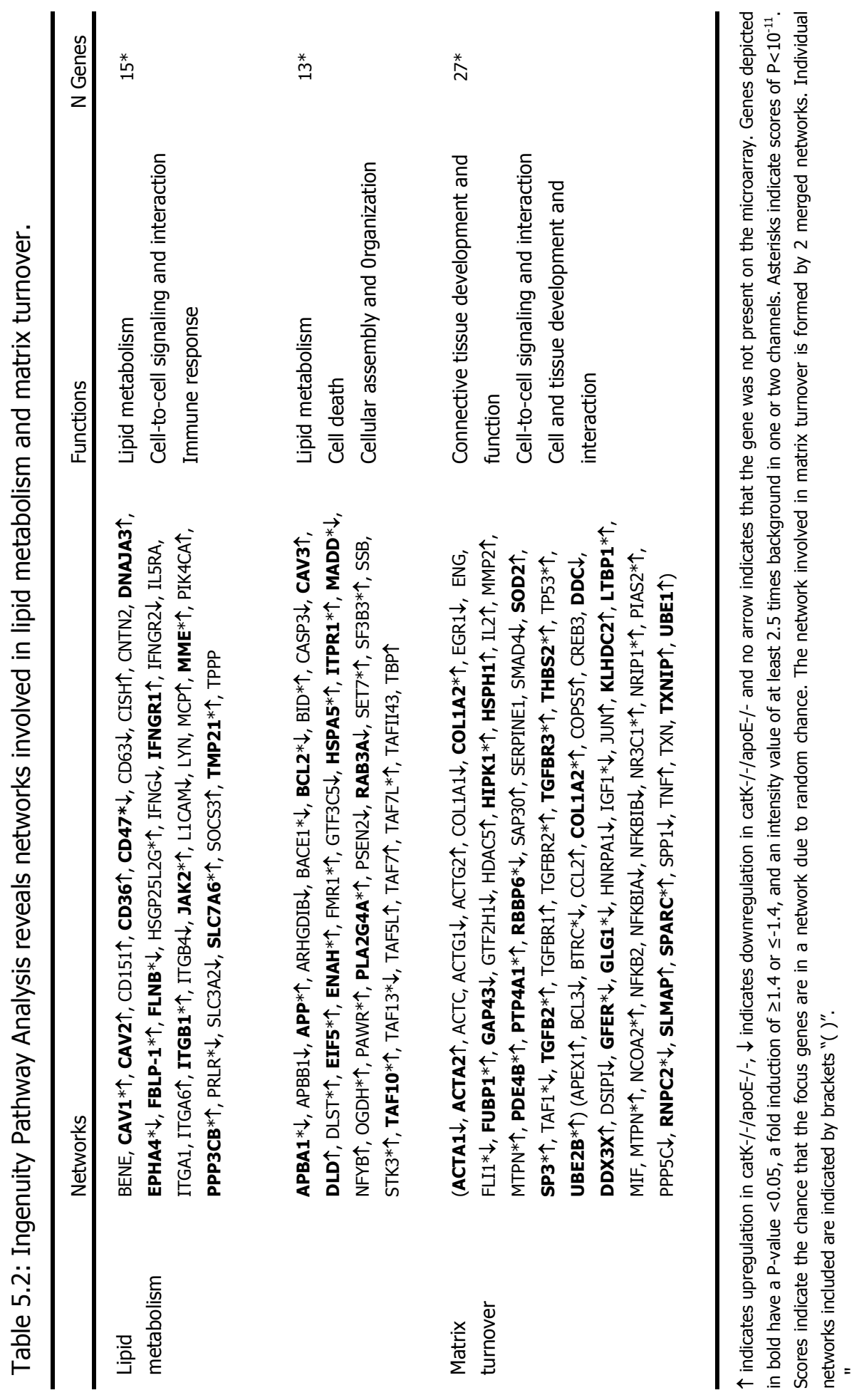


Table 5.3: GenMAPP reveals several processes and components involved in caveolae, actin cytoskeleton and TGF $\beta$ signaling. GenMAPP not only confirmed pathways already found in Ingenuity Pathway Analysis (lipid metabolism and matrix turnover), but also revealed an additional pathway involved (actin cytoskeleton).

\begin{tabular}{|c|c|c|}
\hline Process / Component & Genes & Z-score \\
\hline \multirow[t]{2}{*}{ Caveolae } & $\mathrm{CAV} \uparrow, \mathrm{CAV} 2 \uparrow, \mathrm{CAV} 3 \uparrow$ & 5.90 \\
\hline & ALCP7 $\uparrow$, ACTA2 $\uparrow$, ITGB1 $\uparrow$, & \\
\hline \multirow[t]{2}{*}{ Actin cytoskeleton } & ITGB5 $\uparrow$, FLNC $\uparrow$, CAPZA1 $\uparrow$, & 4.61 \\
\hline & PSTPIP1 $\downarrow$, TPM2 $\uparrow$, TNCC $\downarrow$ & \\
\hline TGF $\beta$-signaling & $\begin{array}{l}\text { TGFBR3 } \uparrow, I N H B A \uparrow, ~ L T B P 1 \uparrow, \\
M A D H 1 \uparrow, L I F \downarrow\end{array}$ & 1.46 \\
\hline
\end{tabular}

Only differentially expressed genes are included. $\uparrow$ indicates upregulation in catK-/-/apoE-/-, $\downarrow$ indicates downregulation in catK-/-/apoE-/-. All genes depicted have a P-value $<0.05$, a fold induction of $\geq 1.4$ or $\leq-1.4$, and an intensity value of at least 2.5 times background in one or two channels.

\section{Validation of microarray expression profiles at mRNA level}

Upregulation in catK-/-/apoE-/- aortic arches was confirmed by real-time PCR for caveolin-1, caveolin-2, and caveolin-3, APP, TGF $\beta 2$, latent TGF $\beta$ binding protein-1 (LTBP1), and SPARC (Table 5.4). As reported earlier the increased expression of CD36 was confirmed to be borderline significant (1.9 fold, $P=0.05$ ) in real-time $P C R{ }^{12}$. Expression of SR-A, SR-B1 and ABCA1 was not altered in both microarray and real-time PCR analysis.

\section{Validation of microarray expression levels at protein level}

Atherosclerotic lesions of catK-/-/apoE-/- mice showed increased caveolin-1 (Figure 5.2) and SPARC (Figure 5.3) protein levels in comparison with apoE-/mice. In both genotypes, caveolin-1 was localized in ECs (Figure 5.2C) and sporadically in SMCs (Figure 5.2D). However, in catK-/-/apoE-/- mice caveolin-1 was also localized in lesional macrophages (Figure 5.2E). Positive caveolin-1 stained area to total lesion area was $10.3 \pm 4.7 \%$ of total lesion area in catK-//apoE-/- versus $1.4 \pm 1.3 \%$ in apoE-/-, $\mathrm{P}<0.05$ (Figure 5.2F). Immunohistochemical staining for SPARC showed positivity of chondroid-like cells in both lesion types (Figure 5.3C). In addition, in catK-/-/apoE-/- lesions 


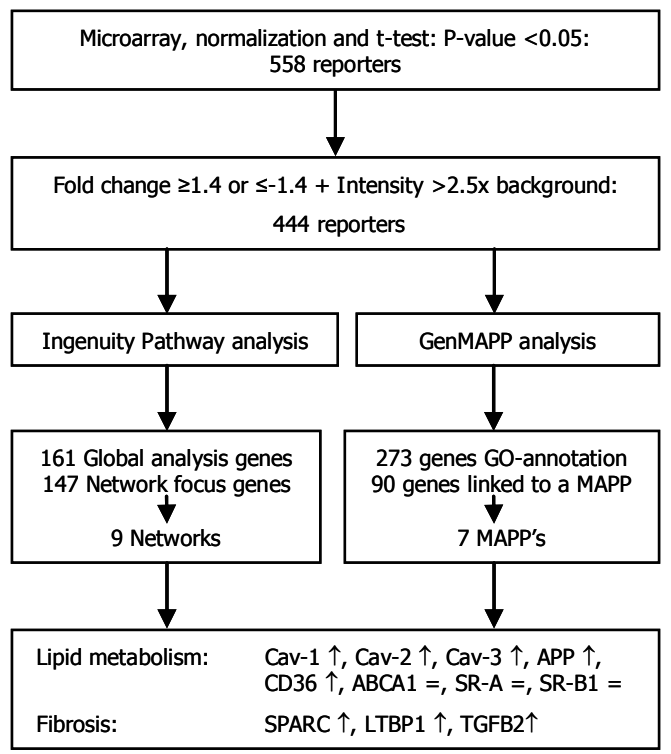

Figure 5.1

Flowchart depicting an overview of Ingenuity Pathway Analysis and GenMAPP. Global analysis genes indicate a biologically related interaction between genes, and Network focus genes (genes eligible for networks) indicate a direct interaction between molecules.

Abbreviations: GO, Gene Ontology annotations; GenMAPP, Gene Map Annotator and Pathway Profiler.

Table 5.4: Fold changes identified by microarray analysis were confirmed on RNA level using real-time PCR.

\begin{tabular}{lll}
\hline Gene & Fold change microarray & Fold change real-time PCR \\
\hline Matrix turnover & & \\
LTBP1 & $4.3^{*}$ & $2.9 \pm 0.7^{*}$ \\
TGFB2 & $2.6^{*}$ & $3.0 \pm 0.5^{*}$ \\
SPARC & 2.2 & $2.5 \pm 0.7$ \\
Lipid metabolism & & \\
Cav-1 & $6.0^{*}$ & $2.4 \pm 0.2^{*}$ \\
Cav-2 & $4.3^{*}$ & $1.6 \pm 0.1^{*}$ \\
Cav-3 & $2.2^{*}$ & $1.8 \pm 0.3^{*}$ \\
CD36 & $1.9^{*}$ & $1.5 \pm 0.1$ \\
APP & $2.9^{*}$ & $1.4 \pm 0.02^{*}$ \\
SR-A & $=$ & $=$ \\
SR-B1 & $=$ & $=$ \\
ABCA1 & $=$ & $=$ \\
\hline
\end{tabular}

Asterisks indicate $\mathrm{P}<0.05$ and data are presented as mean \pm SEM. Cav indicates caveolin; "=" indicates no altered expression. 

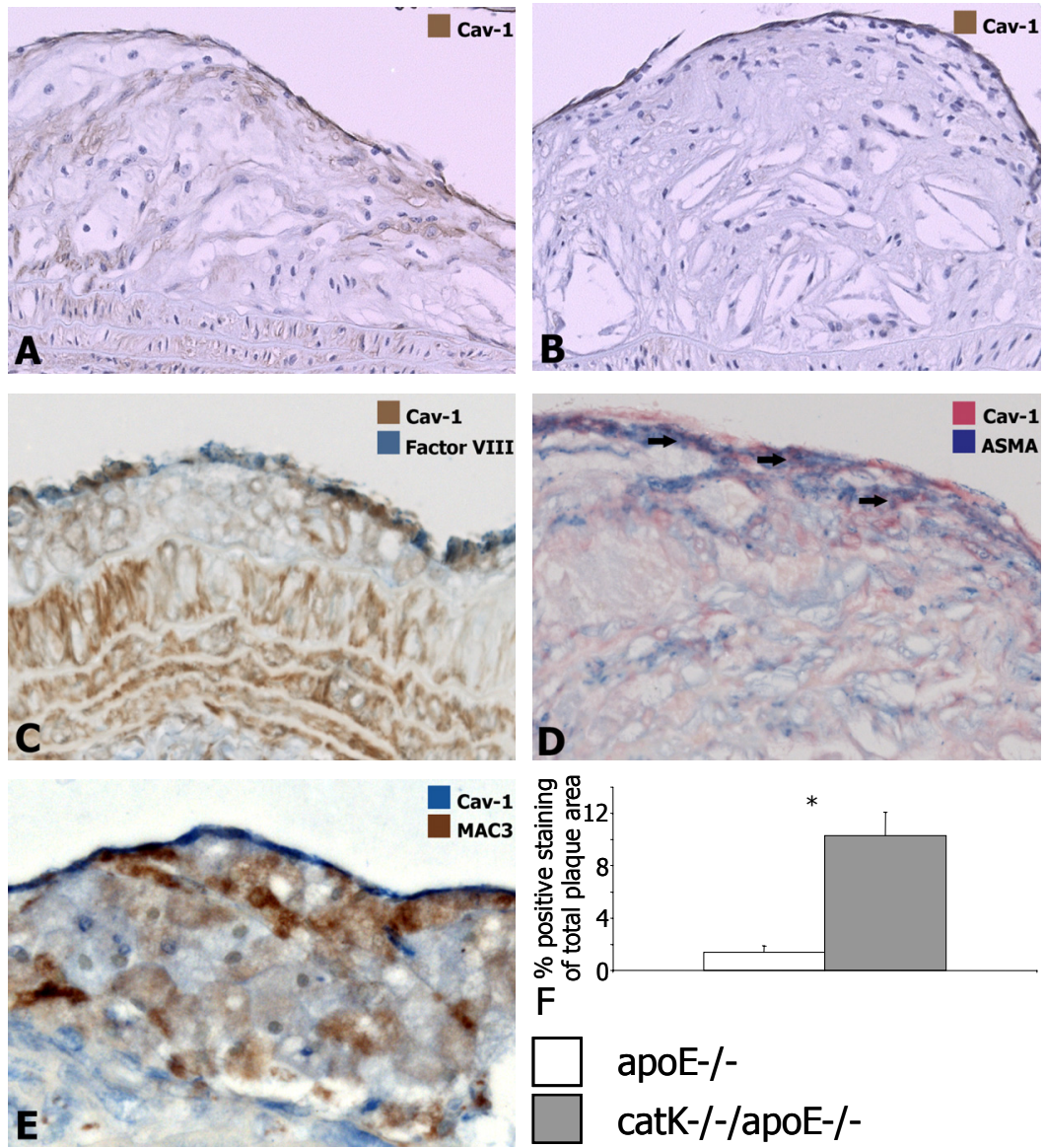

Figure $\mathbf{5 . 2}$

Representative immunohistochemical staining showing that caveolin-1 (brown) was localized, especially in lesional macrophages and endothelial cells, in catK-/-/apoE-/- mice (A) in comparison with apoE-/- mice (B). Double immunohistochemistry showed that caveolin-1 was localized in endothelial cells (C) (caveolin-1 in brown and factor VIII in blue), only sporadically in SMCS (D) (caveolin-1 in red, a-smooth muscle actin in blue, indicated with black arrows), and in macrophages (E) (caveolin-1 in blue, MAC3 in brown). Atherosclerotic lesions of catK-/-/apoE-/- mice showed increased caveolin-1 protein levels when in comparison with apoE-/- (F). Asterisk indicates $\mathrm{P}<0.05$, and data are presented as mean $\pm \mathrm{SEM}$. 

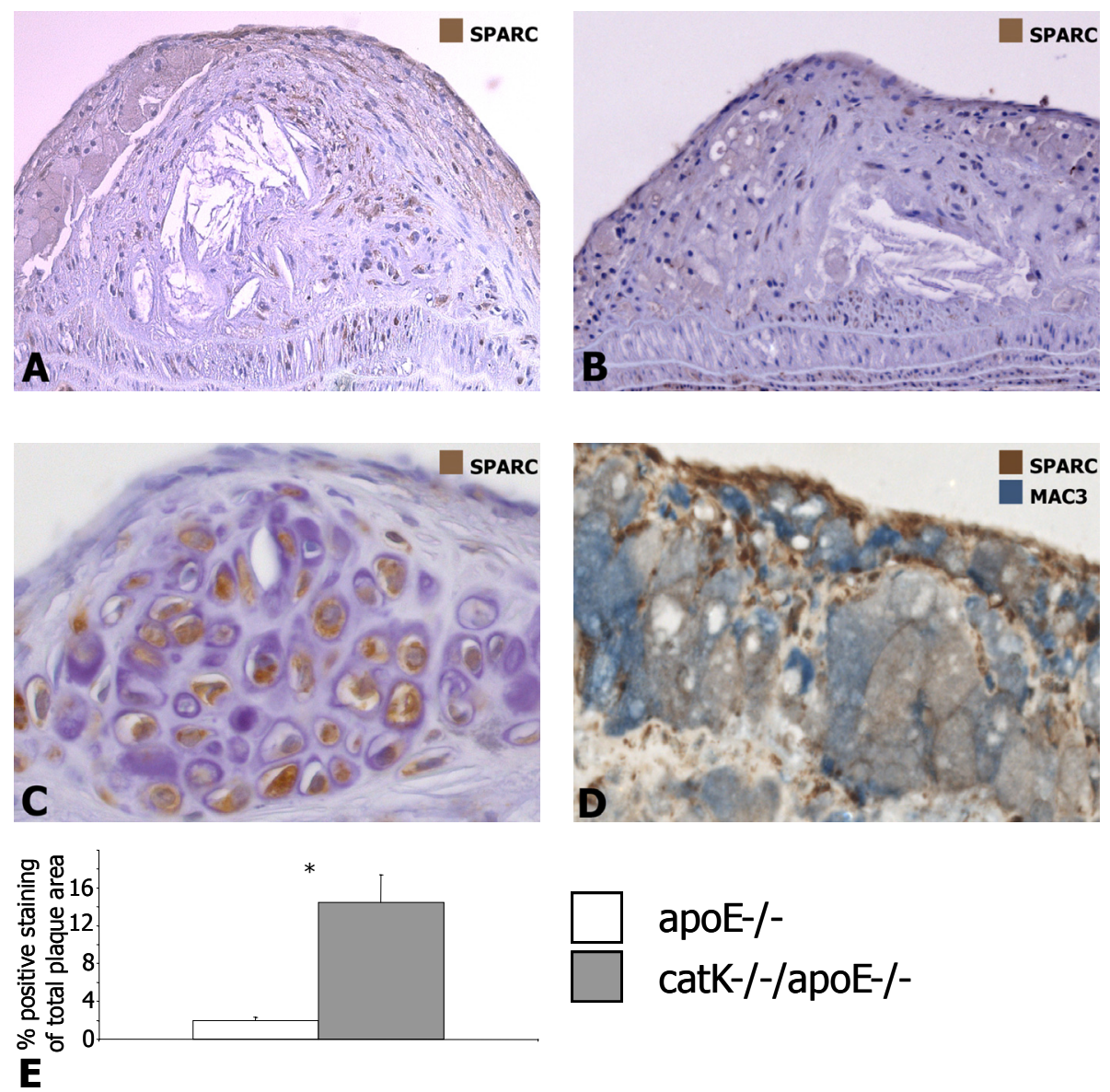

Figure 5.3

Representative immunohistochemical staining showing that SPARC (brown) was especially localized in lesional macrophages and endothelial cells in catK-/-/apoE-/- (A) compared with apoE-/- (B). SPARC staining showed positivity in chondroid-like cells in both lesion types (C). Double immunohistochemistry showed that SPARC was localized in lesional macrophages especially (D) (SPARC in brown, MAC3 in blue). Atherosclerotic lesions of catK-/-/apoE-/- mice showed increased SPARC protein levels in comparison with apoE-/- (E). Asterisk indicates $\mathrm{P}<$ 0.05 , and data are presented as mean $\pm \mathrm{SEM}$.

SPARC protein was also localized in lesional macrophages (Figure 5.3D), while incidentally also some ECs showed SPARC protein expression. Positive SPARC stained area to total lesion area was $14.5 \pm 7.6 \%$ in catK-/-/apoE-/- versus 2.0 $\pm 1.0 \%$ in apoE-/-, $\mathrm{P}<0.05$ (Figure $5.3 \mathrm{E}$ ). We reported previously that CD36 protein levels are increased in catK-/-/cpoE-/- aortic lesions in comparison with apoE-/- ${ }^{12}$. Furthermore, lysates from aortic arches and BM derived macrophages showed increased levels of caveolin-1 in catK-/-/apoE-/- in comparison with apoE-/-. Densitometry analysis showed a significant increase in 


\section{Chapter 5}

caveolin-1 protein expression in lysates from catK-/-/apoE-/- aortic arches compared to apoE- $/-(P<0.05$; Figure 5.4).

Immunohistochemistry also revealed high levels of caveolin-1 protein in human atherosclerotic lesions (Figure 5.5). Caveolin-1 protein expression was especially localized in ECs and macrophages of early lesions and stable advanced lesions, when compared with lesions containing a thrombus.

\section{In vitro pathway validation}

Absolute uptake of DiI-labeled oxLDL uptake without inhibitors was increased in catK-/-/apoE-/- BM derived macrophages as described previously ${ }^{12}$ and indicated in Figure 5.6A. Absolute inhibition of DiI-labeled oxLDL uptake by addition of an inhibitor was related to absolute inhibition of DiI-labeled oxLDL uptake without inhibitor using the following formula: ((Geomean without inhibitor - Geomean with inhibitor) / Geomean without inhibitor) x 100\%. Figure 5.6B shows that disruption of caveolae by methylbetacyclodextrin and inhibition of CD36 by the inhibiting antibody smo lead to increased inhibition of modified LDL uptake in catK-/-/apoE-/- BM derived macrophages in comparison with apoE-/-. Inhibition of SR-A and SR-B by fucoidan and SR-BI/II inhibiting antibody respectively did not lead to a significant inhibition of modified LDL uptake.

A

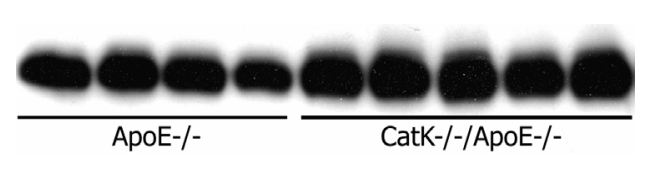

C

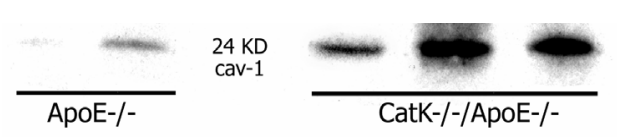

B

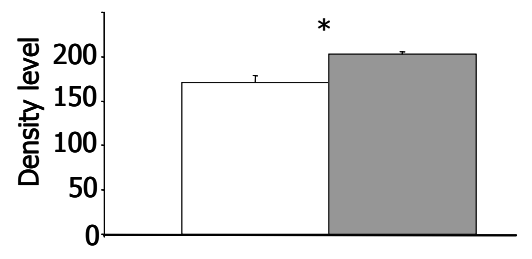

D 200

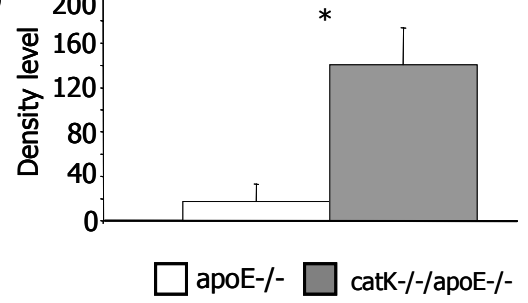

Figure 5.4

Western blot and densitometry analysis showing increased expression of caveolin-1 in catK-/-/apoE-/- compared with apoE-/- aortic arches (A and B) and BM derived macrophages ( $C$ and $\mathrm{D}$ ). Asterisk indicates $\mathrm{P}<0.05$ and data are presented as mean \pm SEM. 

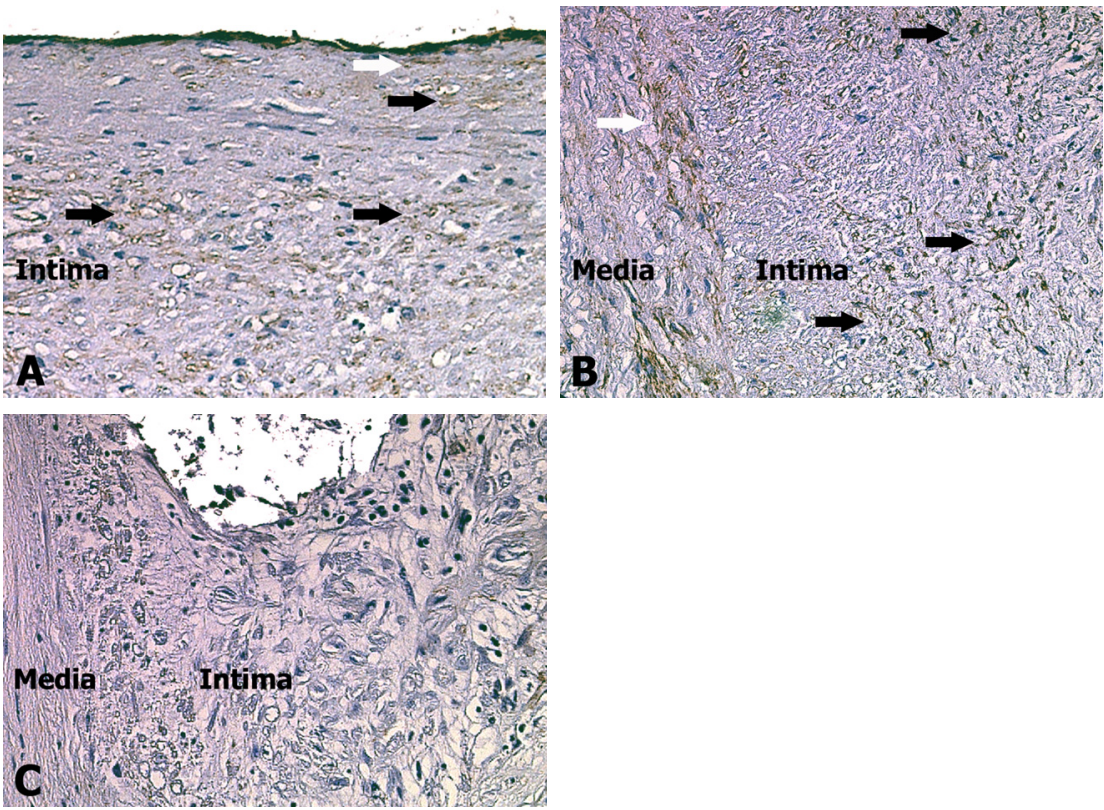

Figure 5.5

Representative immunohistochemical staining of human atherosclerotic lesions. Caveolin-1 staining (brown) is localized in smooth muscle cells (white arrows) and macrophages (black arrows) in early lesions (A) and stable advanced lesions (B), and to a lesser extent in lesions containing a thrombus (C).
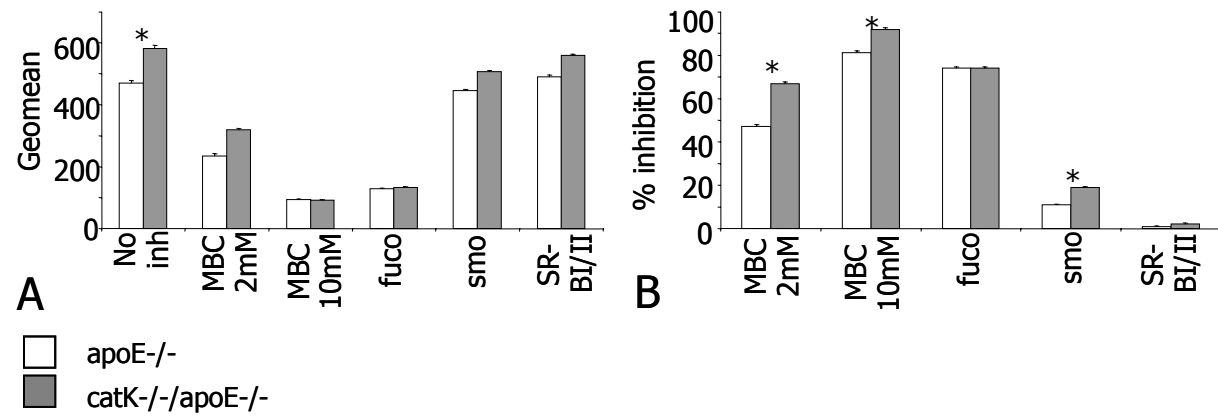

Figure 5.6

In vitro inhibitor assay. Absolute uptake of DiI-labeled oxLDL uptake without inhibitors is increased in catK-//apoE-/- BM derived macrophages (A). To relate the absolute inhibition of DiI-labeled oxLDL uptake by addition of an inhibitor to DiI-labeled oxLDL uptake without inhibitor, relative percentages of inhibition were calculated using the following formula: ((Geomean without inhibitor - Geomean with inhibitor) / Geomean without inhibitor) $x$ $100 \%$. B. Disruption of caveolae by methylbetacyclodextrin (MBC) leads to increased inhibition of DiI labeled oxLDL in catK-/-/apoE-/- in comparison with apoE-/- BM derived macrophages, and inhibition of SR CD36 by the CD36 blocking antibody smo also leads to increased inhibition of DiI labeled oxLDL in catK-/-/apoE-/- in comparison with apoE-/- BM derived macrophages. Inhibition of SR-A and SR-BI/II by fucoidan (fuco) and SR$\mathrm{BI} / \mathrm{II}$ inhibiting $\mathrm{Ab}$, respectively, did not differ between the two genotypes. Asterisks indicate $\mathrm{P}<0.05$ and data are presented as mean \pm SEM. 


\section{DISCUSSION}

In the present study, microarray analysis comparing aortic arches of catK-//apoE-/- with those of apoE-/- mice revealed upregulation of several genes and pathways, including (1) lipid metabolism and caveolae, (2) actin cytoskeleton, and (3) matrix turnover and more specifically TGF $\beta$ signaling. The role of TGF $\beta$ is well known and has been described on many occasions ${ }^{13,18,19}$. However, our finding that cathepsin $\mathrm{K}$ deficiency also increased lipid uptake and storage by macrophages and aggravated subsequent foam cell formation was unexpected 12. Foam cell formation plays an important role in lesion destabilization and given the current quest for cathepsin $\mathrm{K}$ inhibitors as a therapeutic modality for atherosclerosis, the role of cathepsin $\mathrm{K}$ in foam cell formation needs further exploration. Therefore we mainly focused on the functional mechanisms by which cathepsin $\mathrm{K}$ deficiency leads to changes in lipid uptake and storage.

Our study suggests a role for cathepsin $\mathrm{K}$ in lipid metabolism, since mediators such as caveolin-1, -2, -3 and CD36 were significantly upregulated in cathepsin $\mathrm{K}$ deficient atherosclerotic lesions. Caveolins have been shown to play a role in atherosclerosis, especially in cholesterol metabolism ${ }^{20-26}$. However, the overall effect is still unknown since both pro-atherogenic and anti-atherogenic properties are attributed to caveolins ${ }^{8,27,28}$. In aortic arch atherosclerotic lesions of catK-/-/apoE-/- mice, we found that both caveolins and CD36 were upregulated, but other SRs, like SR-A and SR-B1, were not differentially regulated. This suggests that cathepsin $\mathrm{K}$ deficiency leads to increased lipid uptake through a mechanism involving both caveolae and CD36, but not SR-A and SR-B1. We reported earlier that cathepsin K deficiency leads to increased uptake and storage of modified LDL by BM derived macrophages ${ }^{12}$. Here, we confirm the role of caveolins and CD36 in increasing lipid uptake when cathepsin $\mathrm{K}$ is deficient, since disruption of caveolae and inhibition of CD36 leads to increased inhibition of modified LDL uptake by catK-/-/apoE-/- in comparison with apoE-/- BM derived macrophages. SR-A, although playing an important role in lipid uptake, does not seem to have an additional contribution to increasing lipid uptake in cathepsin $\mathrm{K}$ deficient lesions, nor does SR-BI/II. The potential role for CD36 in lipid uptake has been described earlier, but CD36 has not been previously associated with cathepsin K. Alternatively, our observations of increased intracellular lipid storage could not only be the result of an increased lipid influx but also the result of a decrease in lipid efflux. However, our data did not reveal altered expression of the main efflux associated genes, including several ABCA and ABCG transporters. This finding is supported by Lindstedt et al who showed that cathepsins $\mathrm{F}$ and $\mathrm{S}$ have an important role in cholesterol efflux and suggested only a minor role for cathepsin $\mathrm{K}^{29}$. mRNA levels of the efflux associated gene SR-B1 are also not altered in catK-/-/apoE-/- aortic arch atherosclerotic lesions. The role of caveolin-1 in affecting this SR-B1 mediated cholesterol efflux is uncertain ${ }^{30-32}$. 
We demonstrated that caveolin-1 is not only present in murine atherosclerotic lesions but also in human atherogenesis. Recently, Schwencke et al already showed that the proliferation of vascular SMCs in human atheromata is associated with a decrease in caveolin-1 expression ${ }^{33}$.

Furthermore, we found upregulation of several genes involved in the actin cytoskeleton. Caveolar endocytosis mediated by the actin cytoskeleton has been descibed in the literature ${ }^{15,34-36}$. Several of the upregulated genes in this study are related to caveolar endocytosis. Integrin beta-1 activates the internalization of caveolae ${ }^{34,37}$, while the actin-binding protein filamin is a ligand for caveolin$1^{38}$, and microtubules are needed for transport of caveolar vesicles ${ }^{39}$. This suggests that the increased lipid storage, as described earlier ${ }^{12}$, may be the result of increased lipid transport mediated by the actin cytoskeleton.

We and others previously showed that disruption of TGF $\beta$ signaling led to a decrease in fibrosis in atherosclerotic lesions ${ }^{13,18}$. Interestingly, Buhling et al found an increase in extracellular matrix deposition in lungs when cathepsin $\mathrm{K}$ was disrupted 7,8 . Data from our own lab also showed that disruption of cathepsin $\mathrm{K}$ in apoE-/- mice resulted in an increase in collagen content in atherosclerotic lesions ${ }^{12}$.

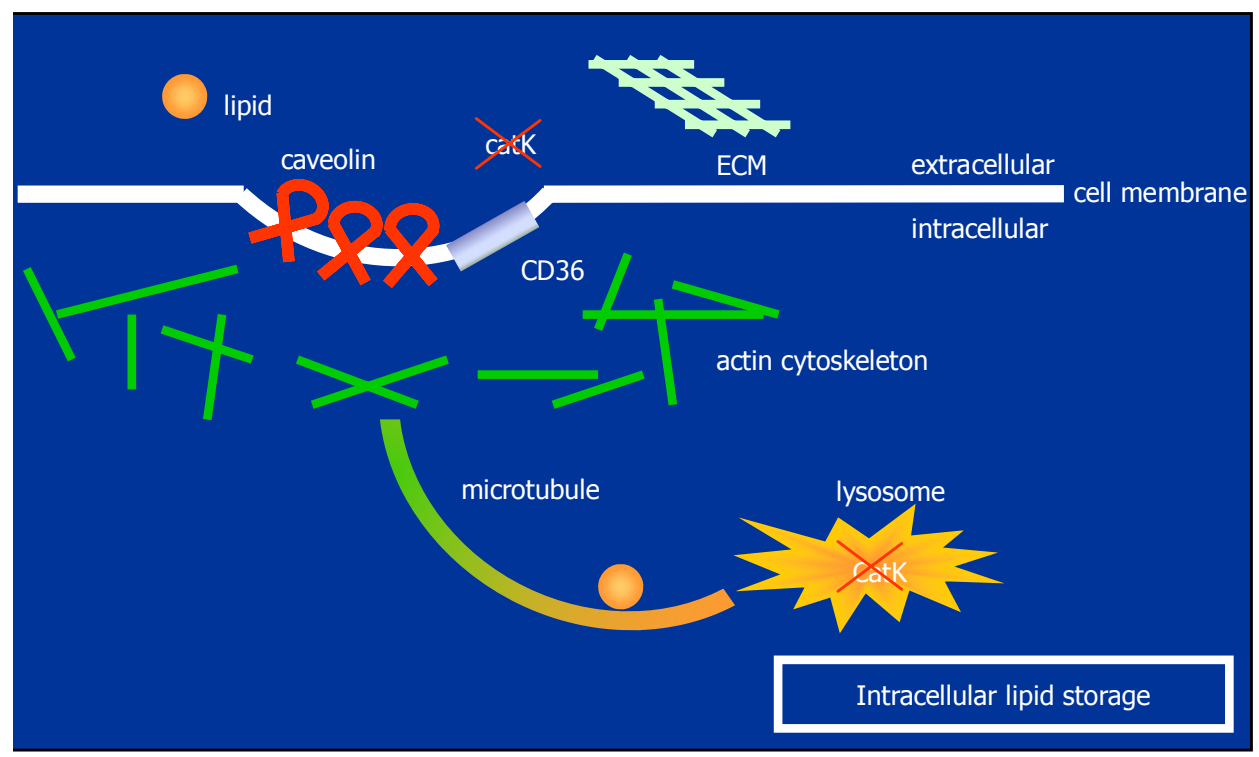

Figure 5.7

Putative mechanism by which cathepsin K (catK) deficiency leads to a pro-fibrotic, but also lipogenic lesion phenotype. In the cathepsin $\mathrm{K}$ deficient macrophage, lipid uptake is increased. This increased lipid uptake is mediated by both CD36 and caveolins. Then, lipid is transported, possibly via the actin cytoskeleton, to the interior of the cell and stored in lysosomes which have increased in size. 


\section{Chapter 5}

This increase in collagen content was not reflected by an increase in vascular SMC content (initial lesions: $0.8 \pm 0.3 \%$ of total lesion area in catK-/-/apoE-/versus $0.7 \pm 0.2 \%$ and advanced lesions: $0.7 \pm 0.2 \%$ in catK-/-/apoE-/- versus $0.8 \pm 0.2 \%$ in apoE-/-, $\mathrm{P}>0.05$ ). The upregulation of genes involved in matrix turnover and TGF $\beta$ signaling suggests that cathepsin $\mathrm{K}$ deficiency increases lesion fibrosis not only by decreasing proteolytic activity but also by stimulating genes involved in matrix turnover and TGF $\beta$ signaling.

One question that remains to be answered here is the mechanism by which cathepsin $\mathrm{K}$ deficiency leads to the induction of gene transcription and translation of the differentially expressed genes as found in this study. Until now, caveolin-1 has been described as being involved in regulation, activation, and expression of cathepsin $\mathrm{B}^{40}$. However, no such relation between cathepsin $\mathrm{K}$ and caveolin-1, and more generally between cathepsin $\mathrm{K}$ and lipid metabolism, has been described.

In view of the role of the lysosomal cysteine protease cathepsin $\mathrm{K}$ in foam cell formation, we hypothesize that the increased lipid uptake and storage in enlarged lysosomes in the cathepsin $\mathrm{K}$ deficient macrophage is the net result of increased CD36 and caveolin-1 protein levels, which facilitate lipid uptake into the cell. After transportation across the cell membrane into the cell, lipid is transcytosed through the interior of the cell by the actin cytoskeleton and its associated proteins. Finally, lipid is stored, owing to the absence of the lysosomal cysteine protease cathepsin $\mathrm{K}$, in the enlarged lysosomes, eventually resulting in a macrophage foam cell that contains more lipids compared to the "normal" apoE-/- macrophages (summarized in Figure 5.7).

In conclusion, we suggest that cathepsin $\mathrm{K}$ deficiency not only induces a profibrotic atherosclerotic lesion phenotype but also results in a lipogenic lesion phenotype. Assuming similar effects for the human lesion phenotype, the use of cathepsin $\mathrm{K}$ as a possible therapeutic target should be evaluated with care. 


\section{REFERENCES}

1. Garnero P, Borel O, Byrjalsen I, et al. The collagenolytic activity of cathepsin $\mathrm{K}$ is unique among mammalian proteinases. J Biol Chem. Nov 27 1998;273(48):32347-32352.

2. Gelb BD, Moissoglu K, Zhang J, et al. Cathepsin K: isolation and characterization of the murine cDNA and genomic sequence, the homologue of the human pycnodysostosis gene. Biochem Mol Med. Dec 1996;59(2):200-206.

3. Bromme D, Okamoto $\mathrm{K}$, Wang BB, et al. Human cathepsin $\mathrm{O} 2$, a matrix protein-degrading cysteine protease expressed in osteoclasts. Functional expression of human cathepsin $\mathrm{O} 2$ in Spodoptera frugiperda and characterization of the enzyme. J Biol Chem. Jan 26 1996;271(4):2126-2132.

4. Chapman HA, Riese RJ, Shi GP. Emerging roles for cysteine proteases in human biology. Annu Rev Physiol. 1997;59:63-88.

5. Inaoka T, Bilbe G, Ishibashi O, et al. Molecular cloning of human CDNA for cathepsin K: novel cysteine proteinase predominantly expressed in bone. Biochem Biophys Res Commun. Jan 5 1995;206(1):89-96.

6. Shi GP, Chapman HA, Bhairi SM, et al. Molecular cloning of human cathepsin O, a novel endoproteinase and homologue of rabbit OC2. FEBS Lett. Jan 3 1995;357(2):129-134.

7. Buhling F, Peitz U, Kruger $S$, et al. Cathepsins $K, L, B, X$ and $W$ are differentially expressed in normal and chronically inflamed gastric mucosa. Biol Chem. May 2004;385(5):439-445.

8. Buhling F, Rocken $\mathrm{C}$, Brasch $\mathrm{F}$, et al. Pivotal role of cathepsin $\mathrm{K}$ in lung fibrosis. $A m \mathrm{~J}$ Pathol. Jun 2004;164(6):2203-2216.

9. Littlewood-Evans AJ, Bilbe G, Bowler WB, et al. The osteoclast-associated protease cathepsin $\mathrm{K}$ is expressed in human breast carcinoma. Cancer Res. Dec 1 1997; 57(23):5386-5390.

10. Sukhova GK, Zhang Y, Pan JH, et al. Deficiency of cathepsin S reduces atherosclerosis in LDL receptor-deficient mice. J Clin Invest. Mar 2003;111(6):897-906.

11. Sukhova GK, Shi GP, Simon DI, et al. Expression of the elastolytic cathepsins S and K in human atheroma and regulation of their production in smooth muscle cells. $J$ Clin Invest. Aug 1 1998;102(3):576-583.

12. Lutgens $\mathrm{E}$, Lutgens SP, Faber BC, et al. Disruption of the cathepsin $\mathrm{K}$ gene reduces atherosclerosis progression and induces plaque fibrosis but accelerates macrophage foam cell formation. Circulation. Jan 3 2006;113(1):98-107.

13. Lutgens $\mathrm{E}$, Gijbels M, Smook M, et al. Transforming growth factor-beta mediates balance between inflammation and fibrosis during plaque progression. Arterioscler Thromb Vasc Biol. Jun 1 2002;22(6):975-982.

14. Lutgens E, Gorelik L, Daemen MJ, et al. Requirement for CD154 in the progression of atherosclerosis. Nat Med. Nov 1999;5(11):1313-1316.

15. Faber $B C$, Cleutjens $\mathrm{KB}$, Niessen $\mathrm{RL}$, et al. Identification of genes potentially involved in rupture of human atherosclerotic plaques. Circ Res. Sep 14 2001;89(6):547-554. 


\section{Chapter 5}

16. Virmani $\mathrm{R}$, Kolodgie $\mathrm{FD}, \mathrm{Burke} A \mathrm{P}$, et al. Lessons from sudden coronary death: a comprehensive morphological classification scheme for atherosclerotic lesions. Arterioscler Thromb Vasc Biol. May 2000;20(5):1262-1275.

17. Kanters $E$, Pasparakis M, Gijbels MJ, et al. Inhibition of NF-kappaB activation in macrophages increases atherosclerosis in LDL receptor-deficient mice. $J$ Clin Invest. Oct 2003;112(8):1176-1185.

18. Mallat Z, Gojova A, Marchiol-Fournigault C, et al. Inhibition of transforming growth factorbeta signaling accelerates atherosclerosis and induces an unstable plaque phenotype in mice. Circ Res. Nov 9 2001;89(10):930-934.

19. Robertson AK, Rudling $M$, Zhou $X$, et al. Disruption of TGF-beta signaling in $T$ cells accelerates atherosclerosis. $J$ Clin Invest. Nov 2003;112(9):1342-1350.

20. Schroeder F, Gallegos AM, Atshaves BP, et al. Recent advances in membrane microdomains: rafts, caveolae, and intracellular cholesterol trafficking. Exp Biol Med (Maywood). Nov 2001;226(10):873-890.

21. Gargalovic P, Dory L. Caveolins and macrophage lipid metabolism. J Lipid Res. Jan 2003;44(1):11-21.

22. Fielding $\mathrm{CJ}$, Fielding PE. Intracellular cholesterol transport. $J$ Lipid Res. Aug 1997;38(8):1503-1521.

23. van Deurs B, Roepstorff $K$, Hommelgaard AM, et al. Caveolae: anchored, multifunctional platforms in the lipid ocean. Trends Cell Biol. Feb 2003;13(2):92-100.

24. Razani B, Woodman SE, Lisanti MP. Caveolae: from cell biology to animal physiology. Pharmacol Rev. Sep 2002;54(3):431-467.

25. Schnitzer JE. Caveolae: from basic trafficking mechanisms to targeting transcytosis for tissue-specific drug and gene delivery in vivo. Adv Drug Deliv Rev. Jul 28 2001;49(3):265280.

26. Simionescu M, Gafencu A, Antohe F. Transcytosis of plasma macromolecules in endothelial cells: a cell biological survey. Microsc Res Tech. Jun 1 2002;57(5):269-288.

27. Frank PG, Lee H, Park DS, et al. Genetic ablation of caveolin-1 confers protection against atherosclerosis. Arterioscler Thromb Vasc Biol. Jan 2004;24(1):98-105.

28. Frank PG, Lisanti MP. Caveolin-1 and caveolae in atherosclerosis: differential roles in fatty streak formation and neointimal hyperplasia. Curr Opin Lipidol. Oct 2004;15(5):523-529.

29. Lindstedt L, Lee M, Oorni K, et al. Cathepsins F and S block HDL3-induced cholesterol efflux from macrophage foam cells. Biochem Biophys Res Commun. Dec 26 2003;312(4):1019-1024.

30. Frank PG, Marcel YL, Connelly MA, et al. Stabilization of caveolin-1 by cellular cholesterol and scavenger receptor class B type I. Biochemistry. Oct 1 2002;41(39):11931-11940.

31. Wang L, Connelly MA, Ostermeyer AG, et al. Caveolin-1 does not affect SR-BI-mediated cholesterol efflux or selective uptake of cholesteryl ester in two cell lines. $J$ Lipid Res. Apr 2003;44(4):807-815.

32. Matveev S, Uittenbogaard A, van Der Westhuyzen D, et al. Caveolin-1 negatively regulates SR-BI mediated selective uptake of high-density lipoprotein-derived cholesteryl ester. Eur J Biochem. Nov 2001;268(21):5609-5616. 
33. Schwencke C, Schmeisser A, Walter C, et al. Decreased caveolin-1 in atheroma: loss of antiproliferative control of vascular smooth muscle cells in atherosclerosis. Cardiovasc Res. Oct 1 2005;68(1):128-135.

34. Navarro A, Anand-Apte B, Parat MO. A role for caveolae in cell migration. Faseb J. Dec 2004;18(15):1801-1811.

35. Parton RG, Joggerst B, Simons K. Regulated internalization of caveolae. J Cell Biol. Dec 1994;127(5):1199-1215.

36. Pol A, Lu A, Pons M, et al. Epidermal growth factor-mediated caveolin recruitment to early endosomes and MAPK activation. Role of cholesterol and actin cytoskeleton. $\mathrm{J}$ Biol Chem. Sep 29 2000;275(39):30566-30572.

37. Upla $\mathrm{P}$, Marjomaki $\mathrm{V}$, Kankaanpaa $\mathrm{P}$, et al. Clustering induces a lateral redistribution of alpha 2 beta 1 integrin from membrane rafts to caveolae and subsequent protein kinase C-dependent internalization. Mol Biol Cell. Feb 2004;15(2):625-636.

38. Stahlhut $M$, van Deurs B. Identification of filamin as a novel ligand for caveolin-1: evidence for the organization of caveolin-1-associated membrane domains by the actin cytoskeleton. Mol Biol Cell. Jan 2000;11(1):325-337.

39. Mundy DI, Machleidt T, Ying YS, et al. Dual control of caveolar membrane traffic by microtubules and the actin cytoskeleton. J Cell Sci. Nov 15 2002;115(Pt 22):4327-4339.

40. Cavallo-Medved D, Mai J, Dosescu J, et al. Caveolin-1 mediates the expression and localization of cathepsin $\mathrm{B}$, pro-urokinase plasminogen activator and their cell-surface receptors in human colorectal carcinoma cells. J Cell Sci. Apr 1 2005;118(Pt 7):14931503. 



\section{Chapter 6}

Stage specific gene expression profiles of macrophages isolated from human atherosclerotic lesions: focus on the transcription factors TGIF and ID4

Natasja Kisters, Wanwisa van Dijk-Jamnongluk, Moniek Faessen, Oscar L. Volger, Anton .J Horrevoets, Ann P. Bijnens, Kitty B. Cleutjens, Mat J. Daemen

In preparation 


\section{Chapter 6}

\section{ABSTRACT}

Monocyte-derived macrophages play a pivotal role in the initiation and progression of atherosclerotic lesions. However, little is known about lesion stage related differences in the transcriptome of atherosclerotic macrophages. Therefore, we compared the gene expression profiles of macrophages microdissected from early lesions with macrophages microdissected from advanced lesions. We identified 2487 genes (13.3\%) to be significantly differentially expressed $(p<0.01)$ between macrophages isolated from early and advanced atherosclerotic lesions. Pathway analysis revealed prominent roles for the pathways involved in cell death, cell cycle, cellular growth and proliferation, cell-cell signaling and cell-cell interaction. Several genes in these networks are related to Transforming Growth Factor $\beta$ (TGF $\beta$ ). Two interesting transcription factors, inhibitor of DNA binding 4 (ID4) and TGF $\beta$ induced factor (TGIF) were upregulated in macrophages microdissected from advanced lesions as compared to macrophages from initial lesions and macrophages isolated from non-atherosclerotic tissues such as the lung, liver and spleen. Immunohistochemistry demonstrated a higher protein expression of ID4 and TGIF in macrophages (subsets) of advanced atherosclerotic lesions compared to macrophages from early atherosclerotic lesions.

Our results clearly show atherosclerotic lesion stage associated transcription profiles of macrophages, with a prominent role for TGF $\beta$, and the transcription factors ID4 and TGIF. 


\section{INTRODUCTION}

Monocyte-derived macrophages are present in all stages of human atherosclerosis and play a central role in the initiation and progression of atherosclerosis ${ }^{1-3}$. Macrophages in atherosclerotic lesions originate from circulating monocytes and are recruited into the arterial wall, after activation of endothelial cells and secretion of chemokines. These stimuli lead to monocyte adhesion and their subsequent migration through the endothelial layer. In the arterial wall monocytes differentiate into macrophages and scavenge modified $\mathrm{LDL}$, resulting in foam cell formation ${ }^{1-4}$.

In the recent past, several studies aimed to understand the mechanisms involved in activation and foam cell formation, using either cell lines ${ }^{5-7}$ peripheral blood monocytes ${ }^{8,9}$ or macrophages from mice ${ }^{10}$ and macrophagerich inflammatory infiltrates isolated from the human ${ }^{11}$ atherosclerotic lesions. These studies show that the early differentiation from monocyte to macrophage is associated with upregulation of transcription factors, whereas later differentiation and lipid loading activates genes related to lipid metabolism, inflammation, proliferation, migration, cell survival and activation of antioxidative systems. Interestingly, there is no head to head comparison of the expression profiles of macrophages isolated from different human atherosclerotic lesion stages.

In this study, we used genome wide microarray analysis and laser microdissection to identify lesion stage specific expression profiles of atherosclerotic macrophages. Besides downregulation of a large number of TGF $\beta$ related genes, the transcription factors TGIF (TGF $\beta$ induced factor) and ID4 (inhibitor of DNA binding 4) were found to be upregulated in macrophages isolated from advanced lesions. These transcription factors not only showed an increase in expression during lesion progression, but were also upregulated in atherosclerotic macrophages compared to non-atherosclerotic macrophages (liver, lung and spleen) of the same patients.

\section{MATERIAL AND METHODS}

\section{Tissue samples}

Atherosclerotic (carotid arteries) and non-atherosclerotic (lung, liver and spleen) tissues were obtained from autopsies that were performed within 24 hours after decease (Department of Pathology, University Hospital Maastricht). The mean age of the donors was $67.7 \pm 12.1$ years and all were male (Table 6.1A). None of the patients showed clinical symptoms of systemic inflammation or malignancies. After resection, carotid arteries were directly transferred to ice- 
cold RNase-free Phosphate Buffered Saline (PBS) and embedded in TissueTek $\circledast$ OCT compound (Sakura Finetek, Zoeterwoude, The Netherlands). Based on haematoxylin-eosin stained sections $(5 \mu \mathrm{m})$, the vascular specimens were classified according to Virmani et $a l^{12}$ and the lesions were stratified as early (intimal xanthoma) and advanced (thin or thick fibrous cap atheroma) macrophage containing lesions. Tissue samples of lung, liver and spleen were directly transferred into ice-cold calcium magnesium free Hank's buffer (Invitrogen, NY, USA) and kept in the freezer until use. Collection, storage in the Maastricht Pathology Tissue Collection (MPTC) and use of all tissues and patient data were performed in agreement with the "Code for Proper Secondary Use of Human Tissue" (http://www.fmwv.nl).

\section{Macrophage isolation}

Atherosclerotic macrophages were isolated by Laser Capture Microdissection (LCM, PixCell II LCM system, Arcturus Engineering, Mountain View, CA, USA) from 4 to 18 consecutive frozen sections (2000 pulses per lesion) using CD68immuno-positivity on parallel sections as a navigator. Frozen sections $(5 \mu \mathrm{m})$ were fixed in cold acetone $\left(-20^{\circ} \mathrm{C}, 5\right.$ minutes), washed in RNase-free Tris Buffered Saline (TBS) (15 seconds), stained with haematoxylin (30 seconds) followed by two washes. Subsequently, the sections were dehydrated in graded ethanol solutions (70\%, 30 seconds; $96 \%, 30$ seconds; $100 \%$, 30 seconds) and cleared in xylene (twice, 3 minutes). After air-drying the sections for at least 10 minutes, macrophages were harvested from the macrophage-rich shoulder areas using LCM.

Non-atherosclerotic macrophages were isolated using immunomagnetic beads coated with CD68 mouse anti-human antibody (Santa Cruz Biotechnology) using the CELLection Pan Mouse IgG Kit (Dynal Biotech, Norway) according to the manufacturer's protocol. In brief, fresh tissues obtained during autopsy were collected in ice-cold calcium and magnesium free Hank's buffer. Cell suspensions were obtained by passage through RNase-free nylon membrane (BD Falcon, San Jose, CA, USA) and were washed twice in ice-cold RNase-free calcium magnesium free PBS buffer (CMF-PBS, pH 7.2). After resuspension of cell pellets in ice-cold CMF-PBS (pH 7.2) containing 0.1\% BSA and 2 mM EDTA, macrophages were isolated using CD68 antibody-coated magnetic beads. 
Table 6.1: Donor characteristics

A. Donors of samples for isolation of macrophages

\begin{tabular}{cccll}
\hline $\begin{array}{c}\text { Patient } \\
\text { Code }\end{array}$ & $\begin{array}{l}\text { Age } \\
\text { (years) }\end{array}$ & Gender & Tissue & Used for \\
\hline Q-1 & 75 & M & Early lesion carotid artery & Microarray \\
Q-2 & 66 & M & Early lesion carotid artery & Microarray \\
Q-3 & 50 & M & Early lesion carotid artery & Microarray \\
Q-4 & 73 & M & Early lesion carotid artery & Microarray \\
Q-5 & 54 & M & Early lesion carotid artery & Microarray \\
Q-6 & 51 & M & Advanced lesion carotid artery & Microarray \\
Q-7 & 70 & M & Advanced lesion carotid artery & Microarray \\
Q-8 & 81 & M & Advanced lesion carotid artery & Microarray \\
Q-9 & 82 & M & Advanced lesion carotid, liver, lung, spleen & Q-PCR \\
Q-10 & 75 & M & Advanced lesion carotid, liver, lung, spleen & Q-PCR \\
Q-11 & 74 & F & Advanced lesion carotid, liver, lung, spleen & Q-PCR \\
Q-12 & 86 & M & Advanced lesion carotid, liver, lung, spleen & Q-PCR \\
Q-13 & 75 & M & Advanced lesion carotid, liver, lung, spleen & Q-PCR \\
\hline
\end{tabular}

B. Donors of carotid artery samples for immunohistochemical analysis

\begin{tabular}{ccccccc}
\hline \multirow{2}{*}{$\begin{array}{c}\text { Patient } \\
\text { Code }\end{array}$} & Age & Gender & \multicolumn{3}{c}{ Stage of atherosclerosis carotid artery sample } \\
\cline { 6 - 7 } (years) & & IT & IX & Thick FCA & Thin FCA \\
\hline IA-1 & 82 & M & & & $\bullet$ \\
IA-2 & 75 & M & & & $\bullet$ \\
IA-3 & 74 & F & & & $\bullet$ \\
IA-4 & 86 & M & & & $\bullet$ \\
IA-5 & 75 & M & & & $\bullet$ \\
IA-6 & 50 & M & & & $\bullet$ \\
IA-7 & 80 & F & $\bullet$ & & \\
IA-8 & 63 & F & $\bullet$ & & \\
IA-9 & 60 & M & & $\bullet$ & \\
IA-10 & 78 & F & & $\bullet$ & \\
IA-11 & 78 & M & & $\bullet$ & \\
IA-12 & 57 & F & & $\bullet$ & \\
IA-13 & 75 & F & & $\bullet$ & \\
IA-14 & 62 & M & & & $\bullet$ \\
IA-15 & 74 & M & & & \\
\hline
\end{tabular}


C. Donors of non-atherosclerotic tissues for immunohistochemical analysis

\begin{tabular}{cccll}
\hline $\begin{array}{c}\text { Patient } \\
\text { code }\end{array}$ & $\begin{array}{c}\text { Age } \\
\text { (years) }\end{array}$ & Gender & Tissue & Disease \\
\hline INA-1 & 3 & $\mathrm{~F}$ & Tonsil & Inflamed tonsil \\
INA-2 & 3 & $\mathrm{~F}$ & Tonsil & Inflamed tonsil \\
INA-3 & 24 & $\mathrm{~F}$ & Ileum & Crohn's disease \\
INA-4 & 25 & $\mathrm{M}$ & Colon & Crohn's disease \\
INA-5 & 76 & $\mathrm{~F}$ & Skin & Scar \\
INA-6 & 56 & $\mathrm{~F}$ & Skin & Scar \\
INA-7 & 20 & $\mathrm{M}$ & Epidermis & Epidermal cyst \\
INA-8 & 56 & $\mathrm{~F}$ & Epidermis & Epidermal cyst \\
INA-9 & 63 & $\mathrm{~F}$ & Epidermis & Epidermal cyst \\
INA-10 & 77 & $\mathrm{~F}$ & Cartilage & Giant cell arthritis \\
INA-11 & 81 & $\mathrm{~F}$ & Cartilage & Giant cell arthritis \\
INA-12 & 62 & $\mathrm{M}$ & Lung & Sarcoidosis \\
INA-13 & 64 & $\mathrm{~F}$ & Lung & Sarcoidosis \\
INA-14 & 48 & $\mathrm{M}$ & Lung & Sarcoidosis \\
INA-15 & 82 & $\mathrm{M}$ & Heart & Myocardial infarction \\
INA-16 & 32 & $\mathrm{~F}$ & Heart & Myocardial infarction \\
INA-17 & 66 & $\mathrm{~F}$ & Heart & Myocardial infarction \\
INA-18 & 59 & $\mathrm{~F}$ & Heart & Myocardial infarction \\
INA-19 & 50 & $\mathrm{~F}$ & Gall bladder & Choleresterolosis \\
INA-20 & 46 & $\mathrm{M}$ & Gall bladder & Choleresterolosis \\
INA-21 & 71 & $\mathrm{~F}$ & Skin & Xanthelasma \\
INA-22 & 54 & $\mathrm{~F}$ & Skin & Xanthelasma \\
\hline
\end{tabular}

Abbreviations: $M$, male; $F$, female; Q-PCR, quantitative PCR; IT, intimal thickening; IX, intimal xanthoma; Thick FCA, thick fibrous cap atheromas; Thin FCA, thin fibrous cap atheroma

\section{RNA isolation and amplification}

Total RNA was isolated from isolated tissue macrophages using the Absolutely RNA microprep kit (Stratagene, La Jolla, CA, USA) according to the manufacturer's protocol. To remove potential genomic DNA contamination, RNA samples were treated with $50 \mathrm{U}$ RNase-free DNase (Qiagen, Valencia, CA, USA). The integrity of the isolated RNA was determined by $\beta$-actin reverse transcriptase PCR. Total RNA of approximately 2000 atherosclerotic macrophages and $30 \mathrm{ng}$ of non-atherosclerotic macrophage RNA was amplified two rounds using the RiboAmp RNA Amplification Kit (Arcturus, Mountain View, CA, USA), and aRNA concentration was determined using a NanoDrop-1000 Spectrophotometer (NanoDrop, Wilmington, DE, USA). 


\section{Microarray hybridization and data analysis}

Microarray hybridization was performed as described in Chapter 2 of this thesis. Microarray analyses were performed using Rosetta Biosoftware (Seattle, WA, USA) and Ingenuity Pathway Analysis software (IPA) (Ingenuity Systems, Mountain View, CA, USA; https://analysis.ingenuity.com/pa). Only genes with a signal to background ratio of 2.5 or more for at least one of the dyes, a fold change $\geq 1.4$ or $\leq-1.4$ and a $p$-value $<0.01$ were subjected to IPA analysis.

\section{Quantitative real-time PCR (Q-PCR)}

Macrophages isolated from carotid, liver, lung and spleen $(n=5)$, (Table 6.1A) were included for quantitative real-time polymerase chain reaction (Q-PCR) analysis. CDNA was synthesized using $1 \mu \mathrm{g}$ of total RNA, $50 \mathrm{ng}$ Random Primer (Promega, Madison, USA) and 100 units M-MLV reverse transcriptase (Promega, Madison, WI, USA). Q-PCR was performed on $40 \mathrm{ng}$ of CDNA of two rounds amplified aRNA from macrophages isolated from carotid, liver, lung and spleen. Q-PCR was performed using iQ SYBR® Green Supermix (BioRad, Hercules, CA, USA), a BioRad iCycler iQ PCR (BioRad) and 3mM of the following primers: cyclophilin A forward 5'-CTCGAATAAGTTTGACTTGTGTTT-3', cyclophilin A

reverse 5'-CTAGGCATGGGAGGGAACA-3'; TGIF forward 5'GCAGAGATGGAGCTTCAGG-3', TGIF reverse 5'-GACATCTCAGTAACAGGAAGCT$3^{\prime}$ and ID4 forward 5'-GGATGAGGAAATGCTTGG-3', ID4-reverse 5'TITGGTAGCAAGCAG AGAAC-3'. All Q-PCR measurements were performed in duplicate. Relative expression values were calculated using a standard curve and normalized to housekeeping gene (cyclophylin A) mRNA expression.

\section{Immunohistochemistry}

Immunohistochemistry was performed on $5 \mu \mathrm{m}$ sections of paraffin-embedded human carotid atherosclerotic lesions (Table 6.1B) and 10 different macrophage-rich non-atherosclerotic tissues (Table 6.1C). (Double) immunohistochemistry was performed using the following antibodies: TGIF, ID4, CD68 (macrophages), ASMA (smooth muscle cells) or CD31 (endothelial cells). Detailed immunohistochemical methods can be found in Table 6.2. Sections incubated without the primary antibody served as negative control. ID4 immunoreactivity was assessed semiquantitatively by two observers (WvD] and APB) and was scored as: -, no staining; +, little staining; ++, clear staining; +++ , strong staining. 
Chapter 6

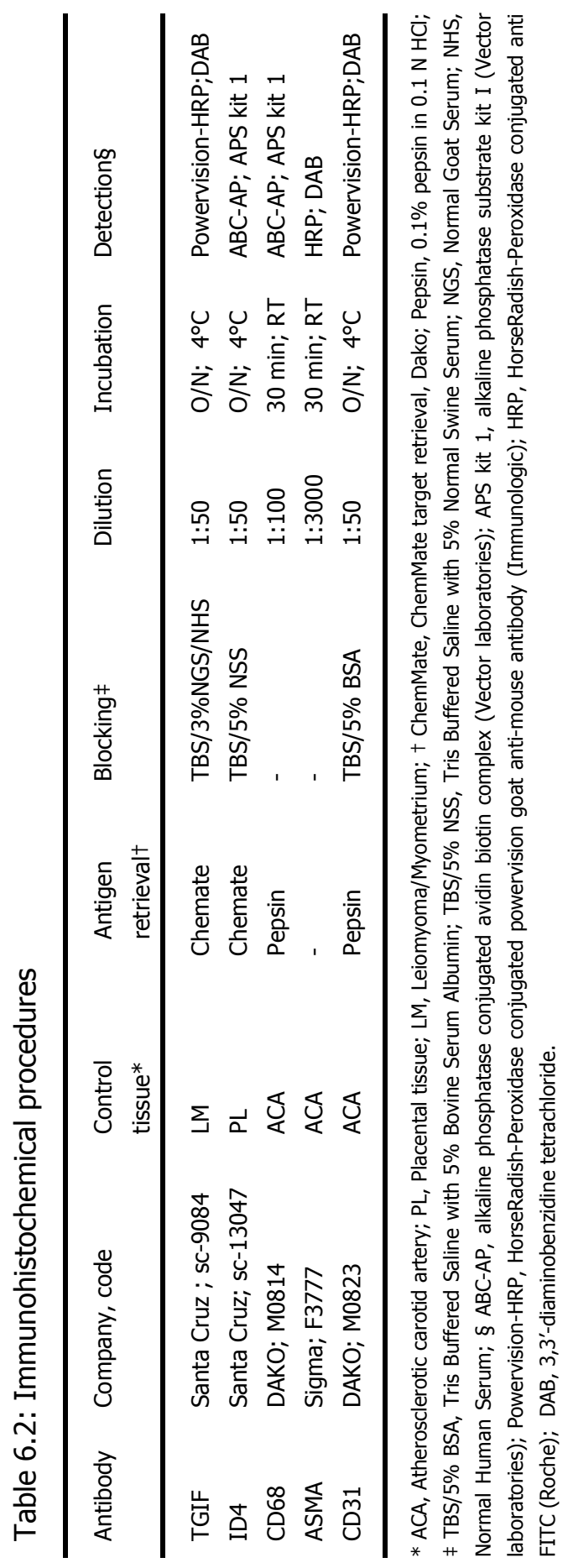




\section{Statistics}

Data are expressed as means \pm SEM. Groups were compared using the nonparametric Mann-Whitney U exact test (SPSS 12.0, Chicago, USA) and were considered statistically different when $\mathrm{p}<0.05$.

\section{RESULTS}

\section{Expression profiling of macrophages isolated from early and advanced lesions}

In total, $2487(13.3 \%)$ of the 18,658 genes represented on the microarrays showed a statistically significant difference $(p<0.01)$ in expression levels between macrophages microdissected from early and advanced human carotid artery lesions. Of these 2487 genes, 1448 genes (58.2\%) were downregulated and 1039 genes (41.8\%) were upregulated in macrophages from advanced lesions. Of the downregulated genes, 21 genes (1.5\%) showed at least a 5 fold difference in expression, while 351 genes (24.2\%) were downregulated 2 to 5 fold and 1076 genes (74.3\%) between 1.14 and 2 fold. Of the significantly upregulated genes, 696 genes (67\%) were upregulated between 1.14 and 2 fold, 322 genes $(31.0 \%)$ were upregulated 2 to 5 fold, while 21 genes $(2.0 \%)$ showed an over 5 fold up difference in expression levels.

To identify biological functions and molecular and cellular pathways represented by these differentially expressed genes, we performed extensive pathway analysis. Table 6.3 lists the most important differentially expressed networks, revealing the involvement of cell death, cell cycle, cellular growth and proliferation, cell-cell signaling and cell-cell interaction. Although TGF $\beta$ itself was not significantly differentially expressed between macrophages from early and advanced lesions, a large group of TGF $\beta$ related genes, including cyclin dependent kinase 4 (CDK4), insulin-like growth factor 2 (IGF2) and insulin-like growth factor-binding protein (IGFBP) were downregulated in macrophages from advanced lesions. In addition to an upregulation of 1.5 fold of the transcription regulator TGIF (TGF $\beta$ induced factor), one of the top networks included the transcription regulator, ID4, which was 6.4 fold higher expressed in macrophages derived from advanced lesions compared to macrophages from early atherosclerotic lesions. 
Table 6.3: Top 3 differential networks between macrophages from early and advanced lesions demonstrated by Ingenuity Pathway Analysis

\begin{tabular}{|c|c|c|c|c|}
\hline & networks & Score & $\begin{array}{l}\text { Focus } \\
\text { genes } \\
\end{array}$ & Fur \\
\hline & 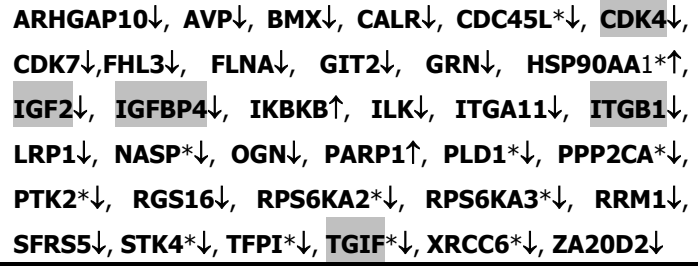 & 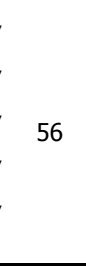 & 35 & $\begin{array}{l}\text { Cell death, } \\
\text { Cell cycle, } \\
\text { Cellular growth and } \\
\text { proliferation }\end{array}$ \\
\hline & 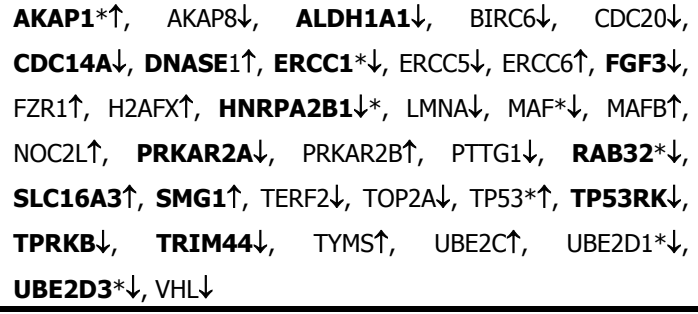 & 14 & 15 & $\begin{array}{l}\text { DNA replication, } \\
\text { recombination and repair, } \\
\text { Nucleic acid metabolism, } \\
\text { Small molecule biochemistry }\end{array}$ \\
\hline & 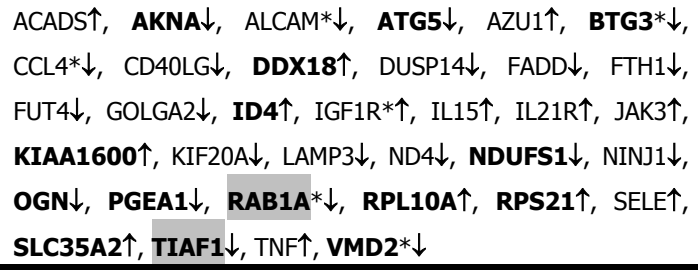 & 14 & 15 & $\begin{array}{l}\text { Cell-to-cell signaling and } \\
\text { interaction, hematological } \\
\text { system development and } \\
\text { function, Immune and } \\
\text { lymphatic system } \\
\text { development and function }\end{array}$ \\
\hline \multicolumn{5}{|c|}{$\begin{array}{l}\text { Ingenuity Pathway Analysis reveals differential expression of networks involved cell death and cell cycle, cellular } \\
\text { growth and proliferation, DNA replication, cell-to-cell signaling and interaction, hematolological system } \\
\text { development and immune and lymphatic system development and function. } \uparrow \text { indicates increased expression in } \\
\text { macrophages from advanced lesions; } \downarrow \text { indicates decreased expression in macrophages from advanced lesions. } \\
\text { All genes depicted in bold have an intensity level }>50 \text { ( } 2.5 x \text { background }) \text { in at least one phenotype, a fold change } \\
>1.4 \text { or }<-1.4 \text { and a } p \text {-value }<0.01 \text {. Scores indicate the chance that the focus genes are in a network due to } \\
\text { random chance. Asterisks indicate scores of individual genes with a } p<10^{-11} \text { chance that the focus genes are in a } \\
\text { network due to random chance. Genes highlighted in gray are the TGF } \beta \text { related genes. }\end{array}$} \\
\hline
\end{tabular}

\section{TGIF is expressed during lesion progression}

Strong TGIF immunoreactivity was observed in macrophages from both early and advanced lesions (Figures 6.1A and 6.1B). The most intense staining was observed in subendothelial macrophages, whereas macrophages at the rim of the necrotic core showed weak TGIF staining. TGIF immunoreactivity was also observed in other cell types, including subpopulations of medial and neo-intimal vascular SMCs and in ECs lining the lumen and microvessels in the lesion and adventitia. 


\section{Higher expression levels of TGIF in atherosclerotic macrophages compared to non-atherosclerotic macrophages}

Triggered by the observed difference in TGIF immunoreactivity in atherosclerotic macrophage subsets, we investigated whether TGIF expression was also different between atherosclerotic and non-atherosclerotic macrophages. To exclude the effect of confounders such as medication and age, we performed a paired comparison of TGIF mRNA expression levels in macrophages isolated from advanced (thick fibrous cap atheroma) carotid lesions and lung, liver and spleen (Table 6.1A). Q-PCR analysis showed a significant upregulation of TGIF mRNA expression ( 8 fold, $P=0.017$ ) in atherosclerotic macrophages compared to non-atherosclerotic macrophages (Figure 6.2A). Although TGIF immunoreactivity was clearly upregulated in atherosclerotic lesions, macrophages of the non-atherosclerotic tissues (Figure 6.3 A-D) also showed TGIF protein expression.

\section{ID4 is differentially expressed during lesion progression}

Macrophages from advanced atherosclerotic lesions showed strong ID4 immunoreactivity (Figure 6.1D), while macrophages from early lesions (Figure 6.1C) showed weak ID4 immunoreactivity. Interestingly, ID4 immunoreactivity was reversely correlated with the TGIF immunoreactivity. Strong ID4 immunoreactivity was observed in macrophages at the rim of the lipid core, whereas subendothelial macrophages and macrophages in the shoulder region showed weaker staining. In addition, strong ID4 immunoreactivity was observed in the ECs of the microvessels within the lesion and the adventitia. For both TGIF and ID4, the immunoreactivity in the lesional macrophages was heterogeneous.

\section{Higher expression level of ID4 in atherosclerotic macrophages compared to non-atherosclerotic macrophages}

Q-PCR analysis showed a significant upregulation of ID4 mRNA expression (24 fold, $\mathrm{P}=0.015$ ) in atherosclerotic macrophages compared to non-atherosclerotic macrophages (Figure 6.2B). Although atherosclerotic macrophages showed strong ID protein expression, expression of ID4 was absent in macrophages from non-atherosclerotic tissues (Figures 6.3E-H). The prominent differences in ID4 mRNA and protein expression of non-atherosclerotic and atherosclerotic macrophages as well as between macrophages in early and advanced atherosclerotic lesions prompted us to focus on ID4. 
Chapter 6

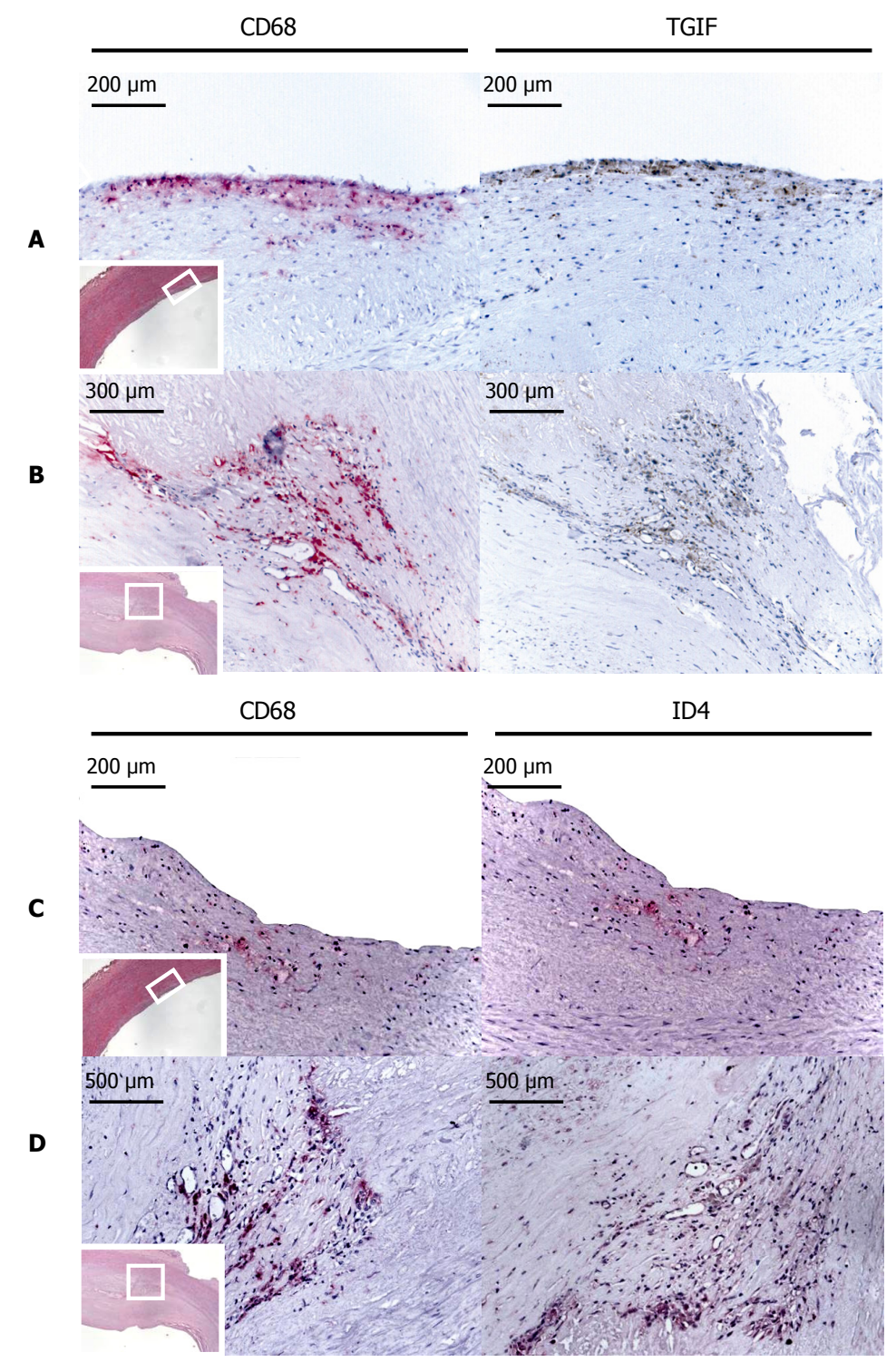

Figure 6.1

Co-localization of TGIF, ID4 and CD68 protein in human atherosclerotic lesions. Immunohistochemical detection of TGIF (brown), ID4 (red) and CD68 (macrophages, red) in carotid arteries with early (,$C$ ) and advanced stable lesions (B, D). 


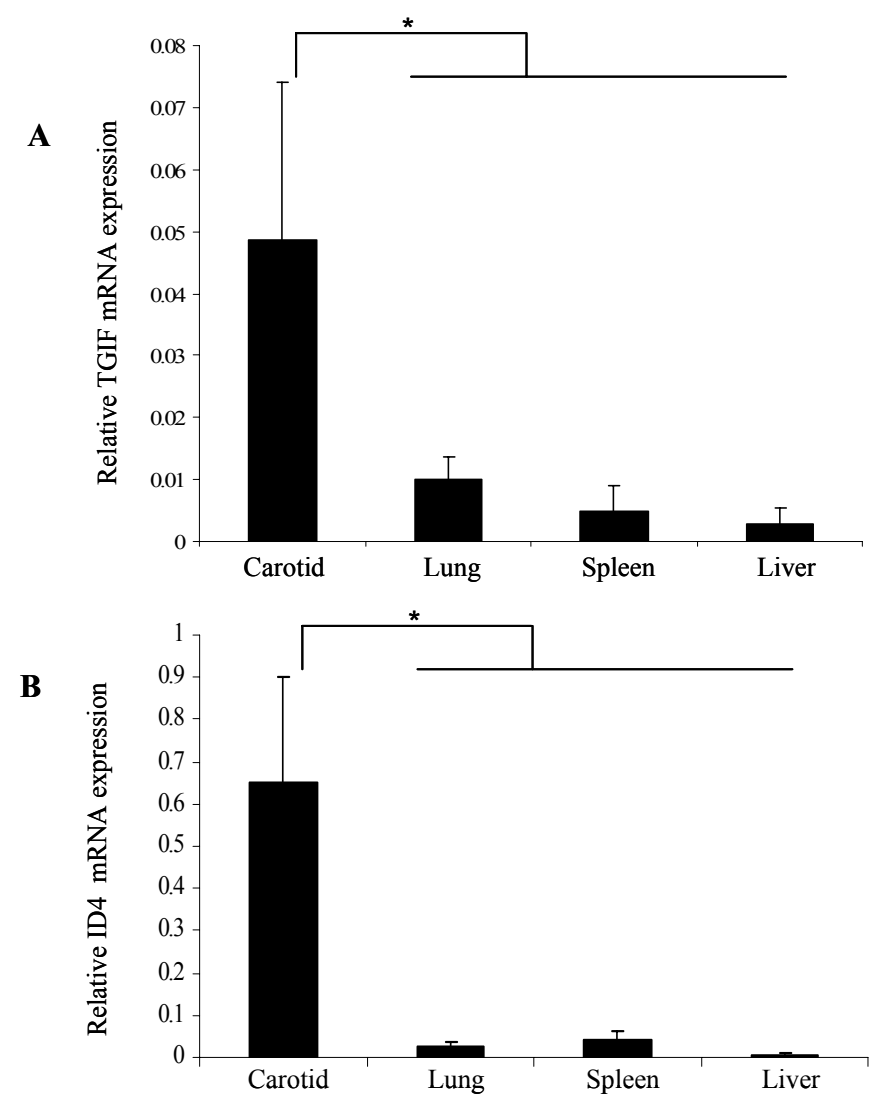

Figure 6.2

Both TGIF (A) and ID4 (B) mRNA levels are upregulated in atherosclerotic macrophages compared to the mean expression levels in non-atherosclerotic macrophages (liver, lung and spleen). Quantification of TGIF and ID4 mRNA levels in atherosclerotic (carotid) macrophages and non-atherosclerotic (lung, spleen and liver) macrophages by Q-PCR. TGIF and ID4 mRNA levels are normalized to the housekeeping gene cyclophilin A. $* \mathrm{p}<0.05$.

\section{Non-atherosclerotic macrophages from inflamed tissues lack ID4}

Analysis of ID4 immunoreactivity in parallel with CD68 stained slides, revealed that ID4 was not expressed in the macrophages of any of the evaluated 7 different non-atherosclerotic tissues (e.g. tonsils, lung, ileum) with a chronic inflammation, characterized by a massive macrophage infiltration ( $n=2$ to 4 samples per tissue, see Table 6.1C) inflamed non-atherosclerotic tissues (Figure 6.4A-B). These findings confirm that ID4 is not a universal marker for macrophages or macrophages in inflamed tissues, but its expression seems to be unique for (a subset of) macrophages. 
Chapter 6
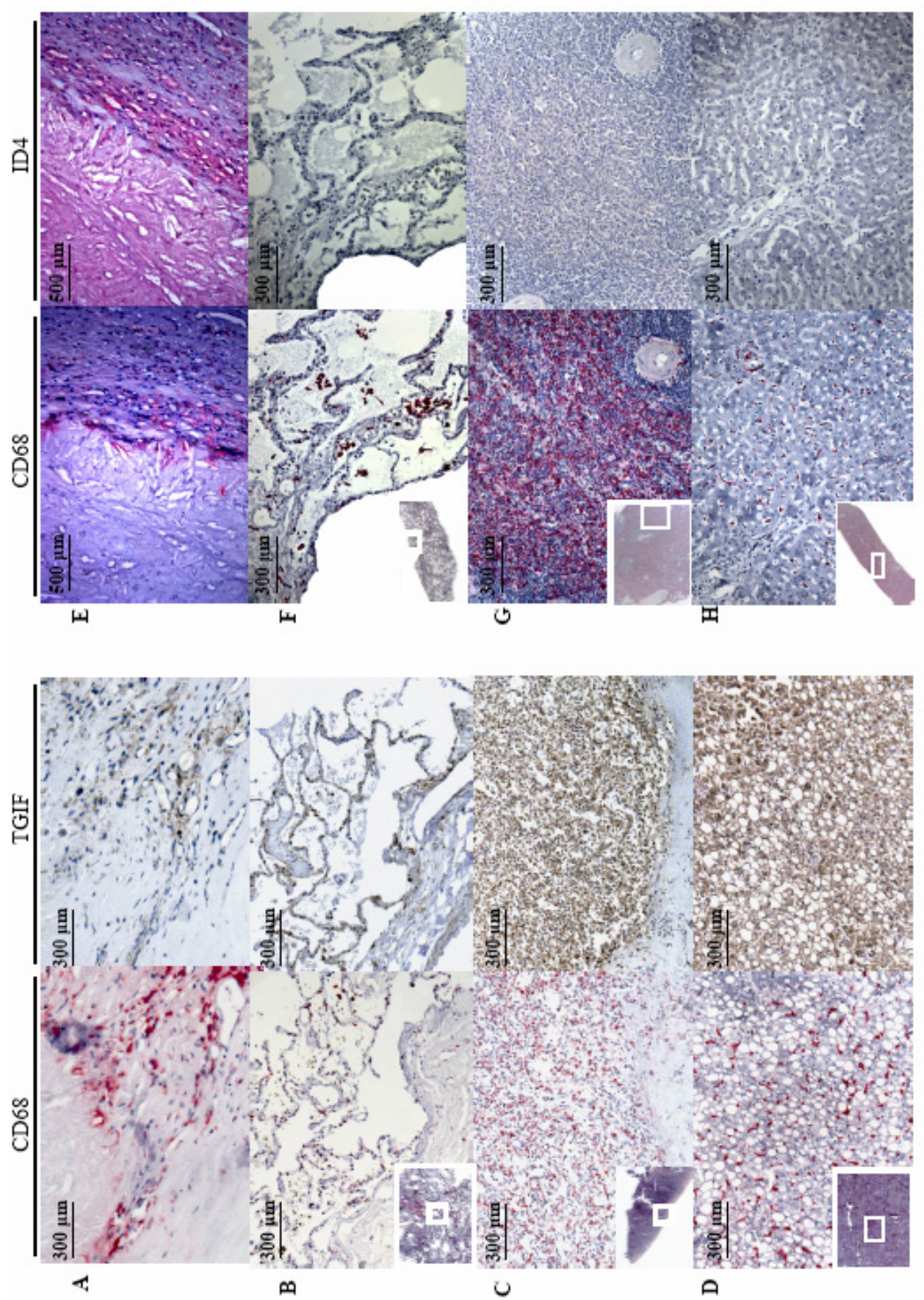


\section{Figure 6.3}

Immunolocalization of ID4 and TGIF in atherosclerotic and non-atherosclerotic tissues. Immunohistochemical detection of CD68 (macrophages, red), TGIF (brown) and ID4 (red), in advanced atherosclerotic lesions (A, E) normal lung $(B, F)$, spleen $(C, G)$, liver $(D, H)$. TGIF is expressed in CD68 positive macrophages from advanced atherosclerotic lesions (A), lung (B), spleen (C) and liver (D). ID4 is expressed in macrophage-derived foam cells in advanced stable atherosclerotic lesions (E), but absent in CD68 positive macrophages of the lung (F), spleen (G) and liver ( $\mathrm{H}$ ).

Table 6.4: Immunohistochemical evaluation of ID4 expression in human macrophages

\section{A. Atherosclerotic lesions}

\begin{tabular}{llll}
\hline Tissue type & Disease & $\mathrm{N}$ & ID4 score \\
\hline Carotid artery & Fibrous cap atheroma & 5 & ++ \\
Carotid artery & Intraplaque bleeding & 5 & ++ \\
\hline
\end{tabular}

\section{B. Non-inflamed tissues}

\begin{tabular}{llll}
\hline Tissue type & Disease & N & ID4 score \\
\hline Liver & None & 4 & - \\
Lung & None & 4 & - \\
Spleen & None & 4 & - \\
\hline
\end{tabular}

\section{Inflamed tissues}

\begin{tabular}{llll}
\hline Tissue type & Disease & $\mathrm{N}$ & ID4 score \\
\hline Tonsil & Inflamed & 2 & - \\
Colon & Crohn's disease & 1 & - \\
Ileum & Crohn's disease & 1 & - \\
Skin & Scar & 2 & - \\
Skin & Epidermal cyst & 3 & - \\
Artery & Arteritis & 2 & - \\
Lung & Sarcoidosis & 2 & - \\
Heart & Myocardial infarction & 4 & - \\
\hline
\end{tabular}

D. Tissues with foam cells

\begin{tabular}{llll}
\hline Tissue type & Disease & N & ID4 score \\
\hline Gall bladder & Cholesterolosis & 2 & ++ \\
Skin & Xanthelasma & 2 & ++ \\
\hline
\end{tabular}

Abbreviations: $\mathrm{N}$, number of samples; -, no staining; + , little staining; ++ , clear staining; +++ , strong staining. 


\section{ID4 expression in foamy macrophages}

To evaluate whether ID4 expression is associated with the in vivo differentiation of macrophages into foam cells, we performed immunohistochemistry on nonatherosclerotic tissues containing foamy macrophages, i.e. a gall bladder mucosa with cholesterolosis $(n=2)$ and skin with xanthelasma $(n=2)$ (Table 6.1C). Immunohistochemistry on serial sections showed co-localization of ID4 and CD68 in non-atherosclerotic foamy macrophages in the mucosa of the gall bladder (Figure 6.4C) and in xanthelasma (Figure 6.4D), with higher levels of ID4 immunoreactivity in atherosclerotic foam cells when compared to nonatherosclerotic foam cells (Table 6.4).

\section{DISCUSSION}

To our knowledge, this is the first study comparing the expression profiles of macrophages isolated by Laser Capture Microdissection (LCM) from two different stages of human atherosclerotic lesions. Two different macrophage isolation methods were used; LCM was used for atherosclerotic tissue and immunomagnetic beads were used for non-atherosclerotic tissues. To exclude that differences in isolation method are responsible for the observed differences in gene expression profiles, we compared the expression levels of 10 macrophage and 12 SMC representative genes. Based on the microarray data, no difference in the expression levels of macrophage and SMC representative genes was observed between both macrophage isolation approaches (data not shown).

Genome wide microarray analysis revealed that the expression levels of $13.3 \%$ of the genes were significantly different between macrophages microdissected from early lesions compared to macrophages isolated from advanced lesions. A majority of these genes have previously been implicated in various biological functions related to the development of atherosclerosis, including cell death, cell cycle, cellular growth and proliferation, cell-cell signaling and cell-cell interaction and haematological and immune system development and function. Although we identified individual differentially expressed genes involved in classic atherosclerosis-related functions, such as lipid metabolism, the networks containing these genes were not ranked in the top of the most prominent differential networks. This finding can be easily explained by the fact that in both lesions stages the majority of the isolated macrophages represent foam cells characterized by the intra-cellular presence of lipids.

In addition to genes involved in the above mentioned biological functions previously linked to atherosclerosis, pathway analysis revealed several significant networks and based on their significance and biological relevance the 


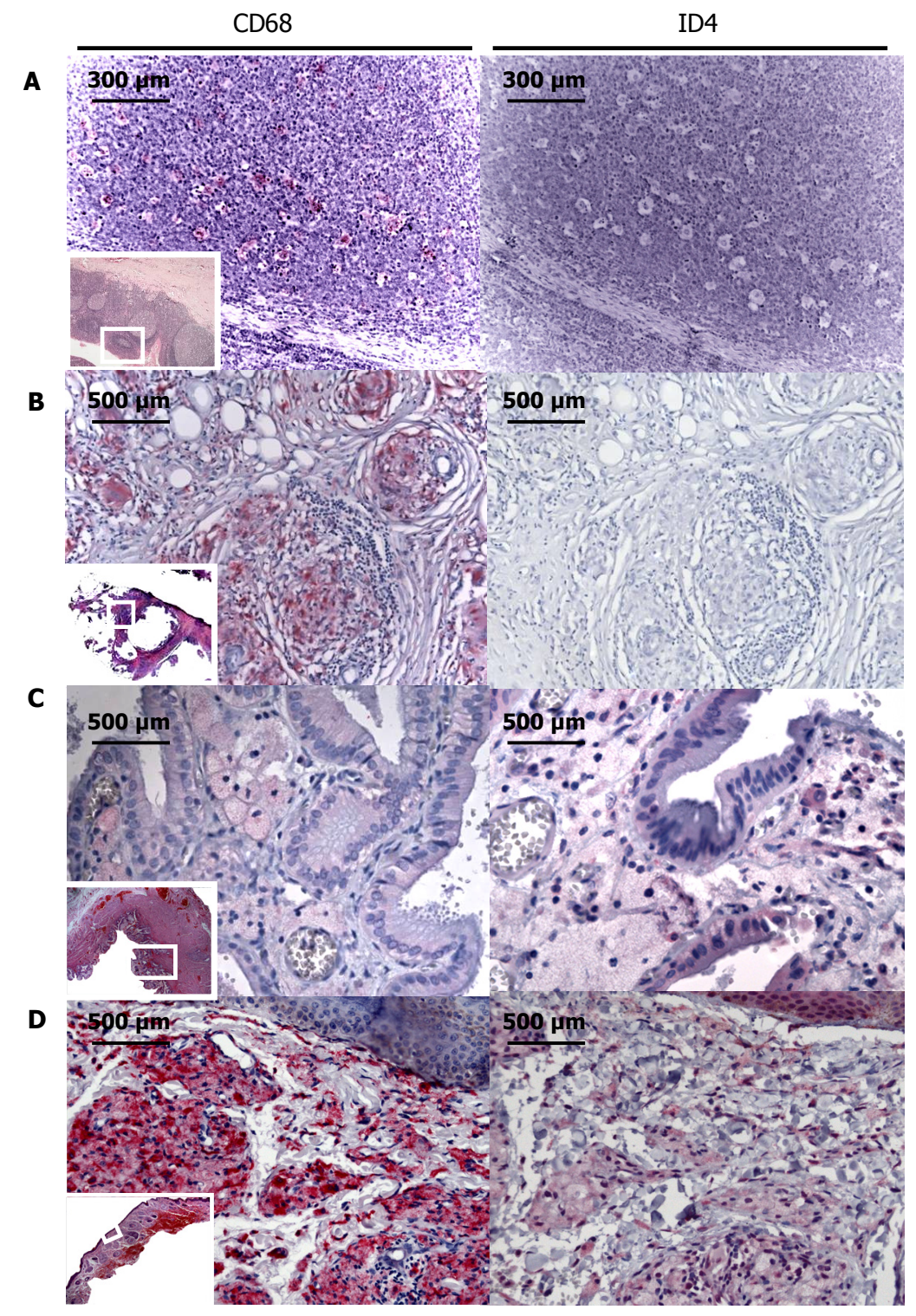

Figure 6.4

Immunolocalization of ID4 in non-atherosclerotic tissues. Immunohistochemical detection of ID4 (red) and CD68 (macrophages, red) protein expression in inflamed tonsil (A), lung with sarcoidosis (B), gall bladder with cholesterolosis (C) and skin with xanthelesma (D). ID4 is expressed in macrophage-derived foam cells in gall bladder with cholesterolosis (C) and skin with xanthelesma (D), but absent in the CD68 positive macrophages of inflamed tonsil (A) and lung with sarcoidosis (B). 
networks including TGIF and ID4 were noteworthy. TGIF, transforming growth factor $\beta$ induced factor, is a member of the three-amino acid loop extension (TALE) superclass of atypical homeodomain containing family of transcriptional factors ${ }^{13}$. TGIF can either bind directly to DNA to repress transcription or acts via interaction with TGF $\beta$ activated Smads, thereby repressing genes normally activated by TGF $\beta{ }^{14,15}$. This is reflected by the finding in this study that the expression of most TGF $\beta$ related genes was downregulated in macrophages from advanced atherosclerotic lesions. The importance of TGF $\beta$ in the maintenance of the balance between inflammation and fibrosis of atherosclerosis is well acknowledged ${ }^{16,17}$. Lutgens et al ${ }^{18}$ showed that inhibition of TGF $\beta$ signaling resulted in a shift towards a lesion with features of lesion vulnarability, including more inflammation, low fibrosis, larger lipid cores and an increase in intraplaque hemorrhages in atherosclerotic-susceptible mice (apoE mice), suggesting an important role for TGF $\beta$ signaling atherogenesis. In addition, Robertson et al ${ }^{19}$ demonstrated that disruption of the TGF $\beta$ signaling in T cells from apoE deficient mice increases atherosclerosis. Our observation of TGIF overexpression in atherosclerotic versus non-atherosclerotic macrophages derived from lung, liver and spleen is consistent with a study from Patino et al ${ }^{8}$ which demonstrated TGIF overexpression in macrophages derived from atherosclerotic lesions when compared to macrophages derived from lung tissue. Our results show that overexpression of TGIF results in suppression of TGF $\beta$ signaling. Based on these findings it is tempting to suggest that TGIF overexpression may be an underlying cause of decreased TGF $\beta$ function in atherosclerotic macrophages leading to progression of lesion development.

Recently it was also shown that TGIF interacts with the ligand binding domain of the retinoic acid receptor RXRa, resulting in the suppression of transcription from retinoid response elements ${ }^{20}$. TGIF knockout mice were much more sensitive to retinoic acid induced teratogenesis and retinoid target genes were expressed at a much higher level. The relevance of these findings were put into perspective by a recent report of Lalloyer et $a{ }^{21}$, which demonstrated that the RXR agonist bexarotene improves cholesterol homeostasis and inhibits progression of atherosclerosis in a mouse model of mixed dyslipidemia which develops macrophage-rich lesions. In the macrophage a marked enhanced efflux capacity of the extracellular lipids was observed. It would be of great interest to explore whether this is related to TGIF function.

The ID4 protein belongs to a family of transcription factors containing a helixloop-helix (HLH) domain, which mediates interaction with other proteins that are implicated in the control of differentiation and cell cycle progression. ID4 exerts its action via dominant negative regulation of other bHLH transcription factors, controlling cell type specific gene expression and the expression of cell cycle regulatory genes ${ }^{22,}{ }^{23}$ and thus acts as a tumour suppressor. Members of 
the ID protein family have been implicated in tumour progression and the formation of microvessels supporting the growth of the tumour ${ }^{24-26}$.

Its precise role in atherosclerotic lesion progression remains obscure. Our in vivo data showed increased ID4 mRNA and/or protein expression in macrophages/foam cells in atherosclerotic lesions, gall bladder mucosa with cholesterolosis and skin with xanthelasma. In contrast, macrophages derived from inflamed and non-inflamed tissues did not show any ID4 expression. This might suggest a possible role for ID4 in the involvement of foam cell formation. However, previous expression profiling of cholesterol loaded macrophages did not report any differential expression of ID4 after oxidized and/or acetylated LDL loading ${ }^{5,7}$.

In the present study, we show strong ID4 immunoreactivity in a subset of macrophages located at the rim of the lipid core, which are suggested to be prone to apoptosis ${ }^{27}$. Several studies showed the ability of ID4 to induce apoptosis both in vitro ${ }^{28}$ and in vivo ${ }^{29}$.

As reported by Tabas et al, the effect of macrophage death on lesion progression is dependent on the lesion stage ${ }^{30}$ and relies on the ability of phagocytes in different stages of atherosclerosis to efficiently clear dead macrophages. In early lesions, where phagocytic clearance appears to be efficient, macrophage apoptosis is associated with diminished lesion cellularity and a decrease in lesion progression. In advanced lesions phagocytic clearance of apoptotic macrophages appears to be defective ${ }^{31}$. The overall effect of this defect is the generation of a necrotic core, promotion of further inflammation, lesion instability and thrombosis. Thus, in advanced lesions, where phagocytic clearance of apoptotic cells is defective or impaired, macrophage apoptosis is considered to be detrimental for lesion progression and vulnerability. It is tempting to hypothesize that the localization of ID4 in macrophages surrounding the core indicates a link between ID4 and apoptosis in lesional macrophages.

The strong ID4 immunoreactivity in the ECs of the microvessels within the lesion and the adventitia is remarkable. ID family members have been implicated in the formation of microvessels. Besides a possible effect on apoptosis, ID4 might therefore also play a role in microvessel formation in atherosclerosis

In conclusion, we demonstrated disease stage related differences in the transcriptome of atherosclerotic macrophages. After extensive pathway analysis, two transcription factors, TGIF, which is involved in TGF $\beta$ signaling and ID4, which is involved in cell proliferation, differentiation and apoptosis, were selected for further analysis. Besides being differentially regulated during disease progression, both genes were also expressed at significantly higher levels in atherosclerotic macrophages when compared to non-atherosclerotic macrophages. Although, the role of both TGIF and ID4 during atherogenesis 
Chapter 6

remains to be defined and although it is unknown whether both genes are only markers, or also causally related to atherogenesis, it is tempting to speculate that both TGIF (fibrosis and inflammation) and ID4 (apoptosis and neovascularization) may be upstream factors of multiple atherogenic pathways and thus form an attractive molecular target to modulate the progression of atherosclerosis. 


\section{REFERENCES}

1. Ross R. Atherosclerosis--an inflammatory disease. N Eng/ J Med. Jan 14 1999;340(2):115126.

2. Lusis AJ. Atherosclerosis. Nature. Sep 14 2000;407(6801):233-241.

3. Libby P. Inflammation in atherosclerosis. Nature. Dec 19-26 2002;420(6917):868-874.

4. Hansson GK, Libby P. The immune response in atherosclerosis: a double-edged sword. Nat Rev Immunol. Jul 2006;6(7):508-519.

5. Shiffman D, Mikita T, Tai JT, et al. Large scale gene expression analysis of cholesterolloaded macrophages. J Biol Chem. Dec 1 2000;275(48):37324-37332.

6. Tuomisto $T$, Riekkinen MS, Viita $\mathrm{H}$, et al. Analysis of gene and protein expression during monocyte-macrophage differentiation and cholesterol loading--cDNA and protein array study. Atherosclerosis. Jun 2005;180(2):283-291.

7. Hung YC, Hong MY, Huang GS. Cholesterol loading augments oxidative stress in macrophages. FEBS Lett. Feb 6 2006;580(3):849-861.

8. Patino WD, Kang JG, Matoba $S$, et al. Atherosclerotic plaque macrophage transcriptional regulators are expressed in blood and modulated by tristetraprolin. Circ Res. May 26 2006;98(10):1282-1289.

9. Patino WD, Mian OY, Kang JG, et al. Circulating transcriptome reveals markers of atherosclerosis. Proc Natl Acad Sci U S A. Mar 1 2005;102(9):3423-3428.

10. Tuomisto $T$, Korkeela A, Rutanen J, et al. Gene expression in macrophage-rich inflammatory cell infiltrates in human atherosclerotic lesions as studied by laser microdissection and DNA array: overexpression of HMG-COA reductase, colony stimulating factor receptors, CD11A/CD18 integrins, and interleukin receptors. Arterioscler Thromb Vasc Biol. Dec 2003;23(12):2235-2240.

11. Trogan E, Choudhury RP, Dansky HM, et al. Laser capture microdissection analysis of gene expression in macrophages from atherosclerotic lesions of apolipoprotein E-deficient mice. Proc Natl Acad Sci U S A. Feb 19 2002;99(4):2234-2239.

12. Virmani R, Kolodgie FD, Burke AP, et al. Lessons from sudden coronary death: a comprehensive morphological classification scheme for atherosclerotic lesions. Arterioscler Thromb Vasc Biol. May 2000;20(5):1262-1275.

13. Gehring WJ, Qian YQ, Billeter M, et al. Homeodomain-DNA recognition. Cell. Jul 29 1994;78(2):211-223.

14. Wotton D, Lo RS, Lee S, et al. A Smad transcriptional corepressor. Cell. Apr 2 1999;97(1):29-39.

15. Melhuish TA, Wotton D. The interaction of the carboxyl terminus-binding protein with the Smad corepressor TGIF is disrupted by a holoprosencephaly mutation in TGIF. $J$ Biol Chem. Dec 15 2000;275(50):39762-39766.

16. Mallat Z, Gojova A, Marchiol-Fournigault C, et al. Inhibition of transforming growth factorbeta signaling accelerates atherosclerosis and induces an unstable plaque phenotype in mice. Circ Res. Nov 9 2001;89(10):930-934. 


\section{Chapter 6}

17. Mallat $Z$, Tedgui A. The role of transforming growth factor beta in atherosclerosis: novel insights and future perspectives. Curr Opin Lipidol. Oct 2002;13(5):523-529.

18. Lutgens $\mathrm{E}$, Gijbels M, Smook M, et al. Transforming growth factor-beta mediates balance between inflammation and fibrosis during plaque progression. Arterioscler Thromb Vasc Biol. Jun 1 2002;22(6):975-982.

19. Robertson AK, Rudling $M$, Zhou $X$, et al. Disruption of TGF-beta signaling in $T$ cells accelerates atherosclerosis. J Clin Invest. Nov 2003;112(9):1342-1350.

20. Bartholin L, Powers SE, Melhuish TA, et al. TGIF inhibits retinoid signaling. Mol Cell Biol. Feb 2006;26(3):990-1001.

21. Lalloyer F, Fievet C, Lestavel S, et al. The RXR agonist bexarotene improves cholesterol homeostasis and inhibits atherosclerosis progression in a mouse model of mixed dyslipidemia. Arterioscler Thromb Vasc Biol. Dec 2006;26(12):2731-2737.

22. Lassar AB, Skapek SX, Novitch B. Regulatory mechanisms that coordinate skeletal muscle differentiation and cell cycle withdrawal. Curr Opin Cell Biol. Dec 1994;6(6):788-794.

23. Benezra R, Rafii S, Lyden D. The Id proteins and angiogenesis. Oncogene. Dec 20 2001;20(58):8334-8341.

24. Riechmann V, van Cruchten I, Sablitzky F. The expression pattern of Id4, a novel dominant negative helix-loop-helix protein, is distinct from Id1, Id2 and Id3. Nucleic Acids Res. Mar 11 1994;22(5):749-755.

25. Benezra $R$, Davis $R L$, Lockshon $D$, et al. The protein Id: a negative regulator of helix-loophelix DNA binding proteins. Cell. Apr 6 1990;61(1):49-59.

26. Norton JD, Deed RW, Craggs G, et al. Id helix-loop-helix proteins in cell growth and differentiation. Trends Cell Biol. Feb 1998;8(2):58-65.

27. Kolodgie FD, Gold HK, Burke AP, et al. Intraplaque hemorrhage and progression of coronary atheroma. N Engl J Med. Dec 11 2003;349(24):2316-2325.

28. Andres-Barquin PJ, Hernandez MC, Israel MA. Id4 expression induces apoptosis in astrocytic cultures and is down-regulated by activation of the cAMP-dependent signal transduction pathway. Exp Cell Res. Mar 15 1999;247(2):347-355.

29. Bedford $L$, Walker R, Kondo $T$, et al. Id4 is required for the correct timing of neural differentiation. Dev Biol. Apr 15 2005;280(2):386-395.

30. Tabas I. Consequences and therapeutic implications of macrophage apoptosis in atherosclerosis: the importance of lesion stage and phagocytic efficiency. Arterioscler Thromb Vasc Biol. Nov 2005;25(11):2255-2264.

31. Schrijvers DM, De Meyer GR, Kockx MM, et al. Phagocytosis of apoptotic cells by macrophages is impaired in atherosclerosis. Arterioscler Thromb VasC Biol. Jun 2005;25(6):1256-1261. 




\section{Chapter 7}

\section{TWIST1: A marker of macrophage foam cells}

Wanwisa van Dijk-Jamnongluk, Wouter J. Eijgelaar, Natasja Kisters, Joost O. Fledderus, Oscar L. Volger, Erwin P. Wijnands, Kitty B. Cleutjens, Johan Kuiper, Theo J. van Berkel, Anton J. Horrevoets, Hans Pannekoek, Mat J. Daemen, Ann P. Bijnens

Submitted 


\section{ABSTRACT}

Lipid-laden macrophage-derived foam cells are an early component of atherosclerotic lesions and play a key role in disease progression. Therefore, macrophage-derived foam cells may have a unique, atherosclerotic lesionspecific transcriptional profile. To this end, we compared the transcriptome of human macrophages isolated from atherosclerotic lesions and three nonatherosclerotic tissues using microarrays. We identified 42 genes showing significantly higher expression in atherosclerotic macrophages. Validation focused on TWIST1, a transcription factor involved in inflammation, but not linked to atherosclerosis before.

Microarray and quantitative PCR revealed 13.2 and 3.7 fold higher TWIST1 transcript levels in atherosclerotic macrophages. Immunohistochemistry showed nuclear and cytoplasmatic TWIST1 staining in atherosclerotic lesions. None of the macrophages in 11 non-atherosclerotic tissues showed positive TWIST1 signal. In contrast, macrophage foam cells in gall bladder and xanthelasma showed positive staining. In vitro foam cell formation of THP-1 macrophages increased TWIST1 expression up to 4.3 fold. TWIST1 was not expressed in blood monocytes. LPS stimulation increased TWIST1 transcript levels 9.5 fold and incubation with IFN $\alpha$ led to an increase in TWIST levels 2 fold in THP-1 macrophage foam cells. These findings reveal that TWIST1 is specifically expressed in foamy macrophages and in macrophages stimulated with LPS. 


\section{INTRODUCTION}

Phenotypic and functional diversity between macrophage populations reflects the plasticity of these cells in response to microenvironmental signals. Cytokine milieu and interactions with extracellular matrix and neighboring cells affect the transcriptional activity and intracellular signaling of macrophages, which drive them to differentiation and functional specialization ${ }^{1}$.

Macrophages play a pivotal role in atherosclerosis, both as lipid scavengers and as mediators of inflammation ${ }^{2}$. Atherosclerotic lesion macrophages originate from circulating monocytes and are recruited into the arterial wall after activation of ECs and secretion of chemokines. These stimuli lead to monocyte adhesion and subsequent migration through the endothelial layer. In the arterial wall monocytes differentiate into macrophages and scavenge modified $\mathrm{LDL}$, resulting in foam cell formation.

Recent studies in vivo have indicated that macrophages have distinct gene signatures in different murine models of infectious diseases ${ }^{3}$ and cancer ${ }^{3,4}$. The comparison of the transcriptomes of these macrophage populations provided valuable information to define the molecular basis for differences in macrophage phenotype and function. Based on this evidence, we hypothesize that macrophages in atherosclerotic lesions express a set of macrophage atherosclerosis-specific genes, which characterize the atherosclerotic macrophage phenotype and represent key molecules regulating the atherosclerotic process.

In this study, we aim to identify key regulators of macrophage differentiation during atherogenesis. To this end, we compared the transcriptional profile of human macrophages microdissected from atherosclerotic lesions with that of isolated Kupffer cells, alveolar macrophages and splenic macrophages. To exclude the effect of confounders such as medication and age, the expression profiles of macrophages were compared within the same patient.

We identified in an in vivo setting 42 genes, including the transcription factor TWIST1, which were differentially upregulated in lesion residing macrophages. The atherosclerosis specificity of TWIST1 was validated on a larger series of human artery samples with different stages of atherosclerosis and twelve different macrophage-rich non-atherosclerotic tissues using Q-PCR and immunohistochemistry. In vitro experiments indicated that TWIST1 expression is induced in THP-1 macrophages after incubation with oxLDL and LPS. 


\section{MATERIALS AND METHODS}

\section{Tissue samples}

Atherosclerotic (carotid arteries) and non-atherosclerotic (lung, liver and spleen) tissues were obtained at autopsies within 24 hours after decease. Collection, storage in the Maastricht Pathology Tissue Collection (MPTC) and use of tissue and patient data were performed in agreement with the "Code for Proper Secondary Use of Human Tissue in the Netherlands" (http://www.fmwv.nl). The same patients and tissues were used as in Chapter 6 of this thesis, with some additional samples being used for the isolation of the macrophages and immunohistochemical analysis of carotid arteries. Detailed tissue and patient characteristics of these additional samples are listed in Tables 7.1A and B.

None of the patients had any clinical symptoms of systemic inflammation or malignancies. Immediately after resection, 4 parallel tissue samples were collected for histological analysis, RNA quality assessment, and macrophage isolation. Tissue parts destined for histological analysis were embedded in paraffin, while parts for RNA quality assessment were immediately frozen in liquid nitrogen and stored at $-80^{\circ} \mathrm{C}$.

\section{Isolation of macrophages from human tissues}

Atherosclerotic lesion macrophages and the non-atherosclerotic macrophages were isolated as being described in Chapter 6 of this thesis.

\section{RNA isolation and amplification}

To evaluate RNA quality of the tissue before macrophage isolation, total RNA of whole mount tissue was isolated using a combination of TRIZol reagent (Invitrogen, Grand Island, NY, USA) and RNeasy mini kit (Qiagen, Hilden, Germany). RNA integrity of whole mount tissues was evaluated using Agilent's 2100 Bioanalyzer System and RNA 6000 Nano LabChip Kit (Agilent Technologies, Palo Alto, CA, USA). Patients were only included for microarray analysis if the RNA integrity value of each tissue was higher than $6(n=2)$.

Total RNA was isolated from isolated tissue macrophages using the Absolutely RNA microprep kit (Stratagene, La Jolla, CA, USA) according to the manufacturer's protocol. DNA was removed by using $50 \mathrm{U}$ DNase (Qiagen, Valencia, CA, USA). RNA concentration was determined using a NanoDrop-1000 
Table 7.1: Donor characteristics of additional samples

A. Donors of samples for isolation of macrophages

\begin{tabular}{ccccc}
\hline Patient Code & $\begin{array}{c}\text { Age } \\
\text { (years) }\end{array}$ & Gender & Tissue & Used for \\
\hline Q-1 & 29 & M & Blood & Q-PCR \\
Q-2 & 33 & M & Blood & Q-PCR \\
Q-3 & 28 & F & Blood & Q-PCR \\
Q-4 & 25 & M & Blood & Q-PCR \\
Q-5 & 31 & F & Blood & Q-PCR \\
\hline
\end{tabular}

B. Donors of carotid artery samples for immunohistochemical analysis

\begin{tabular}{ccccc}
\hline Patient Code & Age & Gender & \multicolumn{2}{c}{ Stage of atherosclerosis carotid artery sample } \\
\cline { 3 - 4 } & (years) & & IT & IPH \\
\hline IA-1 & 80 & F & $\bullet$ & $\bullet$ \\
IA-2 & 78 & M & & $\bullet$ \\
IA-3 & 63 & F & & $\bullet$ \\
IA-4 & 78 & M & & $\bullet$ \\
IA-5 & 66 & M & & $\bullet$ \\
\hline
\end{tabular}

Abbreviations: $M$, male; F, female; Q-PCR, quantitative PCR; IT, intimal thickening; IPH, intra plaque haemorrhage.

Spectrophotometer (NanoDrop Wilmington, DE, USA). Total RNA of approximately 2000 atherosclerotic macrophages and $30 \mathrm{ng}$ of nonatherosclerotic macrophages RNA was amplified two rounds using the RiboAmp RNA Amplification Kit (Arcturus, Mountain View, CA, USA).

Total RNA was isolated from blood monocytes and PMA-induced THP-1 macrophages using the RNeasy mini kit (Qiagen, Hilden, Germany) according to the manufacturer's instructions.

\section{Microarray hybridization and analysis}

Microarray hybridization was performed as described in Chapter 2 of this thesis. For microarray analysis, genes differentially expressed in lesion residing macrophages compared to Kupffer cells, alveolar and splenic macrophages were identified through intra patient comparisons assessing significantly upregulated $(P<0.01$, Rosetta ratio-error model for gene expression analysis) in lesion macrophages compared to macrophages from each tissue separately ${ }^{5}$. The analysis was performed using Rosetta Biosoftware (Seattle, WA, USA). 
Subsequently the genes that were identified by all 3 intra patient tissuecomparisons as consistently overexpressed in atherosclerotic macrophages were selected. These 2 steps were performed on the data sets of both patients.

The third step the overlapping genes that were selected in both patients were annotated as genes significantly upregulated in atherosclerotic lesion residing macrophages. In Figure 7.1 a schematic representation of the microarray analysis is given.

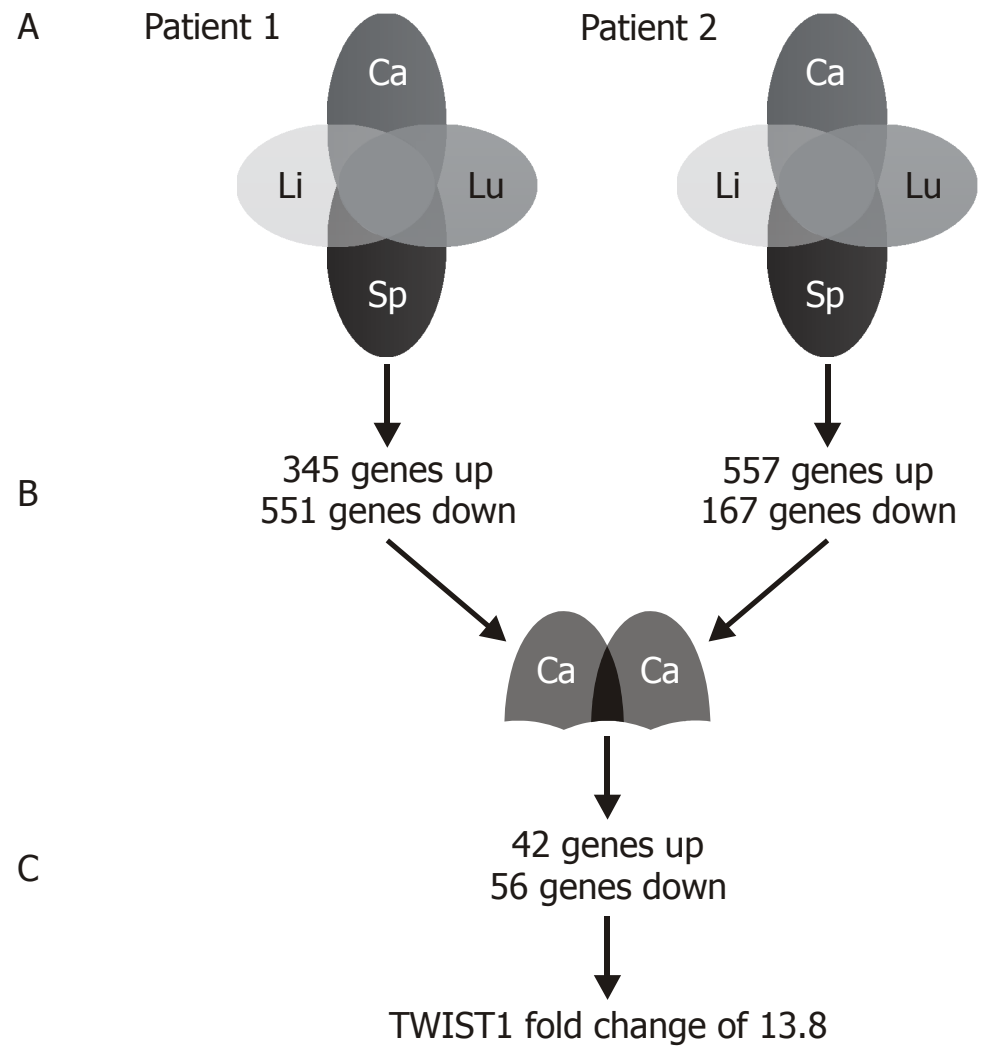

\section{Figure 7.1}

A schematic representation of the microarray analysis. First genes differentially expressed in lesion residing macrophages compared to Kupffer cells, alveolar and splenic macrophages were identified through intra patient comparisons assessing significantly upregulated $(P<0.01$, Rosetta ratio-error model for gene expression analysis) in lesion macrophages compared to macrophages from each tissue separately (A). Secondly, the genes that were identified by all 3 intra patient tissue-comparisons as consistently overexpressed in atherosclerotic macrophages were selected (B). These 2 steps were performed on the data sets of both patients. Subsequently, in the third step the overlapping genes that were selected in both patients were annotated as genes significantly upregulated in atherosclerotic lesion residing macrophages (C). 


\section{Quantitative real-time PCR (Q-PCR)}

Quantitative real-time polymerase chain reaction (Q-PCR) was performed after two rounds of amplification of RNA from macrophages isolated from carotid, liver, lung and spleen, from blood monocytes (see Chapter 6 of this thesis and Table 7.1A), or on $40 \mathrm{ng}$ CDNA from cells cultured in vitro. CDNA was synthesized using $1 \mu \mathrm{g}$ of total RNA, random primers (Promega, Madison, WI, USA) and M-MLV reverse transcriptase (Promega, Madison, WI, USA).

Q-PCR was performed using iQ SYBR ${ }^{\circledR}$ Green Supermix (BioRad, Hercules, CA, USA), a BioRad iCycler iQ PCR (BioRad) and the following primers: TWIST1 forward 5'-CATTCTCAAGAGGTCGTGC-3' and TWIST1 reverse $5^{\prime}$ CAGGCCAGTTTGATCCC-3' and cyclophilin A forward 5'CTCGAATAAGTITGACTTGTGTTT-3' and cyclophilin A reverse $5^{\prime}$ CTAGGCATGGGAGGGAACA-3'. All Q-PCR measurements were performed in duplicate. Relative mRNA expression values were calculated using a standard curve and normalized to housekeeping gene (cyclophylin A) mRNA expression. Data are expressed as means \pm SEM.

\section{Immunohistochemistry}

Five- $\mu \mathrm{m}$ sections of routine formalin-fixed and paraffin-embedded atherosclerotic carotid arteries $(n=17$ patients, see Chapter 6 of this thesis and Table 7.1B) and 12 different macrophage-rich non-atherosclerotic tissues $(n=26$ patients) were analyzed. Before staining, tissues were pretreated by boiling in antigen retrieval buffer (DAKO, Glostrup, Denmark) for 10 minutes in a microwave and incubated with $5 \%$ normal swine serum for 30 minutes to block nonspecific antigens. The sections were then incubated overnight at $4^{\circ} \mathrm{C}$ with polyclonal TWIST1 (1:50, Santa Cruz Biotechnology, Santa Cruz, CA) antibodies. Secondary antibodies were biotinylated goat anti-rabbit antibody (1:200, DAKO, Glostrup, Denmark) and biotinylated rabbit anti-goat antibody (1:500, DAKO, Glostrup, Denmark). Prostate cancer samples were used as positive control for TWIST1. Sections incubated without the primary antibody were used as negative control. The identification of macrophages was performed using CD68 antibody (1:100, DAKO Glostrup, Denmark).

To determine the co-localization, immunohistochemical stainings were performed on serial sections or double staining was performed. The presence of immunoreactivity was semi-quantitatively assessed by two observers (WvDJ and APB) as follows: - = no staining; $+=$ low intensity and/or few cells; $++=$ moderate intensity and/or moderate amount of cells; $+++=$ high intensity and/or many cells. 


\section{Isolation of blood monocytes for Q-PCR}

Peripheral blood monocytes (PBMC) were isolated from healthy volunteers, using Ficoll-hypaque density gradient centrifugation and Monocyte enrichment kit II (Miltenyi Biotec, Utrecht, The Netherlands) according to manufacturer's instructions. In brief, $8 \mathrm{ml}$ peripheral blood was collected in BD Vacutainer CPT tubes (BD, Franklin lakes, USA) spun at $1650 \mathrm{xg}$ for 20 minutes at $18^{\circ} \mathrm{C}$, after which plasma was discarded. PBMC were washed twice in $10 \mathrm{ml}$ ice-cold PBE (CMF-PBS, pH 7.2, 0.5\% BSA, 2mM EDTA) buffer at $150 \mathrm{xg}$ for 10 minutes without brake at $4{ }^{\circ} \mathrm{C}$, to remove platelets and remaining plasma. Cells were incubated with FcR blocking reagent and Biotin-antibody cocktail for 10 minutes at $4^{\circ} \mathrm{C}$, followed by 15 minutes of incubation with Anti-biotin microbeads at $4^{\circ} \mathrm{C}$ and subsequent magnetic separation. RNA was isolated using the RNeasy mini kit (Qiagen, Hilden, Germany) according to manufacturer's instructions.

\section{THP1 cell culture and stimulation}

Human THP-1 cells were obtained from the American Type Culture Collection (ATCC 10801, Manassas, VA). Cells were grown in RPMI 1640 medium (GibcoInvitrogen, Grand Island, NY, USA) containing $10 \%$ FetalClone ${ }^{\circledR}$ III (Hyclone, Pe-bio, Hogan, UT, USA) (v/v), 1\% GlutaMAX ${ }^{\mathrm{TM}}$ I (w/v) (Gibco-Invitrogen, Grand Island, NY, USA), $125 \mathrm{mM}$ Hepes, penicillin (100 units $/ \mathrm{ml}$ ), and streptomycin $(100 \mu \mathrm{g} / \mathrm{ml})$ (Gibco-Invitrogen, Grand Island, NY, USA) at $37^{\circ} \mathrm{C}$ in a humidified incubator with a $5 \% \mathrm{CO}_{2}$ atmosphere. To differentiate THP-1 cells into macrophages, cells were seeded at a density of $1 \times 10^{6}$ cells $/ \mathrm{ml}$ and incubated for 72 hours with $0.2 \mu \mathrm{M}$ phorbol 12-myristate 13-acetate (PMA, Sigma, Saint Louis, MO, USA).

Differentiated human THP-1 cells were exposed to LPS $(10 \mathrm{ng} / \mathrm{ml}$ SIGMAAldrich) or IFNy (1000 U/ml, R\&D) for 1,4 or 24 hours and with IFN $\alpha$ (3000 $\mathrm{U} / \mathrm{ml}$, Universal type I interferon, PBL biomedical Laboratories) for 24 or 48 hours. Foam cell formation was induced by incubation with oxLDL $(50 \mu \mathrm{g} / \mathrm{ml})$ (Intracel resource, Frederick, MD, USA) for 24,48 or 72 hours.

\section{Statistical analysis}

Statistical significance was calculated with the Mann-Whitney $U$ test or Wilcoxon signed rank test for paired samples, using Sigma Stat version 12.0.1 (SPSS, Chicago, IL, USA). For each experimental setup, results were confirmed in at least 2 independent experiments. Statistical probability of $P<0.05$ was considered significant. 


\section{RESULTS}

\section{Identification of a transcript fingerprint of atherosclerotic macrophages}

For 42 out of the 18,658 genes represented on the microarrays, the expression level was significantly higher $(P<0.01)$ in atherosclerotic compared to nonatherosclerotic macrophages of both donors (Table 7.2). Gene ontology analysis revealed that $29 \%$ of these 42 genes are involved in metabolism (12/42) and $19 \%$ in signal transduction (8/42). Five of the genes are transcription regulators: inhibitor of DNA binding 4 (ID4), Twist homolog 1 (TWIST1), vasculin, TGF $\beta$-induced factor (TGIF) and Fos-like antigen 2 (FOSL2) having 60, $13,4.9,3.9$ and 3.4-fold higher transcript levels in atherosclerotic than in nonatherosclerotic macrophages, respectively.

No difference was observed in the expression levels of macrophage and SMC representative genes between LCM and immunomagnetic beads isolated macrophages, indicating that differences in the macrophage isolation procedure did not introduce a bias in the expression profile (Figure 7.2).

\section{TWIST1 is expressed in atherosclerotic macrophages but not in liver, lung or spleen}

Among the 42 upregulated genes in atherosclerotic macrophages compared to non atherosclerotic macrophages, the transcription factor TWIST1 stood out as an attractive candidate for validation. TWIST1 was not linked to atherosclerosis yet, but was known to be involved in several processes underlying atherogenesis such as inflammation ${ }^{6}$ and apoptosis ${ }^{7}$ and was the second most upregulated transcription factor. ID4, described in Chapter 6 of this thesis, showed the highest differential expression. The average TWIST1 mRNA levels were 7.0-fold higher in atherosclerotic compared to non-atherosclerotic macrophages, $(p<0.05$; Figure 7.3). Significantly lower TWIST1 transcript levels were also seen in blood monocytes compared to lesional macrophages.

Strong TWIST1 immunoreactivity was present in CD68 positive macrophages in atherosclerotic lesions (Figure 7.4A), in some medial and neo-intimal vascular SMCs and in fibroblasts. In addition, we observed TWIST1 in ECs lining the lumen, in the microvessels in the lesion and in the adventitial layer. Both nuclear and cytoplasmatic localization of TWIST1 immunoreactivity was observed.

In agreement with the microarray and Q-PCR data, no TWIST1 immunoreactivity was found in CD68 positive macrophages in lung, liver and spleen (Figure 7.4B-D; Table 7.3). 
Chapter 7

Table 7.2: Genes higher expressed in atherosclerotic macrophages compared to non-atherosclerotic macrophages

\begin{tabular}{|c|c|c|c|c|}
\hline Gene & $\begin{array}{l}\text { Accession } \\
\text { No. }\end{array}$ & $\begin{array}{c}\text { Fold } \\
\text { change }\end{array}$ & Sequence description & Function \\
\hline ID4 & NM_001546 & 60 & Inhibitor of DNA binding 4 & $\begin{array}{l}\text { Transcription } \\
\text { regulator }\end{array}$ \\
\hline ADAM8 & NM_001109 & 34 & A disintegrin and metalloproteinase domain 8 & Peptidase \\
\hline DDEF2 & NM_003887 & 15 & $\begin{array}{l}\text { Development and differentiation enhancing } \\
\text { factor } 2\end{array}$ & \multirow{3}{*}{$\begin{array}{l}\text { Regulation of } \\
\text { GTPase activity } \\
\text { Enzyme } \\
\text { Nucleotide } \\
\text { binding }\end{array}$} \\
\hline RASD1 & NM_016084 & 14 & RAS, dexamethasone-induced 1 & \\
\hline TNRC6C & NM_018996 & 14 & Trinucleotide repeat containing $6 \mathrm{C}$ & \\
\hline TWIST1 & Y11177 & 13 & Twist homolog 1 & $\begin{array}{l}\text { Transcription } \\
\text { regulator }\end{array}$ \\
\hline CHD1 & NM_001270 & 13 & $\begin{array}{l}\text { Chromodomain helicase DNA binding protein } \\
1\end{array}$ & Enzyme \\
\hline GRB10 & NM_005311 & 12 & Growth factor receptor-bound protein 10 & $\begin{array}{l}\text { Signal } \\
\text { transduction }\end{array}$ \\
\hline $\begin{array}{l}\text { ZNF331 } \\
\text { HDC }\end{array}$ & $\begin{array}{l}\text { NM_018555 } \\
\text { NM_002112 }\end{array}$ & $\begin{array}{l}11 \\
11\end{array}$ & $\begin{array}{l}\text { Zinc finger protein } 331 \\
\text { Histidine decarboxylase }\end{array}$ & $\begin{array}{l}\text { DNA binding } \\
\text { Enzyme }\end{array}$ \\
\hline $\begin{array}{l}\text { CDNA } \\
\text { FLJ10696 }\end{array}$ & AK001558 & 11 & CDNA FL10696 fis, clone NT2RP3000484 & Unknown \\
\hline MAP1B & NM_005909 & 10 & Microtubule-associated protein 1B & $\begin{array}{l}\text { Structural } \\
\text { molecule }\end{array}$ \\
\hline $\begin{array}{l}\text { ARL7 } \\
\text { DOC1 } \\
\text { ASPH }\end{array}$ & $\begin{array}{l}\text { NM_005737 } \\
\text { NM_014890 } \\
\text { NM_004318 }\end{array}$ & $\begin{array}{l}9.2 \\
8.8 \\
7.4\end{array}$ & $\begin{array}{l}\text { ADP-ribosylation factor-like } 7 \\
\text { downregulated in ovarian cancer } 1 \\
\text { Aspartate beta-hydroxylase }\end{array}$ & $\begin{array}{l}\text { Enzyme } \\
\text { Unknown } \\
\text { Enzyme }\end{array}$ \\
\hline $\begin{array}{l}\text { LOC3398 } \\
03\end{array}$ & AK023856 & 6.6 & Hypothetical protein LOC339803 & Unknown \\
\hline SFRP2 & AF311912 & 5.8 & Secreted frizzled-related protein 2 & $\begin{array}{l}\text { Receptor } \\
\text { signaling }\end{array}$ \\
\hline LRRC17 & NM_005824 & 5.5 & Leucine rich repeat containing 17 & Unknown \\
\hline $\begin{array}{l}\text { LOC1585 } \\
63\end{array}$ & AK025562 & 5.2 & Hypothetical protein LOC158563 & $\begin{array}{l}\text { Cell growth and } \\
\text { maintenance }\end{array}$ \\
\hline CENTD3 & AK001579 & 5.2 & Centaurin, delta 3 & $\begin{array}{l}\text { Signal } \\
\text { transduction }\end{array}$ \\
\hline FLJ22655 & AK026308 & 5.0 & Hypothetical protein FL 22655 & $\begin{array}{l}\text { Signal } \\
\text { transduction }\end{array}$ \\
\hline $\begin{array}{l}\text { DKFZp76 } \\
1 \text { C169 }\end{array}$ & AL161991 & 4.9 & Vasculin & $\begin{array}{l}\text { Transcription } \\
\text { regulator }\end{array}$ \\
\hline $\begin{array}{l}\text { FCGBP } \\
\text { MCOLN3 }\end{array}$ & $\begin{array}{l}\text { NM_003890 } \\
\text { NM_018298 }\end{array}$ & $\begin{array}{l}4.8 \\
4.7\end{array}$ & $\begin{array}{l}\text { Fc fragment of IgG binding protein } \\
\text { Mucolipin } 3\end{array}$ & $\begin{array}{l}\text { Cell adhesion } \\
\text { Ion channel }\end{array}$ \\
\hline $\begin{array}{l}\text { U1SNRNP } \\
\text { BP }\end{array}$ & NM_007020 & 4.6 & U11/U12 snRNP 35K & $\begin{array}{l}\text { Nucleotide } \\
\text { binding }\end{array}$ \\
\hline QKI & АК021834 & 4.2 & Quaking homolog, KH domain RNA binding & $\begin{array}{l}\text { Nucleic acid } \\
\text { binding }\end{array}$ \\
\hline AKAP12 & NM_005100 & 4.1 & A kinase (PRKA) anchor protein (gravin) 12 & Transporter \\
\hline LRP12 & NM_013437 & 3.9 & Low density lipoprotein-related protein 12 & $\begin{array}{l}\text { Regulation of } \\
\text { growth }\end{array}$ \\
\hline ADM & NM_001124 & 3.9 & Adrenomedullin & Hormone activity \\
\hline TGIF & NM_003244 & 3.9 & TGF $\beta$-induced factor (TALE family homeobox) & $\begin{array}{l}\text { Transcription } \\
\text { regulator }\end{array}$ \\
\hline GALNT10 & AK021777 & 3.6 & $\begin{array}{l}\text { UDP-N-acetyl-alpha-D- } \\
\text { galactosamine:polypeptide } \mathrm{N} \text { - } \\
\text { acetylgalactosaminyltransferase } 10\end{array}$ & Enzyme \\
\hline $\begin{array}{l}\text { CDNA } \\
\text { FLJ20387 }\end{array}$ & AK000394 & 3.4 & Hypothetical gene supported by AK000394 & Unknown \\
\hline FOSL2 & AK026959 & 3.4 & FOS-like antigen 2 & $\begin{array}{l}\text { Transcription } \\
\text { regulator }\end{array}$ \\
\hline
\end{tabular}


TWIST1: A marker of macrophage foam cells

\begin{tabular}{|c|c|c|c|c|}
\hline Gene & $\begin{array}{l}\text { Accession } \\
\text { No. }\end{array}$ & $\begin{array}{c}\text { Fold } \\
\text { change }\end{array}$ & Sequence description & Function \\
\hline $\mathrm{HA}-1$ & D86976 & 3.4 & Minor histocompatibility antigen $\mathrm{HA}-1$ & $\begin{array}{l}\text { Intracellular } \\
\text { signaling }\end{array}$ \\
\hline SON & AK024752 & 2.9 & SON DNA binding protein & Cell death \\
\hline SUPV3L1 & NM_003171 & 2.7 & Suppressor of var1, 3-like 1 (S. cerevisiae) & Unknown \\
\hline SSB & $304 \overline{2} 05$ & 2.7 & Sjogren syndrome antigen B (autoantigen La) & Enzyme \\
\hline FLJ21865 & AL110283 & 2.7 & endo-beta- $\mathrm{N}$-acetylglucosaminidase & Enzyme \\
\hline RHBDF1 & AK026010 & 2.6 & Rhomboid family 1 (Drosophila) & $\begin{array}{l}\text { Copper ion } \\
\text { binding }\end{array}$ \\
\hline GLMN & NM_007070 & 2.5 & Glomulin, FKBP associated protein & Vasculogenesis \\
\hline GGA3 & AF190864 & 2.2 & $\begin{array}{l}\text { Golgi associated, gamma adaptin ear } \\
\text { containing, ARF binding protein } 3\end{array}$ & Transporter \\
\hline DDEFL1 & NM_017707 & 2.0 & $\begin{array}{l}\text { Development and differentiation enhancing } \\
\text { factor-like } 1\end{array}$ & $\begin{array}{l}\text { Carboxylic acid } \\
\text { metabolism }\end{array}$ \\
\hline
\end{tabular}

Genes higher expressed in atherosclerotic macrophages than in non-atherosclerotic macrophages (lung, liver and spleen) from the same donor. Only genes with significantly $(p<0.01)$ higher mRNA levels in the atherosclerotic macrophages of the two donors are selected. Transcription factors are marked in grey.

In all stages of atherosclerosis, TWIST1 co-localized with CD68 positive lesional macrophages (Figure 7.5). In early lesions, subendothelial macrophages showed high TWIST1 expression. In advanced stable lesions and lesions with a thrombus, subendothelial macrophages and macrophages in the shoulder region showed high TWIST1 expression (Figure 7.5).

TWIST1 was not expressed in the macrophages in any of the nonatherosclerotic tissues (e.g. tonsils, lung, ileum) with a chronic inflammation ( $n=1$ to 4 samples per tissue, Table 7.3, Figure 7.4E-F).

Interestingly, a strong co-localization of TWIST1/CD68 was found in foamy macrophages in the mucosa of the gall bladder with cholesterolosis and in skin with xanthelasma (Figure 7.4G-H), with almost similar TWIST1 expression levels for atherosclerotic and non-atherosclerotic foam cells (Table 7.3).

\section{TWIST1 is expressed after in vitro differentiation of macrophages into foam cells}

Similar to the absence of TWIST1 mRNA in blood monocytes, TWIST1 was not expressed in non-differentiated THP-1 cells. However, incubation of PMAinduced THP-1 macrophages with $50 \mu \mathrm{g} / \mathrm{ml}$ oxLDL, which results in foam cell formation without affecting cell viability, induced an increase in TWIST1 mRNA levels, i.e. 1.8 fold after 24 hours, 2.4 fold after 48 hours and 4.3 fold after 72 hours incubation (Figure 7.6). 
A

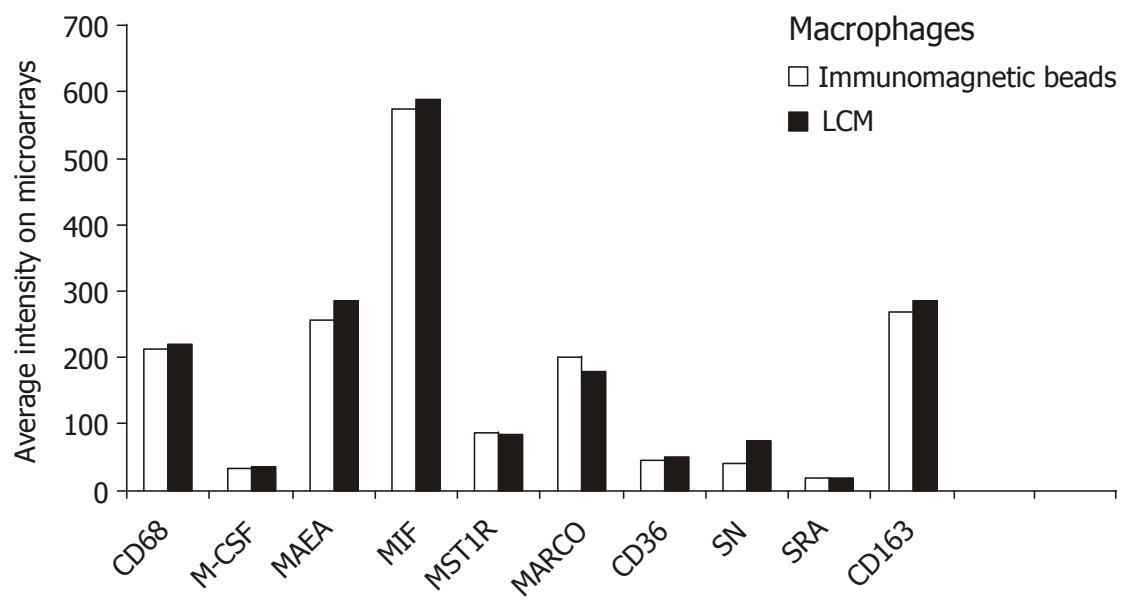

B

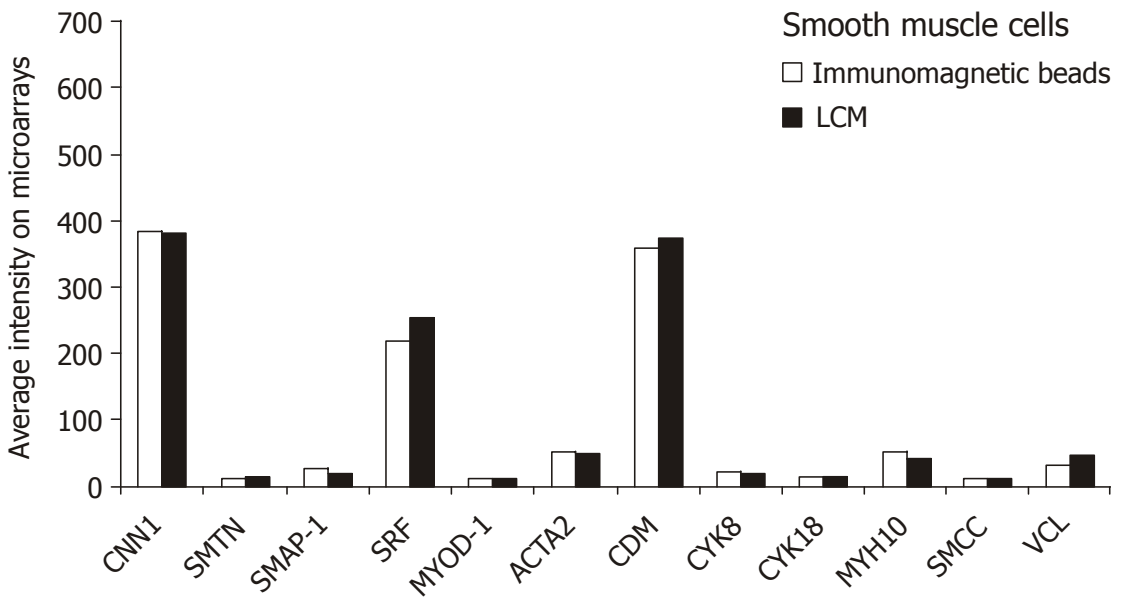

Figure 7.2

No difference in the expression level of macrophage and SMC genes between macrophage isolated with LCM or immunomagnetic beads. Microarray data show no significant differences between the mRNA levels of 10 macrophage genes (A) and 11 SMC genes (B) of macrophages isolated by immunomagnetic beads ( $\square$ ) and LCM

$(\square)$. Data are the average intensity on the duplicate microarrays of the two donors for macrophages of the carotid artery and lung, liver and spleen.

Abbreviations: CD68, macrosialin; M-CSF, macrophage colony stimulating factor 1; MAEA, macrophage erythroblast attacher; MIF, macrophage migration inhibitory factor; MST1R, macrophage stimulating 1 receptor; MARCO, macrophage receptor with collageous structure; CD36, collagen type I receptor; SN, sialoadhesin; SRA, macrophage scavenger receptor; CD163, hemoglobin scavenger receptor. CNN1, calponin; SMTN, smoothelin; SMAP-1, smooth muscle cell associated protein-1; SRF, serum response factor; MYOD-1, myogenic factor 3; ACTA2, alpha smooth muscle actin; CDM, caldesmon-1; CYK8, cytokeratin 8; CYK18, cytokeratin 18; MYH10, non SM myosin; SMCC, SM22 alpha; VCL, Metavinculin; 


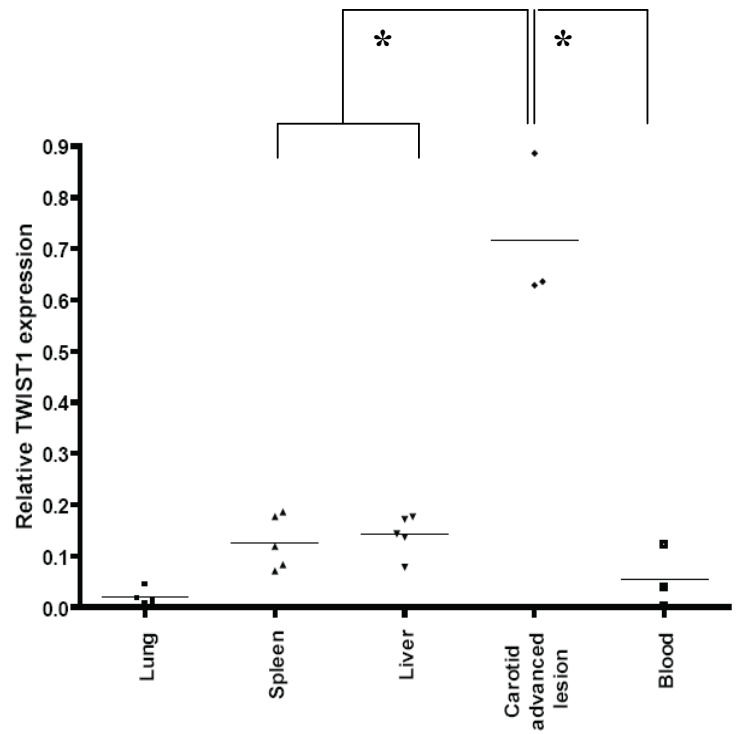

Figure 7.3

TWIST1 mRNA levels in human resident tissue macrophages and blood monocytes in vivo. Quantification of TWIST1 mRNA levels in isolated human myeloid cell populations by Q-PCR. Data are mean of duplicate runs of the respective cells of 3 to 5 different donors. TWIST1 levels are normalized to the housekeeping gene cyclophilin A. $* \mathrm{P}<0.05$ Mann-Whitney U test.

\section{TWIST1 is expressed after IFN $\alpha$ induced macrophage activation in THP-1 macrophages}

To evaluate the differential expression of TWIST1 during macrophage activation, we investigated TWIST1 mRNA levels in macrophages exposed to various stimuli in vitro. Incubation of THP-1 macrophages with LPS, the prototypical stimulus for innate activation and leading to a type I immune response, increased TWIST1 mRNA levels 4.7-fold after 1 hour, 4.6-fold after 4 hours and 9.5-fold after 24 hours (Figure 7.7A). Alternatively, incubation of THP-1 macrophages with IFNy, leading via a classical activation to a type I immune response, did not influence the TWIST1 mRNA levels after 1, 4 and 24 hours incubation, respectively (Figure 7.7A).

Likewise, incubation with the cytokines IL4 and IL13 that induce alternative activation, or IL10, which is involved in the deactivation of macrophages, did not affect the macrophage TWIST1 levels (data not shown). After 24 and 48 hours incubation of PMA-induced THP-1 macrophages with IFN $\alpha$, TWIST1 levels increased 1.4 and 1.9 fold, respectively (Figure 7.7B). These data demonstrate that TWIST1 is expressed after IFN $\alpha$ or LPS stimulation. 
Chapter 7
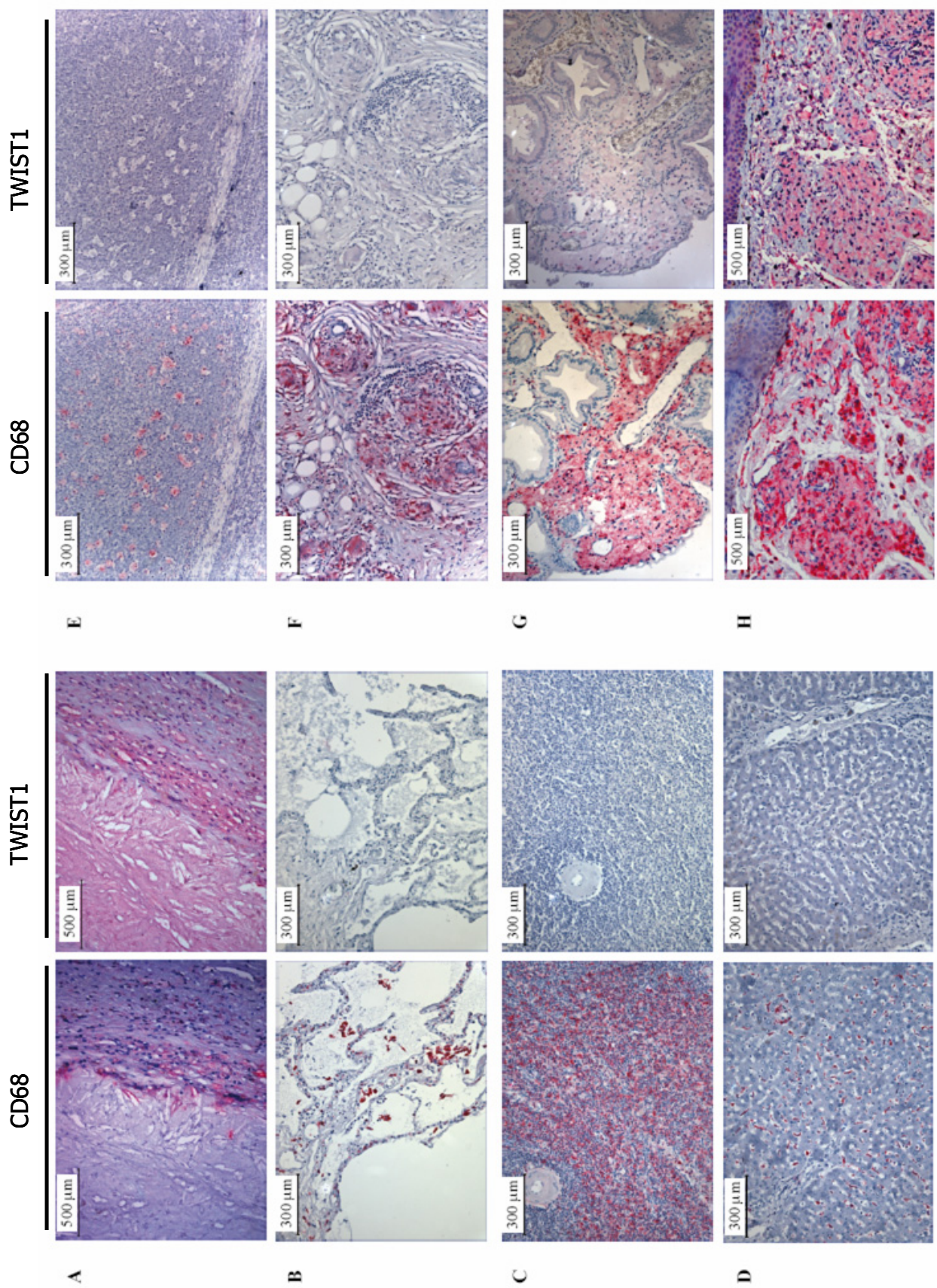

$a$ 
Figure 7.4

Immunolocalization of TWIST1 in human atherosclerotic and non-atherosclerotic tissues. Immunohistochemical detection of CD68 (macrophages, red) and TWIST1 (red) in advanced stable atherosclerotic lesions (A), normal lung (B), spleen (C), liver (D), inflamed tonsil (E), lung with sarcoidosis $(F)$, gall bladder with cholesterolosis (G) and skin with xanthelasma (H). TWIST1 is expressed in macrophage-derived foam cells in atherosclerotic lesions $(A)$, gall bladder with cholesterolosis $(G)$ and skin with xanthelasma $(H)$, but absent in the CD68 positive macrophages of other inflamed (E-F) and non-inflamed (B-D) tissues.

Table 7.3: Immunohistochemical evaluation of TWIST1 expression in human macrophages

\begin{tabular}{|c|c|c|c|c|}
\hline & Tissue type & Disease & $\mathrm{N}$ & $\begin{array}{c}\text { TWIST1 staining in } \\
\text { macrophages }\end{array}$ \\
\hline \multirow[t]{5}{*}{ A. } & Atherosclerotic lesions & & & \\
\hline & Carotid artery & Intimal thickening & 2 & - \\
\hline & Carotid artery & Intimal xanthoma & 6 & + \\
\hline & Carotid artery & Fibrous cap atheroma & 10 & +++ \\
\hline & Carotid artery & Intraplaque bleeding & 5 & +++ \\
\hline \multirow[t]{4}{*}{ B. } & Non-inflamed tissues & & & \\
\hline & Liver & None & 5 & - \\
\hline & Lung & None & 5 & - \\
\hline & Spleen & None & 5 & - \\
\hline \multirow[t]{9}{*}{ C. } & Inflamed tissues & & & \\
\hline & Tonsil & Inflamed & 2 & - \\
\hline & Colon & Crohn's disease & 1 & - \\
\hline & Ileum & Crohn's disease & 1 & - \\
\hline & Skin & Scar & 2 & - \\
\hline & Skin & Epidermal cyst & 3 & - \\
\hline & Artery & Giant cell arteritis & 2 & - \\
\hline & Lung & Sarcoidosis & 2 & - \\
\hline & Heart & Myocardial infarction & 4 & - \\
\hline \multirow[t]{3}{*}{ D. } & Tissues with foam cells & & & \\
\hline & Gall bladder & Cholesterolosis & 2 & ++ \\
\hline & Skin & Xanthelasma & 2 & ++ \\
\hline
\end{tabular}

Abbreviations: $\mathrm{N}$, number of samples;,- , no staining; + , little staining; ++ , clear staining; +++ , strong staining. 


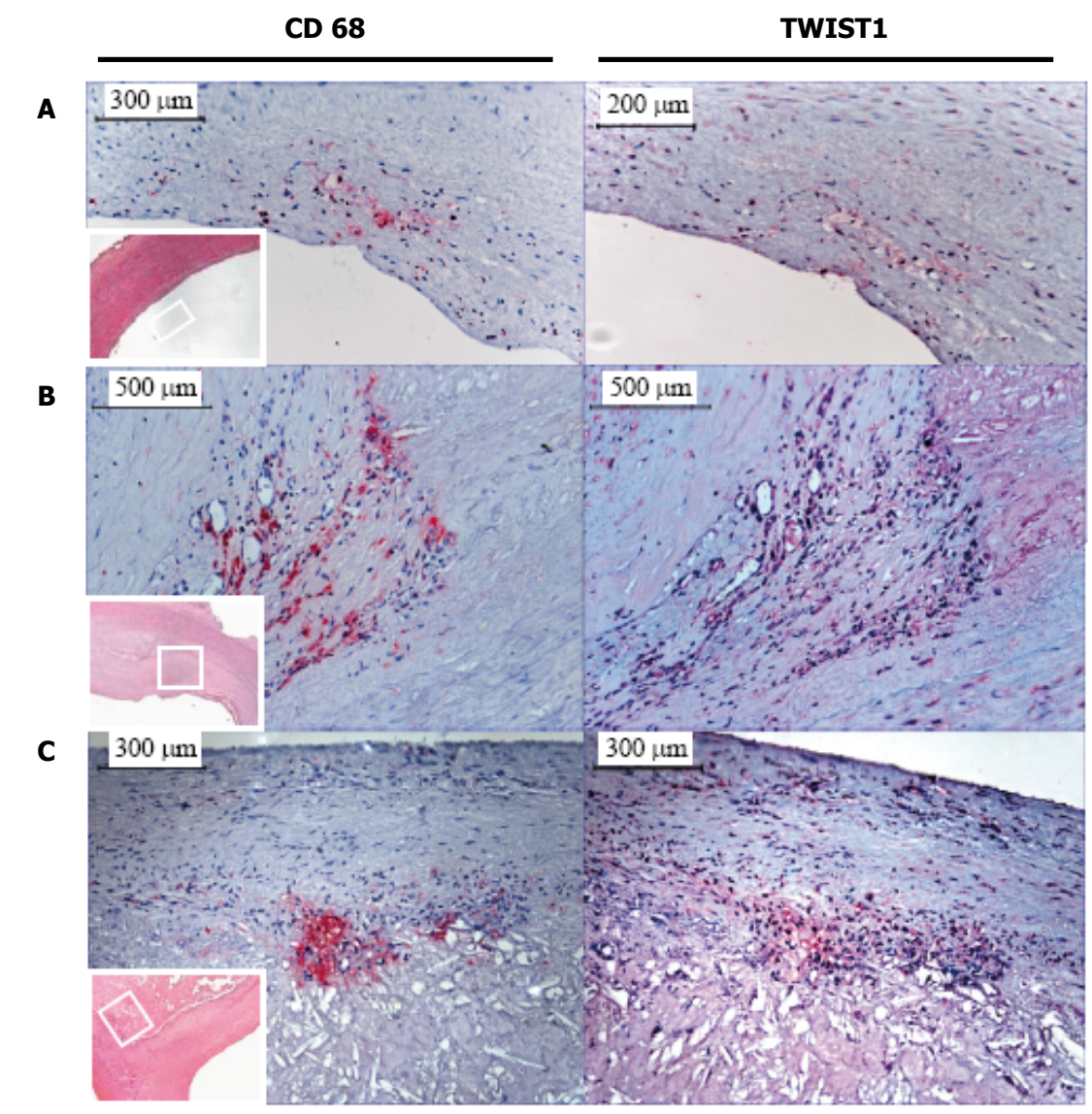

Figure 7.5

Immunolocalization of CD68 and TWIST1 in human carotid arteries with different stages of atherosclerosis. Immunohistochemical detection of CD68 (macrophages, red) and TWIST1 (red) in carotid arteries with intimal thickening (A), advanced stable lesion (B) or lesion with a thrombus (C ).

\section{DISCUSSION}

In this chapter, the expression profile of atherosclerotic lesion residing macrophages is compared to macrophages of non-atherosclerotic tissues, we identified 42 genes with significantly higher expression levels in atherosclerotic lesion macrophages compared to non-atherosclerotic macrophages. We have identified 42 genes that are significantly higher expressed in atherosclerotic macrophages compared to non-atherosclerotic macrophages. Five of these genes are transcription factors. Previous evidence supporting the differential expression of three of these genes in atherosclerotic macrophages consists of the upregulation of TGIF and FOSL2 in lesional versus alveolar macrophages ${ }^{8}$, 
and the higher expression levels of vasculin in thrombus-containing lesions compared to stable advanced human lesions 9,10 .

Here we focused on the validation of the differential upregulation of TWIST1 in atherosclerotic macrophages. TWIST1 is a basic helix-loop-helix (bHLH) transcription factor that reduces the expression of pro-inflammatory cytokines ${ }^{6}$, suppresses apoptosis ${ }^{7}$, stimulates cell migration and invasion ${ }^{11}{ }^{12}$, regulates cellular differentiation $7,11,13$ and is involved in embryonic development ${ }^{14}$. TWIST1 has a tissue-restricted expression profile and employs various mechanisms to regulate transcription. TWIST1 can act as a transcriptional repressor that binds as a homo- or heterodimer to its target DNA binding sequence in the promoters of downstream genes. Further, TWIST1 can have an effect on transcription that is independent of DNA binding ${ }^{15-18}$. TWIST1-/- mice are embryonically lethal ${ }^{14}$, but the homozygous knockout of TWIST1's analogue TWIST2 (TWIST2-/-) and double heterozygous TWIST1+/-/TWIST2+/- mice develop a severe neonatal systemic inflammatory syndrome with wasting and enhanced pro-inflammatory cytokine production ${ }^{6}$. So far, mammalian TWIST1 expression has been studied in embryonic fibroblast cells ${ }^{6}$, osteoblasts ${ }^{19}$ and in a variety of solid tumours $7,11-13,20$. In addition, recent work showed that TWIST1 is also expressed in macrophages in response to IFN ${ }^{21}$. However, no study investigated the role of TWIST1 during foam cell differentiation.

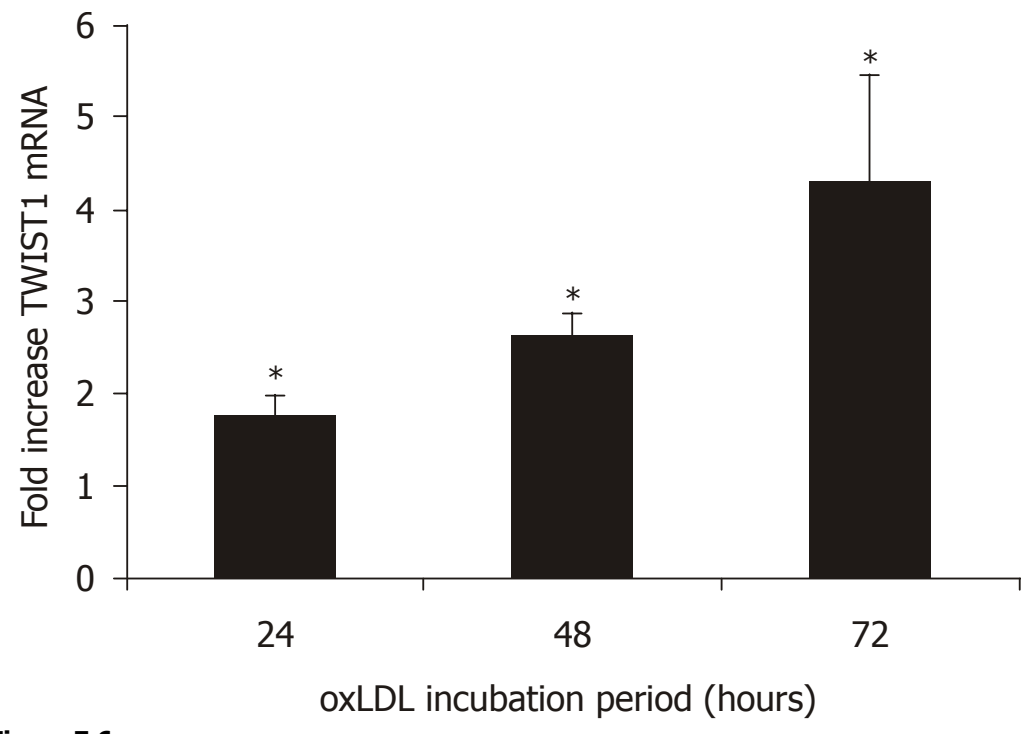

Figure 7.6

Increased TWIST1 mRNA levels after in vitro differentiation of THP-1 macrophages into foam cells. Quantification of TWIST1 mRNA levels by Q-PCR. Results are given as fold increase in TWIST1 mRNA level after incubation of THP-1 macrophages with oxLDL $(50 \mu \mathrm{g} / \mathrm{ml})$ for 24,48 or 72 hours. Data are the means \pm SEM of 7 independent experiments performed in duplicate. TWIST1 levels were normalized to cyclophilin A gene expression. $* \mathrm{P}<0.05$ Wilcoxon signed rank test. 

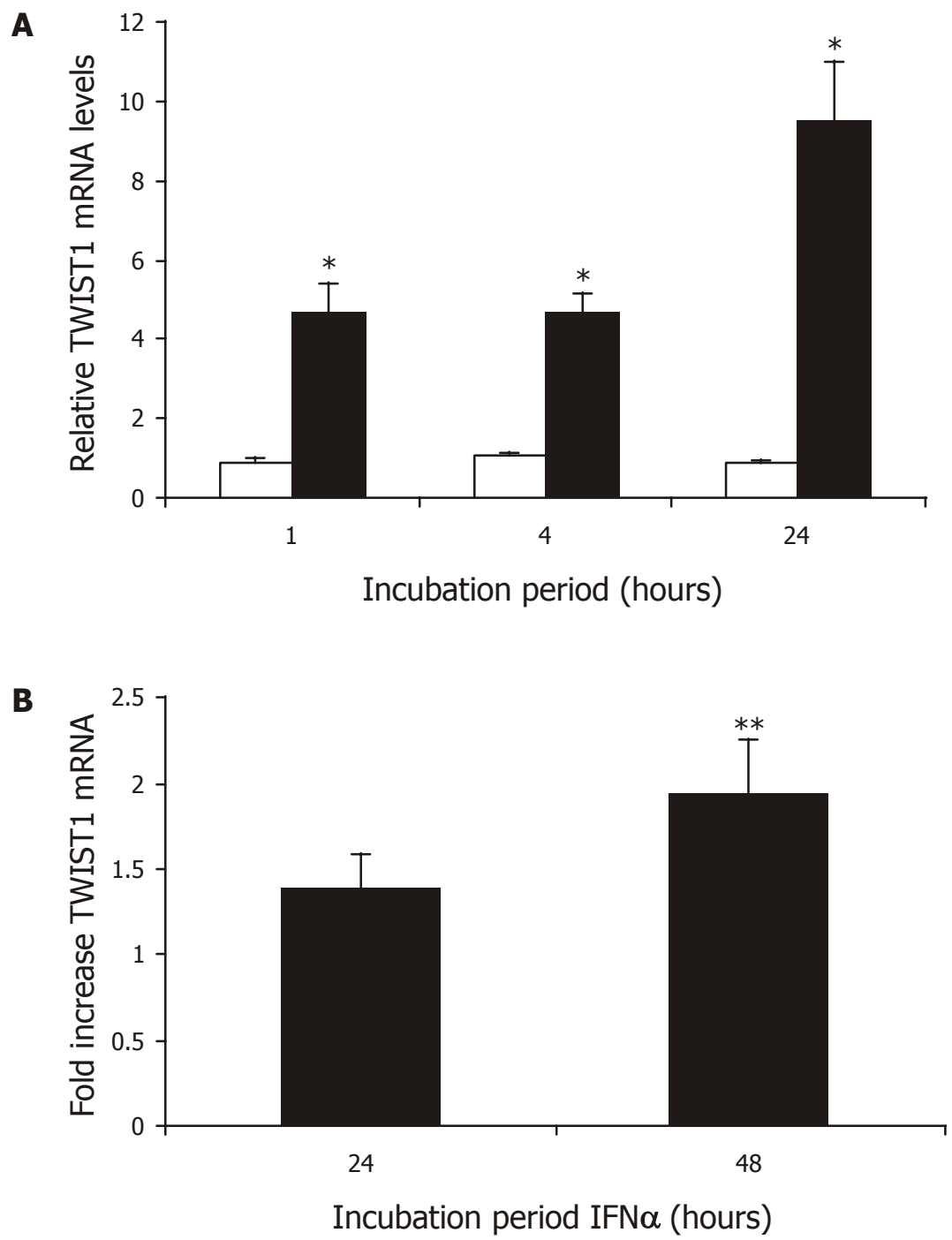

\section{Figure 7.7}

TWIST1 mRNA levels of THP-1 macrophages exposed to activationing stimuli in vitro. Quantification of TWIST1 mRNA levels in differentiated THP-1 macrophages after incubation with LPS ( $\mathbf{a} 10 \mathrm{ng} / \mathrm{ml})$ or IFN $\gamma(\square 1000 \mathrm{u} / \mathrm{ml})$ for 1,4 and 24 hours (* $\mathrm{P}<0.05$ Wilcoxon signed rank test) $(\mathrm{A})$, or with IFN $\alpha(-3000 \mathrm{u} / \mathrm{ml})(* * \mathrm{P}<0.01$ Wilcoxon signed rank test) (B). Results are given as fold difference in mRNA level between treated and mock incubated PMA-induced THP-1 macrophages. Statistics were performed on the increase of TWIST1 mRNA levels in treated versus mock. TWIST1 Q-PCR data are means \pm SEM of 7 (A) or 8 (B) independent experiments performed in duplicate. TWIST1 levels were normalized to cyclophilin A gene expression. 
Our in vitro and in vivo data showed increased TWIST1 mRNA and protein expression in foam cells in atherosclerotic lesions, gall bladder mucosa with cholesterolosis, in skin with xanthelasma and in in vitro differentiated foam cells. In contrast, no TWIST1 expression was observed in macrophages from non-inflamed and inflamed tissues, in circulating blood monocytes and in in vitro cultured monocytes and macrophages. Together, these data suggest a role for TWIST1 in foam cell differentiation, albeit that it is not clear whether TWIST1 acts as regulator or whether TWIST1 expression is increased as a consequence of an increase in lipid uptake and/or a decrease in lipid efflux. Adipose deficiency and the presence of atrophic adipocytes in TWIST2 null mice ${ }^{6}$ suggest a causal role for TWIST1 in lipid accumulation in macrophages, promoting lesion progression. However, the molecular mechanism of lipid accumulation in brown fat adipocytes is likely to differ from that of atherosclerotic lesional macrophages.

TWIST1 functions in a negative feedback loop that represses NFKB-induced cytokine expression ${ }^{6}$. Recently, inhibition of $\mathrm{NF}_{\kappa} B$ activity has been shown to reduce macrophage foam cell formation ${ }^{22,}{ }^{23}$ and NFKB deficiency has been shown to result in smaller atherosclerotic lesions ${ }^{23}$. These data might indicate that the high TWIST1 levels in foam cells decrease foam cell formation and attenuate atherosclerosis through modulation of the NFKB pathway.

TWIST1 expression was increased after incubation with LPS, a classic in vitro activation stimulus that leads via TLR4 to a type I immune response and an increase in NFKB activity. This observation is compatible with the fact that NFKB activates TWIST1 expression as part of a pathway to repress cytokine expression ${ }^{6}$. Interestingly, oxidized low-density lipoproteins are candidate TLR ligands in the atherosclerotic lesion that lead to the activation of intracellular signaling pathways, especially of $\mathrm{NFKB}^{24}$. In addition, macrophage scavenger receptors implicated in innate recognition of microorganisms (e.g. via LPS), are also involved in foam cell formation and uptake of modified lipoproteins ${ }^{25}$. Therefore, our in vitro data indicating that oxLDL loading of macrophages increases TWIST1 transcript levels, may suggest that TWIST1 is part of a common pathway of oxLDL and LPS to regulate macrophage NFKB activity and its downstream transcriptional and non-transcriptional responses.

In contrast, IFNy, the classical activation stimulus of macrophages leading to a type I immune response, did not influence the macrophage TWIST1 transcript levels. Likewise, IL4, IL10 and IL13, stimuli that moderate the inflammatory macrophage response, did not affect TWIST1 levels.

Incubation with the antiviral cytokine IFN $\alpha$ leads to an increase in TWIST levels up to 2-fold. IFN $\alpha$ is a type I interferon best known for its vital function in host immune responses that protect from infections. Recently Sharif et al ${ }^{21}$ reported that monocyte-derived macrophages express TWIST1 in response to IFN $\alpha$, leading to the suppression of inflammatory cytokines production. Interestingly, 
Niessner et $a{ }^{26}$ showed high IFN $\alpha$ concentrations in the shoulder region of atherosclerotic lesions, i.e. in plasmacytoid dendritic cells, which are positive for CD123, but also for CD68, the marker which we use in this study. IFN $\gamma$ expression levels correlated strongly with lesion instability. Together, these data hint for a role for TWIST1 in the modulation of immunological responses during atherogenesis.

Apart from the molecular interactions described above, TWIST1 has also been shown to be involved in the regulation of TNF $\alpha{ }^{6}, \mathrm{E}$-cadherin ${ }^{11,13}, \mathrm{~N}$-cadherin ${ }^{20}$ $\alpha$-catenin ${ }^{13}, \beta$-catenin ${ }^{13}, \mathrm{p} 21^{19}$ and the p53 pathway ${ }^{7,}{ }^{27-29}$. Moreover, TWIST1 interacts with MYOD, MEF2, histone acetyltransferases p300 and PCAF ${ }^{15-17}$ and functions downstream of $\beta 1$ integrin ${ }^{20}, \operatorname{TNF} \alpha{ }^{6}, \operatorname{IL} 1 \beta{ }^{6}, \operatorname{IFN} \gamma{ }^{21}, A x{ }^{21}$, Gas6 ${ }^{21}$ and protein $S{ }^{21}$. However, checking the expression levels of these genes in our microarray data did not show a link between TWIST1 expression and the expression of these genes. These interactions have not been investigated in atherosclerotic macrophages. Therefore, their contribution to the role of TWIST1 during atherogenesis remains to be defined.

The full elucidation of the role of TWIST1 in atherosclerotic macrophages may provide evidence whether TWIST 1 is only a marker of, or also causally related to atherogenesis. Given the current data, it is tempting to speculate that TWIST1 may be an upstream regulator of multiple atherogenic pathways, including foam cell formation and inflammatory response, and thus an attractive molecular target to modulate the progression of atherosclerosis. 
TWIST1: A marker of macrophage foam cells

\section{REFERENCES}

1. Gordon S. Alternative activation of macrophages. Nat Rev Immunol. Jan 2003;3(1):23-35.

2. Hansson GK, Libby P. The immune response in atherosclerosis: a double-edged sword. Nat Rev Immunol. Jul 2006;6(7):508-519.

3. Ghassabeh $\mathrm{GH}$, De Baetselier $P$, Brys $L$, et al. Identification of a common gene signature for type II cytokine-associated myeloid cells elicited in vivo in different pathologic conditions. Blood. Jul 15 2006;108(2):575-583.

4. Biswas SK, Gangi L, Paul S, et al. A distinct and unique transcriptional program expressed by tumor-associated macrophages (defective NF-kappaB and enhanced IRF-3/STAT1 activation). Blood. Mar 1 2006;107(5):2112-2122.

5. Weng $L$, Dai $H$, Zhan $Y$, et al. Rosetta error model for gene expression analysis. Bioinformatics. May 1 2006;22(9):1111-1121.

6. Sosic D, Richardson JA, Yu K, et al. Twist regulates cytokine gene expression through a negative feedback loop that represses NF-kappaB activity. Cell. Jan 24 2003;112(2):169180.

7. Maestro R, Dei Tos AP, Hamamori $Y$, et al. Twist is a potential oncogene that inhibits apoptosis. Genes Dev. Sep 1 1999;13(17):2207-2217.

8. Patino WD, Kang JG, Matoba $S$, et al. Atherosclerotic plaque macrophage transcriptional regulators are expressed in blood and modulated by tristetraprolin. Circ Res. May 26 2006;98(10):1282-1289.

9. Faber $\mathrm{BC}$, Cleutjens $\mathrm{KB}$, Niessen $\mathrm{RL}$, et al. Identification of genes potentially involved in rupture of human atherosclerotic plaques. Circ Res. Sep 14 2001;89(6):547-554.

10. Bijnens AP, Gils $A$, Jutten $B$, et al. Vasculin, a novel vascular protein differentially expressed in human atherogenesis. Blood. Oct 15 2003;102(8):2803-2810.

11. Yang X, Matsuda K, Bialek P, et al. ATF4 is a substrate of RSK2 and an essential regulator of osteoblast biology; implication for Coffin-Lowry Syndrome. Cell. Apr 30 2004;117(3):387-398.

12. Hoek K, Rimm DL, Williams KR, et al. Expression profiling reveals novel pathways in the transformation of melanocytes to melanomas. Cancer Res. Aug 1 2004;64(15):52705282.

13. Kwok WK, Ling MT, Lee TW, et al. Up-regulation of TWIST in prostate cancer and its implication as a therapeutic target. Cancer Res. Jun 15 2005;65(12):5153-5162.

14. Chen ZF, Behringer RR. twist is required in head mesenchyme for cranial neural tube morphogenesis. Genes Dev. Mar 15 1995;9(6):686-699.

15. Spicer DB, Rhee J, Cheung WL, et al. Inhibition of myogenic bHLH and MEF2 transcription factors by the bHLH protein Twist. Science. Jun 7 1996;272(5267):1476-1480.

16. Hamamori $\mathrm{Y}, \mathrm{Wu} \mathrm{HY}$, Sartorelli V, et al. The basic domain of myogenic basic helix-loophelix (bHLH) proteins is the novel target for direct inhibition by another bHLH protein, Twist. Mol Cell Biol. Nov 1997;17(11):6563-6573. 


\section{Chapter 7}

17. Hamamori Y, Sartorelli V, Ogryzko V, et al. Regulation of histone acetyltransferases p300 and PCAF by the bHLH protein twist and adenoviral oncoprotein E1A. Cell. Feb 5 1999;96(3):405-413.

18. Firulli BA, Krawchuk D, Centonze VE, et al. Altered Twist1 and Hand2 dimerization is associated with Saethre-Chotzen syndrome and limb abnormalities. Nat Genet. Apr 2005;37(4):373-381.

19. Funato $\mathrm{N}$, Ohtani $\mathrm{K}$, Ohyama $\mathrm{K}$, et al. Common regulation of growth arrest and differentiation of osteoblasts by helix-loop-helix factors. Mol Cell Biol. Nov 2001;21(21):7416-7428.

20. Alexander $\mathrm{NR}$, Tran $\mathrm{NL}$, Rekapally $\mathrm{H}$, et al. $\mathrm{N}$-cadherin gene expression in prostate carcinoma is modulated by integrin-dependent nuclear translocation of Twist1. Cancer Res. Apr 1 2006;66(7):3365-3369.

21. Sharif MN, Sosic D, Rothlin CV, et al. Twist mediates suppression of inflammation by type I IFNs and Axl. J Exp Med. Aug 7 2006;203(8):1891-1901.

22. Ferreira $V$, van Dijk KW, Groen AK, et al. Macrophage-specific inhibition of NF-kappaB activation reduces foam-cell formation. Atherosclerosis. Aug 262006.

23. Kanters E, Gijbels MJ, van der Made I, et al. Hematopoietic NF-kappaB1 deficiency results in small atherosclerotic lesions with an inflammatory phenotype. Blood. Feb 1 2004;103(3):934-940.

24. Miller YI, Chang MK, Binder $\mathrm{CJ}$, et al. Oxidized low density lipoprotein and innate immune receptors. Curr Opin Lipidol. Oct 2003;14(5):437-445.

25. Peiser L, Mukhopadhyay S, Gordon S. Scavenger receptors in innate immunity. Curr Opin Immunol. Feb 2002;14(1):123-128.

26. Niessner A, Sato K, Chaikof EL, et al. Pathogen-sensing plasmacytoid dendritic cells stimulate cytotoxic T-cell function in the atherosclerotic plaque through interferon-alpha. Circulation. Dec 5 2006;114(23):2482-2489.

27. Lill NL, Grossman SR, Ginsberg D, et al. Binding and modulation of p53 by p300/CBP coactivators. Nature. Jun 19 1997;387(6635):823-827.

28. Valsesia-Wittmann S, Magdeleine M, Dupasquier S, et al. Oncogenic cooperation between $\mathrm{H}$-Twist and $\mathrm{N}-\mathrm{Myc}$ overrides failsafe programs in cancer cells. Cancer Cell. Dec 2004;6(6):625-630.

29. Stasinopoulos IA, Mironchik Y, Raman A, et al. HOXA5-twist interaction alters p53 homeostasis in breast cancer cells. J Biol Chem. Jan 21 2005;280(3):2294-2299. 




\section{Chapter 8}

General discussion 


\section{Chapter 8}

In this thesis, we assessed the impact of various sources of heterogeneity on the outcome of genome wide expression studies in human atherosclerosis. We hypothesized that heterogeneity introduces variability in gene expression profiles, which will drop the statistical power to detect differentially expressed genes. By taking heterogeneity not into account, subtle, but possibly relevant changes in gene expression might be missed. Since such subtle changes in gene expression might yield crucial information on the regulation of genes and pathways, we felt that it is important to study aspects of heterogeneity in the expression profiles of human atherosclerotic lesions.

We hypothesized that a study design that takes heterogeneity into account will increase the statistical power of a study and subsequently enable the detection of genes with subtle but specific changes in expression.

\section{Heterogeneity}

Heterogeneity is an important factor responsible for inducing variability and ambiguity within gene expression profile study designs. In this paragraph we discuss the main sources of heterogeneity as identified in the introduction, and their relation with the data presented in this thesis.

\section{Patient heterogeneity}

Several sources of patient heterogeneity can be identified such as gender, age, ethnical background and clinical record ${ }^{1-3}$. All these factors can influence the gene expression profiles and thus introduce variability in the results. In chapter 4 we compared gene expression profiles of early and advanced atherosclerotic lesions within the carotid artery of the same patient, thereby eliminating patient heterogeneity. In the past, microarray datasets were often analysed based on a fold change cut off value without any statistical information ${ }^{4-7}$ or using statistical analysis without correction for multiple testing ${ }^{8-10}$. Due to the large biological variation, correction for multiple testing sometimes leads to no significantly regulated genes ${ }^{11}$.

The reduction of patient heterogeneity enabled us to generate a gene expression profile associated with both early and advanced lesion stage within the carotid artery based on only 4 patients. By comparing these different stages within the same patient, 524 statistically significant differentially expressed genes were identified after stringent multiple testing analysis. Because of this large number of differentially expressed genes we were able to perform a comprehensive pathway analysis. By using different pathway analysis tools, 
apoptosis related pathways with only subtle but consistent changes in expression levels were identified.

\section{Sample source heterogeneity}

As can easily be appreciated, the collection of atherosclerotic and control tissue is the basis for a study on gene expression. Tissue collection is more or less controllable in experimental animal studies. However, in studies involving human atherosclerotic material things become more complicated. Histologically classified human atherosclerotic specimens are not always available, and sample collection is less uniform compared to animal studies and depends on the expertise of surgeons and pathologists. Besides this heterogeneity in the source and classification of collected material, sample heterogeneity can arise from the differences in location within the vascular bed the sample is taken from. Both types of sample heterogeneity were investigated in this thesis. In chapter 2 it was shown that atherosclerotic lesions with the same histological classification, but isolated from either surgery (i.e. living donors) or autopsy (i.e. deceased donors) have different gene expression profiles. This was especially reflected in genes and pathways involved in basal cell metabolism and hypoxia.

In chapter 3 we clearly demonstrate that identical lesion stages at different sites within the vascular bed exhibited different gene expression profiles. This finding is underlined by the results of several animal studies where experimental systemic treatments lead to different effects on atherogenesis within different sites of the vascular system. Fredrikson et al for example demonstrated a significant reduction in lesion size in the descending aorta and not in the aortic valve leaflets in apoE deficient mice after immunization with apoB $100{ }^{12}$. The effect of gamma-irradiation followed by bone marrow transplantation (BMT) in low density lipoprotein receptor deficient (LDLR) mice also resulted in different effects. The thoracic lesion size was smaller in BMT mice fed a high fat diet compared to no BMT treated mice, whereas the lesions in the aortic sinus were larger compared to no BMT mice ${ }^{13}$. Furthermore it was shown that probucol treatment in apoE deficient mice had an anti atherogenic effect in the aortic arch, descending thoracic aorta and proximal in the abdominal aorta, whereas this treatment had a pro atherogenic effect in the aortic sinus ${ }^{14}$. This underlines that the identification of site specific expression profiles is accompanied by site specific reaction to different experimental treatments. However, extrapolating these findings to the human situation is challenging, since differences in RNA profiles not always lead to differences in subsequent protein levels and biological responses. 
Chapter 8

\section{Lesion heterogeneity}

Atherosclerosis is a multifactorial and dynamic pathological condition. As is apparent from the literature ${ }^{15-18}$, atherosclerotic lesions progress in time and cell types can have a different role in different lesion stages. In our view it is therefore important to distinguish the role of the individual cell types in the initiation and (or) progression of atherosclerosis. Cells of the monocyte/macrophage lineage play a crucial role in atherogenesis ${ }^{18-21}$ and cell culture models have been used to determine the gene expression profiles under atherogenic conditions ${ }^{22-24}$. However, limited information is available about the gene expression profiles and underlying biological pathways and functions of in vivo atherosclerotic macrophages. We used laser capture microdissection (see section "Application of LCM) to dissect macrophages from atherosclerotic lesions. Isolated and amplified RNA from these macrophages was assessed with microarray technology and pathway analysis in order to identify the gene expression profile of macrophages in atherogenesis. The data presented in this thesis clearly show that it is feasible to study the transcriptional changes of individual microdissected macrophages from atherosclerotic lesions (chapter 6) and non atherosclerotic tissue (chapter 7). We identified two transcription factors, TWIST and ID4, both overexpressed in macrophages from advanced lesions compared with early lesions, and in atherosclerotic macrophages compared to non atherosclerotic macrophages.

In addition, these studies show the presence of heterogeneity between macrophages from different atherosclerotic lesion stages and between macrophages from atherosclerotic and other inflammatory tissues. Until now it was only possible to identify these subtypes of macrophages in a biased way, for example by staining of known makers or activation molecules ${ }^{25,}{ }^{26}$. Our ability to identify transcriptional changes of individual macrophages within the atherosclerotic lesion provides the opportunity to relate transcriptional changes in circulating monocytes with resident macrophages from the same patient. This comparison will yield additional valuable information regarding the (molecular) mechanisms underlying the initiation of atherosclerosis and will provide information on the validity of circulating monocytes as a biomarker for the severity of atherosclerosis. Using microdissected macrophages and/or blood monocytes in combination with other technologies such as the phage display based technique Serological Antigen Screening (SAS) it might be possible to identify circulating marker proteins that might even have clinically relevant predictive information ${ }^{27-29}$. In this way, the activation or inflammation state of lesional macrophages can be linked to circulating markers of disease. This can ultimately lead to the timely identification of patients at risk for clinical complications, such as a myocardial infarction or stroke caused by rupture of an atherosclerotic lesion. 
We clearly show that variability in gene expression profiles can be introduced from the patient down to the cellular level. From the above discussed issues it becomes apparent that it is of importance to acknowledge heterogeneity when designing an experimental setup in atherosclerotic research. Therefore the hypothesis underlining the research question should determine the experimental setup and the allowed level of heterogeneity (reviewed in ${ }^{30}$ ). When aiming to determine a so called "common denominator" for atherosclerosis (a gene expressed irrespective of gender, site, source, cell type) it is necessary to include heterogeneity in the study design. An example of such a common denominator is cathepsin $\mathrm{K}$ (chapter 5 ). When aiming for a specific gene expression signature for a subpopulation, stage or location, heterogeneity should be avoided as much as possible or at least taken into account. This will increase the chance to detect subpopulation specific genes without the need to increase the number of patients or amount of material that has to be incorporated in the study.

\section{Application of LCM}

The application of the LCM technique in atherosclerosis research is limited compared to other fields such as the oncology research ${ }^{31}$. Not only is the technique much less frequently applied, also the combination with other applications, such as microarray analysis ${ }^{32}$, proteomics ${ }^{33}$ chromatin immune precipitation (ChiP) ${ }^{34}$, comparative genomic hybridization (CGH) ${ }^{35}$ and phage display ${ }^{36}$ is not as widespread. The difficulty to isolate sufficient amounts of high quality material out of atherosclerotic specimens is the most straightforward explanation why use of laser capture microdissection is so limited in atherosclerotic research. Several reasons underlie this quality problem, such as the occurrence of apoptotic and necrotic areas, calcification and regions of fibrosis that result in RNA, DNA and protein degradation within the atherosclerotic lesion. Another possible explanation for the limited use of LCM in atherosclerosis research is the limited availability of (histological classified) human atherosclerotic specimens. The treatment of atherosclerosis is predominantly aimed at reducing the risk factors instead of "excising" (part) of the diseased vessel. This lack of tissue availability hampers researchers to perform a well designed study, containing enough samples to generate statistically reliable data.

To overcome the issue of obtaining sufficient amounts of high quality material necessary for microarray hybridizations several technological advances have been made. Over the last years it has become possible to amplify small amounts of RNA to yield sufficient amounts for microarray hybridization ${ }^{37}$. Additionally, microarray probes can be designed in such way that they are short 
and located at the $3^{\prime}$ position of the gene. This means that even hybridization of suboptimal, fragmented RNA yields reproducible and reliable results. Besides this the sensitivity of fluorescent or other detection techniques has been improved ${ }^{38}$.

Besides isolation of RNA from microdissected cells, it is also possible to study alterations on a DNA level. Progress in this field has been made by the recent discovery of different SNPs that are associated with coronary artery disease or in stent restenosis ${ }^{39-41}$. However, unlike for example research in the cancer field, cardiovascular research in the past years did not focus on other DNArelated processes such as detection of DNA methylation and histone modifications and/or chromosomal regions leading to repression or activation of genes. Therefore techniques suitable to detect these changes are not commonly used so far in atherosclerosis. Since it is becoming evident that these processes are indeed involved in initiation or progression of atherosclerosis, it might be expected that techniques such as ChiP or methylation assays will be applied in the atherosclerosis research in the coming years ${ }^{42-44}$. The heterogeneous nature of atherosclerotic lesions emphasizes the need to combine these techniques with LCM in order to yield cell specific information regarding epigenetic modifications.

Besides studying the genome one can also study the proteome of an individual cell type using LCM. At present, the techniques available to study the proteome, such as liquid chromatography ${ }^{45,} 46$, (maldi-TOF) massspectometry ${ }^{47,48}$, two dimensional (2D) gel electrophoresis ${ }^{49,50}$ and antibody arrays ${ }^{51}$ require a relatively large amount of protein as starting material. As a result of this, the small number of cells that is typically harvested by LCM, severely limits proteome coverage and biomarker discovery potential achievable by conventional proteomics platforms. An effort is being made to improve and optimize the procedures in such way that less starting material is needed to obtain reliable, representative data. Nettikadan et $a^{52}$ constructed a protein ultra microarray with which they were able to detect prostate-specific antigen (PSA) secreted from 100 LNCaP cells in $3 \mathrm{~h}$. Furthermore, Umar et al ${ }^{53}$ demonstrated that it is feasible to analyse protein digest of 3000 LCM derived tumour cells, corresponding to $300 \mathrm{ng}$ of total protein, using Nano Liquid Chromatography-Fourier Transform Ion-Cyclotron Resonance Mass Spectrometry (LC-FT-ICR MS). Also in the field of atherosclerosis, proteomic research is improving. Recently, a study has been published in which the authors demonstrate that it is feasible to isolate sufficient cell material from an atherosclerotic lesion to perform liquid chromatography and tandem mass spectrometry ${ }^{54}$. As soon as these techniques have improved and optimized to obtain reliable and representative data with small amounts of material, they most likely will be applied more frequently in atherosclerosis research. 


\section{Pathway analysis}

In the past our lab and others based the decision to validate a specific candidate gene (or to further elucidate its role) on known features of the gene. Examples can be the gene's involvement in other physical and pathological processes or the role of its family members in either atherosclerosis or related physical and pathological conditions. This can be seen as the so-called "single gene" approach. This single gene approach suffers from the risk that researchers focus on candidate genes they recognize. This bias could result in the loss of very relevant but unknown genes. In this thesis we aimed to select genes for further validation based on their involvement/presence in differentially regulated biological pathways or a group of functionally related genes, the "pathway profiling" approach. The presence of such differentially regulated pathways or group of functionally related genes in the expression data can be detected using pathway profiling programs. We show that the pathway profiling approach has an important additional value since it enabled us to focus on genes which would not have drawn our attention using solely/exclusively the single gene approach (chapters 4, 5 and 6).

Although the use of pathway analysis has enabled a more biological interpretation of our data, some aspects have to be considered. Current pathway analysis tools are based on known pathways, which implies that the identification of novel pathways is not possible. For example, the commonly used analysis tools Ingenuity and GENMAPP use information derived from databases such as BioCarta and KEGG. Improvements have been made in this field and programs are now becoming more flexible. For example, in Gene Set Enrichment Analysis it is possible to include gene sets or pathways based on own observations or findings ${ }^{55}$. In this way, it is possible to screen microarray data with a personalized pathway program.

One of the ultimate goals of genome wide expression studies is to be able to identify a set of genes that predicts progression of lesion formation and the subsequent clinical outcome as is already being performed in the oncology field 56-58. In this respect, Seo et a/ analyzed atherosclerotic lesion samples varying in degree of lesion formation in order to identify gene expression signatures that could predict severity of disease. They were able to identify a set of 207 genes that could predict the severity of the disease with $94 \%$ accuracy ${ }^{9}$. However, due to lack of sufficient sample material, they were not able to test these predictive genes on a separate independent sample set that would actually proof their clinical relevance.

As we show in this thesis, limiting the amount of heterogeneity in the study design increases the statistical power of the study. Therefore, less, but well classified, human atherosclerotic specimens are needed to obtain similar statistical power. This implies that predictive gene sets can be identified with a 
limited number of samples, and that validation of this set can be performed on a separate independent sample set.

Although pathway analysis will reduce the chance that physiologically nonrelevant genes are identified, it will still be of importance to validate potential candidates. This validation can be performed on a single gene level by PCR, Western blotting etc. More biologically relevant will be pathway based validation, for example by studying functional relevant indicators of activity of the identified pathway.

A biologically relevant gene characterization using microarray and pathway analysis can be found in chapter 5 . Here we studied the functional role of cathepsin $\mathrm{K}$ in a mouse model for atherosclerosis. We found this gene to be upregulated in advanced lesions compared to early lesions in human atherosclerotic material within the carotid artery of the same patient. We compared these results with previous studies from our group where cathepsin $\mathrm{K}$ was also identified as being upregulated in advanced stable human atherosclerotic lesions compared to early and thrombotic lesions ${ }^{59,60}$. These studies used a far more heterogeneous sample collection, making cathepsin $\mathrm{K}$ a so called "common denominator" for advanced human atherosclerotic lesions. To further elucidate the role of this important gene in atherogenesis, we used microarray analysis to identify the effects of cathepsin $\mathrm{K}$ deficiency on an apoE-/- background during atherogenic conditions. We used pathway analysis to identify biological pathways affected by cathepsin $\mathrm{K}$ disruption. A two step protocol can be seen in this process. First, cathepsin $\mathrm{K}$ was identified as candidate and subsequently the functionality of this gene was investigated. In chapter 5 we were able to identify cathepsin $\mathrm{K}$ as a modulator of lipid metabolism by repressing CD36 and caveolin expression and on the other hand as a repressor of profibrotic TGF $\beta$ signaling.

\section{Current limitations and future applications}

Although large progress has been made in the field of atherogenomics, several issues still remain that will need attention in the near future. As already mentioned earlier in this thesis and in previous literature, the availability of well classified and well stored atherogenic and control non-diseased human tissue is limited ${ }^{39}$. It can easily be appreciated that the need for such larger and well structured databases is needed. Communication and cooperation both within and between (academic) hospitals would be necessary to address this urgent problem. The multi-centre approach can be beneficiary for all parties, as local strengths can be combined to broaden the scope and quality of research.

The availability of larger datasets will enable us in the near future to identify real predictive gene signatures linked to different stages of disease that are 
actually validated in a large and well controlled study, which could further refine the gene signatures identified by Seo et $a l^{9}$.

When such signature gene sets are available, it opens the way to predictive medicine, for example by addressing lesion vulnerability based on gene expression profiles of isolated material from atherectomies. Another possible clinical application can be the already mentioned linkage of markers on circulating monocytes with expression profiles of microdissected macrophages. It would then be possible to determine the status of the atherosclerotic lesions by using a minimally invasive technique, such as taking a blood sample. Furthermore, it can be envisioned that even pre-symptomatic patients at risk for lesion rupture can be identified by using this method.

However it is to be noted that RNA expression profiles do not always correlate with protein expression and subsequent biological activity ${ }^{39}$. Post translational modifications, such as phosphorylation and posttranslational activity should be taken into account for a more detailed and comprehensive understanding at a functional level. Possible techniques that will enable the detection of these posttranslational modifications include large scale analysis using phosphospecific antibodies, protein arrays or SAS ${ }^{61,62}$. Combining all the available techniques can lead to a more comprehensive overview of the functional biology in atherosclerosis.

Ideally this would lead to a more personalized and more specific risk profile and treatment. In this respect it can be noted that further treatments will address the various sources of heterogeneity regarding the underlying pathology. This means that the same disease in different patients, in different locations and in different stages will be treated in different ways. A possible application can for example be artery-specific drug eluting stents.

\section{Summary and concluding remarks}

We conclude that depending on the research question, it can be important to acknowledge heterogeneity in a study design in atherosclerotic research. Representative results can be obtained with a lower number of patients, material or effort. The amplification of RNA material from just a few cells opened the way to minimize heterogeneity. We therefore think that further improvement in the experimental design should be focused on the data processing side. For example, the introduction of pathway analysis is valuable in atherogenomic research as it opens the way to biologically relevant data interpretation. This tool enabled the detection of genes with only slightly modulated expression that would have been missed with a single gene approach. However, further development in software and statistical analysis tools is still necessary in the following years. 


\section{Chapter 8}

It can be concluded from this thesis that the use of microarrays in cardiovascular research has matured. Both on the sample collection side and the data analysis side, major improvements have been made. When microarrays were previously regarded as just " $a$ " tool that identifies genes, it is now possible to use microarray based transcriptional analysis in hypothesis driven research. In this way, we are able to identify both relevant pathways and genes.

By decreasing heterogeneity in experimental design in cardiovascular research in combination with the introduction of pathway analysis, we provide an elegant research strategy to identify novel genes and pathways underlying atherosclerosis. 


\section{REFERENCES}

1. Iemolo F, Martiniuk A, Steinman DA, et al. Sex differences in carotid plaque and stenosis. Stroke. Feb 2004;35(2):477-481.

2. Marchesi S, Lupattelli G, Sensini A, et al. Racial difference in endothelial function: role of the infective burden. Atherosclerosis. Mar 2007;191(1):227-234.

3. Orakzai $\mathrm{SH}$, Orakzai $\mathrm{RH}$, Nasir K, et al. Subclinical coronary atherosclerosis: racial profiling is necessary! Am Heart J. Nov 2006;152(5):819-827.

4. Hiltunen MO, Tuomisto $\pi$, Niemi $M$, et al. Changes in gene expression in atherosclerotic plaques analyzed using DNA array. Atherosclerosis. Nov 2002;165(1):23-32.

5. Martinet W, Schrijvers DM, De Meyer GR, et al. Gene expression profiling of apoptosisrelated genes in human atherosclerosis: upregulation of death-associated protein kinase. Arterioscler Thromb Vasc Biol. Dec 1 2002;22(12):2023-2029.

6. McCaffrey TA, Fu C, Du B, et al. High-level expression of Egr-1 and Egr-1-inducible genes in mouse and human atherosclerosis. J Clin Invest. Mar 2000;105(5):653-662.

7. Woodside KJ, Hernandez A, Smith FW, et al. Differential gene expression in primary and recurrent carotid stenosis. Biochem Biophys Res Commun. Mar 14 2003;302(3):509-514.

8. Tuomisto TT, Korkeela A, Rutanen J, et al. Gene expression in macrophage-rich inflammatory cell infiltrates in human atherosclerotic lesions as studied by laser microdissection and DNA array: overexpression of HMG-CoA reductase, colony stimulating factor receptors, CD11A/CD18 integrins, and interleukin receptors. Arterioscler Thromb Vasc Biol. Dec 2003;23(12):2235-2240.

9. Seo D, Wang $\mathrm{T}$, Dressman $\mathrm{H}$, et al. Gene expression phenotypes of atherosclerosis. Arterioscler Thromb Vasc Biol. Oct 2004;24(10):1922-1927.

10. Papaspyridonos M, Smith A, Burnand KG, et al. Novel candidate genes in unstable areas of human atherosclerotic plaques. Arterioscler Thromb Vasc Biol. Aug 2006;26(8):18371844.

11. Dahl TB, Yndestad A, Skjelland M, et al. Increased expression of visfatin in macrophages of human unstable carotid and coronary atherosclerosis: possible role in inflammation and plaque destabilization. Circulation. Feb 27 2007;115(8):972-980.

12. Fredrikson GN, Soderberg I, Lindholm M, et al. Inhibition of atherosclerosis in apoE-null mice by immunization with apoB-100 peptide sequences. Arterioscler Thromb Vasc Biol. May 1 2003;23(5):879-884.

13. Schiller NK, Kubo N, Boisvert WA, et al. Effect of gamma-irradiation and bone marrow transplantation on atherosclerosis in LDL receptor-deficient mice. Arterioscler Thromb Vasc Biol. Oct 2001;21(10):1674-1680.

14. Witting PK, Pettersson K, Letters J, et al. Site-specific antiatherogenic effect of probucol in apolipoprotein E-deficient mice. Arterioscler Thromb Vasc Biol. Aug 2000;20(8):E26-33.

15. Ross R. The pathogenesis of atherosclerosis: a perspective for the 1990s. Nature. Apr 29 1993;362(6423):801-809.

16. Owens GK, Kumar MS, Wamhoff BR. Molecular regulation of vascular smooth muscle cell differentiation in development and disease. Physiol Rev. Jul 2004;84(3):767-801. 
17. Hansson GK. Inflammation, atherosclerosis, and coronary artery disease. $N$ Engl J Med. Apr 21 2005;352(16):1685-1695.

18. Ross R. Atherosclerosis--an inflammatory disease. N Engl J Med. Jan 14 1999;340(2):115126.

19. Tiwari RL, Singh V, Barthwal MK. Macrophages: An elusive yet emerging therapeutic target of atherosclerosis. Med Res Rev. Nov 142007.

20. Yan ZQ, Hansson GK. Innate immunity, macrophage activation, and atherosclerosis. Immunol Rev. Oct 2007;219:187-203.

21. Hung YC, Hong MY, Huang GS. Cholesterol loading augments oxidative stress in macrophages. FEBS Lett. Feb 6 2006;580(3):849-861.

22. Shiffman D, Mikita T, Tai JT, et al. Large scale gene expression analysis of cholesterolloaded macrophages. J Biol Chem. Dec 1 2000;275(48):37324-37332.

23. Andersson $\mathrm{T}$, Borang $\mathrm{S}$, Larsson $\mathrm{M}$, et al. Novel candidate genes for atherosclerosis are identified by representational difference analysis-based transcript profiling of cholesterolloaded macrophages. Pathobiology. 2001;69(6):304-314.

24. Mikita T, Porter G, Lawn RM, et al. Oxidized low density lipoprotein exposure alters the transcriptional response of macrophages to inflammatory stimulus. $\mathrm{J}$ Biol Chem. Dec 7 2001;276(49):45729-45739.

25. Wen J, Wang P, Smith SV, et al. Syndecans are differentially expressed during the course of aortic aneurysm formation. J Vasc Surg. Nov 2007;46(5):1014-1025.

26. Yilmaz A, Lipfert B, Cicha I, et al. Accumulation of immune cells and high expression of chemokines/chemokine receptors in the upstream shoulder of atherosclerotic carotid plaques. Exp Mol Pathol. Jun 2007;82(3):245-255.

27. Lee SY, Jeoung D. The reverse proteomics for identification of tumor antigens. $J$ Microbiol Biotechnol. Jun 2007;17(6):879-890.

28. Seliger B, Kellner R. Design of proteome-based studies in combination with serology for the identification of biomarkers and novel targets. Proteomics. Dec 2002;2(12):16411651.

29. Cleutjens KB, Faber BC, Rousch M, et al. Autoantibody Profiling as Rapid and NonInvasive Diagnostic Tool for the Presence of Ruptured Atherosclerotic Lesions. Provisionally accepted for publication in the Journal of clinical Chemistry.

30. Bijnens AP, Lutgens E, Ayoubi $T$, et al. Genome-wide expression studies of atherosclerosis: critical issues in methodology, analysis, interpretation of transcriptomics data. Arterioscler Thromb Vasc Biol. Jun 2006;26(6):1226-1235.

31. Espina V, Heiby M, Pierobon M, et al. Laser capture microdissection technology. Expert Rev Mol Diagn. Sep 2007;7(5):647-657.

32. Luzzi VI, Holtschlag V, Watson MA. Gene expression profiling of primary tumor cell populations using laser capture microdissection, RNA transcript amplification, and GeneChip microarrays. Methods Mol Biol. 2005;293:187-207.

33. Gutstein HB, Morris JS. Laser capture sampling and analytical issues in proteomics. Expert Rev Proteomics. Oct 2007;4(5):627-637. 
34. Shur I, Socher R, Benayahu D. In vivo association of CReMM/CHD9 with promoters in osteogenic cells. J Cell Physiol. May 2006;207(2):374-378.

35. Fukasawa S, Kino M, Kobayashi M, et al. Genetic changes in $\mathrm{pT} 2$ and pT3 prostate cancer detected by comparative genomic hybridization. Prostate Cancer Prostatic Dis. Oct 9 2007.

36. Lu H, Jin D, Kapila YL. Application of laser capture microdissection to phage display peptide library screening. Oral Surg Oral Med Oral Pathol Oral Radiol Endod. Dec 2004;98(6):692-697.

37. Nygaard V, Hovig E. Options available for profiling small samples: a review of sample amplification technology when combined with microarray profiling. Nucleic Acids Res. 2006;34(3):996-1014.

38. Ashley EA, Spin JM, Tabibiazar R, et al. Frontiers in nephrology: genomic approaches to understanding the molecular basis of atherosclerosis. J Am Soc Nephrol. Nov 2007;18(11):2853-2862.

39. Miller DT, Ridker PM, Libby $\mathrm{P}$, et al. Atherosclerosis: the path from genomics to therapeutics. J Am Coll Cardiol. Apr 17 2007;49(15):1589-1599.

40. Monraats PS, Pires NM, Agema WR, et al. Genetic inflammatory factors predict restenosis after percutaneous coronary interventions. Circulation. Oct 18 2005;112(16):2417-2425.

41. Monraats PS, Rana JS, Zwinderman AH, et al. $-455 \mathrm{G} / \mathrm{A}$ polymorphism and preprocedural plasma levels of fibrinogen show no association with the risk of clinical restenosis in patients with coronary stent placement. Thromb Haemost. Mar 2005;93(3):564-569.

42. Hiltunen MO, Yla-Herttuala S. DNA methylation, smooth muscle cells, and atherogenesis. Arterioscler Thromb Vasc Biol. Oct 1 2003;23(10):1750-1753.

43. Hiltunen MO, Turunen MP, Hakkinen TP, et al. DNA hypomethylation and methyltransferase expression in atherosclerotic lesions. Vasc Med. Feb 2002;7(1):5-11.

44. Kawahara K, Watanabe S, Ohshima T, et al. Hypernuclear acetylation in atherosclerotic lesions and activated vascular smooth muscle cells. Biochem Biophys Res Commun. Dec 20 1999;266(2):417-424.

45. Godin JP, Fay LB, Hopfgartner G. Liquid chromatography combined with mass spectrometry for $13 \mathrm{C}$ isotopic analysis in life science research. Mass Spectrom Rev. NovDec 2007;26(6):751-774.

46. Matt $\mathrm{P}$, Carrel $\mathrm{T}$, White $\mathrm{M}$, et al. Proteomics in cardiovascular surgery. $\mathrm{J}$ Thorac Cardiovasc Surg. Jan 2007;133(1):210-214.

47. Gingras AC, Gstaiger M, Raught $B$, et al. Analysis of protein complexes using mass spectrometry. Nat Rev Mol Cell Biol. Aug 2007;8(8):645-654.

48. Albrethsen J. Reproducibility in protein profiling by MALDI-TOF mass spectrometry. Clin Chem. May 2007;53(5):852-858.

49. Donners MM, Verluyten MJ, Bouwman FG, et al. Proteomic analysis of differential protein expression in human atherosclerotic plaque progression. J Pathol. May 2005;206(1):3945. 


\section{Chapter 8}

50. Marengo E, Robotti E, Antonucci F, et al. Numerical approaches for quantitative analysis of two-dimensional maps: a review of commercial software and home-made systems. Proteomics. Feb 2005;5(3):654-666.

51. Kricka LJ, Master SR. Validation and quality control of protein microarray-based analytical methods. Mol Biotechnol. Jan 2008;38(1):19-31.

52. Nettikadan S, Radke $\mathrm{K}$, Johnson J, et al. Detection and quantification of protein biomarkers from fewer than 10 cells. Mol Cell Proteomics. May 2006;5(5):895-901.

53. Umar A, Luider TM, Foekens JA, et al. NanoLC-FT-ICR MS improves proteome coverage attainable for approximately 3000 laser-microdissected breast carcinoma cells. Proteomics. Jan 2007;7(2):323-329.

54. Bagnato C, Thumar J, Mayya V, et al. Proteomics analysis of human coronary atherosclerotic plaque: a feasibility study of direct tissue proteomics by liquid chromatography and tandem mass spectrometry. Mol Cell Proteomics. Jun 2007;6(6):1088-1102.

55. Subramanian A, Tamayo P, Mootha VK, et al. Gene set enrichment analysis: a knowledgebased approach for interpreting genome-wide expression profiles. Proc Natl Acad Sci U S A. Oct 25 2005;102(43):15545-15550.

56. Lau SK, Boutros PC, Pintilie M, et al. Three-gene prognostic classifier for early-stage non small-cell lung cancer. J Clin Oncol. Dec 10 2007;25(35):5562-5569.

57. Ogawa K, Murayama S, Mori M. Predicting the tumor response to radiotherapy using microarray analysis (Review). Oncol Rep. Nov 2007;18(5):1243-1248.

58. van 't Veer $\mathrm{L}$, Dai $\mathrm{H}$, van de Vijver $\mathrm{MJ}$, et al. Gene expression profiling predicts clinical outcome of breast cancer. Nature. Jan 31 2002;415(6871):530-536.

59. Faber $\mathrm{BC}$, Cleutjens $\mathrm{KB}$, Niessen $\mathrm{RL}$, et al. Identification of genes potentially involved in rupture of human atherosclerotic plaques. Circ Res. Sep 14 2001;89(6):547-554.

60. Lutgens $\mathrm{E}$, Lutgens SP, Faber $\mathrm{BC}$, et al. Disruption of the cathepsin $\mathrm{K}$ gene reduces atherosclerosis progression and induces plaque fibrosis but accelerates macrophage foam cell formation. Circulation. Jan 3 2006;113(1):98-107.

61. Vazquez-Martin A, Colomer R, Brunet J, et al. Overexpression of fatty acid synthase gene activates HER1/HER2 tyrosine kinase receptors in human breast epithelial cells. Cell Prolif. Feb 2008;41(1):59-85.

62. Meinnel $\mathrm{T}$, Giglione $\mathrm{C}$. Tools for analyzing and predicting $\mathrm{N}$-terminal protein modifications. Proteomics. Jan 182008. 



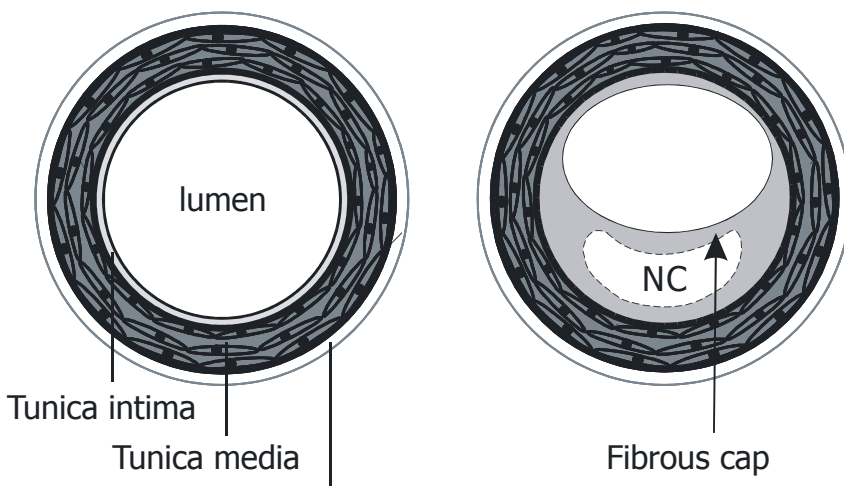

Fibrous cap

Tunica adventitia
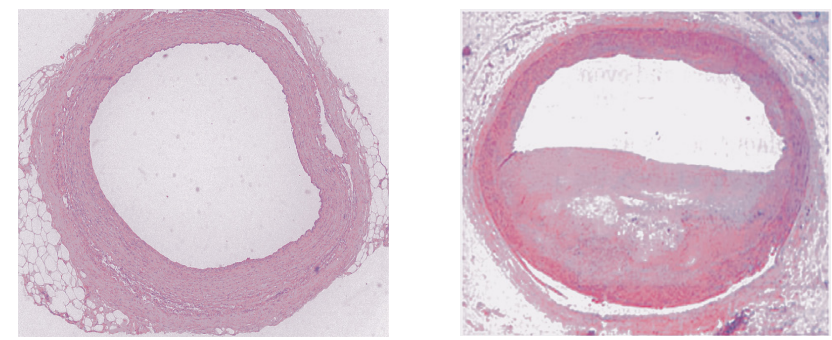

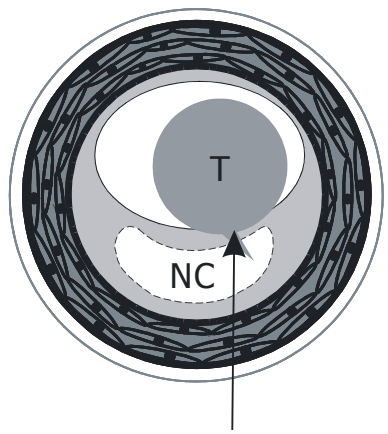

Site of rupture

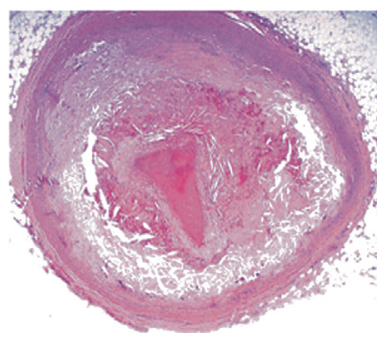

Figure 1.5

Schematic representation of human atherosclerotic lesion development (upper panel). A normal artery (left picture) consist of three layers: the tunica intima (the innermost layer), tunica media (the middle layer) and the tunica adventitia (the outermost layer). During lesion development cells, lipid and matrix accumulate in the tunica intima leading to the development of a necrotic core, which is covered by a fibrous cap (illustrated by the middle figure). Thinning and weakening of the fibrous cap may lead to rupture of the lesion and formation of a thrombus, which may (partially) occlude the lumen of the vessel (right picture). Hematoxylin and Eosin (HE) stained sections of the corresponding lesion stages are shown in the lower panel. 
Full color pictures

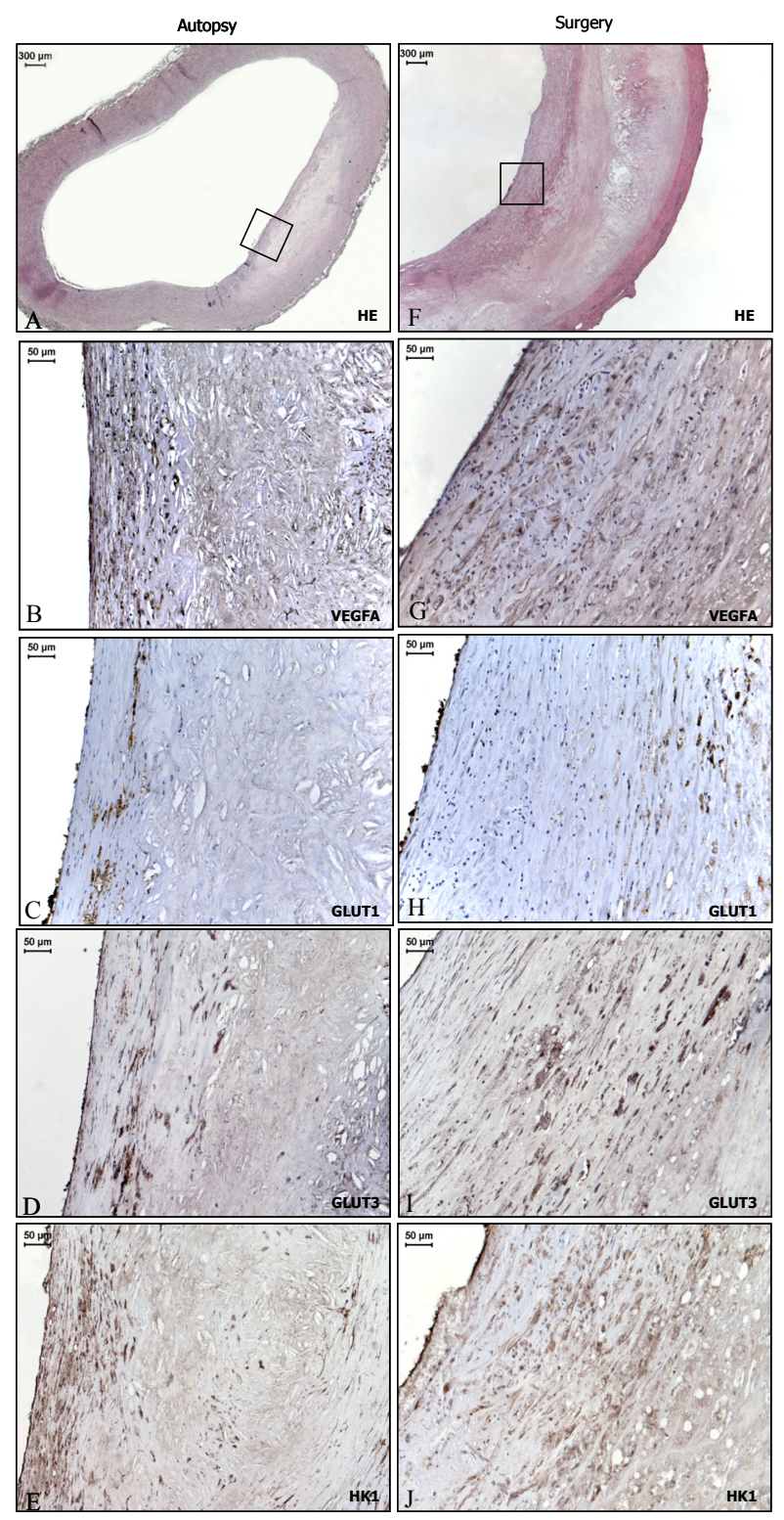

Figure 2.2

Immunohistochemical staining of proteins involved in hypoxia-driven pathways. Advanced lesions from autopsy (A-E) and surgery (F-J) were immunohistochemically stained and quantitative analysis showed similar immunoreactivity of VEGFA (B, G), GLUT1 (C, H), GLUT3 (D, I) and HK1 (E, J) between autopsy and surgery. 


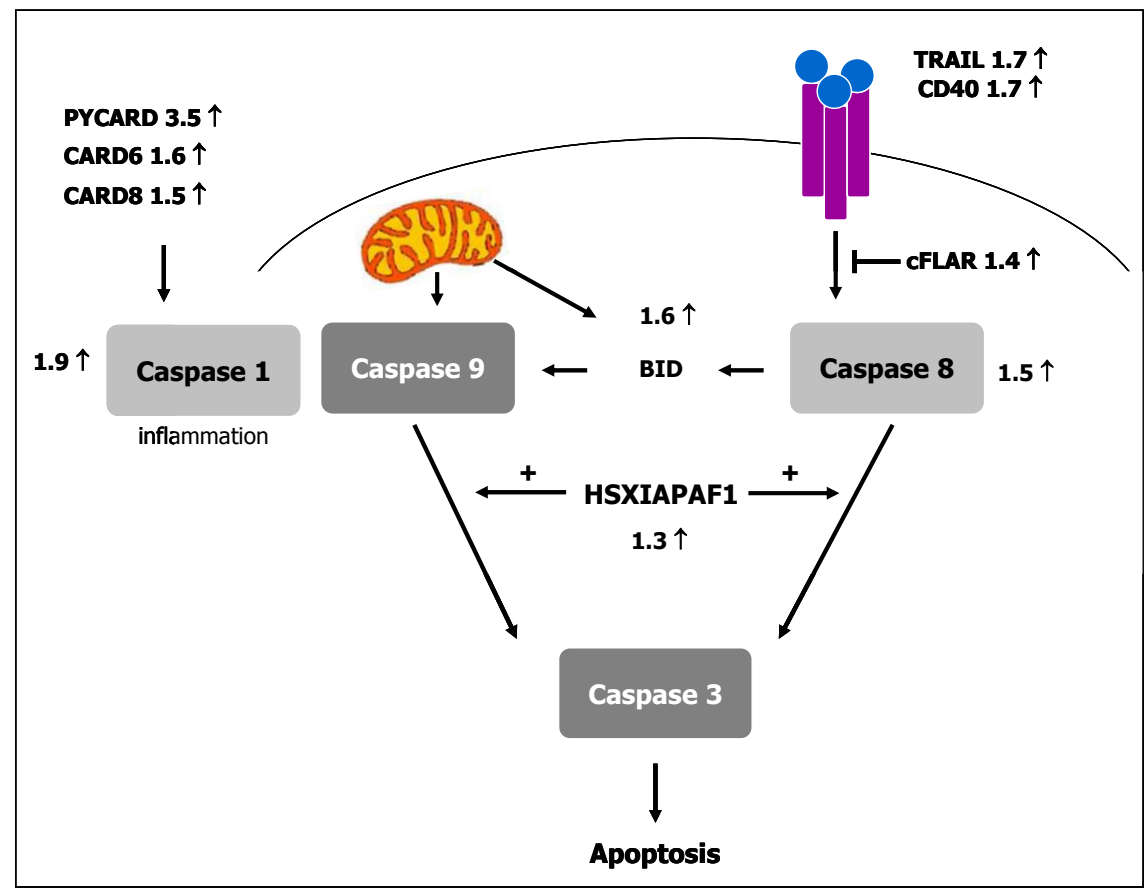

Figure 4.1

Summary of the interactions between the differentially expressed genes in relation to the initiation of apoptosis. Pathway analysis and extensive literature mining resulted in the following connections. Caspase1, CARD 6, CARD8 and PYCARD are involved in the intrinsic mediated initiation of apoptosis. TRAIL, CD40, Caspase 8 and cFLAR are involved in the initiation of apoptosis via the extrinsic pathway. HSXIAPAF and BID are genes which are involved in downstream effects after initiation of the two pathways. The fold increase in mRNA levels in advanced lesions is indicated for each gene 

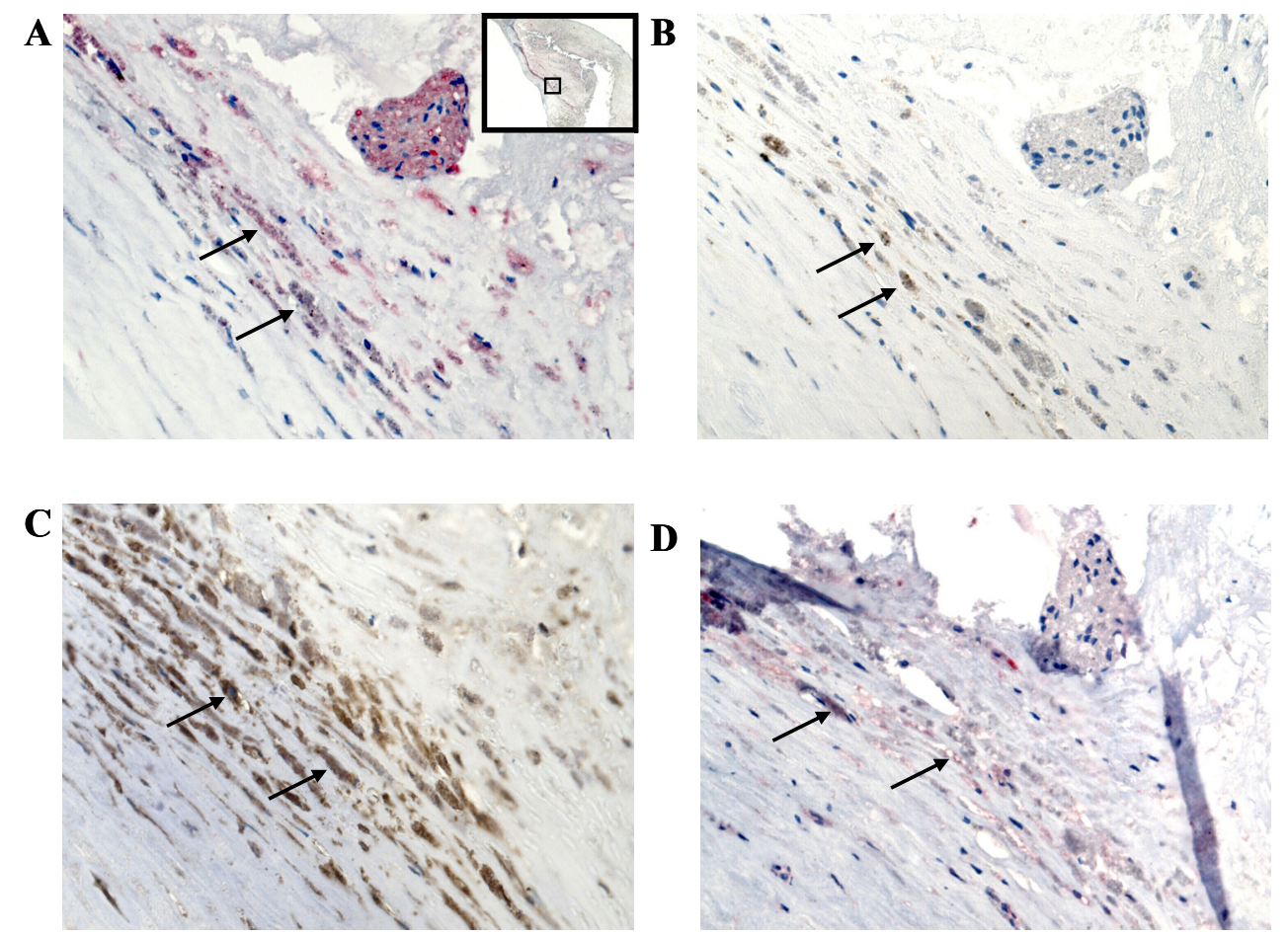

\section{Figure 4.3}

Human atherosclerotic macrophages undergo apoptosis. CD68 immunoreactivity (red) showing the localization of macrophages in an advanced atherosclerotic lesion (A). Macrophages are the predominant cell type staining positive (brown) for cleaved caspase 3 (B), indicative for apoptosis, and the macrophages do express TRAIL (brown) (C). Immunohistochemical analysis also demonstrated that the macrophages express TRAIL receptor with a dead activating domain (red) (D). 400x magnification, inset $25 x$ magnification. 

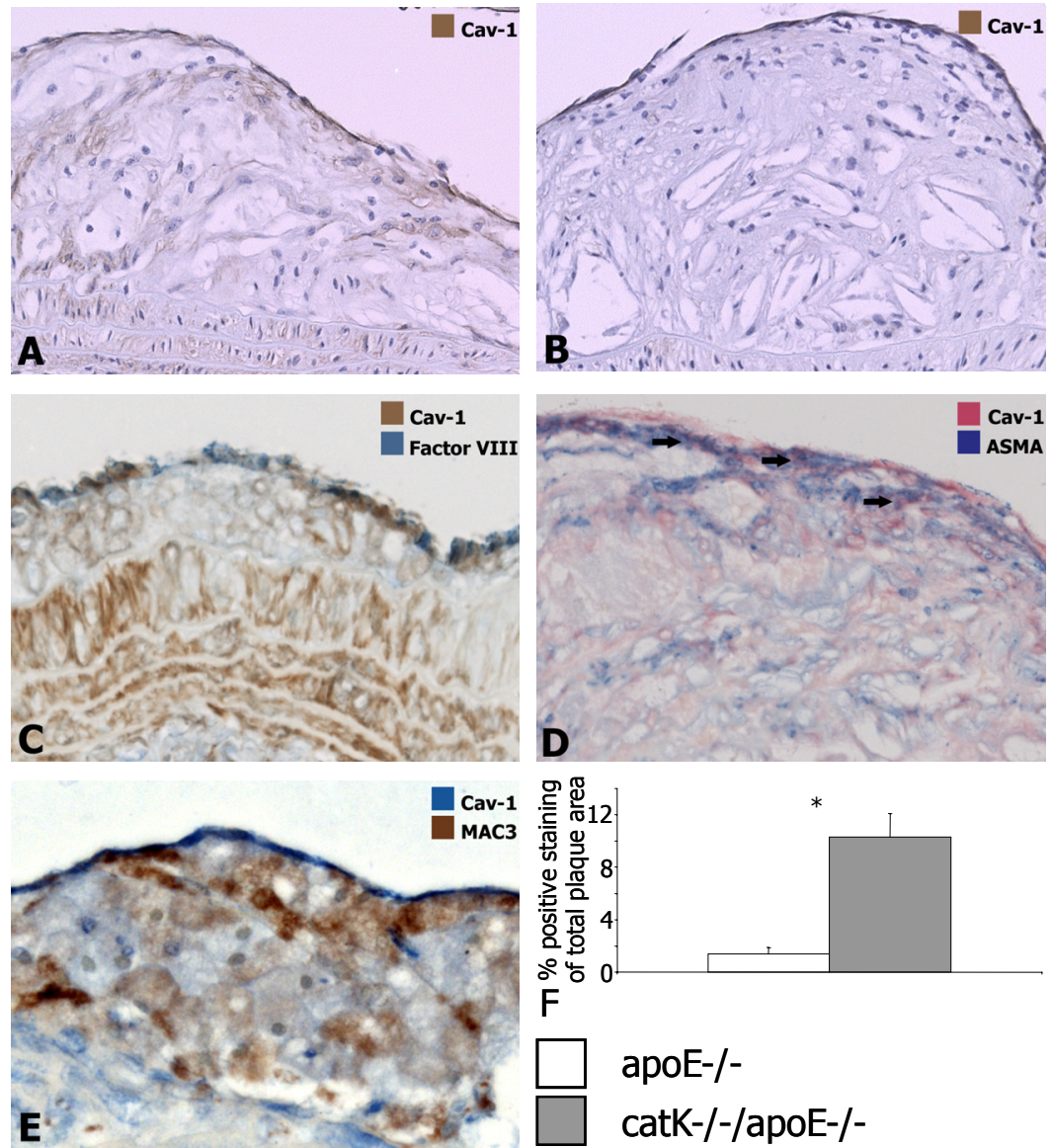

Figure 5.2

Representative immunohistochemical staining showing that caveolin-1 (brown) was localized, especially in lesional macrophages and endothelial cells, in catK-/-/apoE-/- mice (A) in comparison with apoE-/- mice (B). Double immunohistochemistry showed that caveolin-1 was localized in endothelial cells (C) caveolin-1 in brown and factor VIII in blue), only sporadically in SMCS (D) caveolin-1 in red, a-smooth muscle actin in blue, indicated with black arrows), and in macrophages (E) caveolin-1 in blue, MAC3 in brown). Atherosclerotic lesions of catK-/-/apoE-/mice showed increased caveolin-1 protein levels when in comparison with apoE-/- (F). Asterisk indicates $P<0.05$, and data are presented as mean \pm SEM. 

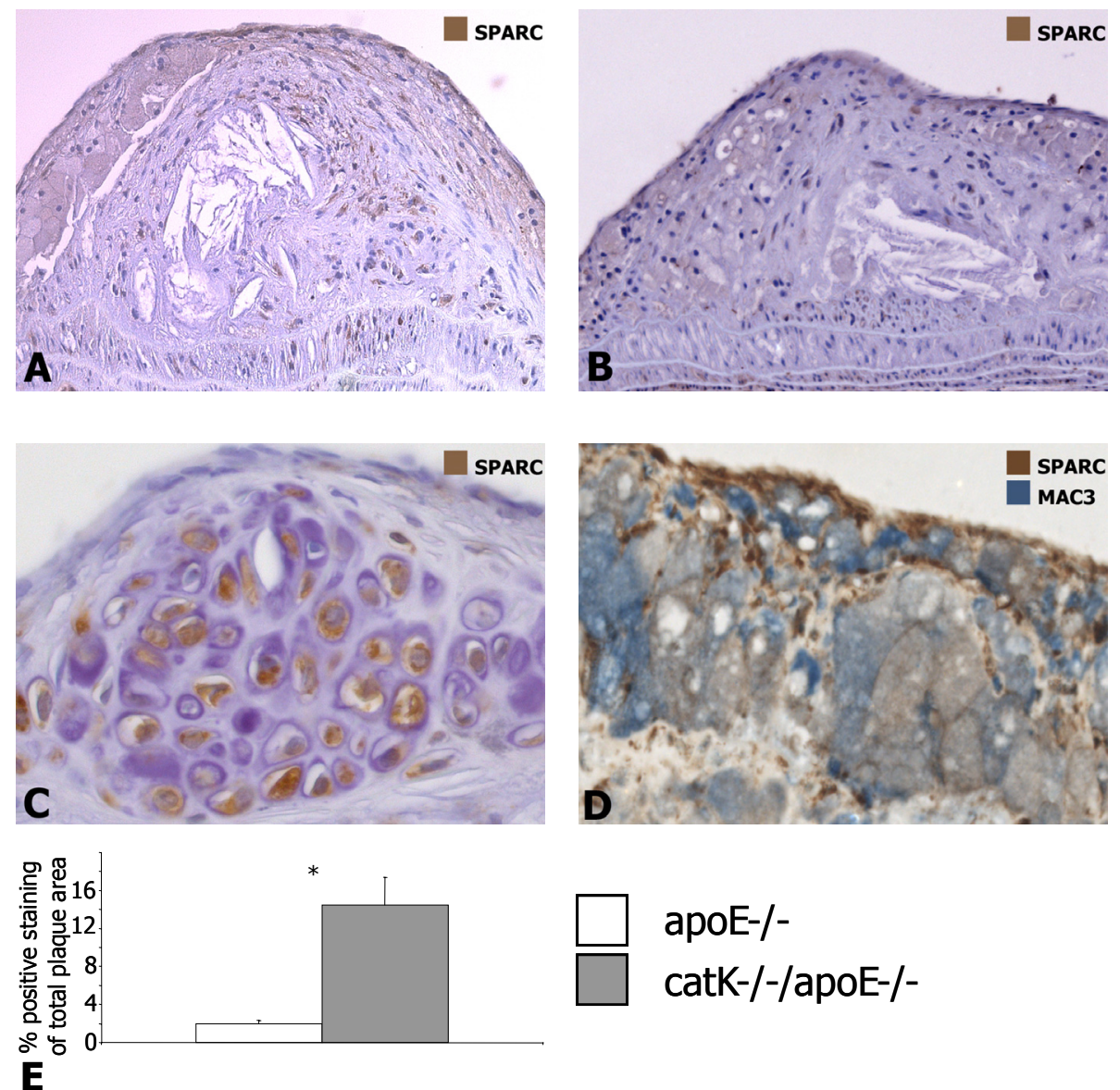

\section{$\mathbf{E}$}

Figure 5.3

Representative immunohistochemical staining showing that SPARC (brown) was especially localized in lesional macrophages and endothelial cells in catK-/-/apoE-/- (A) compared with apoE-/- (B). SPARC staining showed positivity in chondroid-like cells in both lesion types (C). Double immunohistochemistry showed that SPARC was localized in lesional macrophages especially (D) SPARC in brown, MAC3 in blue). Atherosclerotic lesions of catK-//apoE-/- mice showed increased SPARC protein levels in comparison with apoE-/- (E). Asterisk indicates $\mathrm{P}<0.05$, and data are presented as mean \pm SEM. 

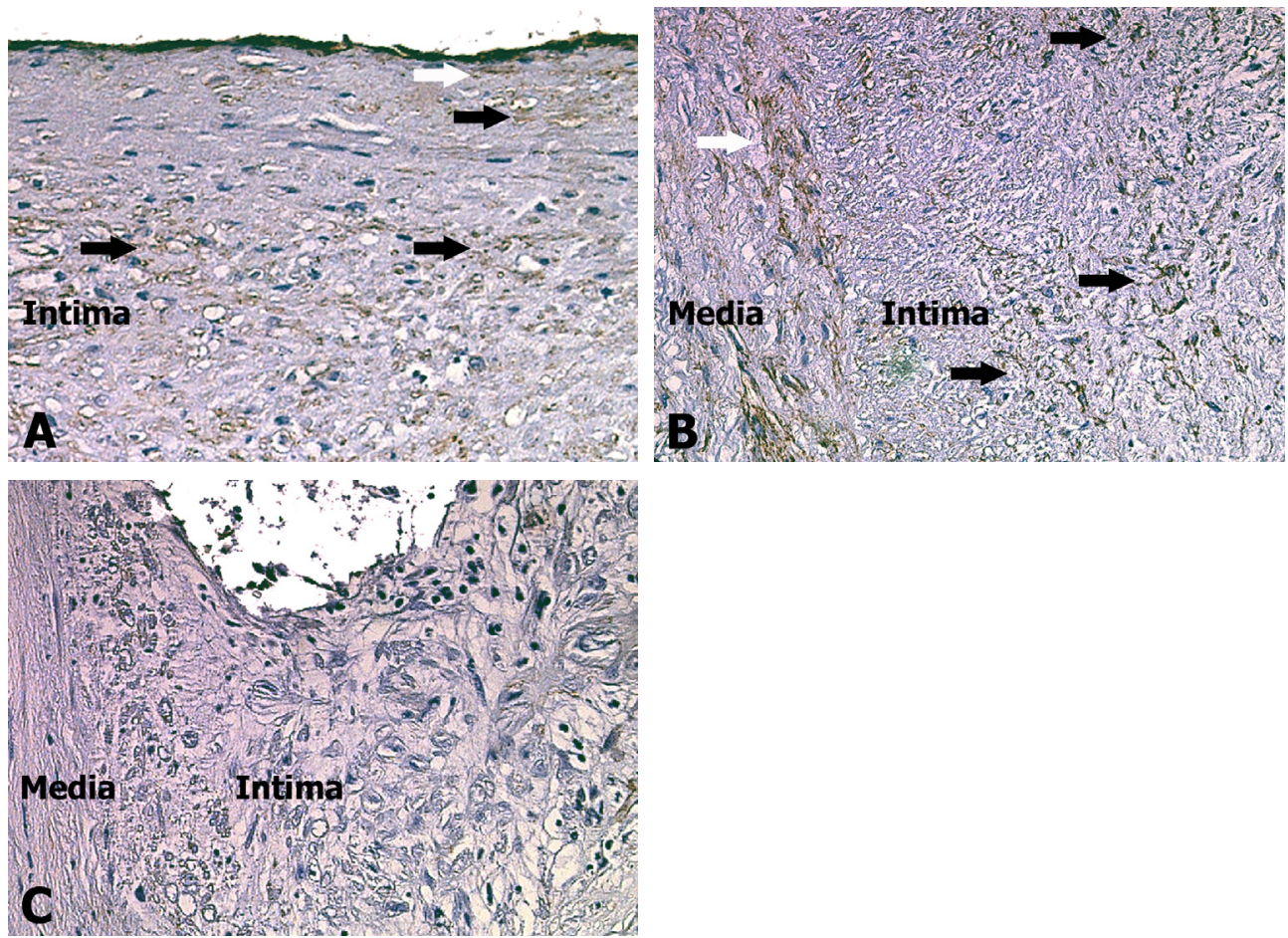

Figure 5.5

Representative immunohistochemical staining of human atherosclerotic lesions. Caveolin-1 staining (brown) is localized in smooth muscle cells (white arrows) and macrophages (black arrows) in early lesions (A) and stable advanced lesions (B), and to a lesser extent in lesions containing a thrombus (C). 
Full color pictures

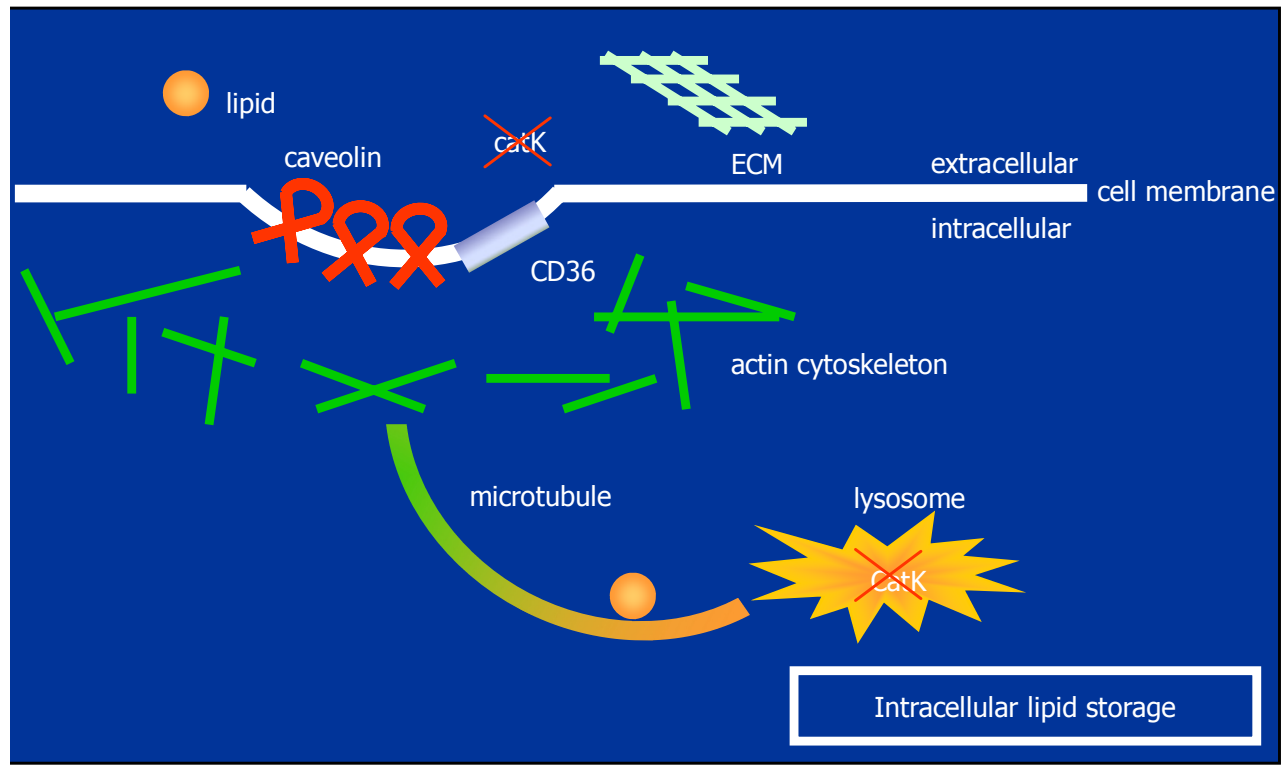

Figure 5.7

Putative mechanism by which cathepsin $\mathrm{K}$ (catK) deficiency leads to a pro-fibrotic, but also lipogenic lesion phenotype. In the cathepsin $\mathrm{K}$ deficient macrophage, lipid uptake is increased. This increased lipid uptake is mediated by both CD36 and caveolins. Then, lipid is transported, possibly via the actin cytoskeleton, to the interior of the cell and stored in lysosomes which have increased in size 
Full color pictures

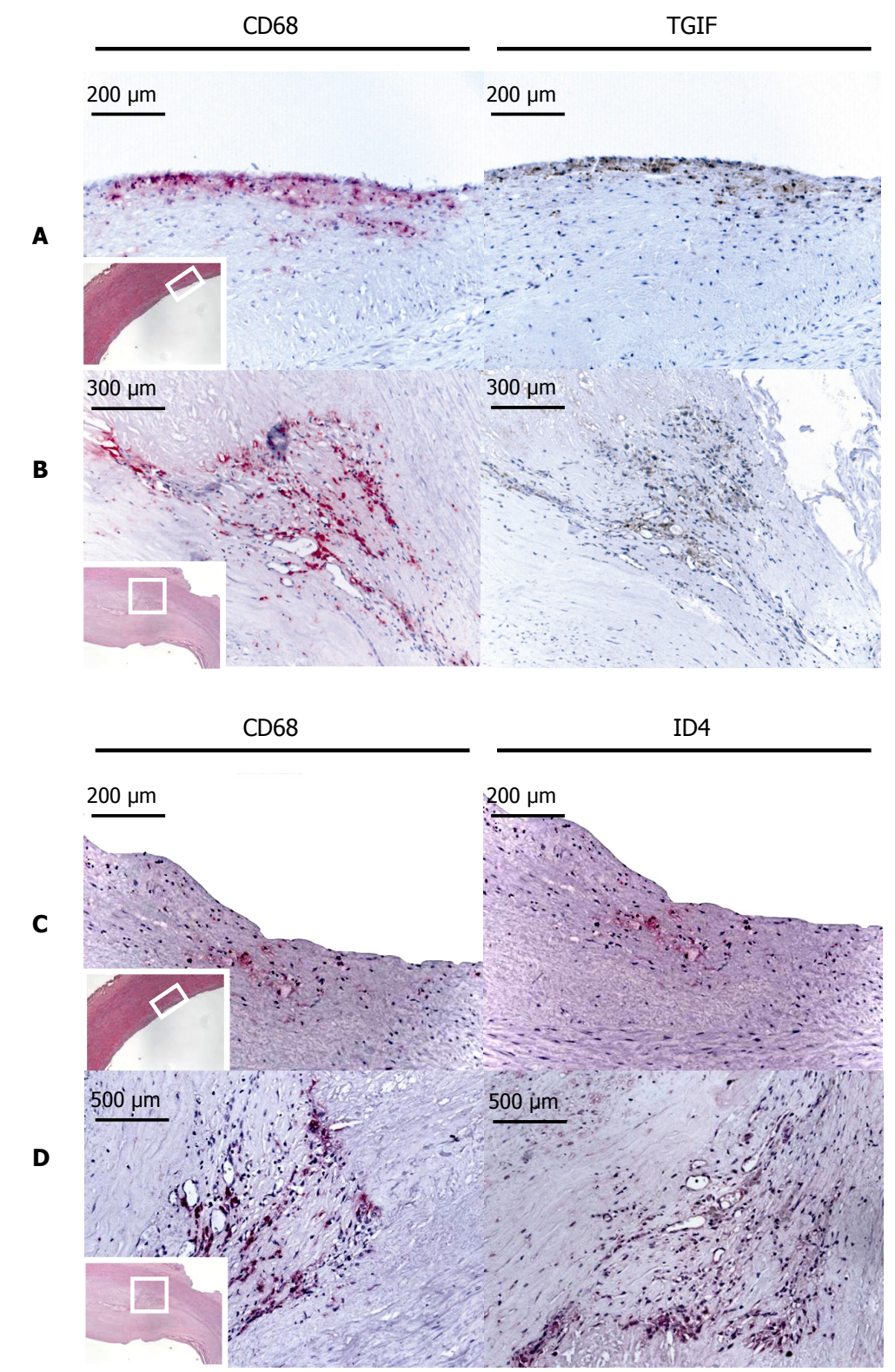

Figure 6.1

Co-localization of TGIF, ID4 and CD68 protein in human atherosclerotic lesions. Immunohistochemical detection of TGIF (brown), ID4 (red) and CD68 (macrophages, red) in carotid arteries with early ( $\mathrm{A}, \mathrm{C}$ ) and advanced stable lesions (B, D). 
Full color pictures
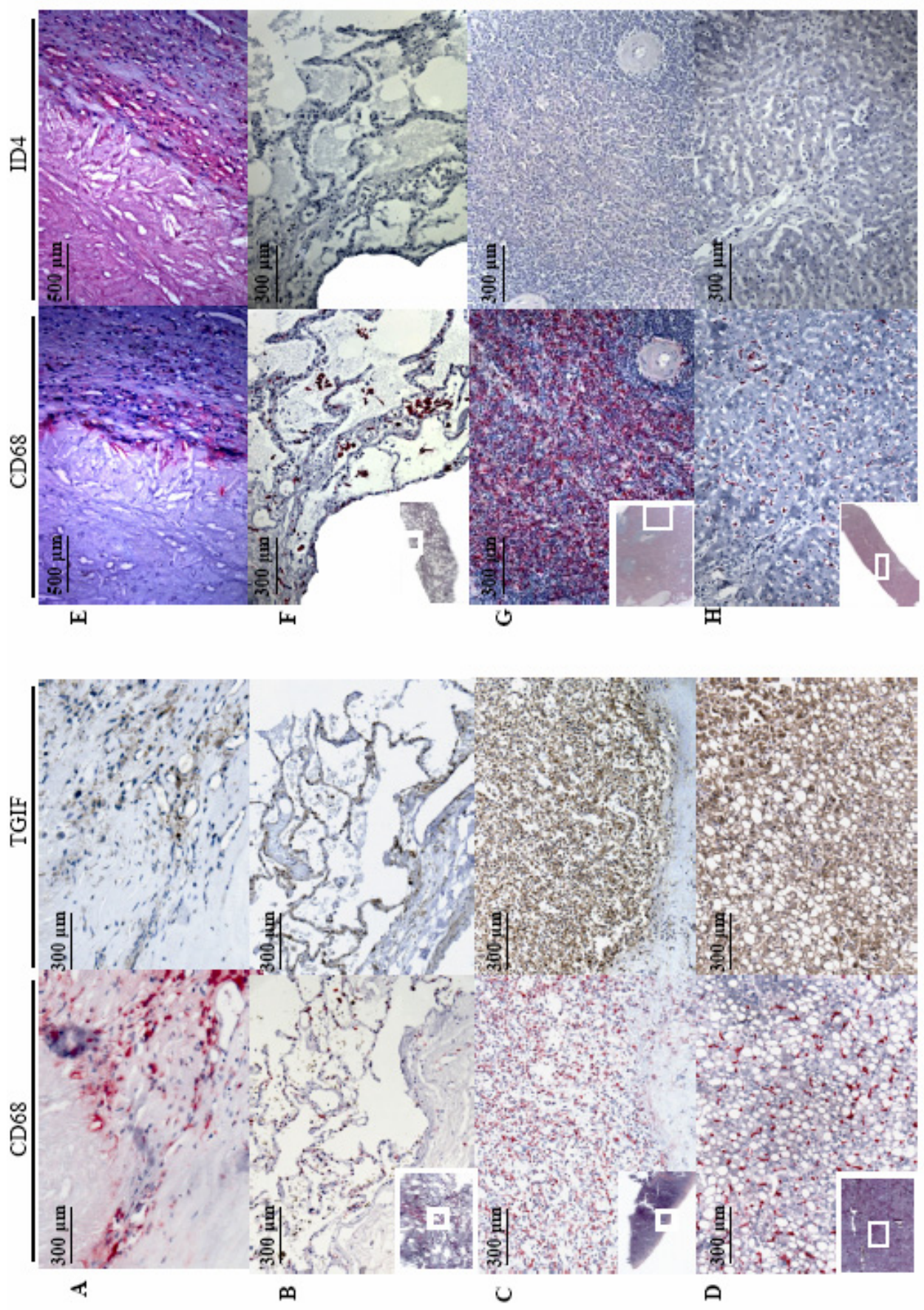
Figure 6.3

Immunolocalization of ID4 and TGIF in atherosclerotic and non atherosclerotic tissues. Immunohistochemical detection of CD68 (macrophages, red), TGIF (brown) and ID4 (red), in advanced atherosclerotic lesions (A, E) normal lung $(B, F)$, spleen $(C, G)$, liver $(D, H)$. TGIF is expressed in CD68 positive macrophages from advanced atherosclerotic lesions (A), lung (B), spleen (C) and liver (D). ID4 is expressed in macrophage-derived foam cells in advanced stable atherosclerotic lesions (E), but absent in CD68 positive macrophages of the lung (F), spleen (G) and liver $(\mathrm{H})$.containing these genes were not ranked in the top of the most prominent differential networks. This finding can be easily explained by the fact that in both lesions stages the majority of the isolated macrophages represent foam cells characterized by the intra cellular presence of lipids 


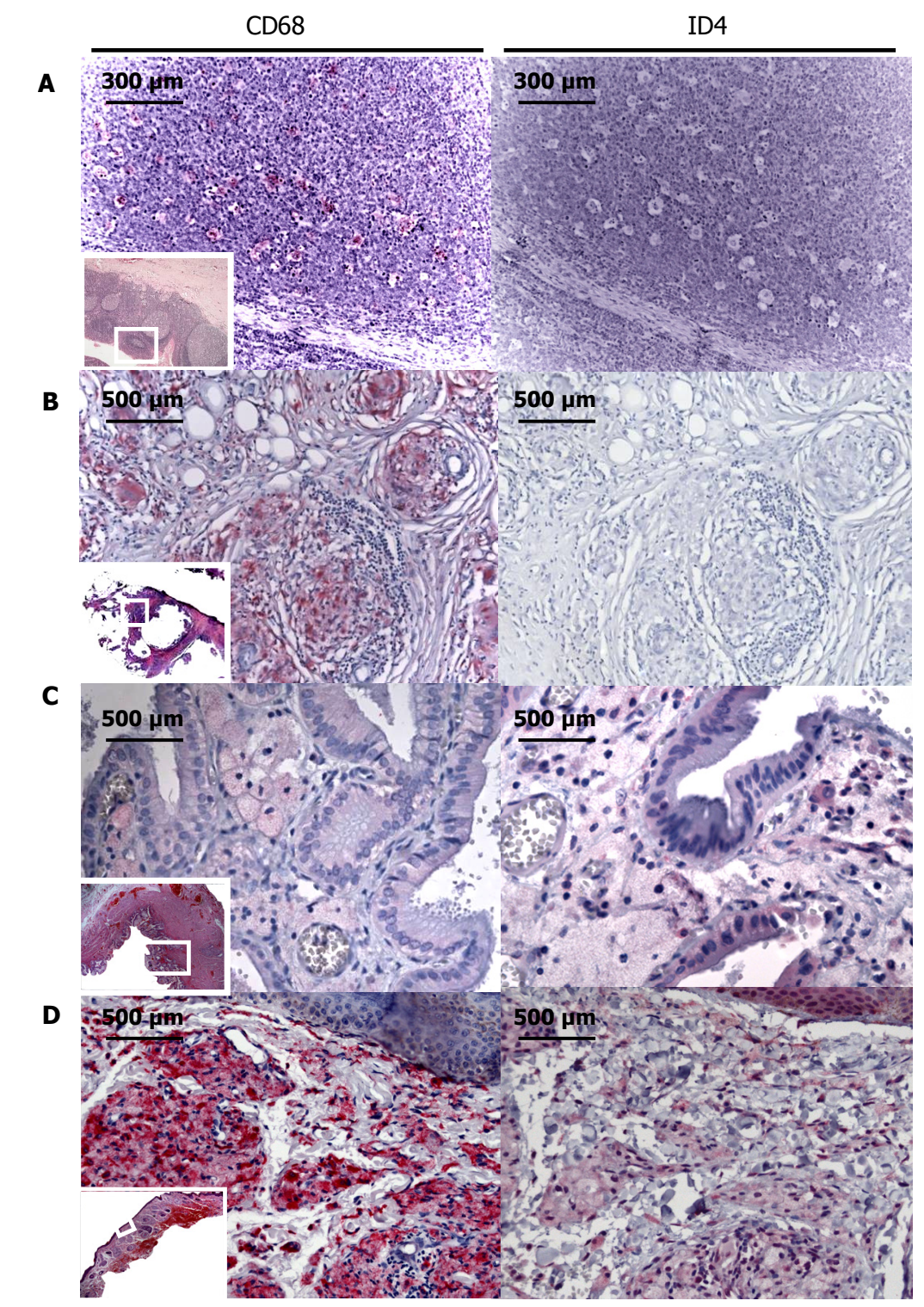

Figure 6.4

Immunolocalization of ID4 in non atherosclerotic tissues. Immunohistochemical detection of ID4 (red) and CD68 (macrophages, red) protein expression in inflamed tonsil (A), lung with sarcoidosis (B), gall bladder with cholesterolosis (C) and skin with xanthelesma (D). ID4 is expressed in macrophage-derived foam cells in gall bladder with cholesterolosis (C) and skin with xanthelesma (D), but absent in the CD68 positive macrophages of inflamed tonsil (A) and lung with sarcoidosis (B). 
Full color pictures
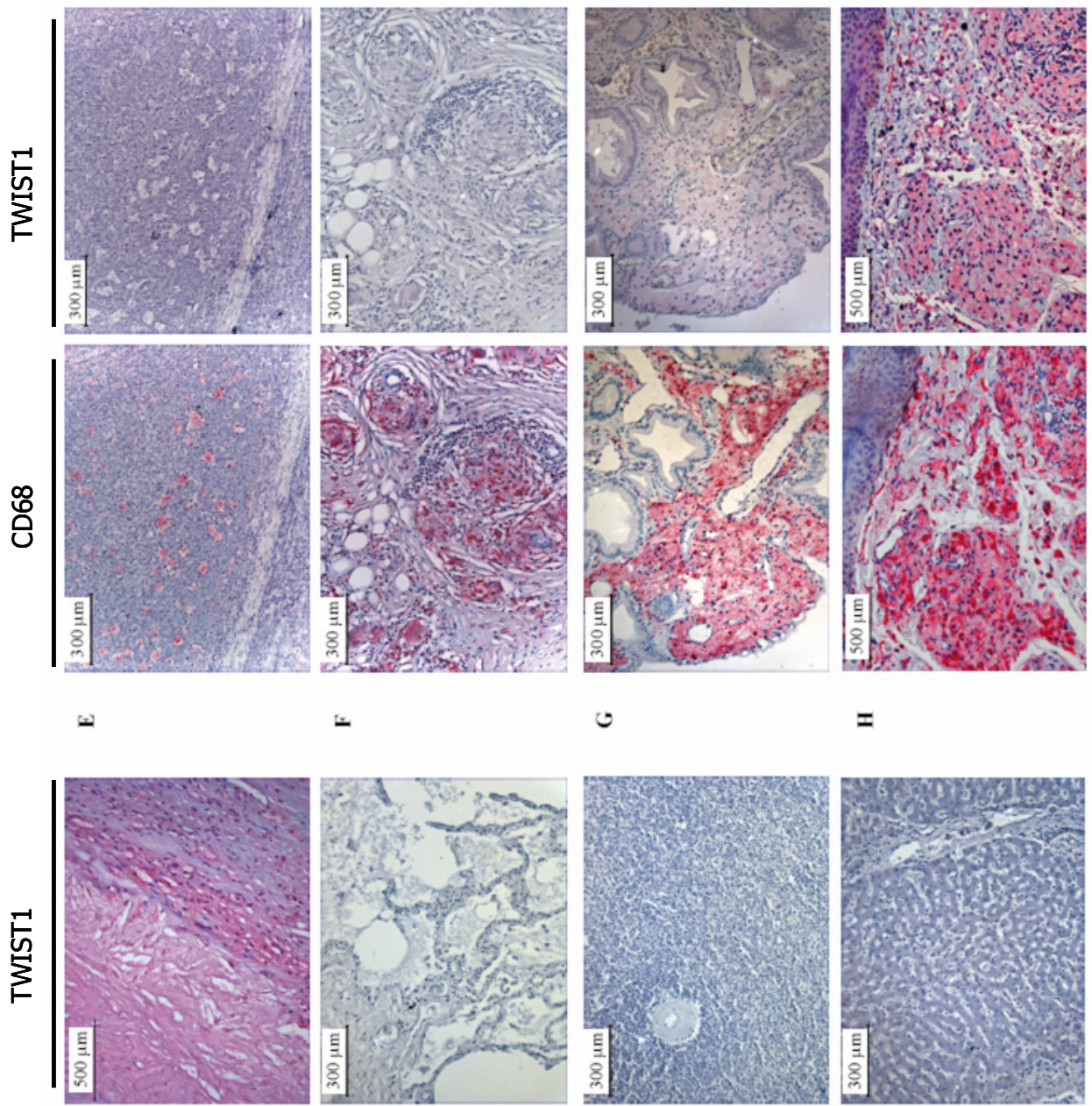

$=$
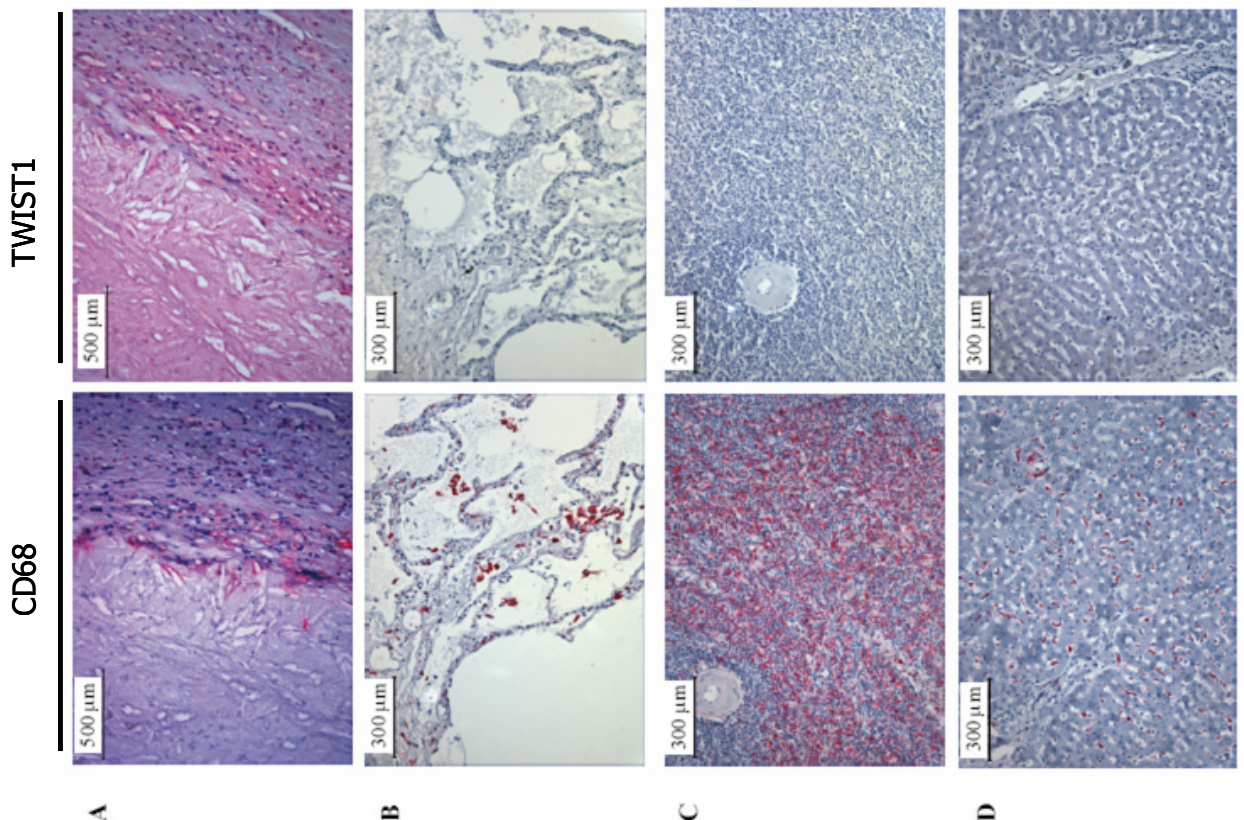

a 
Full color pictures

\section{Figure 7.4}

Immunolocalization of TWIST1 in human atherosclerotic and non-atherosclerotic tissues. Immunohistochemical detection of CD68 (macrophages, red) and TWIST1 (red) in advanced stable atherosclerotic lesions (A), normal lung $(B)$, spleen $(C)$, liver $(D)$, inflamed tonsil $(E)$, lung with sarcoidosis $(F)$, gall bladder with cholesterolosis $(G)$ and skin with xanthelasma(H). TWIST1 is expressed in macrophage-derived foam cells in atherosclerotic lesions (A), gall bladder with cholesterolosis $(\mathrm{G})$ and skin with xanthelasma $(\mathrm{H})$, but absent in the CD68 positive macrophages of other inflamed (E-F) and non-inflamed (B-D) tissues.

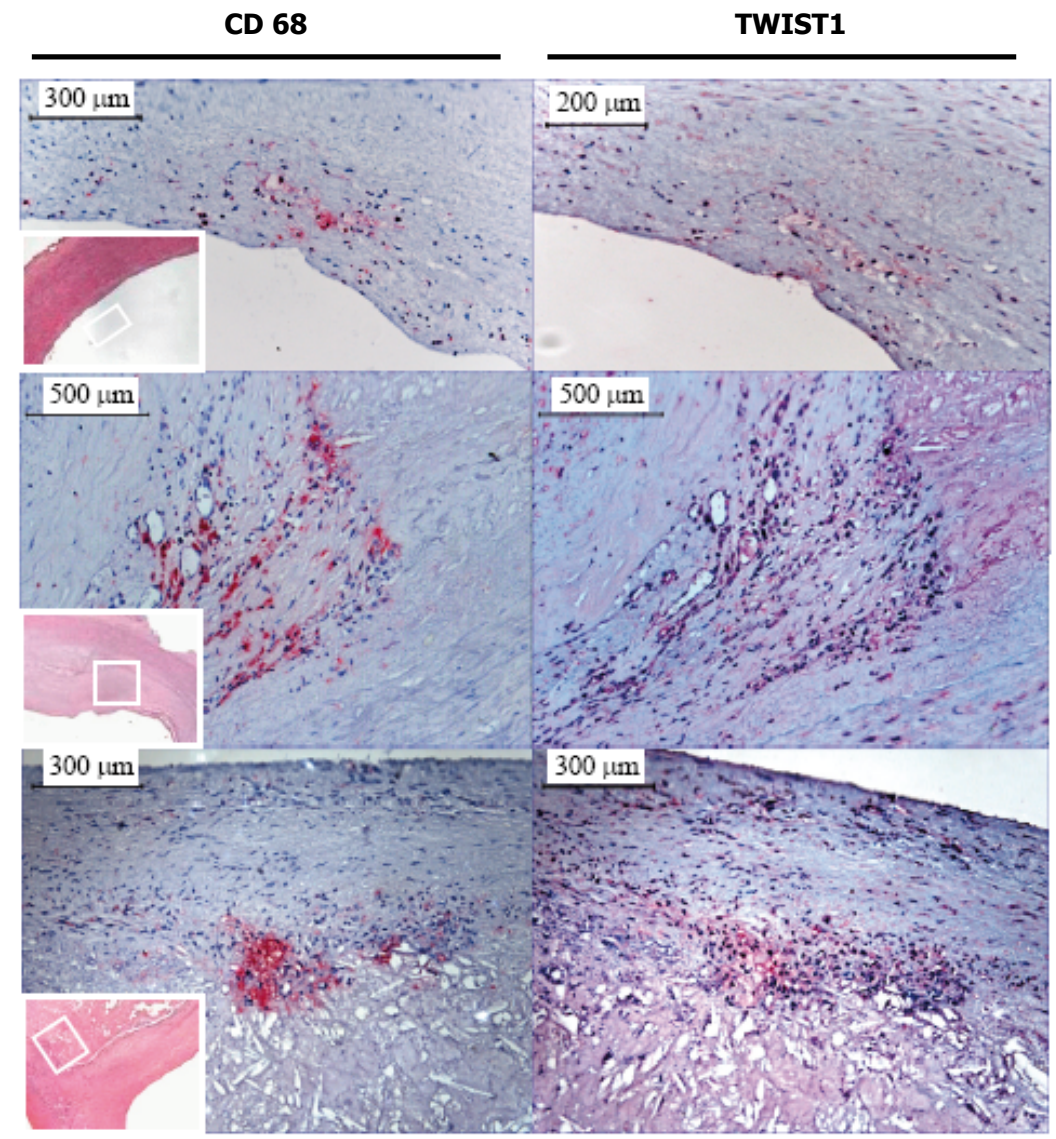

Figure 7.5

Immunolocalization of CD68 and TWIST1 in human carotid arteries with different stages of atherosclerosis. Immunohistochemical detection of CD68 (macrophages, red) and TWIST1 (red) in carotid arteries with intimal thickening (A), advanced stable lesion (B) or lesion with a thrombus (C ). 


\section{SUMMARY}

Cardiovascular diseases, such as myocardial infarction and stroke, are the leading cause of death in the western society. The main underlying pathology of many cardiovascular diseases is atherosclerosis. Atherosclerosis is a progressive, lipid associated inflammatory disease of the larger and medium sized arteries. The early stages of atherosclerosis, which already develop during the first decade of life, usually do not give any clinical symptoms. As the atherosclerotic lesions progress in time they can become more unstable and eventually rupture. Rupture of such an atherosclerotic lesion and the subsequent thrombus formation will lead to the acute clinical complications such as myocardial infarction and stroke.

At present the exact molecular mechanisms underlying (human) atherosclerosis are not fully elucidated. One way to unravel these molecular mechanisms is by performing genome wide gene expression studies such as microarray hybridizations. A potential concern of these human expression studies is the variability or heterogeneity which might be present between or within the samples. This heterogeneity will be reflected in the gene expression profiles and can lead to a decrease in statistical power. The major changes in gene expression profiles, caused by for instance changes in celltypes, locations of the vascular bed or patients, will be detected despite the variability/heterogeneity. However subtle changes in gene expression profiles between a certain patient population, vascular bed or celltype can be missed because of the heterogeneity. Our main hypothesis is that a study design which takes heterogeneity into account will enable the detection of genes and/or pathways that show subtle changes in expression. To test this hypothesis we first defined the different levels of heterogeneity, i.e. sample source heterogeneity, patient heterogeneity and lesion heterogeneity (as described in chapter 1). Subsequently we designed each study in such way that the influence of the defined sources/levels of heterogeneity could be investigated.

In chapter 2 and 3 we focused on sample source heterogeneity. In chapter 2 we compared the gene expression profiles from advanced atherosclerotic lesions obtained either during autopsy or surgery to study the influence of sample source heterogeneity. The gene expression profiles of advanced atherosclerotic lesions obtained during surgery or autopsy are largely similar. However, over 500 genes, mostly involved in basal cell metabolism and hypoxia, were differentially expressed at the mRNA level. Although differential gene expression of the hypoxia-related genes could not be confirmed at the protein level, human gene expression using samples from both sources should be analyzed with care. 
In chapter 3 we compared the gene expression profiles from stable atherosclerotic lesions obtained from various sites of the vasculature. Our analysis revealed several genes to be specifically differentially expressed in the abdominal aorta (36 genes), thoracic aorta (57 genes), aortic arch (58 genes) and the carotid artery (58 genes). Pathway analysis and literature mining on these specific genes could associate several biological processes with a single site of the vascular bed. These data could provide new insights in site specific mechanisms of atherosclerosis and could be further explored to unravel the mechanisms underlying the different susceptibility of distinct sites of the vasculature to develop atherosclerosis.

In chapter 4 of this thesis we performed an intra vessel comparison to eliminate heterogeneity introduced by combining different patients, for instance gender, age and use of medications. We compared the gene expression profiles from early and advanced atherosclerotic lesions within the same carotid artery. Pathway analysis revealed a group of genes with only subtle but consistent upregulated expression levels in advanced atherosclerotic lesions compared to early lesions. These genes were involved in either the intrinsic or extrinsic initiation pathways of apoptosis. One of the genes known to be involved in the initiation of the extrinsic apoptosis pathway, TRAIL, was further validated in vitro. These in vitro studies showed that TRAIL was able to induce apoptosis in macrophages. These data together with the gene expression data indicate TRAIL to be an interesting candidate for therapeutic interventions in atherosclerosis.

In chapter 5 we studied the effect of deficiency of cathepsin K, one of the genes identified to be differentially expressed in chapter 4 , on atherogenesis by performing gene expression profiling on aortic arches of catK-/-/ apoE-/- and apoE-/- mice. Pathway profiling linked the differentially expressed genes CD36 and caveolin-1, 2 and 3 to the lipid metabolism. In vitro validation of these microarray data confirmed the contribution of both CD36 and the caveolins in foam cell formation in cathepsin $\mathrm{K}$ deficient mice. In addition, the microarray data suggested that cathepsin $\mathrm{K}$ deficiency not only alters the lesion phenotype by decreasing proteolytic activity but also by increasing TGF $\beta$ signaling.

In chapter 6 and 7 cellular heterogeneity was addressed. In chapter 6 we compared the gene expression profiles of macrophages microdissected from early lesions with macrophages from advanced atherosclerotic lesions. Pathway profiling of the differential expressed genes revealed prominent roles for pathways involved in cell death, cell cycle, cellular growth and proliferation and cell-cell interaction and signaling in atherosclerotic macrophages. These pathways contained several genes related to TGF $\beta$ and two interesting 
transcription factors, ID4 and TGIF. These two transcription factors were upregulated in macrophages from advanced lesions compared to macrophages from early lesions. Interestingly, both these genes were also expressed at significantly higher levels in atherosclerotic macrophages compared to macrophages from non-atherosclerotic tissues, such as liver, lung and spleen. Although the role of TGIF and ID4 during atherogenesis remains to be defined it is tempting to speculate that both genes form an attractive molecular target to modulate the progression of atherosclerosis. In chapter 7 we further studied atherosclerotic macrophage specific gene expression by comparing the transcriptional profiles of atherosclerotic macrophages and non-atherosclerotic macrophages from liver, lung and spleen. Microarray analysis revealed 42 genes showing significantly higher expression levels in atherosclerotic macrophages. One of these genes was TWIST1, a transcription factor known to be involved in inflammation but not linked to atherosclerosis before. Validation of the microarray confirmed higher TWIST expression in atherosclerotic macrophages and demonstrated the absence of TWIST1 protein expression in the macrophages from 11 non-atherosclerotic macrophages. In contrast, foam cells in gallbladder and xanthelasma did show TWIST1 protein expression. In vitro experiments further showed an increase in TWIST expression during foam cell formation and in response to LPS stimulation. These data demonstrate that TWIST is specifically expressed in foamy macrophages and macrophages subjected to inflammatory stimuli such as LPS.

In chapter 8 the findings of this thesis and their implications are discussed. We showed that variability in the gene expression profiles could be introduced from the patient down to the cellular level. We conclude that the research question should determine the allowed level of heterogeneity and therefore the experimental setup. The development of amplification techniques to obtain sufficient RNA from as little as a few cells has opened ways to minimize heterogeneity. By decreasing the heterogeneity in an experimental design in combination with the introduction of pathways analysis we provide an elegant research strategy to identify novel genes and pathways underlying atherosclerosis. 


\section{SAMENVATTING}

In de westerse wereld zijn cardiovasculaire ziekten zoals een hartinfarct en een herseninfarct de belangrijkste doodsoorzaak. De onderliggende oorzaak van deze cardiovasculaire ziekten is atherosclerose (aderverkalking). Atherosclerose is een progressieve, vet geassocieerde ontstekingsziekte van de middelgrote en grote bloedvaten. De eerste stadia van atherosclerose ontstaan al in de eerste decennia van het leven, maar deze vroege laesies veroorzaken geen klinische complicaties. Naar mate de atherosclerotische laesies groter of gecompliceerder worden kunnen ze instabiel worden en uiteindelijk open scheuren (ruptureren). Wanneer een laesie ruptureert, wordt de inhoud van de leasie blootgesteld aan het bloed waardoor er een bloedstolsel ontstaat (een thrombus). Deze thrombus kan het bloedvat compleet afsluiten en hierdoor ontstaan de klinische symptomen zoals een hartinfarct en een herseninfarct.

Op dit moment zijn de moleculaire mechanismen die verantwoordelijk zijn voor het ontstaan en verergeren van atherosclerose nog niet helemaal ontrafeld. $\mathrm{Er}$ zijn verschillende manieren om dit te onderzoeken. Een manier is om de genexpressie te besturen door gebruik te maken van microarrays. Genen zijn de bouwstenen van ons lichaam .Door te kijken hoeveel en welke bouwstenen er in het ene weefsel monster zitten ten op zichte van het ander, kunnen we een uitspraak doen over de processen die geactiveerd zijn in het ene monster ten op zichte van het ander. Een microarray is een glaasje waarop bijna alle bouwstenen van ons lichaam, een genexpressie profiel, geprint zijn en waarmee we in één keer iets kunnen zeggen over de activatie van al die bouwstenen. Een potentiële zorg van humane genexpressie studies is de heterogeniteit of variabiliteit die mogelijk aanwezig is tussen of in verschillende weefselmonsters. De variabiliteit tussen of in de monsters zal immers weerspiegeld worden in de genexpressie profielen. Dit kan ten koste gaan van de statistische power die nodig is om verschillen te kunnen detecteren. Ondanks heterogeniteit kunnen we de grote verschillen tussen onze groepen detecteren. Echter, de subtiele verschillen in de genexpressie profielen van bijvoorbeeld laesies op een specifieke plek in het vaatbed, een bepaalde groep patiënten of een bepaald type cellen in de laesie zullen waarschijnlijk gemist worden. In dit proefschrift hebben we onderzocht wat het effect is op de genexpressie profielen wanneer we de heterogeniteit zo klein mogelijk maken. Hiervoor hebben we eerst een aantal vormen van heterogeniteit gedefinieerd, te weten weefselmonster oorsprong heterogeniteit, patiënt heterogeniteit en laesie heterogeniteit (dit staat beschreven in hoofdstuk 1). Vervolgens hebben we elke studieopzet zo gedefinieerd dat het mogelijk was om de invloed van een van de hierboven genoemde vormen van heterogeniteit te bestuderen. 
Om de genexpressie profielen van humane atherosclerotische laesies te kunnen bestuderen zijn we vaak genoodzaakt weefselmonsters gebruiken die afkomstig zijn van verschillende plekken in het lichaam of van levende en overleden donoren. Het combineren van monsters van verschillende oorsprong kan heterogeniteit introduceren en dit type heterogeniteit hebben we onderzocht in hoofdstuk 2 en 3.

In hoofdstuk 2 zijn de genexpressie profielen van gevorderde atherosclerotische laesies, die verkregen zijn van een levende donor (tijdens een operatie) vergeleken met de profielen afkomstig van een overleden donor (via obductie). De resultaten van de microarray analyse en de daaropvolgende validatie door middel van kwantitatieve PCR en immunohistochemie lieten zien dat de genexpressie profielen van vergevorderde atherosclerotische laesies van obductie en operatie grotendeels vergelijkbaar waren. De verschillen in genexpressie die werden waargenomen spelen een rol in hypoxie gerelateerde processen en basale cel processen. We concluderen dan ook dat humane genexpressie studies die weefselmonsters gebruiken afkomstig van zowel operatie en obductie zorgvuldig geanalyseerd moeten worden, vooral wanneer men geïnteresseerd is juist deze processen.

In hoofdstuk 3 hebben we de genexpressie profielen van stabiele atherosclerotische laesies, verkregen van verschillende plekken in het lichaam met elkaar vergeleken. De analyse methode die we hebben gebruikt, leverde een kleine hoeveelheid genen op die specifiek voor een bepaalde plek in het lichaam verschillend tot expressie kwamen ten opzichte van het referentie bloedvat. Het bestuderen van de literatuur van deze specifieke genen in combinatie met het toepassen van pathway profiling programma's liet ons zien dat specifieke biologische processen geassocieerd waren met de verschillende plekken van het lichaam. Zo zijn bijvoorbeeld specifiek in de halsslagader genen verschillend geïdentificeerd die betrokken zijn bij het ontstekings/ en immuniteits proces. De resultaten van deze studie kunnen leiden tot het verkrijgen van nieuwe inzichten in het ontstaan van atherosclerose op specifieke plekken in het lichaam.

Het combineren van weefselmonsters verkregen van meerdere patiënten in een studie kan ook heterogeniteit introduceren vanwege onderlinge verschillen. Ze kunnen bijvoorbeeld verschillen in geslacht, leeftijd, levensstijl en geneesmiddelengebruik. Om deze heterogeniteit te verminderen hebben we in hoofdstuk 4 de genexpressie profielen van vroege en vergevorderde laesies binnen één bloedvat (dus binnen één patient) met elkaar vergeleken. De microarray analyse in combinatie met het toepassen van pathway profiling leverde een groep genen op die marginaal, maar consequent verschillend waren 
tussen de twee laesie stadia. Al deze genen kwamen meer tot expressie in het late laesie stadium en waren betrokken bij het induceren van geprogrammeerde celdood (apoptose). Van een van deze genen, TRAIL, is al eerder aangetoond dat het betrokken was bij het induceren van apoptose. Verdere validatie in vitro liet zien dat dit gen in staat was apoptose te induceren in een belangrijk celtype van de atherosclerotische laesie, de macrofaag. Deze resultaten wijzen erop dat TRAIL een interessante kandidaat zou kunnen zijn voor therapeutische interventies binnen atherosclerose.

In hoofdstuk 5 werd het effect op atherosclerose bestudeerd van cathepsine $\mathrm{K}$ deficiëntie, een ander interessant gen dat verschillend tot expressie kwam in hoofdstuk 4. Cathepsine $\mathrm{K}$ is een proteolytisch enzym dat de matrix rondom cellen kan afbreken en zo mogelijk een rol in de progressie van atherosclerose speelt. Hiervoor werden de genexpressie profielen van aortabogen van cathK-//apoE-/- en apoE-/- muizen met elkaar vergeleken door middel van microarrays. Pathway profiling onthulde een mogelijke rol voor CD36 en caveolines in de functie van cathepsine $\mathrm{K}$ in atherosclerose. In vitro validatie experimenten hebben vervolgens bevestigd dat CD36 en de caveolines van belang zijn bij de schuimcelvorming in cathepsine $\mathrm{K}$ deficiënte macrofagen. Daarnaast suggereerde de pathway profiling resultaten dat cathepsine $K$ deficiëntie niet alleen via vermindering van proteolytische activiteit maar ook als gevolg van stimulering van de TGF $\beta$ signalering tot een stabieler laesie fenotype zou kunnen leiden.

Een atherosclerostische laesie bestaat uit verschillen celtypen met elk hun eigen karakteristieke eigenschappen. Wanneer de laesie in zijn geheel onderzocht wordt, kan het verschil in genexpressie van één specifiek celtype verloren gaan. In hoofdstuk 6 en 7 hebben we de invloed van deze cellulaire heterogeniteit bestudeerd.

In hoofdstuk 6 hebben we macrofagen uit vroege en vergevorderde atherosclerotische laesies geïsoleerd en de genexpressie profielen van deze macrofagen met elkaar vergeleken. Ook nu weer hebben we pathway profiling gebruikt om de rol te bepalen van de genen die verschillen tussen de macrofagen van vroege en vergevorderde laesies. De verschilgenen zijn betrokken bij processen zoals de celcyclus, celdood, celgroei en -proliferatie, cel-cel interacties en signalering. Deze processen bevatten veel genen die verbonden zijn aan de TGF $\beta$ pathway en twee interessante transcriptie factoren, ID4 en TGIF. Deze transcriptie factoren kwamen meer voor in macrofagen van een vergevorderde vergeleken met een vroege atherosclerotische laesie. Zeer interessant was het feit dat deze transcriptie factoren ook meer voorkwamen in macrofagen van atherosclerotische laesies in vergelijking met macrofagen van 
niet-atherosclerotische weefsels zoals lever-, milt- en longweefsel. Hoewel de precieze rol van deze twee transcriptie factoren in atherosclerose nog verder onderzocht dient te worden is het verleidelijk om te speculeren dat beide genen een aantrekkelijk moleculair target zouden kunnen zijn om de progressie van atherosclerose te moduleren.

In hoofdstuk 7 hebben we genexpressie specifiek voor de atherosclerotische macrofaag verder bestudeerd door de genexpressie profielen van de atherosclerotische macrofaag te vergelijken met die van niet-atherosclerotische macrofagen van lever, milt en longen. De microarray resultaten lieten 42 genen zien die meer voorkwamen in atherosclerotische macrofagen dan in macrofagen uit de niet-atherosclerotisch weefsels. Een van deze genen was TWIST1, een transcriptie factor die wel al verbonden was aan ontsteking, maar nog niet aan atherosclerose. Validatie experimenten bevestigde dat TWIST1 meer voorkwam in atherosclerotische macrofagen en dat het TWIST1 eiwit niet aanwezig was in de macrofagen van 11 onderzochte niet-atherosclerotische weefsels. Wanneer we echter (niet-atherosclerotische) weefsels onderzochten waarin veel schuimcel macrofagen aanwezig zijn, dan bleek in deze schuimcel macrofagen wel TWIST1 voor te komen. In vitro experimenten lieten vervolgens zien dat de hoeveelheid TWIST1 toenam gedurende schuimcelvorming en als gevolg van stimulatie met ontstekingsmediatoren zoals LPS. Deze data geven aan dat TWIST1 specifiek is voor schuimcel macrofagen en macrofagen die gestimuleerd worden door een ontstekingsstimulus.

In hoofstuk 8 hebben we de bevindingen van dit proefschrift en de verdere implicaties bediscussieerd. We hebben laten zien dat variabiliteit in genexpressie profielen geïntroduceerd kan worden vanaf patiënt nivo tot aan het cellulaire nivo. We concluderen dat de onderzoeksvraagstelling het toelaatbare nivo van heterogeniteit zou moeten bepalen. Verder hebben we laten zien dat het mogelijk is om vanuit enkele cellen voldoende materiaal te verkrijgen en te vermeerderen, zodat analyse van genexpressie mogelijk ismet minimae heterogeniteit. Het verminderen van heterogeniteit in combinatie met pathway profiling technieken is een elegante researchstrategie om nieuwe genen en pathways te identificeren die ten grondslag liggen aan de ontwikkeling van atherosclerose. Met deze kennis kunnen dan betere (individuele) therapieën ontwikkeld worden om hart- en vaatziekten tegen te gaan. 


\section{DANKWOORD}

En eindelijk is het dan zover..... proefjes gedaan, data geanalyseerd, geschreven, geploeterd, af en toe wat gevloekt en nog maar wat geschreven en dan "opeens" is het boekje dan toch af. Als me iets duidelijk is geworden de afgelopen jaren dan is het wel dat je onderzoek nooit alleen doet. Hulp, motivatie en enthousiasme kan vaak op/uit de meest onverwachte momenten/situaties komen en ik wil dan ook iedereen bedanken die, op welke manier dan ook, een bijdrage heeft geleverd aan de fabricage van dit boekje.

Allereerst mijn promotieteam. Professor Daemen, beste Mat, het is dus toch echt waar wat er in de wandelgangen gezegd wordt; een AIO kan zich in de laatse fase van het promotietraject geen betere promotor wensen dan Mat Daemen. Op de momenten dat het echt nodig was hakte je knopen door, was je (misschien ongemerkt) een enorme stimulans voor me en maakte je altijd eventjes tijd voor me vrij. Je hebt me laten meekijken hoe het eraan toegaat in de wereld die "beetje politiek in de wetenschap" heet en ik heb er ontzettend veel van geleerd. Dank je wel voor alle support.

Dr Cleutjens, beste Kitty, jij was er voor de dagelijkse begeleiding en voor die taak had ik me niemand anders kunnen wensen. Altijd, maar dan ook altijd, kon ik bij je terecht. Uit een weekje experimenteren, waarin in mijn optiek geen enkel experiment gelukt was, wist jij altijd weer de positieve dingen te vinden zodat ik weer vol enthousiasme verder ging. Ik heb enorme bewondering voor jouw tomeloze energie en enorm positieve insteek.

Dr Bijnens, beste Ann-Pascale, ook jij mag hier niet ontbreken. Je hebt een enorme bijdrage aan dit boekje geleverd. Jouw altijd aanwezige enthousiasme en gedrevenheid werkten vaak aanstekelijk.

Kamergenootjes en collega AIO's van het eerste uur (alias The Cardio-Chicks), onbeschrijfelijk was de tijd samen op kamer 5.03 (alias Het Kippenhok). Wat hebben we ontzettend veel plezier samen gehad op de kamer, tijdens cursussen, congressen en de diverse feestjes en stapavondjes. Marjo, buurvrouw en collega-"coffeelover", ontzettend bedankt voor de atherointroductie in mijn "begin" dagen als AIO, al onze discussies, je adviezen, je opbeurende woorden als die nodig waren, je enorme interesse en de gezellige klets. Linda, meis je kunt zo een carrière als "party-planner" beginnen. Geweldig dat ik altijd terecht kon voor hulp, een luisterend oor, een half-om op het OLV of een bakkie koffie op Plein 92. En, als Kitty en ik samen 80 worden kunnen we je dan weer inhuren?? Suus, ik zag dat het aandeel Cote dór aan het zakken was, je bent toch niet allergisch geworden hè?? Met je heerlijke humor en zeer goed ontwikkelde entertainmentkwaliteiten heb je altijd voor een heerlijke sfeer gezorgd op de kamer (en daarbuiten). Judith, gedrevenheid, 
assertief en party-chick zijn de eerste woorden waarmee ik jou associeer. Met plezier denk ik terug aan zowel onze onderzoeks en prive gerelateerde discussies. Veel succes in the USA!! Kitty, jij bent met me mee verhuisd naar level 3 op de uni en wij zijn dus tijdens onze hele AIO periode kamergenootjes geweest! Dank je wel dat je er altijd was als ik even iets kwijt wilde; blijdschap, frustraties en de traantjes. Jammer dat we niet meer dagelijks samen aan de koffie kunnen, ik heb namelijk nog genoeg inspiratie voor "het woord van de dag"!! Ladies, dank jullie wel voor de geweldige tijd en alle steun!!!!

De nieuwere generatie AIO's. Dirk, lieve Belg, onze eerste kennismaking op kamer 5.03 zullen we allebei niet snel vergeten; ik weet nog steeds niet wie zich nu ongemakkelijker voelde. Dank je wel voor al je interesse, steun, de vele bekers koffie en biertjes die we samen hebben gedronken en de gezellige klets. Wouter, collega "microarray-er", "LCM-er" en kabouterbiertjes-aanbidder. Dank je wel voor alle hulp en de gezelligheid. We moeten die kabouter-borrel nu wel maar echt eens gaan plannen, vind je niet? Lilli, thanks for always being interested and for the nice talks we had. Veel succes met jullie onderzoek en de afronding van de boekjes.

De "mensen van het lab" zijn onmisbaar voor elke AIO. Anique, Anouk, Chantal, Coby, Ine, Monique, Moniek, Petra, Barry, Mat, Ruben, en Jeffrey ontzettend bedankt voor alle hulp, interesse en gezellige klets op het lab. Erwin, jij verdient wel een aparte vermelding (en dat is niet omdat er niemand op het lab is die zo "apart" kan zingen als jij!!). Dank je wel voor het uitvoeren van de (last-minute geplande) experimenten terwijl ik op level 3 zat te schrijven. Barry, eerste hulp bij PC/Laptop problematiek, dank je wel voor al je hulp. Ook de drukker zal je dankbaar zijn, hij was beslist niet vrolijk geworden van een proefschrift in de layout van een e-mail. Veel succes met je eigen onderzoek!!

Alle andere "(ex) members" van de cardio-groep; Sylvia, Esther, Jack, Birgit, Cherida, Veronica, Wanwisa, Marc en Robbert-Jan. Allemaal bedankt voor het beantwoorden van al mijn vragen, voor alle hulp en voor de leuke tijd. Wanwisa, het was geweldig om samen met jou aan NWO-genomics te werken. Ik heb alweer zin in onze volgende lunchdate!!

De afstand van Het Kippenhok naar de koffiekamer is niet groot maar doordat iedereen altijd wel interesse toonde, een babbeltje maakte of gewoon wat onzin uitkraamde (voel je niet aan gesproken Robert-Jan) heb ik er vaak lang over gedaan om weer terug achter de PC te geraken. Alle pathologen en assistenten bedankt voor de gezellige tijd. Ladies van het secretariaat, het was altijd gezellig om eventjes halt te houden bij jullie. Alle mensen van de methyleringsen de Angiogenese onderzoeksgroep, dank jullie wel voor het babbeltje op de gang of op één van de feestjes. Succes met jullie onderzoeken. Femke, jij 
kwam Kitty en mij gezelschap houden op de kamer op de uni. Ook met jou heb ik alle (promotie) perikelen kunnen delen. Niets zo ontspannend als onder genot van een koffie naar jouw vakantieverhalen te luisteren op een maandagmorgen. De opmerking "vraag maar aan Elly of Cor" heb ik regelmatig voorbij horen komen de afgelopen jaren. Elly, bewonderenswaardig hoe je altijd wel weer een gaatje in die outlook agenda van Mat kon vrijmaken. Allebei ontzettend bedankt voor alle regeldingetjes en alle interesse.

Boeiende wetenschap bedrijven houdt in dat je ook verder moet kijken dan de Pathologie groot is.

Het NWO-genomics project. Prof. Pannekoek, Prof. Van Berkel, Anton, Johan, Joost, Oscar, Ingrid en Eva, bedankt voor de vele vruchtbare besprekingen en discussies. Joost en Oscar, bedankt voor het plezier en de hulp als het weer eens "microarray-time" was. Eva, ik ben erg blij dat we samen hebben kunnen concluderen dat alcohol toch echt veel beter is dan water!!! Ontzettend bedankt voor de hulp bij de laatste loodjes. Wanneer is de volgende "biersamplemanifestatie"? Organon, Anneke Sijbers en Dianne Delsing bedankt voor de vruchtbare besprekingen. Maarten Sollewijn Gelpke bedankt voor al je hulp bij het analyseren van de microarray. BigCat, Chris en Rachel, bedankt voor jullie hulp bij het analyseren van de muizenmicroarray. Patrick Lindsey van het Genome Centre, ontzettend bedankt voor het schrijven van een "statistisch programmaatje" waarmee we die site specificity study konden analyseren.

Vanuit Maastricht naar Brussel. Laboratoire Epigénétique du cancer; François, Halim, Xavier, Rachel, Carmen, Hélène, Sarah, Pascale, Emily, Eleanore, Mariel, Emma, 'Matladi, Judith et Ioly. Avec vous tous j'ai vécu des moments vraiment inoubliables....ceci fut un temps formidable! Je vous remercie pour l'intérêt que vous avez bien voulu m'accorder lors de la réalisation de ma thèse, ainsi que pour toutes vos réponses à mes questions de traduction du genre "comment dire ceci en français", les bons moments passés autour d'un verre et les sorties agréables. 'Matladi (ze zullen dit stukje beslist voor je willen vertalen mocht jouw frans nog net niet toereikend zijn!), Judith (quand joueras-tu à nouveau du piano ?) et Ioly (Epigénétique de I' Amour!!), espérons que nous resterons toujours en contact. Quand fixons-nous le prochain rendez-vous?

Vanuit Brussel weer terug naar Maastricht. Suzanne en Barbie, we zijn een lekker draaiend "klinisch-genetica-trio" binnen de "adoptie-vakgroep" Anatomie en Embryologie. Els, Paul, Ulrieke, Leo, Andreas, Hennie, Chiel, Roy, Tine, Sonia, Arno, Johan, Leon, Wout, Jaap, Judith, Esther, Greta, Rogier en Hans, bedankt voor jullie interesse, de gezelligheid, de kennismaking met het AEfenomeen "bakwedstrijd" en de cursus "hoe verzin ik 1001 redenen voor een vlaai traktatie". 
Naast werken was er ook tijd voor ontspanning. De "ex-spaubekjes", Willem, Marleen, Claire, Fleur, Caro en Paul, bedankt voor alle gezellige zaterdagen, peptalk en oppasavondjes. Ik heb na vandaag weer wat meer tijd. Dan "die andere tant met aanhang", Annie, Judith, Maurice, Jaap en Patricia. Ik voel me altijd meer dan welkom bij jullie. Bedankt voor alle logeerpartijtjes, saunabezoekjes, BBQs, feestjes en het voorhouden van een spiegel als dat weer eens nodig is. Dennis, Martijn en Steven alle stapavondjes, feestjes en het weekendje Parijs waren mede door jullie altijd voorzien van een hoge gezelligheidsfactor. Mike, complex dekt de lading wel.....thanks for just being you. Ellis, Willy en Sietske, onze vriendschap stamt al uit de HLO-tijd en ik geniet nog steeds van alle etentjes, shop-dates en kroeg-bezoekjes. Marjolein en Hans, het is altijd weer gezellig om even langs te fietsen. En Marjolein, gaan we nog eens een cursus samen doen?? Mirian, meis je hebt geen idee hoe belangrijk Klein-Zwitserland voor me is!!. Het is altijd weer heerlijk om bij jou (en Joris) te zijn. Kim, door jou zal ik rosé altijd met bitterballen blijven associëren!! Ook de gespreksonderwerpen die we onder het genot van deze versnaperingen hadden zal ik niet snel vergeten; "Chromatin remodeling", "Protein Shakes", "het Savelsbos", "het konijn met de oortjes" en "in de spiegel kijken". Dank je wel dat je er in alle stress momenten voor me was en dan doel ik niet alleen op de werk gerelateerde. En nu op naar jouw feessie!!!

Mijn para(de)nimfen, Marjo en Danielle. Marjo, eerst was je mijn buurvrouw op de patho en nu een lieve vriendin. Dank je wel (en Freddy ook natuurlijk) voor al het plezier dat we samen hebben en de hulp en steun bij de moeilijkere momenten. Daan, onder het genot van een koffie, cappuccino, biertje, wijntje en portje hebben we al ettelijke klets-uurtjes op de teller staan. Bedankt (en ook Koen) voor alle hulp, steun en het altijd voor me klaar staan; in roughtimes en de fun-times!!

Leeve, wat kan ik zeggen...... Ontzettend bedankt voor echt alles!!!!

Stefan, een betere broer kan een promovendus zich niet wensen. Zorgen voor de broodnodige ontspanning/afleiding als dat nodig is en me lekker met rust laten als alles op rolletjes loopt. Dank je wel voor alle leuke uitstapjes en ik hoop nog veel van die leuke momenten samen met jou en Inge mee te maken.

Lieve pap en mam, zonder jullie zou ik hier vandaag niet staan. Bedankt voor jullie onvoorwaardelijke liefde en steun in alles wat ik doe, ook al waren jullie het misschien niet altijd eens met mijn acties. Het was altijd fijn om even naar "het nest" toe te gaan voor wat rust, om wat te babbelen of om wat te prutsen. $\mathrm{Na}$ vandaag heb ik weer wat meer tijd...dus zet die koffie maar alvast aan!!! 


\section{CURRICULUM VITAE}

NATASJA KISTERS

3 april 1975

Born in Sittard

\section{Education}

$1987-1992$

HAVO, College Sittard

$1992-1995$

MLO, Walram College, Sittard

$1995-1999$

BSc (HLO) at Hogeschool Limburg, Sittard

\section{Research positions}

$$
\begin{aligned}
& 1999-2002 \\
& 2002-2007 \\
& 2007-2008 \\
& 2008 \text { - present }
\end{aligned}
$$

Research technician, Department of Pathology/Department of Gynaecology, University of Maastricht

PhD student, Department of Pathology (CARIM), University of Maastricht Postdoctoral fellow, Laboratory of Cancer Epigenetics, University of Brussels (U.L.B.)

Research technician, Department of Molecular genetics and cell biology (GROW)

University of Maastricht

\section{Full articles}

Pijnenborg JM, Kisters N, van Engeland M, Dunselman GA, de Haan J, de Goeij AF, Groothuis PG. APC, beta-catenin, and E-cadherin and the development of recurrent endometrial carcinoma. Int J Gynecol Cancer. 2004 SepOct;14(5):947-56.

Lutgens SPM, Kisters N, Lutgens E, van Haaften RIM, Evelo CTA, de Winther MPJ, Daemen MJAP, Heeneman S, Cleutjens KBJM. Gene profiling of Cathepsin $\mathrm{K}$ as a modulator of extracellular matrix turnover and lipid metabolism. Journal of Pathology, 2006 Nov;210(3):334-43. 
Volger OL, Fledderus JO, Kisters N, Fontijn RD, Moerland PD, Kuiper J, van Berkel TJ, Bijnens APJJ, Daemen MJAP, Pannekoek H, Horrevoets AJG. Distinctive roles for chemokines and Transforming Growth Factor- $\beta$ in human arterial endothelium during atherosclerosis. Am J Pathol. $2007 \mathrm{Jul} ; 171(1): 326$ 3).

Kisters N*, Sluimer JC*, Cleutjens KBJM, Volger OL, Horrevoets AJ, Daemen MJAP, Bijnens APJJ. Dead or Alive; Differences and Similarities in gene expression between autopsy and surgical advanced atherosclerotic lesions. Physiol Genomics. 2007 Aug 20;30(3):335-41. * both authors have contributed equally

Sluimer JC, Gasc JM, van Wanrooij J, Kisters N, Sollewijn Gelpke MD, Groeneweg M, Cleutjens JP, Wouters BG, Van den Akker LH, Corvol P, Daemen MJ, Bijnens AP. Hypoxia, hypoxia-inducible transcription factor, and macrophages in human atherosclerotic plaques are correlated with intraplaque angiogenesis. J Am Coll Cardiol. 2008 Apr 1; 51(13):1258-65.

Jamnongluk W, Eijgelaar W, Kisters N, Wijnands EP, Cleutjens KBJM, Kuyper J, Horrevoets A, Daemen MJAP, Bijnens APJJ. TWIST1: A marker of macrophage foam cells. (submitted)

Kisters N, Jamnongluk W, Faessen M, Fledderus JO, Volger OL, Bijnens APJJ, Cleutjens KB, Daemen MJAP. Macrophages and progression of atherosclerotic lesions: stage specific expression of transcription factors TGIF and ID4. (in preparation)

Kisters N, Herias MV, Sollewijn Gelpke MD, Baurschmidt S, Cleutjens KB, Daemen MJAP, Bijnens APJJ. Transcript levels of genes involved in the intrinsic/extrinsic mediated initiation of apoptosis are elevated during progression of human atherosclerosis. (in preparation)

Kisters N, Faessen M, Lindsey PJ, Fledderus JO, Volger OL, Horrevoets AJ, Bijnens APJJ, Cleutjens KB, Daemen MJAP. Site specificity of gene expression signatures in human atherosclerosis. (in preparation)

Groeneweg M, Ghesquiere SAI, van der Made I, Kisters N, Gijbels MJ, Hofker $\mathrm{MH}$, Heeneman S, and de Winther MPJ. Phospholipase expression in different stages of human atherosclerotic lesions (In preparation) 